Universidade de São Paulo

Pedro Ernesto Pereira Paro

\title{
Sistemática de Transformação
}

Desenvolvimento teórico para o alinhamento entre Estratégia e Cultura Organizacional nos Projetos de Lean

São Carlos - SP

2016 



\author{
Pedro Ernesto Pereira Paro
}

\title{
Sistemática de Transformação: desenvolvimento teórico para o alinhamento entre Estratégia e Cultura Organizacional nos Projetos de Lean
}

Dissertação de Mestrado apresentada ao Programa de Pós-Graduação em Engenharia de Produção da Universidade de São Paulo (Escola de Engenharia de São Carlos, EESC/USP) para obtenção do título de Mestre em Engenharia de Produção.

Área de Concentração: Processos

e Gestão de Operações.

Orientador: Prof. Dr. Mateus C. Gerolamo

São Carlos - SP

2016 
AUTORIZO A REPRODUÇÃO TOTAL OU PARCIAL DESTE TRABALHO, POR QUALQUER MEIO CONVENCIONAL OU ELETRÔNICO, PARA FINS DE ESTUDO E PESQUISA, DESDE QUE CITADA A FONTE.

Paro, Pedro Ernesto Pereira

Sistemática de Transformação: desenvolvimento

teórico para o alinhamento entre Estratégia e Cultura

Organizacional nos Projetos de Lean / Pedro Ernesto

Pereira Paro; orientador Mateus Cecílio Gerolamo. São

Carlos, 2016.

Dissertação (Mestrado) - Programa de Pós-Graduação em Engenharia de Produção e Área de Concentração em Processos e Gestão de Operações -- Escola de Engenharia de São Carlos da Universidade de São Paulo, 2016.

1. Mudança Cultural. 2. Cultura Organizacional. 3. Gestão de Mudanças. 4. Lean. 5. Transformação Organizacional. 6. Evolução Organizacional. I. Título. 


\section{FOLHA DE JULGAMENTO}

Candidato: Engenheiro PEDRO ERNESTO PEREIRA PARO.

Título da dissertação: "Sistemática de Transformação - desenvolvimento teórica para o alinhamento entre estratégia e cultura organizacional nos projetos de lean".

Data da defesa: 08/04/2016

Comissão Julgadora:

Resultado:

Prof. Dr. Mateus Cecilio Gerolamo

(Orientador)

(Escola de Engenharia de São Carlos/EESC)

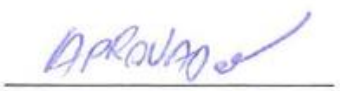

Prof. Dr. Gilberto Tadeu Shinyashiki

(Faculdade de Economia, Administração e Contabilidade de Ribeirão Preto/FEARP-USP)

Profa. Dra. Lilian do Nascimento Gambi

(Universidade Federal de Viçosa/UFV)

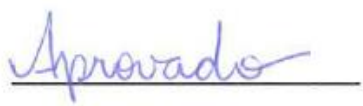

Coordenadora do Programa de Pós-Graduação em Engenharia de Produção:

Profa. Associada Daisy Aparecida do Nascimento Rebelatto

Presidente da Comissão de Pós-Graduação:

Prof. Associado Paulo César Lima Segantine 



\section{AGRADECIMENTOS}

Ao Professor Mateus Cecílio Gerolamo, pelos anos de orientação, ensinamentos, amizade e, sobretudo, pela paciência e discussões que incentivaram este trabalho.

Ao meu Pai e à minha Mãe pela segurança e conforto para proporcionar a educação que tenho. Ao meu irmão Guilherme pelo suporte e pela capacidade de inspirar valorização às coisas mais simples da vida. À Renata pelo amor, incentivo, carinho e compreensão ao longo de todo o período de elaboração deste trabalho. A todos os meus amigos e familiares, pelos momentos de pura descontração, alegria e divertimento.

Aos diretores da Hominiss Consulting, Antonio Freitas Rentes, Ronaldo Mardegan, Cesar Augusto Campos e, em especial ao Ricardo Renovato Nazareno, pelos aprendizados e experiências vivenciadas em diversos projetos e, principalmente, por terem me incentivado e viabilizado a realização deste trabalho.

Ao Professor Gilberto Shinyashiki e à Professora Lillian Gambi, pelas valiosas contribuições e conselhos no exame de qualificação e defesa desta dissertação, ambos indispensáveis para a conclusão deste trabalho.

Agradeço também a todos os grandes amigos que formei na Hominiss Consulting e também às grandes pessoas com quem pude trabalhar em diversos projetos. Aprendi muito com todos vocês. Sem dúvida alguma as conversas e aprendizados obtidos com cada um de vocês, de alguma maneira, está presente e viva neste trabalho.

Por fim, agradeço aos colegas, professores e funcionários do Departamento de Engenharia de Produção da EESC-USP, e também a todas as outras pessoas que de alguma forma contribuíram para a realização deste trabalho. 


\section{"Temos de nos tornar a mudança que queremos ver no mundo"}

Mahatma Gandhi 


\section{RESUMO}

PARO, P. E. P. Sistemática de Transformação: desenvolvimento teórico para o alinhamento entre Estratégia e Cultura Organizacional nos Projetos de Lean. Dissertação de Mestrado apresentada ao Departamento de Engenharia de Produção da Universidade de São Paulo (EESC/USP), para obtenção do título de Mestre em Engenharia de Produção.

Desde o final do Século XX e início do Século XXI, estudos analisam a elevada taxa de insucesso ou insatisfação com os Programas de Lean. Esta taxa tem se demonstrado demasiadamente elevada, variando entre $66 \%$ e $90 \%$. Como efeito deste insucesso, tem-se o desperdício de tempo, dinheiro, recursos e, talvez o pior, tem-se a propagação do medo nos agentes de mudança em empreitar novas iniciativas de mudança. Estudos apontam a falta de alinhamento de tais projetos com a Cultura Organizacional como uma das questões fundamentais deste insucesso. Partindo desta temática de pesquisa, este ensaio teórico pode ser caracterizado como uma abordagem qualitativa de análise do problema, de natureza básica de pesquisa buscando gerar conhecimentos novos e úteis às organizações, sem aplicação prática prevista neste primeiro estágio de pesquisa. A fonte de evidências para sustentar o modelo proposto foi revisão dos estudos de caso encontrados na literatura, sendo utilizadas tanto uma Revisão Bibliográfica Sistemática (RBS) quanto Exploratória, de tal maneira a buscar o "estado da arte" no campo de estudo. A Fundamentação Teórica do trabalho é baseada na literatura de quatro grandes campos de estudo: (i) Estratégia, (ii) Lean, (iii) Cultura Organizacional e (iv) Gestão de Mudanças. A RBS tem foco nas interseções destes grandes campos, agregando 190 trabalhos internacionais. Por sua vez, a Revisão Exploratória traz algumas das principais referências dos três campos de estudo, como: Edgar Schein, John Kotter, Kim Cameron, Robert Quinn, David Mann, dentre outros. Desta maneira, este trabalho estudou a influência da cultura organizacional nos projetos de transformação e, a partir da ruptura com a teoria atual, construiu e propôs uma sistemática teórica, intitulada de "Sistemática de Transformação" (ou simplesmente "Sistemática T"), a qual propõe o alinhamento entre três dimensões: Estratégia, Projeto de Transformação e Cultura Organizacional. Fazendo uso desta sistemática, é esperado que os agentes de mudança consigam ter um planejamento mais eficaz do processo de diagnóstico, avaliação e gestão da cultura organizacional alinhado à Estratégia e também ao Projeto de Transformação da organização, com ênfase nos Programas de Lean. A proposição e uso desta sistemática pode favorecer tanto a discussão acadêmica na área de Gestão de Operações sobre o tema, quanto fornecer subsídios para aplicações práticas mais eficazes.

Palavras-chave: Mudança Cultural; Cultura Organizacional; Gestão de Mudanças; Lean; Transformação Organizacional; Evolução Organizacional. 


\section{ABSTRACT}

PARO, P. E. P. Sistemática de Transformação: desenvolvimento teórico para o alinhamento entre Estratégia e Cultura Organizacional nos Projetos de Lean. Dissertação de Mestrado apresentada ao Departamento de Engenharia de Produção da Universidade de São Paulo (EESC/USP), para obtenção do título de Mestre em Engenharia de Produção.

Since the late twentieth century and early twenty-first century, several studies have analyzed the Lean Continuous Improvement Programs high rate of failure or dissatisfaction. This failure rate is too high, ranging between $66 \%$ and $90 \%$. Because of this rate, companies have lost money, lost time, wasted resources and, perhaps the worst: this failure can spread the fear in the change agents of making new change initiatives. Studies indicate that a key issue for this failure is the lack of alignment between such improvement programs with the organizational culture. Based on this research theme, this theoretical essay can also be characterized as basic research nature seeking to generate new and useful knowledge to organizations without practical application set forth in this first stage of research. The source of evidence to support the proposed systematic will be based on case studies of literature, being both used one Systematic Bibliographic Review (RBS) and Exploratory Review, seeking to achieve the "state of the art" in the field of study. The Theoretical Foundation of the work bases on the literature of three major fields of study: (i) Strategy, (ii) Lean, (iii) Organizational Culture and (iii) Change Management. The RBS focuses on the intersections of these great fields, adding 190 international studies. The Exploratory Review brings some of the main references of the three fields of study, such as Edgar Schein, John Kotter, Kim Cameron, Robert Quinn, David Mann, among others. Thus, this paper studied the influence of organizational culture in transformation projects and, from the disruption with the current theory, this research work built and proposed a theoretical systematic, titled "Transformation Systematic" (or simply "T Systematic") proposing the alignment of three dimensions: Strategy, Transformation Project and Organizational Culture. Making use of this systematic, it is expected that change agents can have a more efficient planning process of diagnosis, evaluation and management of organizational culture aligned to the strategy and also the Transformation Project, with emphasis on Lean programs. The proposition and use of this method can both facilitate academic discussion in Operations Management on the topic, as also provide support for applications best practices.

Keywords: Cultural Change; Organizational Culture; Change Management; Lean; Organizational Transformation; Organizational Evolution. 


\section{LISTA DE FIGURAS}

Figura 1 - Ilustração da principal lacuna de pesquisa abordada no trabalho...............................................22

Figura 2 - Visão geral do processo de pesquisa e construção teórica do trabalho.............................................29

Figura 3 - Estrutura de Trabalho da Revisão Bibliográfica Sistemática (RBS) ............................................ 32

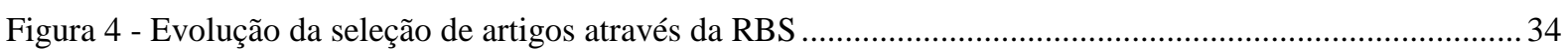

Figura 5 - Algumas das principais referências da revisão exploratória ….....................................................3 37

Figura 6 - O papel da revisão sobre Estratégia no processo desta pesquisa .................................................39

Figura 7 - Modelo de Estratégia Corporativa para uma Gestão Estratégica .................................................39

Figura 8 - Direcionamento estratégico e os níveis de mudança ..........................................................42

Figura 9 - Influência da Cultura no desenvolvimento da Estratégia ............................................................47

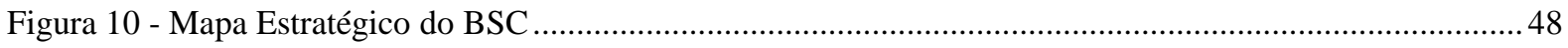

Figura 11 - O papel da revisão sobre Melhoria Contínua no processo da pesquisa ........................................49

Figura 12 - Os Cinco Princípios da Produção Enxuta ............................................................................53

Figura 13 - O Sistema Toyota de Produção (TPS) …............................................................................5

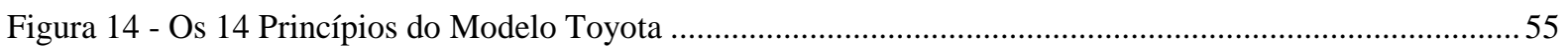

Figura 15 - A visão de Gary Convis sobre o Sistema Toyota de Produção ....................................................57

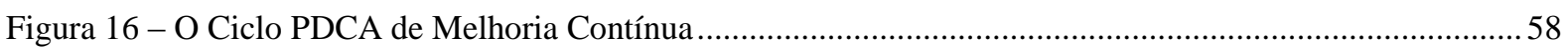

Figura 17 - Ilustração dos principais modelos de melhoria levantados .....................................................60

Figura 18 - O papel da revisão sobre Cultura Organizacional no processo de pesquisa ...................................69

Figura 19 - Cultura Organizacional como variável dependente e independente ..........................................73

Figura 20 - O diagrama de cebola de Hofstede Fonte: adaptado de Hofstede (2010) ......................................77

Figura 21 - Os três níveis culturais de Schein Fonte: adaptado de Schein (1984) .......................................79

Figura 22 - Triângulo metodológico para o diagnóstico da cultura organizacional ........................................84

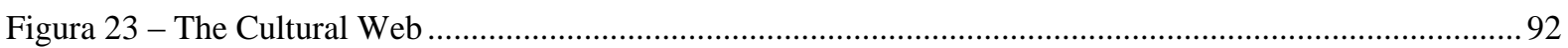

Figura 24 - Ilustração do Competing Values Framework (CVF) ............................................................93

Figura 25 - Ilustração do diagnóstico de Cultura Atual versus Cultura Desejada...........................................95

Figura 26 - Resultados de culturas organizacionais identificadas pelo CVF ............................................96 
Figura 27 - A Cultura Toyota e a Cultura Lean mapeadas no CVF

Figura 28 - A Cultura Lean ideal mapeada no CVF

Figura 29 - Cultura e Liderança, dois lados da mesma moeda 105

Figura 30 - Estrutura do texto sobre Gestão de Mudanças.

Figura 31 - Dimensões e frentes de análise das barreiras à mudança organizacional.

Figura 32 - O modelo em três etapas de Lewin.....

Figura 33 - O modelo da Mudança Planejada

Figura 34 - A fórmula da mudança.

Figura 35 - O modelo de gerenciamento das transições de Carnall

Figura 36 - Modelo de Gerenciamento da Mudança.....

Figura 37 - O modelo dos oito passos de Kotter

Figura 38 - Estrutura ágil de planejamento e execução de mudanças

Figura 39 - O modelo da congruência de Nadler e Tushman.....

Figura 40 - DICE Model

Figura 41 - O ciclo da mudança de Cameron e Green

Figura 42 - Perspectiva evolutiva de mudança e gestão da cultura organizacional

Figura 43 - O modelo psicodinâmico de Virgina Satir

Figura 44 - Estrutura do texto de revisão dos estudos de caso da literatura.

Figura 45 - Segmentação dos estudos de caso

Figura 46 - Visão geral do posicionamento desta seção no processo de pesquisa

Figura 47 - Grupos de Fatores Críticos de Sucesso dos Programas de Lean

Figura 48 - Comparação dos Modelos de Melhoria

Figura 49 - Comparação dos Modelos de Mudança com etapas lineares

Figura 50 - Principal ruptura da teoria atual no processo de transformação

Figura 51 - Visão ampla da Sistemática de Transformação

Figura 52 - Value Disciplines associadas ao Competing Values Framework

Figura 53 - Abordagem proposta de congelamento de algumas iniciativas estratégicas........

Figura 54 - Sistematização do Processo de Transformação alinhado com a Cultura Organizacional 


\section{LISTA DE QUADROS}

Quadro 1 - Sumário dos focos de investigação e principais barreiras ao Lean.

Quadro 2 - Caracterização e justificativa do método de pesquisa ............................................................. 30

Quadro 3 - Orientação geral da contribuição teórica e princípios de pesquisa ...................................................31

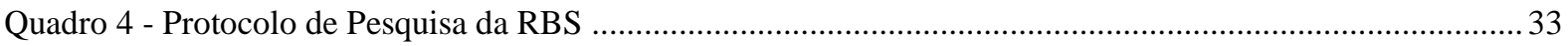

Quadro 5 - A evolução histórica do Lean na Gestão de Operações ............................................................52

Quadro 6 - As fases da Produção Enxuta (quatro décadas de Lean) ........................................................53

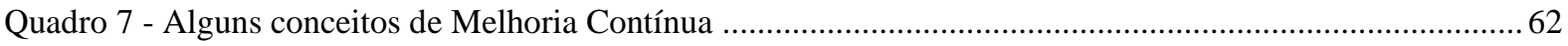

Quadro 8 - Fatores Críticos de Sucesso de Projetos de Transformação utilizando Programas de Melhoria Contínua

Quadro 9 - Principais diferenças entre Cultura e Ideologia ................................................................ 72

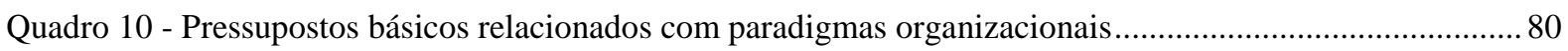

Quadro 11 - Problemas de sobrevivência e adaptação externa …..............................................................82

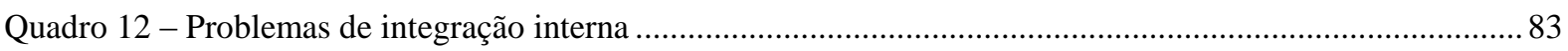

Quadro 13 - Comparação das metodologias de diagnóstico de cultura........................................................ 85

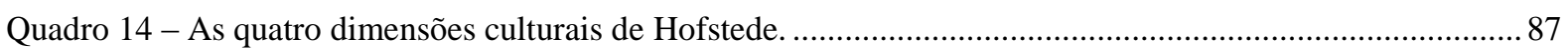

Quadro 15 - As sete dimensões culturais de Trompenaars e Hampden-Turner ............................................ 89

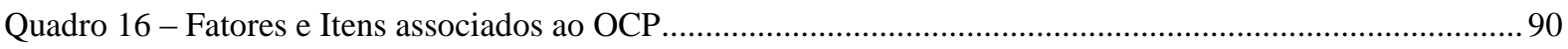

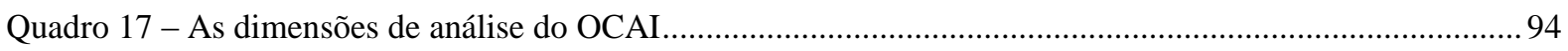

Quadro 18 - Os perfis de cultura organizacional do CVF................................................................ 95

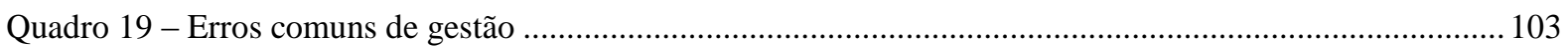

Quadro 20 - Barreiras do Processo de Mudança. ................................................................................. 110

Quadro 21 - Descrição de como as mudanças são tratadas de acordo com as metáforas organizacionais .......... 113

Quadro 22 - Critérios utilizados para a classificação dos estudos de caso .................................................. 137

Quadro 23 - Descrição e segmentação dos estudos de caso levantados na literatura...................................... 140

Quadro 24 - Quantidade de citações dos Modelos de Mudança com base na RBS ....................................... 149

Quadro 25 - Associação dos Modelos de Mudança com as metáforas organizacionais.................................. 150

Quadro 26 - Detalhamento dos passos da Sistemática de Transformação ................................................... 168 


\section{LISTA DE GRÁFICOS}

Gráfico 1 - Barreiras para uma implementação bem-sucedida do Lean ...............................................................20

Gráfico 2 - Obstáculos à transformação organizacional através do Lean .............................................................2

Gráfico 3 - Evolução das citações e publicações da RBS, de 1995 a 2014 ………………………………......... 35

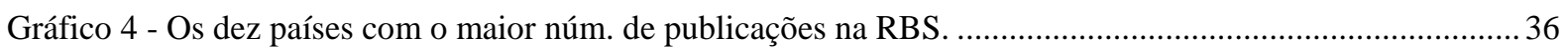

Gráfico 5 - As dez universidades com o maior núm. de publicações na RBS. …………….................................. 36

Gráfico 6 - Os dez periódicos com o maior número de publicações na RBS. ......................................................36 


\section{Sumário}

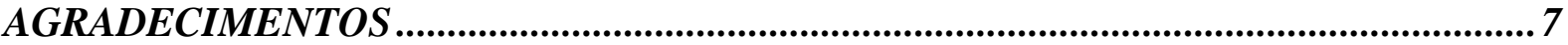

RESUMO

ABSTRACT

1. INTRODUÇÃO

1.1 CONTEXTO GERAL E RELEVÂNCIA DA PESQUISA ......................................... 17

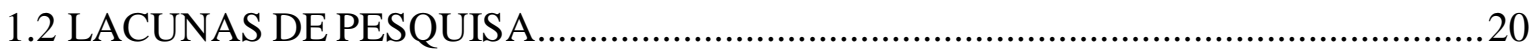

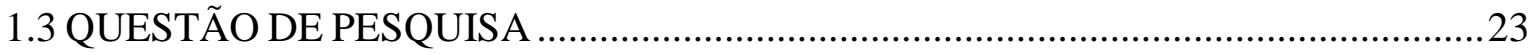

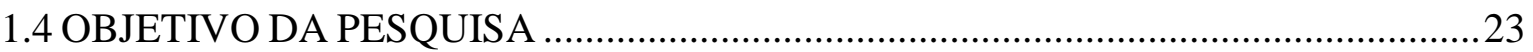

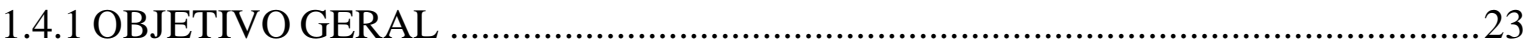

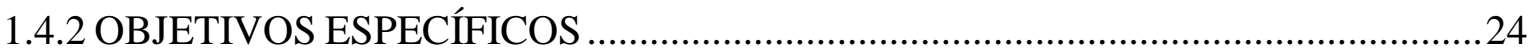

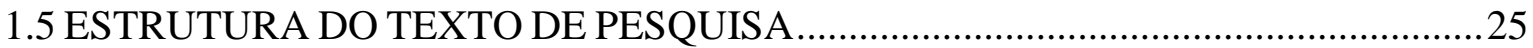

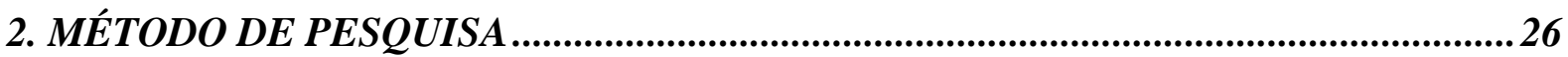

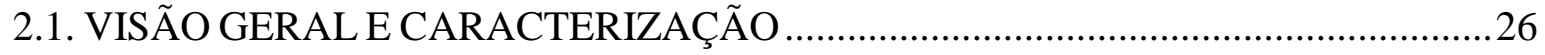

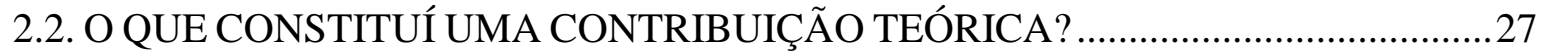

2.3. REVISÃO BIBLIOGRÁFICA SISTEMÁTICA (RBS) ................................................ 31

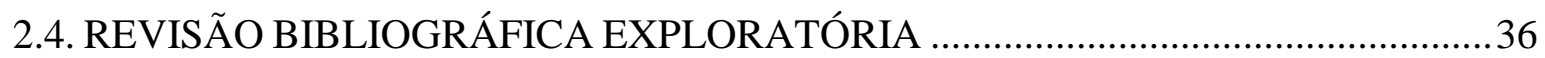

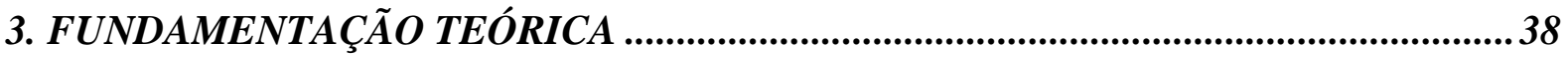

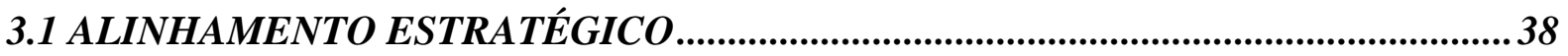

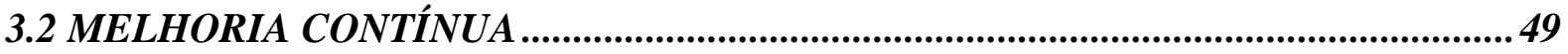

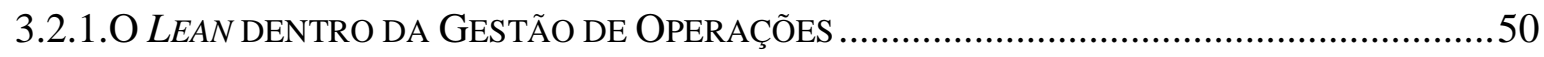

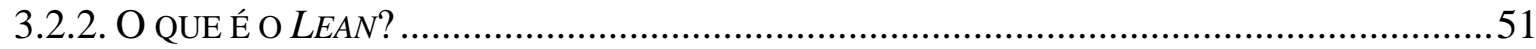

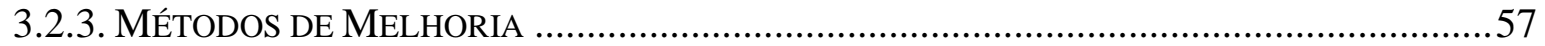

3.2.4. PRINCIPAIS CONCEITOS DE MELHORIA CONTÍNUA ......................................................59

3.2.5. FATORES CRÍticos de SuCESSO dos Programas de LEAN …...................................62

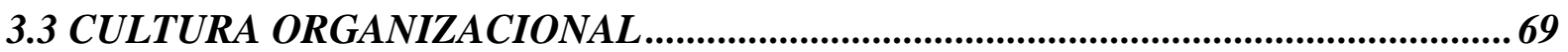

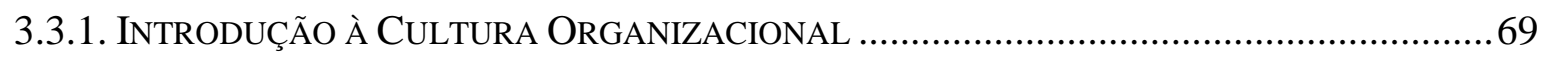




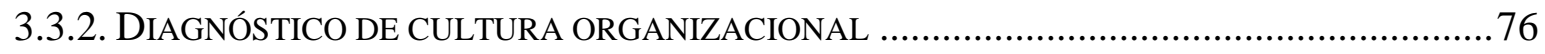

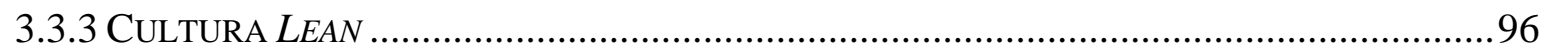

3.3.4. PrÁticas de GeStão de RECURSOS Humanos ...................................................... 101

3.4 GESTÃO DE MUDANÇAS........................................................................ 107

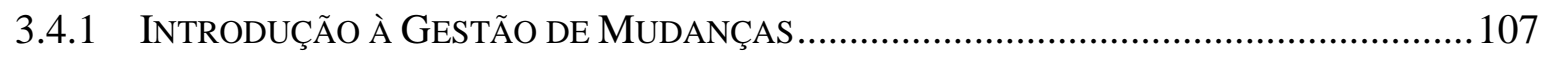

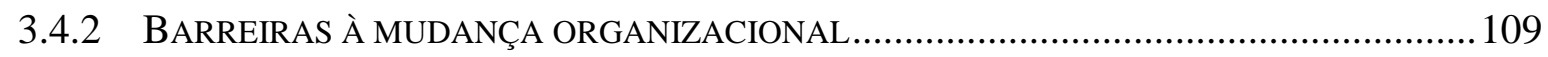

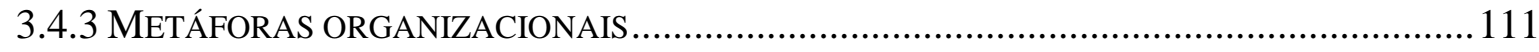

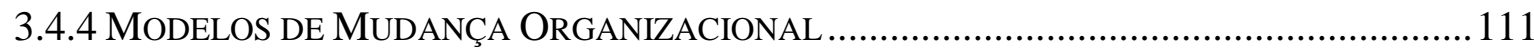

3.4.5. MELHORES PRÁTICAS DE MUDANÇA ORGANIZACIONAL …....................................... 127

3.4.6 EvOLUÇÃo E MUdANÇA DA CULTURA ORGANIZACIONAL ...................................... 129

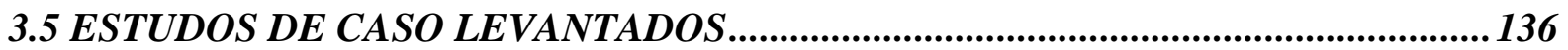

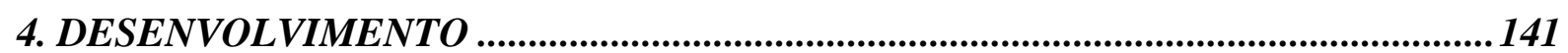

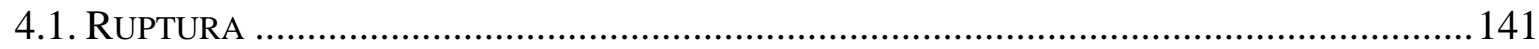

4.2 CONSTRUÇÃ

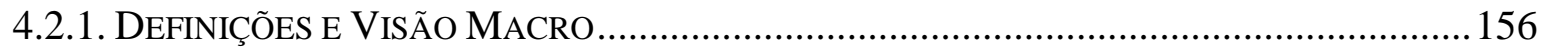

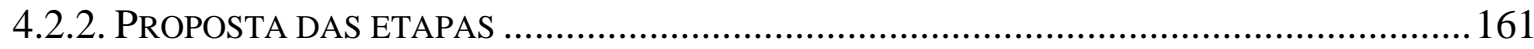

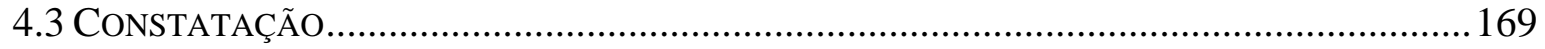

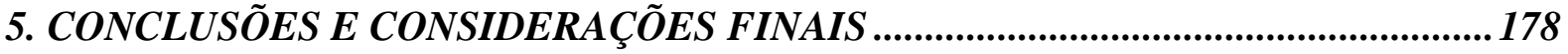

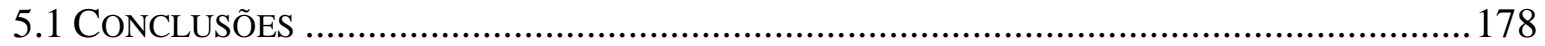

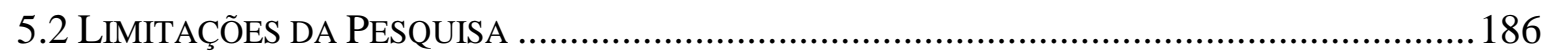

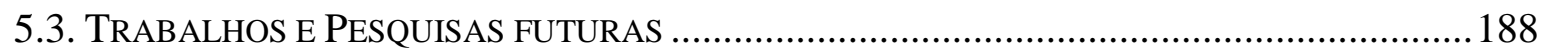

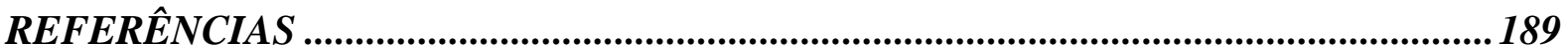




\section{INTRODUÇÃO}

Nesta seção é apresentada uma introdução do trabalho de dissertação, com o objetivo de contextualizar a pesquisa, apresentar suas questões e objetivo. No final da seção há uma explicação da estrutura desta dissertação e das seções seguintes.

\subsection{CONTEXTO GERAL E RELEVÂNCIA DA PESQUISA}

Toda vantagem competitiva é temporária (SLOAN School of Management, 2002). Esta afirmação é feita com respaldo de exemplos históricos de dominação, todos temporários: dominação Mundial - Grécia em 600 a.C., Roma em 100 d.C., Inglaterra em 1800 -, dominação na Indústria Automobilística - Ford em 1920, GM em 1966 e Toyota em 1990 - e dominação na Indústria de Computação - IBM em 1970, DEC em 1980, Intel em 1990.

Poderiam ser incluídos novos exemplos, como os Estados Unidos da América e empresas de base tecnológica como Google, Apple e Facebook. E nos próximos 10, 20, 100 anos ou mais, outros exemplos surgirão. Este contexto de competição tem sido amplamente discutido nas últimas décadas, tanto no meio acadêmico quanto corporativo (Deshpandé et al., 2000; Talib et al., 2010; Pamfilie et al., 2012). O fato é: as organizações estão constantemente duelando em seus mercados, sejam elas as líderes de mercado ou não, todas buscam realizar melhorias e mudanças organizacionais tendo como objetivo se manterem competitivas. Um bom exemplo desta busca por competitividade, é o rápido crescimento de diversos Programas de Melhoria Contínua (TQM, Six Sigma e Lean), objetivando reduzir custos e melhorar a qualidade das empresas (Smeds, 1994; Emiliani, 1998; Handel, 2009; Snee, 2010). Em pouco menos de 20 anos, final do Século XX e início do Século XXI, estes programas não apenas se espalharam por todo o segmento Automobilístico, como também atingiram diversas empresas de Serviços: bancos, hospitais e hotéis, para não citar outros exemplos, passaram a alocar recursos organizacionais para implementar tais práticas e conceitos (Talib et al., 2010). No entanto, embora sejam obtidos bons resultados com tais Programas de Melhoria, na literatura facilmente encontramos pesquisas nas quais, os profissionais das empresas, julgam que os resultados obtidos têm sido aquém do esperado. 
Segundo a literatura (Hines et al., 2008; Sim e Rodgers, 2009; Atkinson, 2010; Bhasin, 2011; Bhasin, 2012), menos de 10\% (dez por cento) das empresas do Reino Unido realizaram uma implantação Lean bem-sucedida. Resultados semelhantes podem ser encontrados para as implantações do Total Quality Management e Six Sigma. Por exemplo, Garud et al. (2011) encontraram evidências de que o Programa de Six Sigma estaria limitando as inovações da 3M, empresa reconhecida como uma das empresas mais inovadoras do mundo. Com relação ao TQM, o cenário não é diferente, as falhas na implantação deste programa são estimadas entre dois terços dos casos (Walker, 1992) e 90 por cento (Graham, 1991). Independentemente do tipo de Programa de Lean, a literatura cita que pelo menos dois terços dos programas de transformação organizacional falham (Graham, 1991; Walker, 1992; Sirkin et al., 2005; Atkinson, 2010; Bhasin, 2011; Bhasin, 2012). Inclusive, para alguns autores (Hawkes, 1993), mesmo os programas que sobrevivem, muitos reportam níveis consideráveis de insatisfação.

Ainda que o fracasso de tais programas possa ser atribuído a vários fatores, diversos autores consideram que algumas causas fundamentais das baixas taxas de sucesso destes programas são evidentes, como Cultura Organizacional e Gestão da Mudança (Bicheno e Holweg, 2009; Atkinson, 2010; Bhasin, 2011-a; Bhasin, 2011-b; Saurin et al., 2011; Bhasin, 2012). As organizações precisam entender que para atingir o estado de excelência da Toyota, por exemplo, não é uma questão de apenas implementar técnicas e obter bons resultados, afinal, a Toyota iniciou um Programa de Lean há mais de 50 anos, e muitas das lições já aprendidas vêm de 100 anos atrás (Bhasin, 2012). Antes ou durante a implantação de qualquer técnica ou ferramenta (aspecto Hard), é necessário desenvolver, fortalecer ou construir uma cultura organizacional (aspecto Soft) favorável aos Programas de Lean, a menos que a cultura atual da organização seja capaz de sustentar comportamentos adequados à implantação (Liker, 2005). Nesse sentido, o conceito de cultura é cada vez mais relevante para o estudo da administração, afinal, a cultura é essencial para viabilizar as estratégias e o processo de mudança (Shinyashiaki, 1995).

Embora existam alguns estudos sobre aspectos soft de melhoria contínua na literatura, pouco tem sido feito para avaliar a efetividade e o desenvolvimento de ações envolvendo o comportamento das pessoas (Wan e Chen, 2008; Behrouzi e Wong, 2011; Bhasin, 2011a; Ahmad, 2013). No levantamento da literatura realizado por Ferreira e Saurin (2008), contemplando 48 artigos de grande relevância internacional nos períodos de 1996 a 2002, relacionados à avaliação do desenvolvimento do Lean nas organizações, apenas dois métodos 
encontrados (Nightingale e Mize, 2002; Kumar e Thomas, 2002) faziam menção específica à satisfação e ao ponto de vista dos colaboradores da organização com o programa. Ou seja, a maioria dos métodos de avalição do Programa de Lean (HOFER e outros 2011; Behrouzi e Wong, 2011; Eswaramoorthi e outros, 2011; Seyedhosseini e outros, 2011; Unver, 2012; Vinodh e Vimal, 2012; Chauhan e Singh, 2012; Anvari, Zulkifli e Yusuff, 2012) não contemplam a manutenção e absorção dos valores de Lean pela Cultura Organizacional atual das empresas.

A avaliação dos Programas de Lean pode ser mais ampla do que apenas verificar seus resultados, suas práticas e ferramentas tradicionais, pode e deveria considerar também os aspectos soft relacionados aos recursos humanos, os quais possuem impactos tanto positivos quanto negativos no sistema organizacional como um todo (Womack e Jones, 2004; Liker, 2005; Ferreira e Saurin, 2008). Tendo em vista este cenário de taxas de insucesso, ou pelo menos insatisfação, com relação a tais programas, é alto o risco de que o resultado das iniciativas de mudança dos próximos anos também seja de acordo com o esperado. Mas, como modificar este contexto? Como avaliar o impacto do comportamento organizacional (pessoas) nos Programas de Lean? O que as empresas podem fazer para melhorar a taxa de sucesso das iniciativas de mudança? Como os agentes de mudança podem melhorar a gestão dessas questões fundamentais que envolvem as crenças e valores dos colaboradores?

Com relação aos Programas de Melhoria Contínua ${ }^{1}$, este trabalho se propõe a estudar o Programas de Lean, por possuírem um caráter de mudança profunda ao introduzir novas “filosofias de gestão", como já reconhecido por inúmeros autores (Liker, 2005; Mann, 2010; Sim e Rodgers, 2009; Atkinson, 2010; Bhasin, 2011; Bhasin, 2012). Este trabalho não se propõe a responder as perguntas levantadas no parágrafo anterior (as questões desta pesquisa são apresentadas na Seção 1.2), porém, apenas reconhece tais questões de pesquisa como inspiradoras e disparadoras deste trabalho. Quando estas questões forem devidamente respondidas, é provável que possam proporcionar um impacto positivo na redução da taxa de insucesso dos Programas de Transformação Organizacional.

\footnotetext{
${ }^{1}$ Embora este trabalho tenha foco nos "Programas de Lean", é importante reconhecer que o Lean é um dos Programas de Melhoria Contínua e, portanto, trabalhos semelhantes a este poderiam ser estendidos para os outros programas, como Total Quality Management e Six Sigma.
} 


\subsection{LACUNAS DE PESQUISA}

Deloitte e Touche (2002) aplicaram uma Survey em 100 organizações, e obtiveram os resultados apresentados no Gráfico 1 sobre as principais barreiras para uma implementação bem-sucedida do Lean. Semelhante à pesquisa de Deloitte e Touche (2002), o Lean Institute Enterprise também conduziu duas pesquisas para avaliar os obstáculos à transformação organizacional através do desenvolvimento e implementação do Lean, os resultados de 2004 e 2005 estão ilustrados no Gráfico 2.

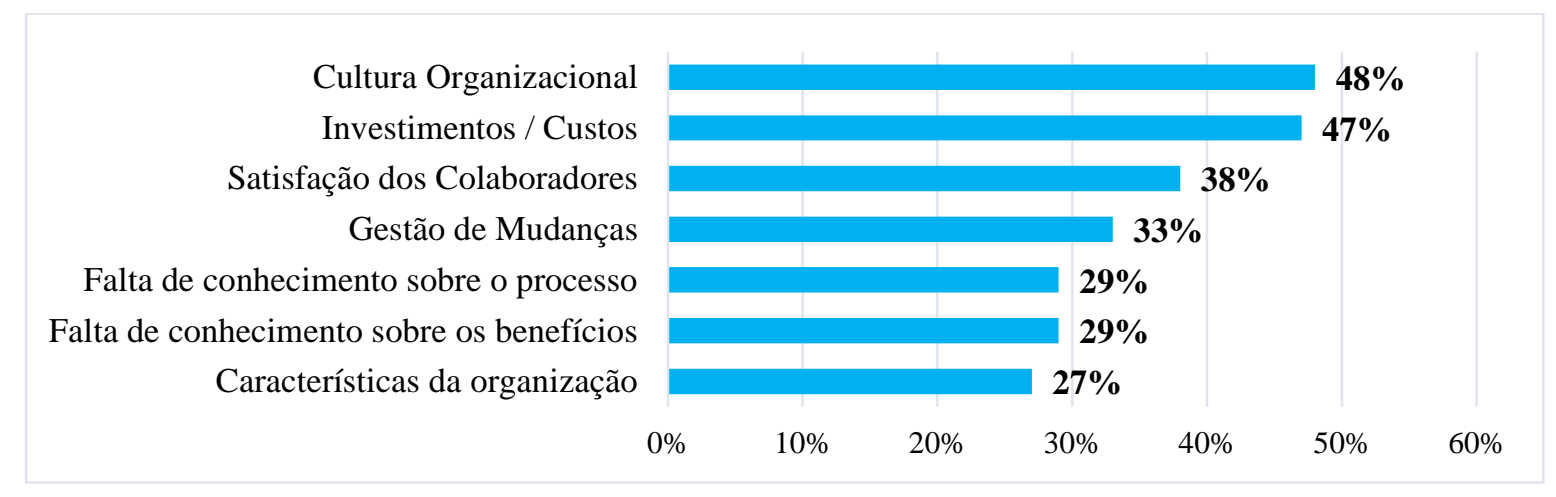

\section{Gráfico 1 - Barreiras para uma implementação bem-sucedida do Lean}

Fonte: adaptado de Deloitte e Touche (2002)

A partir destes trabalhos identificando as principais barreiras e obstáculos ao desenvolvimento e implementação dos programas de Lean, Bhasin (2012b) conduziu uma extensa revisão da literatura sobre as barreiras deste Programa de Lean. Os resultados deste trabalho trazem uma definição de focos de investigação, os quais estão ilustrados no Quadro 1. Analisando as barreiras aos programas de Lean e suas respectivas lacunas de pesquisa, Bhasin (2012b) afirma que:

“As organizações precisam reconhecer que existe pouco que elas podem fazer para atingir o estado atual da Toyota de aprendizado e vivência da filosofia de melhoria contínua, elas precisam compreender o Lean como uma filosofia de negócio, e quanto mais acreditarem nesta doutrina, mais fácil será transformar a empresa como um todo e obter os benefícios deste programa. Esta conclusão é feita a partir da análise das melhores organizações implementado o Lean, dentre uma análise envolvendo 50 organizações. É preciso reconhecer que a Toyota iniciou sua jornada há mais de 50 anos, sendo que muitas de suas lições aprendidas datam de mais de 100 anos atrás". 


\section{Principais obstáculos ao sucesso da Jornada Lean}

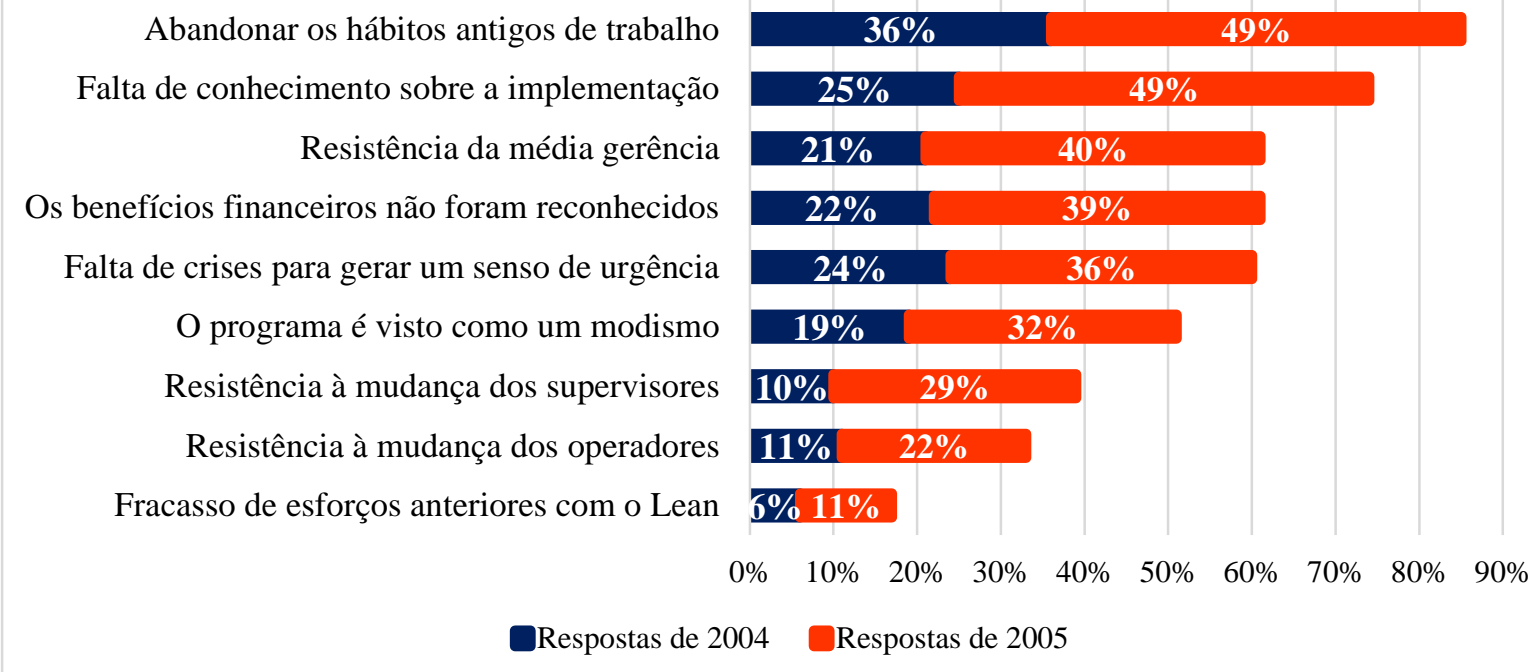

\section{Gráfico 2 - Obstáculos à transformação organizacional através do Lean}

Fonte: adaptado do Lean Enterprise Institute Survey (2004 - 2005)

Os resultados da pesquisa de Bhasin (2012b) são extremamente relevantes para este trabalho, e estes focos de investigação levantados servem como direcionadores. É importante salientar que os focos de investigação "1 - Aceitação do Lean como uma ideologia" e "8 - Lean tido como Cultura Organizacional" serão os mais discutidos, o que por sua vez não implica que os demais citados não serão de certa maneira discutidos. Apenas o foco de investigação "5 - Questões de financiamento", não será discutido neste trabalho de revisão da literatura sobre Lean, Cultura Organizacional e Gestão de Mudanças, justamente por envolver um outro campo de estudo.

A Figura 1 ilustra a principal questão de pesquisa que será abordada neste trabalho, envolvendo o Processo de Transformação Organizacional: como sistematizar o processo de mudança ou evolução da cultura organizacional alinhado ao processo de transformação organizacional, com ênfase nos Programas de Lean. Sob este ponto de vista, Bhasin (2012b) revela características comuns a empresas bem-sucedidas na implementação do Lean: a) Segurança global, limpeza e ordem; (b) Fluxo produtivo e operacional; (c) Processos e operações; (d) Programa de Sustentabilidade do Lean; (e) Cultura organizacional orientada aos colaboradores; (f) Lean reconhecido como um negócio, ou iniciativa rentável para a empresa; (g) Filosofia utilizada; (h) Estratégia de Gestão da Mudança na Jornada Lean. 


\begin{tabular}{|c|c|c|}
\hline & Foco de investigação & Barreiras identificadas \\
\hline \multirow{2}{*}{1} & \multirow{2}{*}{$\begin{array}{l}\text { Aceitação da Melhoria Contínua } \\
\text { como uma ideologia }\end{array}$} & Cultura \\
\hline & & Histórico de iniciativas \\
\hline \multirow{3}{*}{2} & \multirow{3}{*}{$\begin{array}{l}\text { Melhor comunicação interna e definição } \\
\text { das estratégias de implementação }\end{array}$} & Atitude dos colaboradores \\
\hline & & Resistência dos operadores \\
\hline & & Histórico de iniciativas \\
\hline 3 & Gestão de Mudanças & Especificidades da jornada \\
\hline \multirow{3}{*}{4} & \multirow{3}{*}{$\begin{array}{l}\text { Treinamento e uma apreciação do } \\
\text { Programa de Melhoria Contínua }\end{array}$} & $\begin{array}{l}\text { O programa visto como um processo } \\
\text { de longo prazo }\end{array}$ \\
\hline & & $\begin{array}{l}\text { Lean não visto como sinônimo de } \\
\text { ferramentas apenas }\end{array}$ \\
\hline & & Lean aplicado à cadeia de valor \\
\hline 5 & Questões de financiamento & Custo de implementação \\
\hline \multirow{3}{*}{6} & \multirow{3}{*}{ Gestão de performance } & Medição dos benefícios do Lean \\
\hline & & Lean visto como um modelo de negócio \\
\hline & & Sistemas tradicionais de custos \\
\hline 7 & Estrutura Org. e Gestão de Mudanças & Sistemas de comunicação interna \\
\hline 8 & $\begin{array}{l}\text { O programa sendo compreendido } \\
\text { como Cultura Organizacional }\end{array}$ & Abandonar os hábitos antigos \\
\hline
\end{tabular}

Quadro 1 - Sumário dos focos de investigação e principais barreiras ao Lean

Fonte: adaptado de Bhasin (2012b)

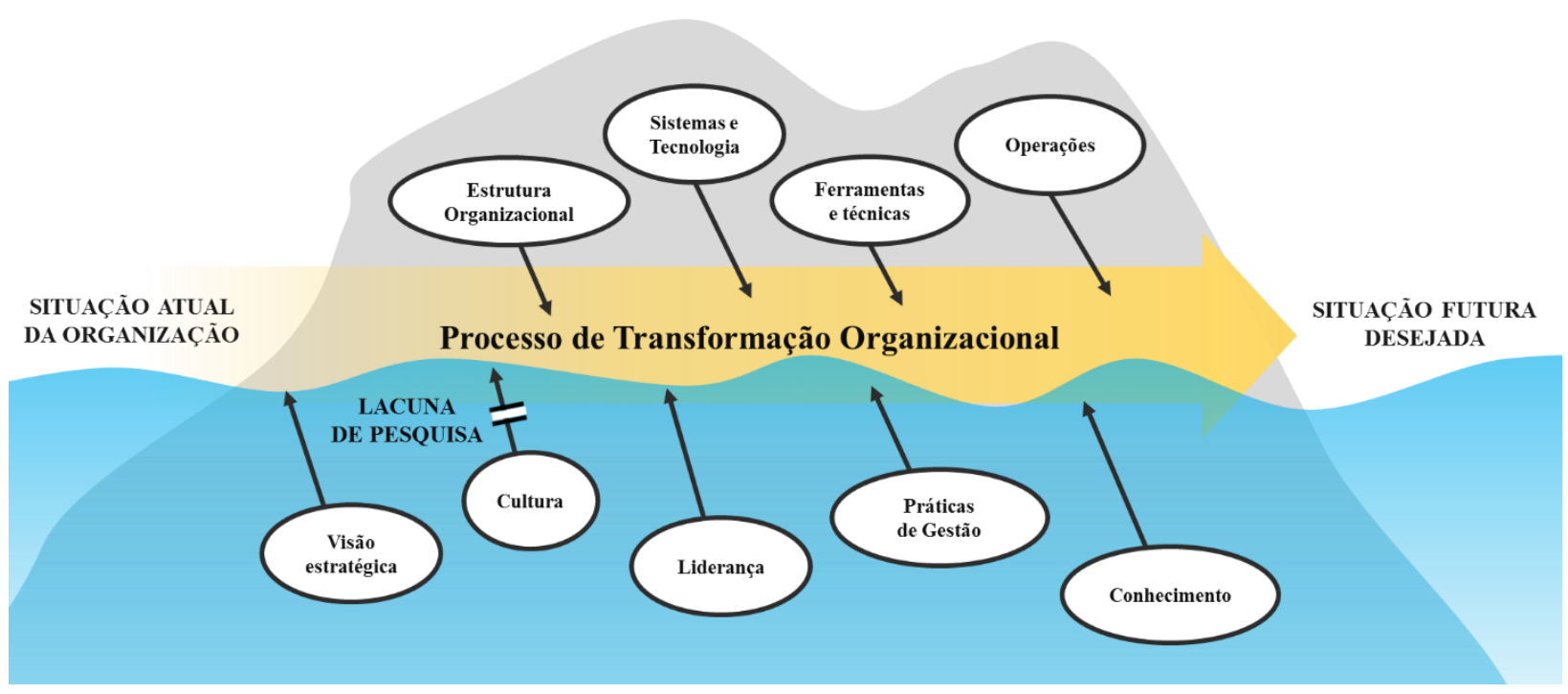

Figura 1 - Ilustração da principal lacuna de pesquisa abordada no trabalho

Para uma empresa global, diversas indagações aparecem com força cada vez mais constante: adotar uma estratégia de centralização e padronização será mais eficiente que adotar uma estratégia de descentralização e preservação da diversidade? Estas e outras indagações 
estão associadas a outras questões fundamentais, relacionadas ao contexto de mudança dos processos internos das organizações: o que mudar? O que fortalecer? O que desenvolver? Como modificar os processos? Estas questões, levantadas por Fleury, Shinyashiki e Stevanato (1997), colocam em evidencia a importância da pesquisa e estudo sobre Cultura Organizacional.

\subsection{QUESTÃO DE PESQUISA}

A principal lacuna de pesquisa deste trabalho é o fato da literatura possuir diversos modelos que tornam explícita a importância de trabalhar aspectos culturais associados aos projetos de transformação, mas, porém, não existir um modelo que explicita como a cultura deve "mudar ou evoluir" (como amplamente citado por Schein) de acordo com determinada estratégia ou projeto de transformação. Tendo em vista esta lacuna de pesquisa, este trabalho se propõe a explorar e responder a seguinte questão de pesquisa:

$\checkmark$ Como pode ser sistematizado o processo de transformação organizacional abrangendo aspectos de mudança ou evolução da cultura organizacional?

O foco do processo de transformação organizacional será no desenvolvimento e implementação dos Programas de Lean, objetivando direcionar esforços para melhorar a taxa de sucesso destes programas.

\subsection{OBJETIVO DA PESQUISA}

\subsubsection{OBJETIVO GERAL}

Este trabalho de pesquisa tem como objetivo: propor uma sistematização teórica do processo de transformação organizacional de desenvolvimento dos Programas de Lean envolvendo mudança ou evolução cultural. 
É importante salientar que o escopo do trabalho será no desenvolvimento dos Programas de Lean, responsável pela busca contínua da Excelência Operacional ${ }^{2}$. Com o atingimento deste objetivo, é esperado que os pesquisadores, agentes de mudança, líderes e gestores organizacionais tenham uma referência para realizar análises e direcionar ações e recursos de maneira mais apropriada e eficiente.

Por sua vez, em Cultura Organizacional, é importante enfatizar que este trabalho se baseia na definição de Schein (2009, p. 16) sobre Cultura Organizacional ("padrão de pressupostos básicos que dado grupo tenha descoberto ou inventado"), utilizando-se o The Competing Values Framework ( $C V F$ ) como modelo referência para diagnosticar e avaliar mudanças ou evoluções culturais. Assim como Schein (2009), este trabalho parte da crença de que sim, é possível gerenciar uma cultura organizacional, embora também reconheça a dificuldade, complexidade e abstração existente neste processo.

Desta maneira, a principal contribuição deste trabalho é sistematizar conhecimentos já existentes para dar suporte a iniciativas de mudança, no sentido de que estas iniciativas busquem reduzir a taxa de insucesso das iniciativas de implementação dos Programas de Lean, a qual tem variado entre 66\% a 90\% dos casos (Graham, 1991; Walker, 1992; Sirkin et al., 2005; Bicheno e Holweg, 2009; Atkinson, 2010; Bhasin, 2011b; Saurin et al., 2011; Bhasin, 2012a). Nesse sentido, este trabalho busca fortalecer e estimular a discussão sobre Cultura Organizacional dentro da área de Gestão de Operações, e não busca questionar, desenvolver ou formular novas teorias sobre Cultura Organizacional, mas sim apenas sistematizar o processo de alinhamento da Cultura com o Programa de Lean.

\subsubsection{OBJETIVOS ESPECÍFICOS}

O objetivo geral deste trabalho pode ser desdobrado nos seguintes objetivos específicos:

\section{$\checkmark$ Estudar e analisar a revisão da literatura em questão;}

$>$ Identificar e levantar o estado da arte da relação entre os principais temas da pesquisa (Lean, Cultura Organizacional e Gestão de Mudanças);

\footnotetext{
2 A Excelência Operacional deve prover aos clientes produtos e serviços altamente confiáveis, com custos competitivos e entregas com o mínimo de inconveniências e desvios de prazo acordados, sendo um posicionamento estratégico adotado por muitas empresas, a exemplo da Dell e Toyota (Treacy e Wieserma, 1993).
} 
$>$ Identificar os estudos de caso de Excelência em Programas de Lean ou de Mudança de Cultura Organizacional ${ }^{3}$;

L Levantar os principais elementos com possibilidade de ação da administração em termos de Cultura Organizacional;

\section{$\checkmark$ Propor uma sistematização conceitual;}

$>$ Analisar a revisão da literatura, relacionando as ações de administração voltadas para mudar ou evoluir a cultura organizacional com os projetos de transformação;

> Analisar e avaliar os estudos de caso (publicados neste campo de estudo) de mudança de cultura organizacional com foco na excelência operacional encontrados na literatura;

> Propor uma sistematização do processo de diagnóstico, avaliação e evolução da cultura organizacional alinhada com os projetos de transformação, sempre tendo como ênfase os Programas de Lean;

\section{$\checkmark$ Sintetizar recomendações e os potenciais benefícios desta sistematização;}

> Promover a discussão sobre Cultura Organizacional dentro da área de Operações e apresentar os benefícios potenciais do modelo proposto e também um direcionamento para pesquisas futuras;

\subsection{ESTRUTURA DO TEXTO DE PESQUISA}

Com base na visão geral do método de desenvolvimento deste trabalho, a estrutura do texto desta dissertação foi organizada em cinco seções, conforme segue:

$\checkmark$ Capítulo 1 - Introdução: apresentação e contextualização da pesquisa.

$\checkmark$ Capítulo 2 - Método de Pesquisa: planejamento e definição do método utilizado.

$\checkmark$ Capítulo 3 - Fundamentação Teórica: revisão e estrutura teórica do trabalho.

$\checkmark$ Capítulo 4-Desenvolvimento: ruptura da teoria atual e construção da proposta teórica.

$\checkmark$ Capítulo 5 -Conclusão e Considerações Finais.

\footnotetext{
${ }^{3}$ Mudança de Cultura Organizacional: não necessariamente remete a uma mudança radical do perfil dominante da cultura organizacional, mas, sim, remete à implementação de mudanças em maior ou menor grau que possam vir a extinguir, reduzir, fortalecer ou desenvolver crenças e valores, caracterizando assim uma mudança de Cultura Organizacional.
} 


\section{MÉTODO DE PESQUISA}

\subsection{VISÃO GERAL E CARACTERIZAÇÃO}

A importância do método de pesquisa advém da necessidade de embasamento científico adequado, sendo caracterizado pela definição da melhor abordagem de pesquisa para responder às questões de pesquisa, além da definição dos métodos e técnicas para seu planejamento e condução (Miguel, 2007). Em virtude do fenômeno desta pesquisa - mudança de Cultura Organizacional com foco na excelência operacional - ser relativamente recente, e também pouco difundido na área de gestão de operações, esta pesquisa pode ser classificada como:

\section{$\checkmark$ Pesquisa qualitativa de caráter exploratório;}

Por ser considerado o mais apropriado para responder às questões de pesquisa e atingir os objetivos propostos por este trabalho, o procedimento de pesquisa utilizado será a pesquisa bibliográfica, tanto exploratória quanto sistemática. Ambas são a base para o desenvolvimento conceitual dos modelos e recomendações propostas neste trabalho. O Quadro 2 traz uma sintetize mais precisa com relação a caracterização desta pesquisa e sua respectiva justificativa, enquanto que a Figura 2 apresenta uma visão geral do processo de pesquisa e construção teórica do trabalho. Pelo caráter teórico desta pesquisa, houve uma preocupação com o cumprimento de certos requisitos formais que todo trabalho desta natureza deva possuir. Nesse sentido, duas referências são muito relevantes nesta pesquisa: Quivy e Campenhoudt (1995) e Whetten (1989), sendo o primeiro discutido nos parágrafos seguintes e o último na seção 2.2.

Com relação à articulação das etapas da pesquisa, Quivy e Campenhoudt (1995) trazem os princípios de uma pesquisa contidos em três principais eixos:

1) Ruptura: A "bagagem teórica" muitas vezes possui grandes armadilhas, pois traz consigo certas aparências enganosas e preconceituosas. Por isto, o primeiro eixo da pesquisa consiste da ruptura de ideais preconcebidas e falsas evidências. 
2) Construção: Envolve a construção teórica, fundamentada em um raciocínio lógico e um sistema conceitualmente organizado, para que posteriormente seja possível colocar esta construção à prova.

3) Constatação: O resultado da pesquisa somente terá caráter científico quando for validado através de constatações da realidade concreta.

Neste trabalho, a "ruptura" terá início na seção “3. Fundamentação Teórica”, sendo concluída no início da seção “4. Desenvolvimento da Proposta Conceitual”, neste momento, deverá ser identificado quais são os problemas, lacunas e oportunidades encontradas na análise dos estudos de caso. A "construção" ocorrerá na seção "4. Desenvolvimento da proposta conceitual", a qual englobará dois conceitos teóricos: (1) Visão geral do contexto do projeto de transformação, realizando o alinhamento dos objetivos da empresa e, também do projeto de transformação, com a cultura organizacional; (2) Estruturação da sistemática de mudança e evolução da cultura organizacional, de acordo com a fundamentação teórica e os estudos de caso da mesma. Por fim, a "constatação" da sistematização proposta somente poderá ser feita com o desenvolvimento de trabalhos futuros, os quais impliquem necessariamente em aplicações práticas da sistemática proposta.

Sob este contexto, é importante enfatizar que Gestão de Mudanças e Transformação são conceitos bem diferentes. Segundo Ashkenas (2015), diferentemente da Gestão de Mudanças, uma Transformação não foca apenas uma mudança bem definida, mas sim em um portfólio de mudanças, desta maneira o objetivo da Transformação não é apenas implementar uma mudança, mas sim garantir que a organização seja capaz de se reinventar e descobrir um novo modelo de negócio. Neste trabalho, o termo Transformação será utilizado para remeter a um portfólio de projetos de mudanças que tenham um escopo de desenvolvimento e implementação com várias mudanças organizacionais, as quais necessariamente estejam associadas a mudanças de paradigma e, portanto, fazem fronteira com o processo de mudança cultural.

\subsection{O QUE CONSTITUÍ UMA CONTRIBUIÇÃO TEÓRICA?}

Para Whetten (1989), pesquisas que estejam no processo de construção de conceitos e de melhoria de teorias existentes são sempre bem-vindos, desde que o processo de desenvolvimento e os respectivos critérios de avaliação sejam claros e bem aceitos. Sob este 
ponto de vista, o autor traz sete principais questões sobre "o que constitui uma contribuição teórica”, assim descritas:

* O que é novo? Segundo Whetten (1989), os autores não estão necessariamente procurando por teorias totalmente novas, mas sim modificações ou extensões de teorias atuais que sejam capazes de influenciar de maneira significativa a visão atual dos estudiosos. Existem dois critérios para julgar os fatores incluídos no trabalho: abrangência (todos os fatores relevantes foram incluídos?) e parcimônia (existe algum fator que deveria ser excluído por não acrescentar valor?). Nestas situações, vale a pena pecar pelo excesso do que pela falta, afinal, em uma validação posterior será mais fácil excluir do que inserir novos fatores ao modelo.

* E daí? O objetivo principal de uma pesquisa com contribuição teórica deve ser alterar a prática da pesquisa provocando alterações na teoria, e não apenas criticar de maneira superficial determinados modelos (Whetten, 1989). Tanto quanto propor soluções novas, tal contribuição deve apontar as correções ou deficiências das teorias atuais.

* Por que dessa forma? Para que haja validade da pesquisa, a lógica do novo modelo deve ser construída de maneira sensata e com base na prática organizacional, inclusive, as suposições do autor devem ser explícitas tanto quanto as evidências que suportam a contribuição teórica proposta (Whetten, 1989).

* Bem-feita? Segundo Whetten (1989), a proposta deve transmitir completude e profundidade, promovendo uma qualidade conceitual ao invés de superficial, com argumentos refletindo amplo entendimento do tema de pesquisa.

* Texto bem elaborado? O texto deve ser longo o suficiente para cobrir todo o tema de pesquisa, porém curto o bastante para ser interessante (Whetten, 1989).

* Por que agora? O tema abordado deve ser relevante para os estudiosos da área, de tal maneira que contribua com questões atuais, e promova novas discussões na área (Whetten, 1989).

* Quem se importa? O texto da pesquisa pode até ser tecnicamente adequado, mas no fundo ele precisa ser direcionado à uma grande parcela de leitores acadêmicos. Segundo Whetten (1989), para que seja bem avaliado e passível de publicação, um texto pouco atraente do ponto de vista do leitor, deve compensar tal deficiência com maior contribuição nas questões 1 e 2 (“O que é novo? " e "E daí? ”, respectivamente). 

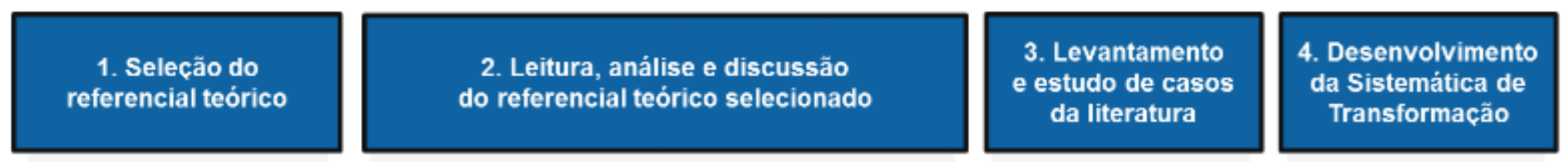

5. Conclusões e

Consideraçōes Finais

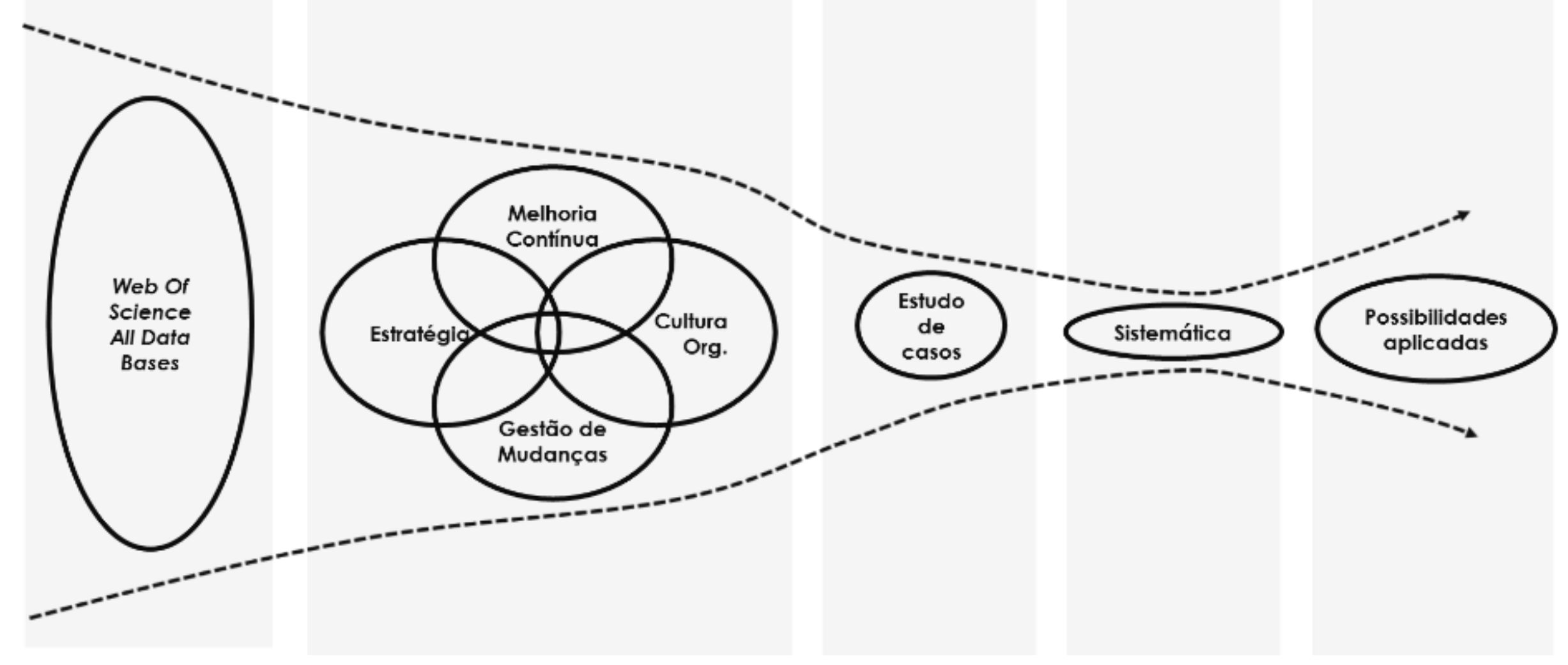

Figura 2 - Visão geral do processo de pesquisa e construção teórica do trabalho

Observação: a "Ruptura" com a teoria atual ocorre ao longo das etapas (2) e (3), sendo concluída logo no início da etapa (4), sendo a etapa (4) responsável pela "Construção" da sistemática proposta. 


\section{Característica Definição Justificativa}

\begin{tabular}{|c|c|c|}
\hline $\begin{array}{l}\text { Abordagem } \\
\text { do problema }\end{array}$ & Qualitativa & $\begin{array}{l}\text { Mais do que quantificar ou comprovar a validade de poucos conceitos, esta pesquisa busca estudar, questionar } \\
\text { e entender o porquê das coisas. Temática relativamente recente e pouco difundida no meio corporativo. Para } \\
\text { Gerhardt e Silveira (2009), esta pesquisa exige, portanto, uma análise de informações mais intuitiva do que } \\
\text { através do uso de procedimentos estatísticos, utilizando-se da coleta de dados sem instrumentos formais e } \\
\text { estruturados. }\end{array}$ \\
\hline $\begin{array}{l}\text { Natureza } \\
\text { da Pesquisa }\end{array}$ & Básica & $\begin{array}{l}\text { A pesquisa busca gerar conhecimentos novos e úteis para o meio corporativo, tendo uma natureza de pesquisa } \\
\text { básica teórica e não prática. Uma pesquisa prática foi desconsiderada devido à inviabilidade de realizar uma } \\
\text { aplicação prática de transformação organizacional envolvendo mudança de cultura e, inclusive, por ser } \\
\text { necessário um projeto com duração de aplicação maior que o tempo desta pesquisa de mestrado. }\end{array}$ \\
\hline Objetivos & Exploratória & $\begin{array}{l}\text { A pesquisa tem como objetivo gerar maior compreensão do problema em estudo, tornando-o mais explícito e } \\
\text { possibilitando a construção de novos modelos teóricos. Segundo Prodanov e Freitas (2013), por possuir um } \\
\text { planejamento flexível, a pesquisa exploratória possibilita a descoberta de um novo tipo de enfoque para o campo } \\
\text { de pesquisa, permitindo o estudo do tema sob diversos ângulos e aspectos. A pesquisa pode envolver } \\
\text { levantamento bibliográfico e análise de exemplos que estimulem a compreensão (Prodanov e Freitas, 2013). }\end{array}$ \\
\hline $\begin{array}{l}\text { Fonte de } \\
\text { evidências }\end{array}$ & Bibliográfica & $\begin{array}{l}\text { Responsável por agregar os estudos de caso da literatura ao trabalho e também para definir a fundamentação } \\
\text { teórica sobre o trabalho de pesquisa. Uso de levantamento bibliográfico sobre referências teóricas e aplicações } \\
\text { práticas já realizadas que abordem o tema de pesquisa, buscando informações que ajudem a compreender o } \\
\text { problema do qual se procura uma resposta (Fonseca, 2002). }\end{array}$ \\
\hline Procedimentos & $\begin{array}{l}\text { Revisão } \\
\text { Bibliográfica } \\
\text { Sistemática } \\
\text { e exploratória }\end{array}$ & $\begin{array}{l}\text { De acordo com Gil (2007), a Pesquisa Exploratória pode conter fundamentação teórica na revisão bibliográfica, } \\
\text { em entrevistas realizadas com pessoas que tiveram experiências com o problema ou através da análise de } \\
\text { exemplos que favoreçam a compreensão do problema em estudo. Devido à necessidade de gerar conhecimentos } \\
\text { novos, e limitações de se realizar um estudo de caso prático, esta pesquisa terá a Revisão Bibliográfica como } \\
\text { único procedimento, fazendo uso dos conceitos e estudos de caso presentes na literatura. Para tal, utilizará uma } \\
\text { revisão sistemática, objetivando levantar o “estado da arte" no campo de estudo, e também uma revisão } \\
\text { exploratória, utilizando-se das principais referências nas áreas deste trabalho. }\end{array}$ \\
\hline
\end{tabular}

\section{Quadro 2 - Caracterização e justificativa do método de pesquisa}


Além de buscar compreender os três Princípios de Pesquisa de Quivy e Campenhoudt (1995), este trabalho se baseará em Whetten (1989) como principal referência para realizar o desenvolver e legitimar a contribuição teórica proposta nesta pesquisa. Neste sentido, o Quadro 3 traz uma compreensão e resumo geral desta pesquisa, associando as seções do trabalho com os passos da Pesquisa anteriormente, com os três princípios de pesquisa de Quivy e Campenhoudt (1995) e também com as questões de Whetten (1989).

\begin{tabular}{|c|c|c|c|}
\hline $\begin{array}{l}\text { SEÇÃO DO } \\
\text { TRABALHO }\end{array}$ & ATIVIDADES & $\begin{array}{c}\text { PRINCÍPIOS } \\
\text { DE PESQUISA }\end{array}$ & $\begin{array}{l}\text { CONTRIBUIÇÃO } \\
\text { TEÓRICA }\end{array}$ \\
\hline 1 - Introdução & $\begin{array}{l}\text { 1.1 Definição do tema e } \\
\text { contexto de pesquisa } \\
\text { 1.2 Definição do objetivos e } \\
\text { questões da pesquisa }\end{array}$ & - & $\begin{array}{l}\text { O que é novo? E } \\
\text { daí? Por que agora? } \\
\text { Quem se importa? }\end{array}$ \\
\hline $\begin{array}{l}\text { 2-Método } \\
\text { de Pesquisa }\end{array}$ & $\begin{array}{l}2.1 \text { Orientação metodológica } \\
\text { 2.2 Definição do método }\end{array}$ & - & $\begin{array}{c}\text { Por que dessa } \\
\text { forma? }\end{array}$ \\
\hline $\begin{array}{l}\text { 3- Fundamentação } \\
\text { Teórica }\end{array}$ & $\begin{array}{l}\text { 3.1 Compreensão do problema } \\
\text { e questões da pesquisa } \\
\text { 3.2 Revisão Bibliográfica } \\
\text { Sistemática e Exploratória }\end{array}$ & \multirow[t]{2}{*}{ Ruptura } & Bem-feita? \\
\hline 4-Desenvolvimento & $\begin{array}{l}\text { 4.1 Análise Crítica da literatura } \\
4.2 \text { Construção e descrição da } \\
\text { proposta teórica }\end{array}$ & & $\begin{array}{l}\text { E daí? } \\
\text { O que é novo? } \\
\text { Por que dessa } \\
\text { forma? }\end{array}$ \\
\hline $\begin{array}{l}\text { 5-Conclusões e } \\
\text { Recomendações }\end{array}$ & $\begin{array}{l}5.1 \text { Conclusões e } \\
\text { Recomendações }\end{array}$ & Construção & $\begin{array}{c}\text { E daí? Pesquisa } \\
\text { bem-feita? Texto } \\
\text { bem elaborado? } \\
\text { Quem se importa? }\end{array}$ \\
\hline
\end{tabular}

Quadro 3 - Orientação geral da contribuição teórica e princípios de pesquisa

\subsection{REVISÃO BIBLIOGRÁFICA SISTEMÁTICA (RBS)}

A Revisão Bibliográfica Sistemática (RBS) foi selecionada para se ter conhecimento do estado da arte da relação existente entre Programas de Lean, Gestão de Mudanças e Cultura Organizacional. Afinal, a interseção destas três grandes áreas apresenta uma grande diversidade de artigos científicos. A RBS segue as fases propostas por Tranfield, Denyer e Smart (2003), ilustrados na Figura 3. 

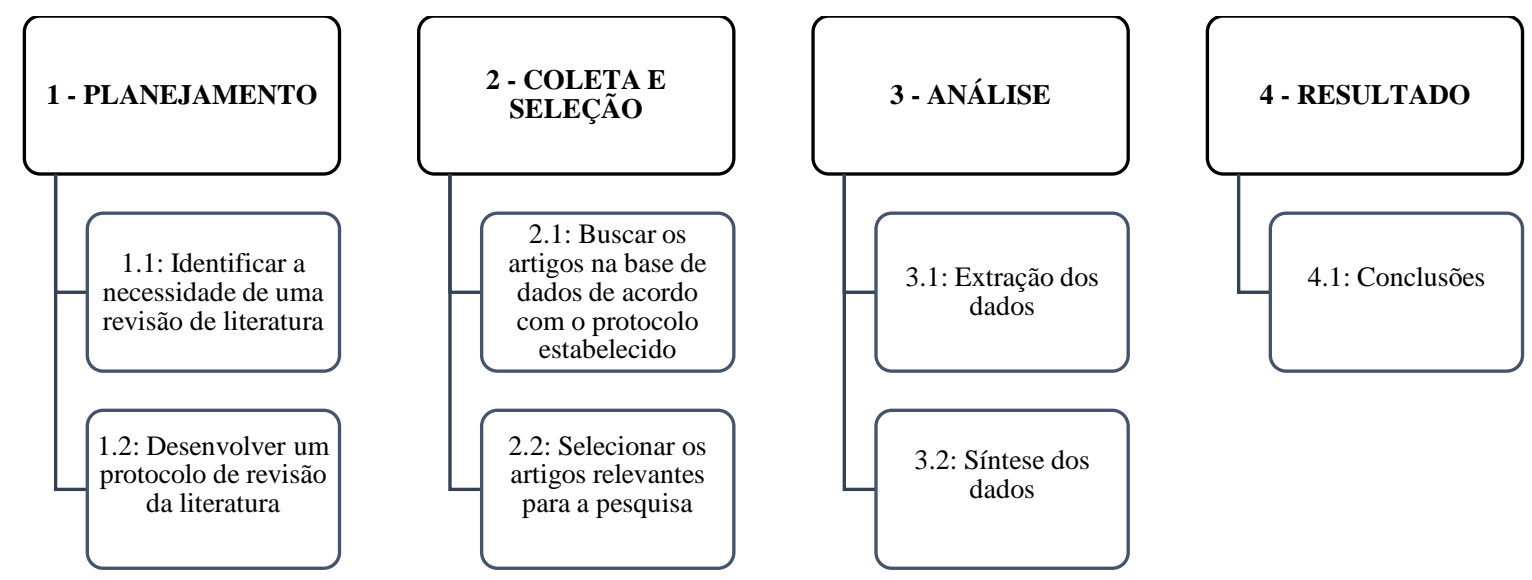

Figura 3 - Estrutura de Trabalho da Revisão Bibliográfica Sistemática (RBS)

Fonte: adaptado de Tranfield, Denyer e Smart (2003) e Mello (2014)

Antes de ter início a Coleta de Dados da RBS, foram feitas cerca de três rodadas de esboço e compreensão do método da RBS. Neste momento, foram analisados: (a) sob o ponto de vista das questões da pesquisa, quais palavras-chave deveriam ser utilizadas, (b) sob o ponto de vista das publicações da área, como e quais palavras-chave deveriam ser utilizadas na RBS, e (c) qual o volume de artigos que resultariam.

No primeiro esboço, durante os meses de março e abril de 2014, foi identificado que buscas como "Lean AND Culture AND Change Management" resultariam em menos de dez artigos. Estes artigos foram analisados, e o protocolo de pesquisa revisado. A partir desta primeira análise, foi tomada a decisão de expandir a pesquisa para além da interseção entre as três áreas de estudo (Melhoria Contínua ${ }^{4}$, Gestão de Mudanças e Cultura Organizacional), passando a valer pelo menos a interseção de duas grandes áreas (Melhoria Contínua E Gestão de Mudanças; Melhoria Contínua E Cultura Organizacional; Cultura Organizacional E Gestão de Mudanças). Inclusive, neste momento, foi identificado que palavras como "Organizational Culture" também poderiam ser utilizadas como "Organisational Culture", expandido desta maneira as possibilidades de pesquisa. Por sua vez, o segundo e o terceiro esboço da RBS foram úteis para definir os domínios de pesquisa que seriam utilizados e também as áreas de pesquisa dentro do Web Of Science. A partir destes esboços, chegou-se ao Protocolo da RBS ilustrado no Quadro 4.

\footnotetext{
${ }^{4}$ Como existiam poucos artigos associados somente ao Lean, dentro da temática de estudo, optou-se por expandir a RBS para outros Programas de Melhoria Contínua, como exemplo do TQM e Six Sigma. Desta maneira, foram identificados mais artigos para compor a fundamentação teórica do trabalho, embora o desenvolvimento da pesquisa tenha foco apenas nos Programas de Lean.
} 


\section{ELEMENTO PROTOCOLO DE PESQUISA DA RBS}

\begin{tabular}{|c|c|}
\hline $\begin{array}{l}\text { Grupos de } \\
\text { Pesquisa }^{5}\end{array}$ & $\begin{array}{l}\text { Grupo 1: Melhoria Contínua } \\
\text { Grupo 2: Cultura Organizacional } \\
\text { Grupo 3: Gestão de Mudanças }\end{array}$ \\
\hline $\begin{array}{l}\text { Palavras-chave } \\
\text { pesquisadas }\end{array}$ & $\begin{array}{l}\text { Grupo 1: Operations, Continuous Improvement, Lean, Supply Chain, Logistics, } \\
\text { Information Technology, Quality, Total Quality, TQM, Agile ou Six Sigma } \\
\text { Grupo 2: Organizational Culture, Organisational Culture ou Corporate Culture } \\
\text { Grupo 3: Change Management }\end{array}$ \\
\hline $\begin{array}{l}\text { Operador } \\
\text { boleano }\end{array}$ & $\begin{array}{l}\text { Entre Grupos: AND } \\
\text { Entre Palavras-chave do grupo: OR }\end{array}$ \\
\hline Base de dados & $\begin{array}{l}\text { Web of Science. Justificativa: foi o mecanismo de busca com melhor avaliação } \\
\text { na análise quantitativa de Buchinger, Cavalcanti e Hounsell (2014). }\end{array}$ \\
\hline $\begin{array}{l}\text { Domínios de } \\
\text { Pesquisa }\end{array}$ & Science Technology ou Social Sciences \\
\hline $\begin{array}{l}\text { Áreas de } \\
\text { Pesquisa } \\
\text { (Resultados) }\end{array}$ & $\begin{array}{l}\text { Management (464), Business (199), Operations Research Management Science } \\
\text { (138), Engineering Industrial (131), Engineering Manufacturing (67), Psychology } \\
\text { Applied (36), Engineering Multidisciplinary (24), Psychology Multidisciplinary } \\
\text { (9), Sociology (6), Psychology (4), Social Issues (4), Anthropology (2), } \\
\text { Humanities Multidisciplinary (2) }\end{array}$ \\
\hline $\begin{array}{l}\text { Critérios } \\
\text { de Exclusão }\end{array}$ & $\begin{array}{l}\text { 1) Artigos que não estavam relacionados a Programas de Melhoria Contínua } \\
\text { (Lean, Six Sigma ou Total Quality Management), Cultura Organizacional ou } \\
\text { Gestão de Mudanças; } \\
\text { 2) Indisponibilidade de artigos ou dificuldade de acesso; } \\
\text { 3) Artigos que discutiram pouco o tema Cultura Organizacional, ou } \\
\text { apresentaram o termo somente uma única vez no texto - sem considerar o } \\
\text { título, resumo ou palavra-chave; } \\
\text { 4) Artigos que não contemplavam aspectos de mudança organizacional; }\end{array}$ \\
\hline Idioma & Inglês \\
\hline $\begin{array}{l}\text { Tipos de } \\
\text { documento }\end{array}$ & Article e Proceedings Paper \\
\hline $\begin{array}{l}\text { Anos de } \\
\text { Publicação }\end{array}$ & Sem filtro \\
\hline
\end{tabular}

\section{Quadro 4 - Protocolo de Pesquisa da RBS}

Seguindo as fases propostas por Tranfield, Denyer e Smart (2003) e Mello (2014), a Fase 3 (Análise) está representada na Seção 4 (Desenvolvimento) deste trabalho, e a Fase 4 (Conclusão) na Seção 5 (Conclusão e Recomendações). A pesquisa foi realizada de acordo com o Protocolo de Pesquisa apresentado no Quadro 4, o qual identificou inicialmente 1.337 artigos dentro do escopo de pesquisa. Neste momento, durante os meses de abril e maio de

\footnotetext{
${ }^{5}$ Devido ao foco no "processo de mudança", a área de Estratégia teve uma revisão Exploratória e não Sistemática nesse trabalho, pois foi observado que a intersecção das quatro áreas de estudo iria restringir demasiadamente o universo de artigos em estudo.
} 
2014, a grande área Gestão de Operações caracterizada por Melhoria Contínua possuía um total de 7.854 artigos, a grande área Gestão de Mudanças possuía um total de 4.269 artigos e, por sua vez, Cultura Organizacional possuía 5.601 artigos dentro da base de dados selecionada. Na primeira seleção da RBS foram selecionados 1.337 artigos $(721+496+143+7)$, representando 7,54\% dos artigos de um total de até 17.724 potenciais artigos de leitura, garantindo e possibilitando desta maneira a leitura dos principais trabalhos em um estudo "no

estado da arte". Após esta primeira seleção de artigos, foram realizadas outras quatro seleccões ilustradas e descritas na Figura 4. considerada como "Exploratória" e não "Sistemática", no intuito de manter foco mais no processo de

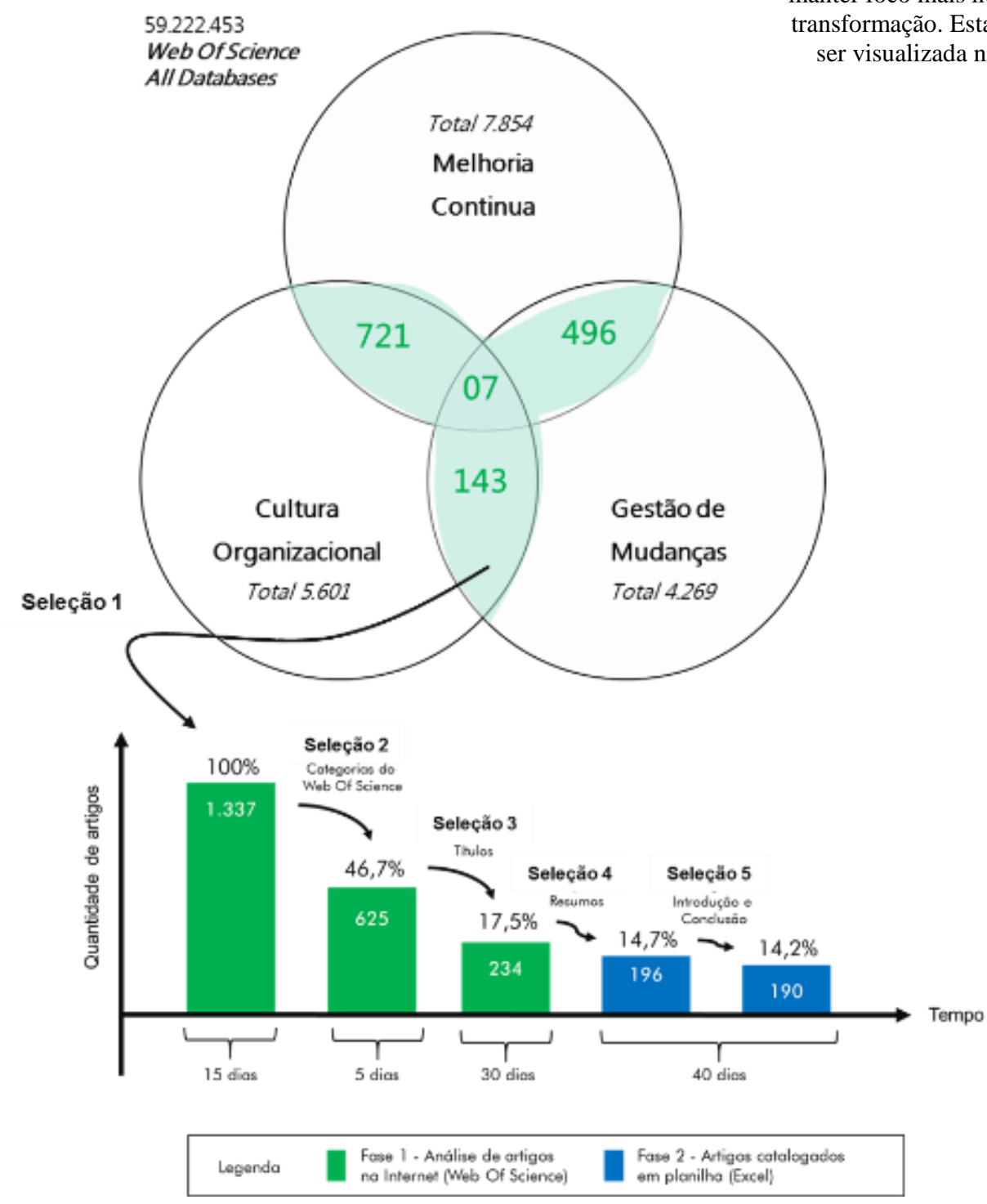

Figura 4 - Evolução da seleção de artigos através da RBS

Ao final destas quatro seleções, chegou-se ao número final de 190 artigos (14,21\% dos 1.337 listados na primeira seleção, ou $1,07 \%$ dos 17.724 potenciais artigos de leitura), dos quais 
todos foram lidos e, eventualmente, foram inseridos ou eliminados do trabalho de acordo com os critérios do Protocolo de Pesquisa.

Com relação aos 1.337 artigos levantados inicialmente na RBS, o Gráfico 3 ilustra o número de publicações e também o número de citações por ano, levando-se em consideração os últimos 20 anos de pesquisas. Vale a pena ressaltar que esta pesquisa no Web Of Science ocorreu em maio de 2014, explicando assim a queda de publicações e citações no ano de 2014. No intuito de manter registro das publicações que ocorreriam ao longo de 2014 e, também durante o ano de 2015 (desenvolvimento do trabalho), foram criados alertas de pesquisa no Web Of Science, de tal maneira que o autor pudesse acompanhar a publicações relacionadas ao escopo de pesquisa inicial. Estas pesquisas novamente passaram pelos mesmos critérios de seleção apresentados no Protocolo de Pesquisa.
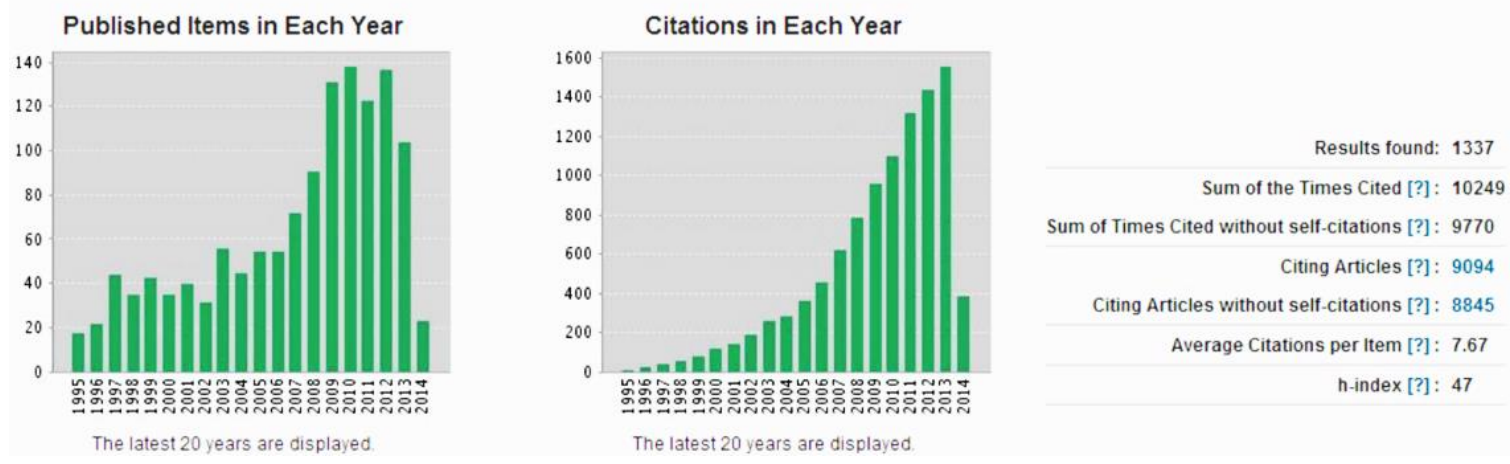

Gráfico 3 - Evolução das citações e publicações da RBS, de 1995 a 2014.

Fonte: www.webofknowledge.com (acesso em 16/05/2014)

Com relação aos 190 artigos selecionados para leitura, os Gráficos 4, 5 e 6 trazem dados que representam a origem destes artigos, sendo: os dez principais países, as dez principais universidades e os dez principais periódicos com o maior número de publicações dentre tais artigos, respectivamente. Após terem sido realizadas as quatro seleções, ilustradas na Figura 4, os artigos passaram a ser excluídos seguindo os critérios do Protocolo de Pesquisa.

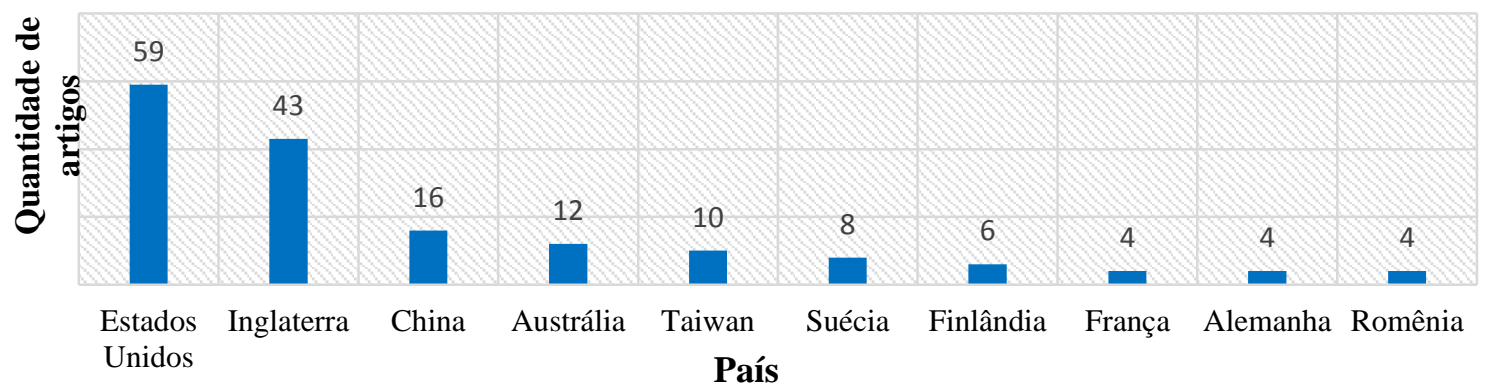




\section{Gráfico 4 - Os dezpaíses com o maior núm. de publicações na RBS.}

Fonte: www.webofknowledge.com (acesso em 16/05/2014)

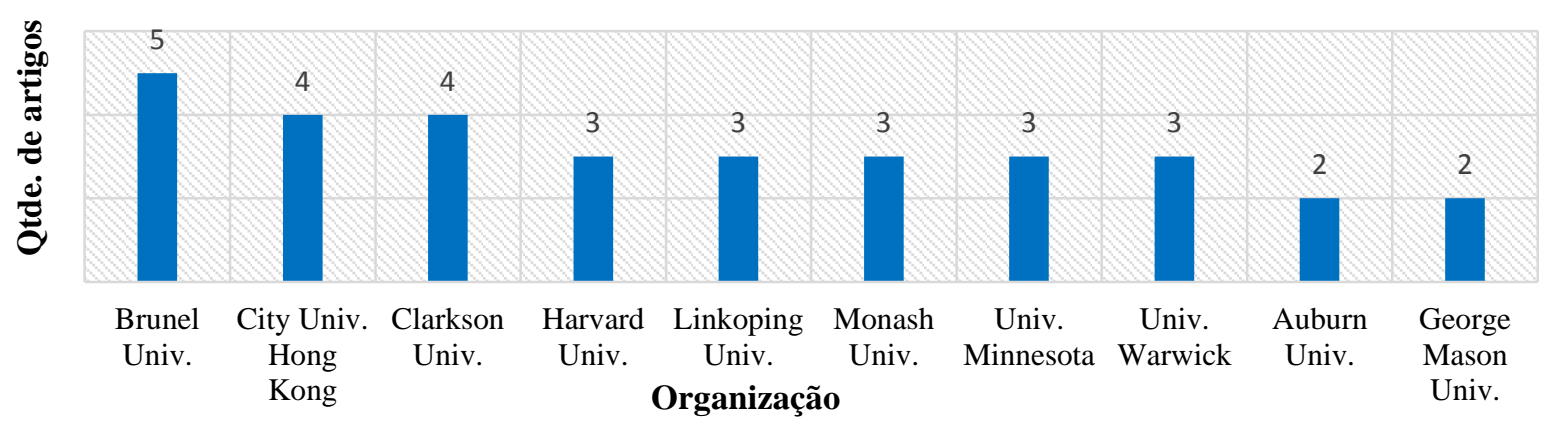

Gráfico 5 - As dez universidades com o maior núm. de publicações na RBS.

Fonte: www.webofknowledge.com (acesso em 16/05/2014)

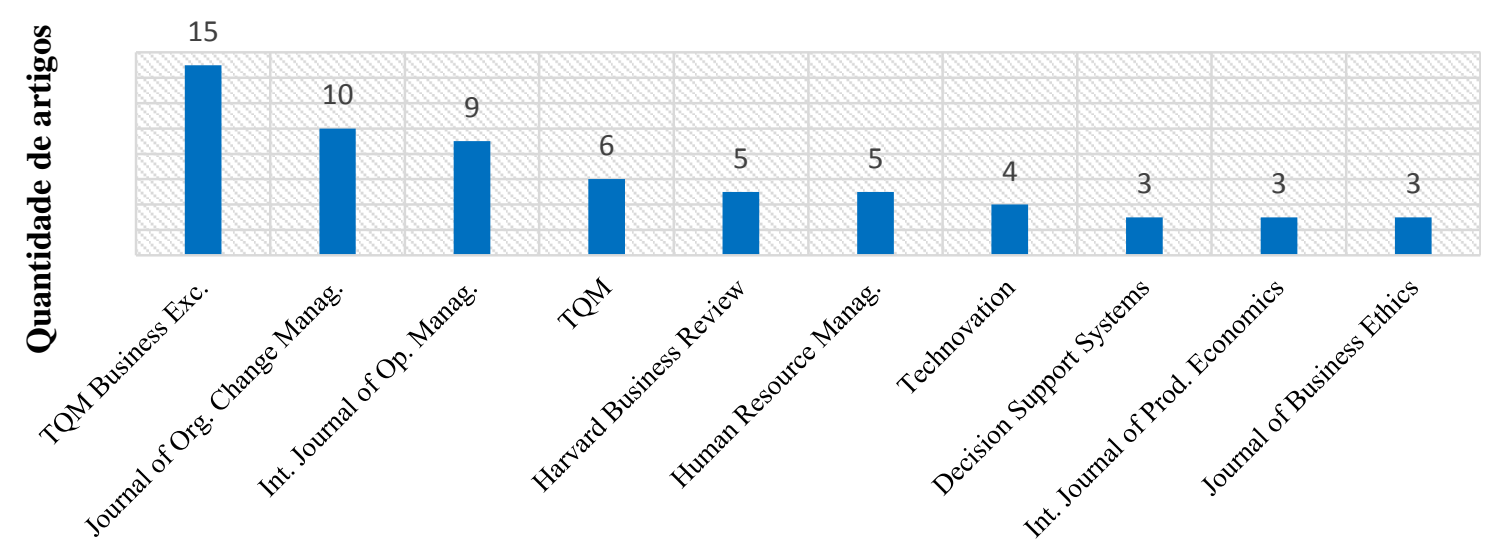

Fonte dos artigos

Gráfico 6 - Os dez periódicos com o maior número de publicações na RBS.

Fonte: www.webofknowledge.com (acesso em 16/05/2014)

\subsection{REVISÃO BIBLIOGRÁFICA EXPLORATÓRIA}

Tendo em vista o fato da Revisão Bibliográfica Sistemática estar concentrada na intersecção das três grandes áreas de estudo, alguns livros tidos como referência nestas áreas não poderiam faltar em uma revisão que se propõe a ser "estado da arte". Nesse sentido, a Revisão Bibliográfica Exploratória busca somar conhecimentos de "referências no assunto" ao corpo de conhecimento em estudo. A Figura 5 retoma os três campos de estudo deste trabalho, 
já apresentados anteriormente, e acrescenta algumas das principais referências que entram no trabalho bibliográfico através desta revisão exploratória.

Neste trabalho, optou-se por inserir Revisão Biográfica Exploratória antes da RBS, de tal maneira que a revisão exploratória forme a "coluna vertebral" do texto de revisão, e os artigos da RBS componham as demais partes do corpo de revisão da literatura e fundamentação teórica da sistemática proposta. Para dar ênfase na revisão sobre o "processo de mudança", a revisão sistemática não contemplou o campo Estratégia, ficando este desafio para a revisão Exploratória do trabalho, como ilustrado na Figura 5.

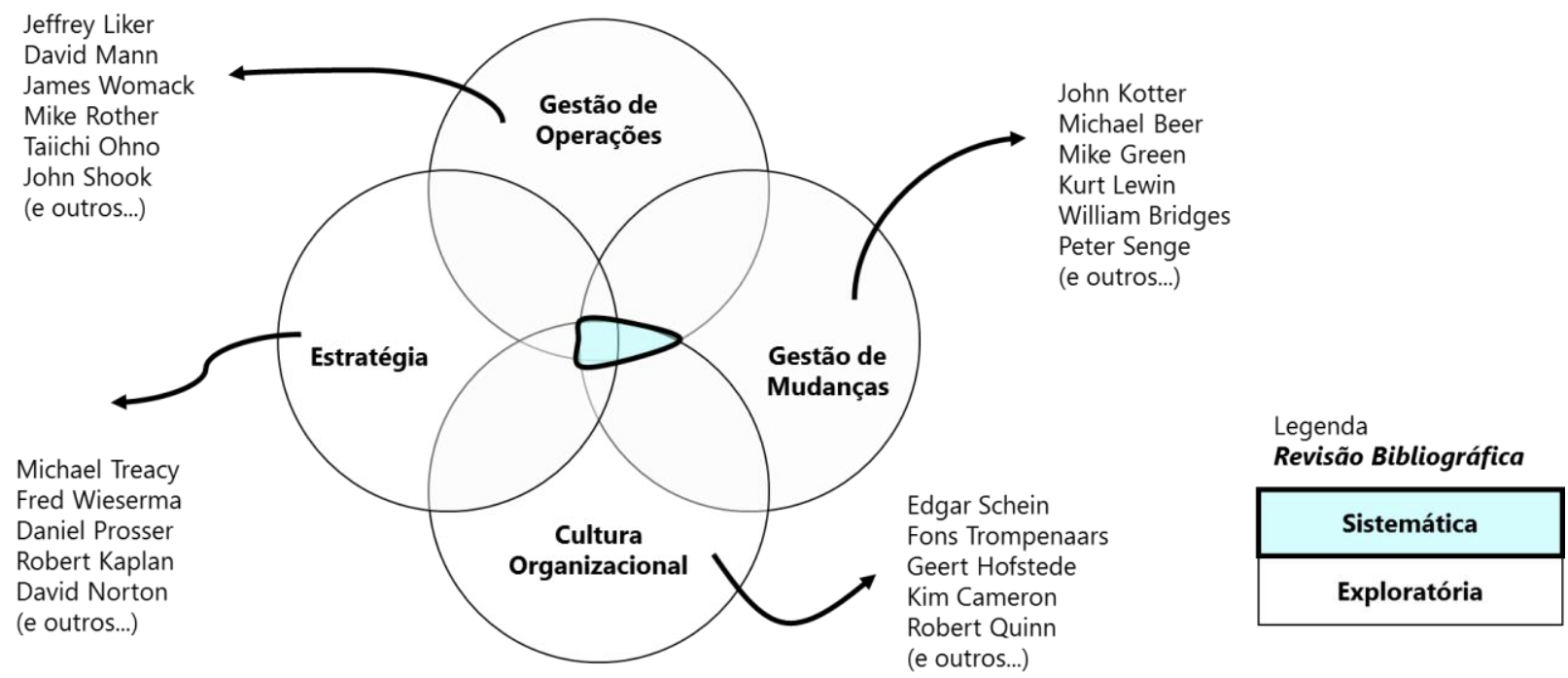

Figura 5 - Algumas das principais referências da revisão exploratória 


\section{FUNDAMENTAÇÃO TEÓRICA}

Este capítulo está organizado em quatro seções: (3.1) Alinhamento Estratégico; (3.2) Melhoria Contínua; (3.3) Cultura Organizacional; (3.4) Gestão de Mudanças; (3.5) Estudos de Caso da Literatura.

\subsection{ALINHAMENTO ESTRATÉGICO}

Este trabalho tem foco no "processo de mudança", e por este motivo a revisão de estratégia é estritamente Exploratória e não Sistemática. O objetivo desta seção é analisar aspectos de alinhamento estratégico, e não todos os modelos e ferramentas de estratégia.

Em termos culturais, é preciso reconhecer que a estratégia definida pela empresa irá guiar a definição da "Cultura Organizacional Desejada" por uma determinada organização. Nesse sentido, a Cultura Futura é tida como uma variável dependente e a Estratégia Futura como variável independente. No entanto, quando analisando o estado atual da organização, é preciso reconhecer que a Estratégia Atual tem caráter de variável dependente e a Cultura Atual variável independente.

No intuito de facilitar a compreensão do leitor sobre o texto, a Figura 2 ("visão geral do processo de pesquisa e construção teórica do trabalho") será resgatada nas próximas seções, ilustrando o papel de cada uma das etapas desta revisão bibliográfica no processo de pesquisa, conforme ilustrado na Figura 6. Isto se faz importante no intuito de posicionar logicamente o leitor no processo de construção da sistemática proposta.

\section{Estratégia}

Segundo Johnson, Scholes e Whittington (2008) uma Estratégia pode ser definida como a direção e o escopo de atuação de uma organização no longo prazo, em busca de obter 
vantagem competitiva em um ambiente de negócios em constante mudança através da configuração dos recursos e das competências organizacionais, tendo como objetivo atender às expectativas dos stakeholders do negócio. Nesse sentido, os autores propõem um Modelo de Estratégia representado pela Figura 7, incluindo aspectos de Posicionamento Estratégico, Escolhas Estratégicas e Ações Estratégicas.

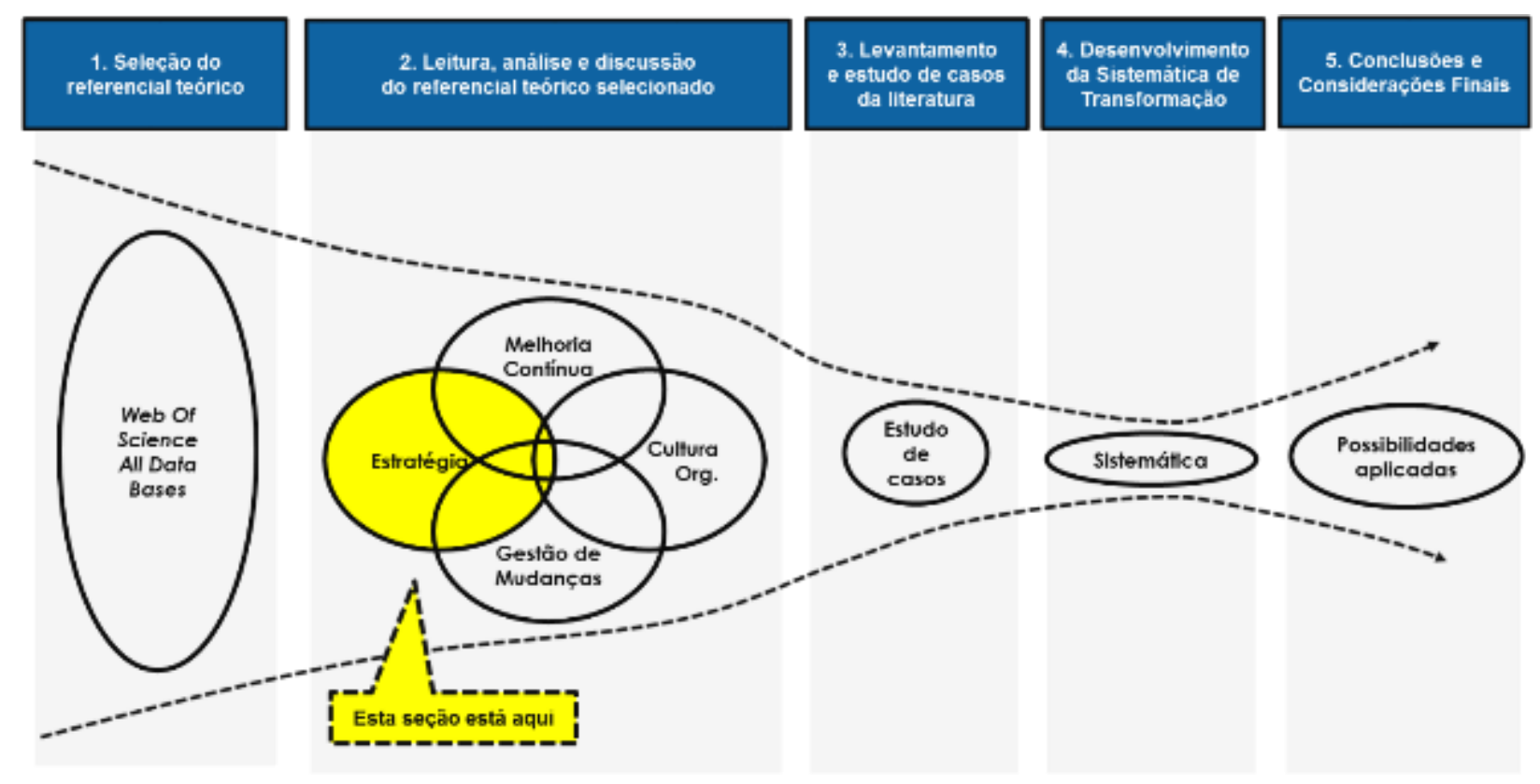

Figura 6 - O papel da revisão sobre Estratégia no processo desta pesquisa

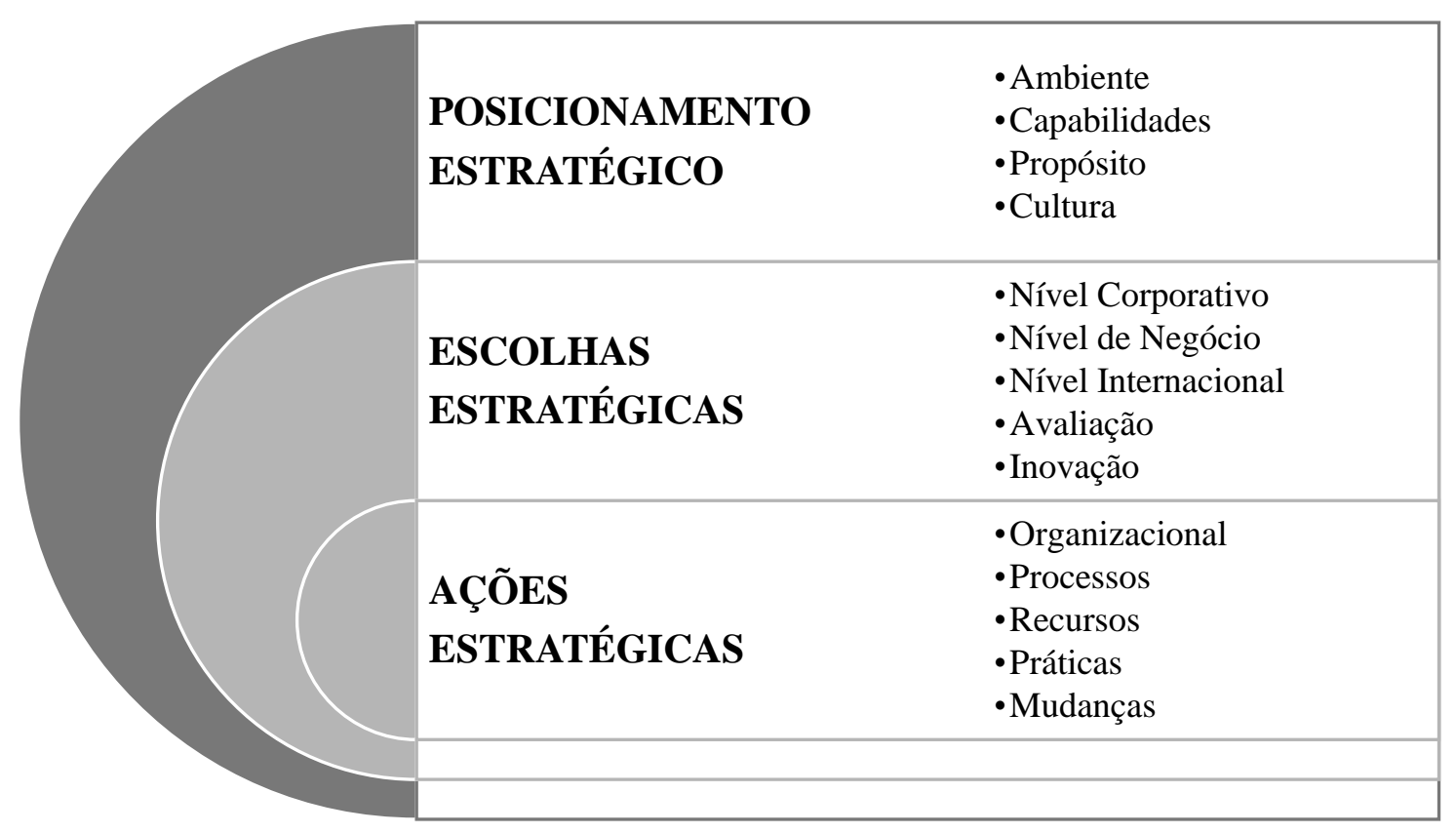

Figura 7 - Modelo de Estratégia Corporativa para uma Gestão Estratégica

Fonte: Johnson, Scholes e Whittington (2008, pp. 12) 
Neste modelo, os autores Johnson, Scholes e Whittington (2008) definem as seguintes decisões estratégicas:

$\checkmark$ Definir a direção de longo prazo da organização;

$\checkmark$ Definir o escopo das atividades organizacionais;

$\checkmark$ Obter vantagem competitiva com relação aos concorrentes;

$\checkmark$ Promover mudanças no ambiente de negócios;

$\checkmark$ Promover novos recursos e competências;

$\checkmark$ Desenvolver uma proposta de valor e gerenciar expectativas dos stakeholders;

Segundo Treacy e Wieserma (1993), as empresas que são destaque em seus respectivos segmentos possuem três pontos em comum, os quais passam pela:

1. Redefinição da proposta de valor no segmento;

2. Construção de um modelo de negócios coerente e capaz de entregar uma proposta de valor mais atraente aos clientes do que os concorrentes;

3. Por fim, ao fazer isto, estas empresas elevam os padrões de expectativas dos clientes a um nível que os concorrentes não conseguem alcançar;

Nesta proposta de Treacy e Wieserma (1993), um conceito que fica visível é o alinhamento coerente da estratégia ("proposta de valor") com a execução no nível operacional ("entrega da proposta de valor"). Sob este ponto de vista, os autores apresentam três disciplinas para a construção deste alinhamento estratégico:

1. Excelência Operacional: segundo os autores (Treacy e Wieserma, 1993), o termo "Excelência Operacional" descreve uma abordagem com uma abordagem estratégica específica para a produção e entrega dos produtos e serviços. Esta estratégia tem como objetivo liderar o segmento em termos de preço, portanto, a empresa está o tempo todo buscando reduzir custos, eliminar desperdícios, reduzir intermediários e transações através dos processos e das funções organizacionais em busca de obter a cadeia de valor mais enxuta possível. O foco desta empresa está na entrega dos produtos e serviços aos clientes com preços competitivos e com a mínima inconveniência. Exemplos de empresas que adotam esta estratégia são: DELL, Federal Express, American Airlines e Wal-Mart.

2. Intimidade com o cliente: enquanto as empresas com a estratégia de Excelência Operacional estão buscando reduzir desperdícios em seus processos produtivos, as 
empresas com a estratégia de Intimidade com o cliente estão constantemente reformulando seus produtos e serviços para que estes estejam de acordo as necessidades dos clientes. Esta abordagem exige um custo mais elevado comparada à primeira, porém, está voltada para um público alvo disposto a gastar mais por um produto e serviço diferenciado. Inclusive, estes clientes tendem a ser mais leais às empresas no longo prazo - caso elas mantenham alto o nível dos serviços prestados. Estas empresas estão sempre olhando os clientes no longo prazo, e não apenas com o olhar de uma única transação. Exemplos de empresas que utilizam esta abordagem são: Home Depot, Nordstrom, IBM, Ciga-Geiby, Kraft e Frito-Lay.

3. Liderança do Produto: por sua vez, as empresas que buscam atingir a terceira disciplina buscam liderar seus respectivos mercados em termos de inovação e desenvolvimento de produto e serviços no estado da arte. Para que isto seja possível, estas empresas são mais criativas que as demais, e gerenciam seus processos para atingir maior velocidade e tempo de resposta às mudanças do ambiente. Elas buscam sanar problemas e desenvolver novas soluções. Alguns exemplos de empresas que adotam esta abordagem são: Johnson e Johnson, Adidas e NIKE.

Segundo Treacy e Wieserma (1993), é possível que uma empresa domine duas disciplinas, no entanto, são poucas as empresas que alcançam tal feito e, quando o fazem, resolvem conflitos entre o modelo operacional e as demandas dos clientes. Os autores citam os casos da Toyota, USAA e Staples. Há muitas décadas a montadora japonesa já era conhecida por sua excelência operacional e, atualmente, ela também passa a ter um foco maior em liderança do produto em seu mercado em termos de tecnologia empregada. Mesmo que esteja em uma competição acirrada de tecnologia com outros gigantes, como BMW, Tesla, Mercedez e Ford, para não citar outros, a montadora japonesa ainda continua dominando a disciplina “excelência operacional”. Outros exemplos citados por Treacy e Wieserman (1993) são os da Staples, fornecedora de materiais para escritório, e da USAA, seguradora norte-americana com foco em militares. Ambas, comumente conhecida por sua excelência operacional, a empresa tem se adaptado às exigências do mercado e dominado a competência de intimidade com o cliente através de diversas melhorias realizadas.

Quando uma empresa define uma ou duas disciplinas de valor para entregarem aos clientes, elas estão ao mesmo tempo selecionando uma determinada categoria de clientes para oferecer tal proposta de valor (Treacy e Wieserman, 1993). Inclusive, os autores comentam o 
fato de que um mesmo cliente pode buscar as três disciplinas de valor, porém, de acordo com o produto ou serviço que ele está buscando - pode comprar materiais de escritório de acordo com o preço dos produtos, alimentos de acordo com seu gosto pessoal e roupas segundo a última tendência da moda. Neste contexto estratégico, esteja a empresa liderando a competição em seu mercado ou não, os gestores estão sempre definindo quais mudanças precisam ser realizadas com o objetivo de garantir que a organização esteja acompanhando as mudanças do ambiente de negócio, as quais são cada vez mais frequentes e com uma velocidade cada vez maior. Se forem bem-sucedidos, os gestores podem liderar as mudanças do mercado, mas, se suas empesas não conseguirem acompanhar a velocidade de tais mudanças, isto pode significar a morte dos negócios. A Figura 8 ilustra este contexto, e introduz quatro fases de mudança apresentadas por Johnson, Scholes e Whittington (2008).

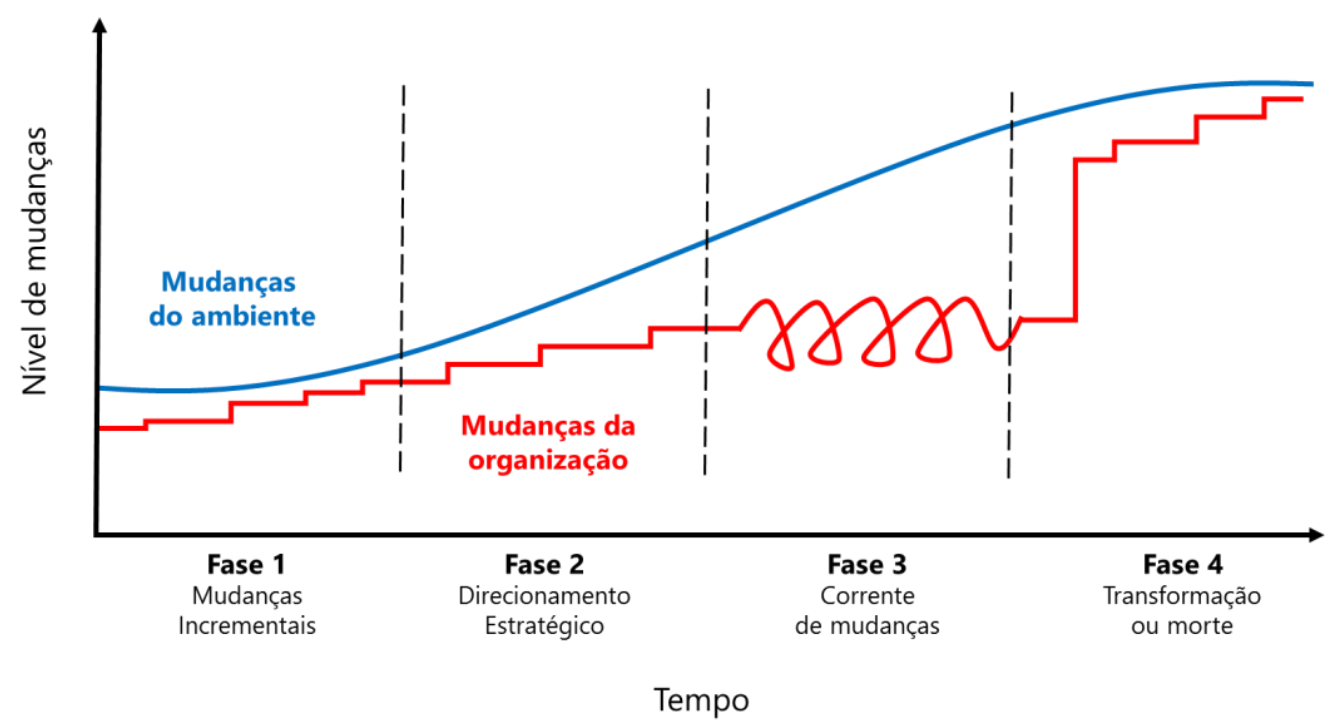

\section{Figura 8-Direcionamento estratégico e os níveis de mudança}

Fonte: Johnson, Scholes e Whittington, Richard (2008, pp. 180)

A Fase 1 representa as mudanças incrementais, as quais os gestores utilizam para garantir um certo alinhamento com o ambiente em mudanças, porém, sempre utilizando como base os sucessos e aprendizados do passado, experimentando estes aprendizados em outras áreas da empresa. No entanto, conforme o ambiente vai mudando, os gestores não podem apenas contar com mudanças incrementais para evitar que haja uma lacuna entre a organização e as práticas do ambiente de negócios. Ainda com o ambiente não mudando de maneira radical, porém já com uma velocidade maior, para que a empresa acompanhe seu mercado ela começa a realizar mudanças de acordo com um direcionamento estratégico. $\mathrm{Na}$ Fase 2, o sucesso das 
mudanças está diretamente relacionado com a busca pela excelência nas relações com os consumidores, fornecedores e colaboradores, além de manter foco em melhorias de performance. Esta é a fase em que as organizações podem "fazer a diferença" e liderar as mudanças do mercado (Johnson, Scholes e Whittington, 2008). Todavia, caso estas mudanças não ocorram na velocidade necessária, com o passar do tempo, o direcionamento estratégico pode não ser suficiente para garantir a evolução da performance do negócio, e tampouco pode acompanhar mudanças mais frequentes no ambiente de negócios.

A próxima fase, traduzida como "Corrente de Mudanças" (period of flux), tem início como uma queda abrupta de performance, indecisões sobre qual a direção estratégica adequada, pressão dos stakeholders sobre os gestores para que sejam realizadas mudanças mais radicais e, inclusive, pode haver uma rivalidade interna sobre qual estratégia seguir. Nesta fase, a ausência de um direcionamento claro das mudanças pode provocar diversos conflitos e, consequentemente, aumentar o distanciamento da organização para com seu ambiente. Conforme este distanciamento aumenta, tem início a Fase 4 da mudança transformacional ou morte do negócio. A organização pode morrer caso não acompanhe o ritmo das mudanças do mercado, pode ser comprada por outras empresas ou, pode realizar uma mudança transformacional. Segundo Johnson, Scholes e Whittington (2008), uma transformação deste tipo não ocorre frequentemente nas organizações, e é sinal de uma queda muito grande de performance. O grande problema desta fase, é o fato das mudanças exigirem uma transformação mais rápida e ágil, sendo as mudanças na grande maioria dos casos relacionadas com modificações no posicionamento cultural da organização.

Segundo Treacy e Wieserman (1993), para que uma empresa se torne líder em seu segmento ela deve definir claramente qual é a sua proposta de valor alinhada com sua capacidade de resposta às necessidades dos clientes e, também, com sua cultura organizacional. Porém, os autores também comentam que o maior desafio neste contexto é manter o foco e a consistência no atendimento a esta disciplina de valor, sendo necessário em muitos casos realizar mudanças radicais. Dunphy e Stace (1990) também compartilham deste ponto de vista, e além da estratégia de mudança (incremental ou transformacional), os autores abordam dois modos de realização das mudanças, as abordagens colaborativa e coerciva.

\section{Por que a execução da estratégia falha?}


Kaplan e Norton (2005) apontam que cerca de 60\% a 90\% das estratégias corporativas não são bem-sucedidas. Segundo Prosser (2015), apenas 13\% das estratégias atingem os resultados esperados. Diversos autores trazem dados neste sentido. Inclusive, estes dados são semelhantes à taxa de insucesso dos Programas de Lean - entre 66\% e 90\% dos programas falham ou não produzem os resultados esperados.

Muitas vezes, quando uma estratégia corporativa não é traduzida em resultados, os gestores apontam problemas culturais como principal causa, por exemplo, citam possuir uma fraca cultura de desempenho (Sull, Homkes e Sull, 2015). Há mais de 20 anos, tratando especificamente de Programas de Mudança, os estudos e pesquisas de Schaffer e Thomson (1992) apontavam que uma das principais falhas da execução da estratégia está na orientação das soluções: foco demasiado nas atividades, ou no processo, e não nos resultados. Com uma forte metáfora, os autores associam uma execução da estratégia sem foco em resultados a uma "dança da chuva" a qual não contribui com a performance organizacional. Esta tese dos autores é baseada em estudos de caso quantitativos e qualitativos, sendo poucos citados com grande profundidade. Basicamente, os autores sugerem que em uma abordagem centrada em resultados ("results-driven") os gestores devam:

Passo 1 - Definir objetivos e metas: solicitar que as diversas unidades definam poucos objetivos e ambiciosas metas de curto prazo, sendo as metas sempre quantificáveis;

Passo 2 - Revisar os objetivos e metas: periodicamente, os gestores devem revisar o processo, analisando os aprendizados obtidos e reformulando a estratégia corporativa;

Passo 3 - Institucionalizar na Cultura: institucionalizar na cultura organizacional as mudanças que funcionarem, e descartar todas as outras;

Passo 4 - Avaliar prioridades: criar um contexto para identificar os reais desafios e prioridades do negócio;

Embora Schaffer e Thomson (1992) façam uma proposição muito interessante ao considerarem o motivo de um programa não ser bem-sucedido (não produzir resultados logo no início), a proposta dos autores carece de embasamento teórico do ponto de vista da Cultura Organizacional: como é possível antever quais mudanças devem funcionar em uma determinada cultura? O trabalho dos autores não responde a esta pergunta. Nesse sentido, há uma possibilidade de que Peter Drucker ainda esteja correto: "culture eats strategy for 
breakfast”. O trabalho de Sull, Homkes e Sull (2015) dá sequência ao pensamento de Schaffer e Thomson (1992). Os autores consideram ser fundamental adotar uma abordagem com foco em resultados, mas, no entanto, apresentam dados que revelam uma lacuna de execução da estratégia presente principalmente na "coordenação" dos recursos em prol das prioridades estratégicas. Estes autores criticam o fato de existirem muitos livros e artigos sobre definição, planejamento e desdobramento da estratégia, mas, por contrapartida, existirem poucos sobre a execução desta estratégia. Em uma pesquisa com cerca de 8.000 gestores em mais de 250 empresas, incluindo também outros 40 estudos de casos com profundidade, a pesquisa ainda não finalizada de Sull, Homkes e Sull (2015) ajuda a derrubar cinco mitos do processo de execução da estratégia:

Mito 1: execução equivale a alinhamento - mais de 50\% dos gestores desejam obter uma estruturação dos processos para coordenar atividades entre as unidades da organização. Embora algumas empresas, consigam realizar um alinhamento vertical em prol dos seus objetivos e indicadores estratégicos, este alinhamento não é suficiente - é preciso também gerenciar de maneira eficiente os compromissos horizontais da organização.

Mito 2: execução significa seguir o plano - para ter uma execução bem-sucedida, mais do que seguir o plano, as empresas precisam estar preparadas para aproveitar rapidamente as oportunidades que surgirem, inclusive, precisam ter agilidade suficiente para abandonar iniciativas que não estejam obtendo os resultados desejados. Aproximadamente $29 \%$ das empresas não consegue aproveitar oportunidades, ou quando aproveitam, cerca de $24 \%$ perdem de vista suas prioridades estratégicas.

Mito 3: Comunicação equivale a compreensão - em uma organização na qual 84\% dos gestores declararam conhecer as altas prioridades da organização, apenas 55\% dos gestores de nível médio conseguem citar pelo menos uma prioridade estratégica para os próximos anos. Ou seja, metade dos líderes com responsabilidade de traduzir e ancorar a estratégia para o nível operacional não consegue nem mesmo citar uma única prioridade estratégica. 
Mito 4: Uma cultura de desempenho impulsiona a execução - as culturas corporativas aparentemente valorizam o desempenho dos colaboradores, no entanto, o problema reside no fato da maioria das culturas não estimular a colaboração e coordenação entre as diversas áreas em prol do atingimento dos objetivos estratégicos. Os únicos dados apresentados pelos autores (Sull, Homkes e Sull, 2015) questionam mais a eficácia da integração horizontal das organizações, e menos o alinhamento cultural da organização. Nesse sentido, a pesquisa dos autores aparenta possuir uma deficiência na construção deste mito.

Mito 5: A execução deve ser conduzida a partir do topo - os dados da pesquisa de Sull, Homkes e Sull (2015) apontam que 90\% dos gestores de nível médio estão à altura dos valores da organização o tempo todo ou na maior parte dele. A partir deste dado, os autores concluem que os gestores do nível médio fazem um bom trabalho em termos de reforçar o desempenho da organização, afinal, a maioria dos colaboradores responsabiliza tais gestores pelos resultados obtidos pela equipe. Embora este dado torne evidente uma relação de colaboração entre os gestores e suas equipes, este dado isoladamente não necessariamente está associado com uma execução adequada da estratégia.

Embora os resultados obtidos na pesquisa de Sull, Homkes e Sull (2015) sejam muito interessantes do ponto de vista de "coordenação de execução da estratégia", os resultados e consequentemente as análises da pesquisa, ainda em andamento, carecem de uma análise mais profunda do ponto de vista da cultura organizacional.

Sob o ponto de vista de Kaplan e Norton (2005), a execução da estratégia falha devido à falta de coordenação dos esforços em busca do atingimento da estratégia definida. Os autores inclusive comentam que a elaboração de um mapa estratégico é um exercício simples e que qualquer empresa consegue realizar, no entanto, o grande diferencial do processo está no alinhamento dos esforços em busca da execução da estratégia. Por exemplo, Kaplan e Norton (2005) comentam que $85 \%$ dos executivos investe menos de uma hora por mês discutindo a estratégia corporativa, cerca de $67 \%$ dos departamentos de RH e TI estão alinhados com a estratégia definida, apenas $40 \%$ dos diretores financeiros fazem um link do orçamento anual com a estratégia, $70 \%$ da média gerencia não possui incentivos para o atingimento dos objetivos estratégicos e, por último, porém não menos importante, os autores citam o fato de 
aproximadamente $95 \%$ da força de trabalho não conhecer ou entender a estratégia corporativa. O mesmo é observado no trabalho de Schaffer e Thomson (1992).

\section{Influência da cultura na estratégia}

São os pressupostos básicos definidos por Schein (2009) que influenciam diretamente o desenvolvimento, implementação e gestão da estratégia (Johnson, Scholes e Whittington, 2008). Pelo fato de ser difícil visualizar, controlar e gerenciar tais pressupostos, torna-se difícil identificar a influência que tais pressupostos estão tendo nas definições estratégicas, ou até mesmo o quanto estes pressupostos estão servindo de barreira às implementações necessárias para o sucesso ou sobrevivência do negócio. No entanto, se uma determinada cultura organizacional estiver bem alinhada com a estratégia do negócio, a cultura pode então servir como driver da estratégia (Johnson, Scholes e Whittington, 2008). O efeito da cultura na estratégia é ilustrado na Figura 9.

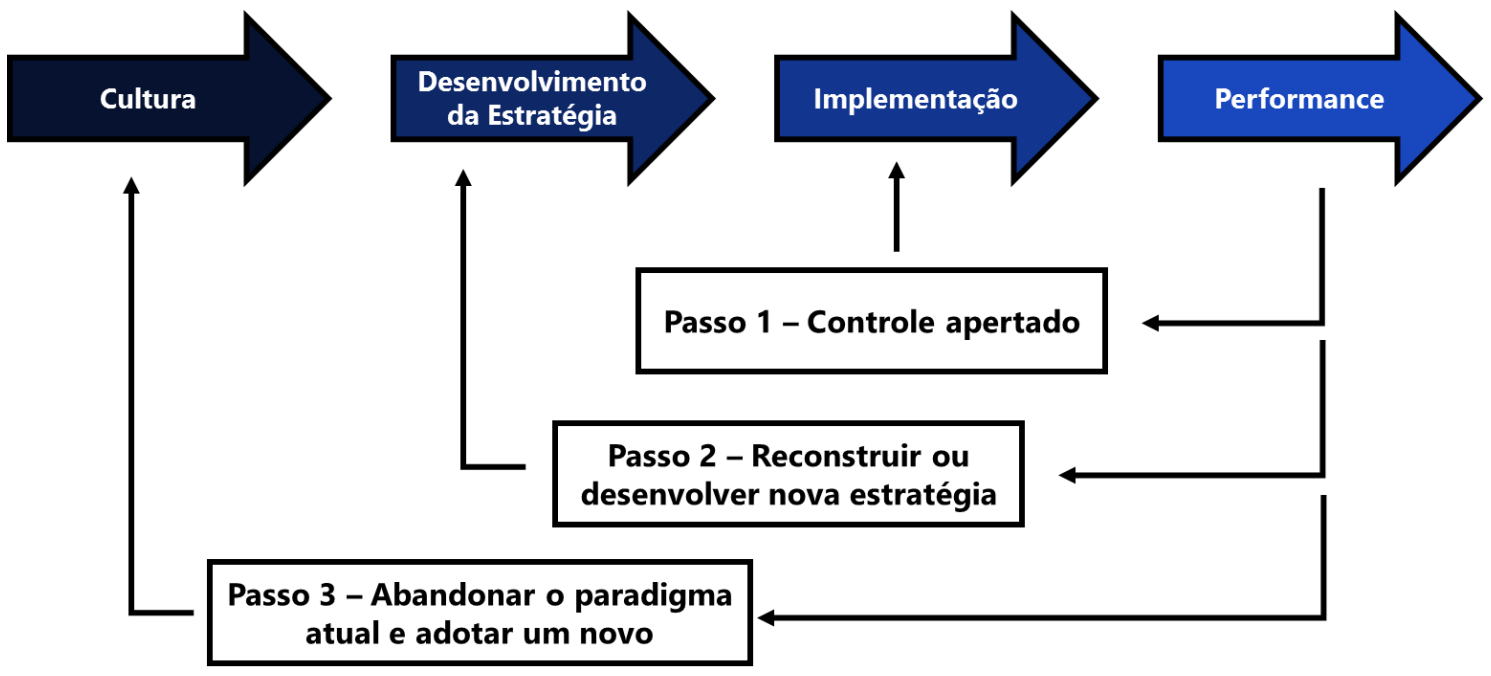

Figura 9 - Influência da Cultura no desenvolvimento da Estratégia

Fonte: Grinyer e Spender (1979) apud Johnson, Scholes e Whittington (2008)

Desenvolvendo o Mapa Estratégico do Balanced Scorecard (BSC, ilustrado na Figura 10) há mais de duas décadas, Kaplan e Norton (2004) propuseram três categorias de ativos intangíveis na perspectiva de Aprendizado e Crescimento, as quais são descritas como:

Capital Humano: as habilidades, talentos e conhecimento que os colaboradores de uma empresa possuem; 
$\checkmark$ Capital de Informação: a base de dados da empresa, sistema de informações, networking e infraestrutura de tecnologia da informação;

$\checkmark$ Capital Organizacional: a cultura organizacional, sua liderança, como as pessoas estão alinhadas em busca de objetivos estratégicos, e habilidade que os colaboradores tem de compartilhar conhecimentos e aprendizados;

Segundo Kaplan e Norton (2004), o Capital Organizacional é composto por quatro elementos principais: Cultura Organizacional, Liderança, Alinhamento e Trabalho em Equipe. Cultura Organizacional é responsável por promover e internacionalizar nas pessoas a missão, visão e valores da empresa necessários para uma execução eficaz da estratégia. Inclusive, associada à cultura, a Liderança da empresa seria responsável por desenvolver outras lideranças em todos os níveis da empresa, sempre mobilizando as diversas pessoas em busca do atingimento dos objetivos estratégicos traçados.

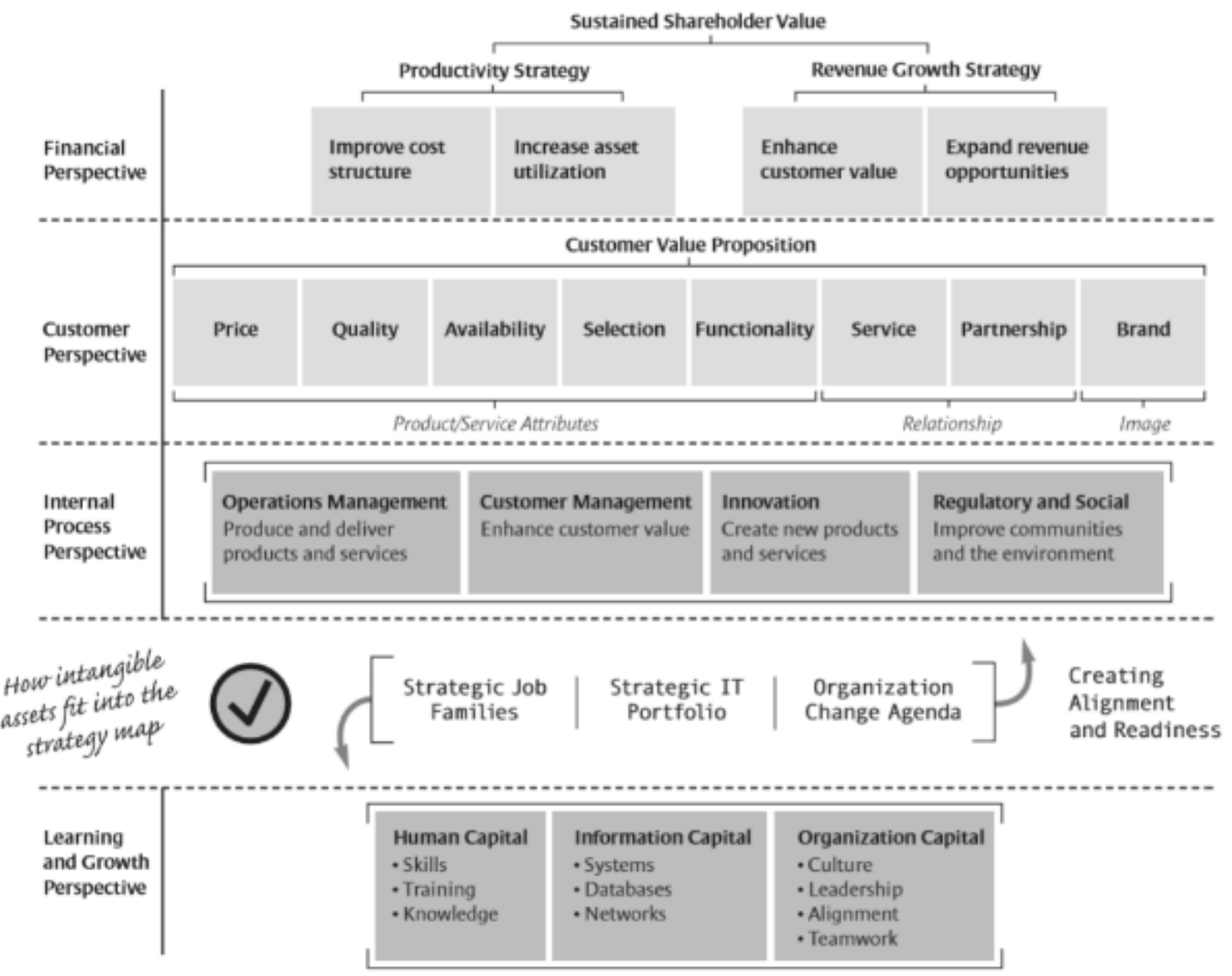

Figura 10 - Mapa Estratégico do BSC

Fonte: Kaplan e Norton (2004) 
Por Alinhamento os autores se referem ao alinhamento de objetivos e incentivos, em todos os níveis da organização, na busca da execução da estratégia. Por fim, o Trabalho em Equipe tem como objetivo garantir que os conhecimentos e aprendizados serão compartilhados por todos. Dentre estes quatro elementos citados, a Cultura Organizacional é considerada a dimensão mais complexa e difícil de ser compreendida, justamente por compreender um território de conhecimento e comportamentos extremamente vasto quando comparada a outros (Kaplan e Norton, 2005). Segundo os mesmos autores, talvez seja por isso que o objetivo shaping the culture ("modelar a cultura") seja frequentemente citado em mapas estratégicos.

\subsection{Melhoria Contínua}

Esta seção inicia-se com uma visão geral sobre Melhoria Contínua e depois mantém foco no Programa de Lean, revisando não apenas os métodos e modelos de melhoria, mas também os modelos de excelência em gestão, resultados sobre a visão dos envolvidos nos programas de melhoria e, por fim, a revisão desta seção é consolidada nos fatores críticos de sucesso dos programas de melhoria contínua. Desta maneira, o texto de revisão sobre Melhoria segue a estrutura das seções em destaque na Figura 11.

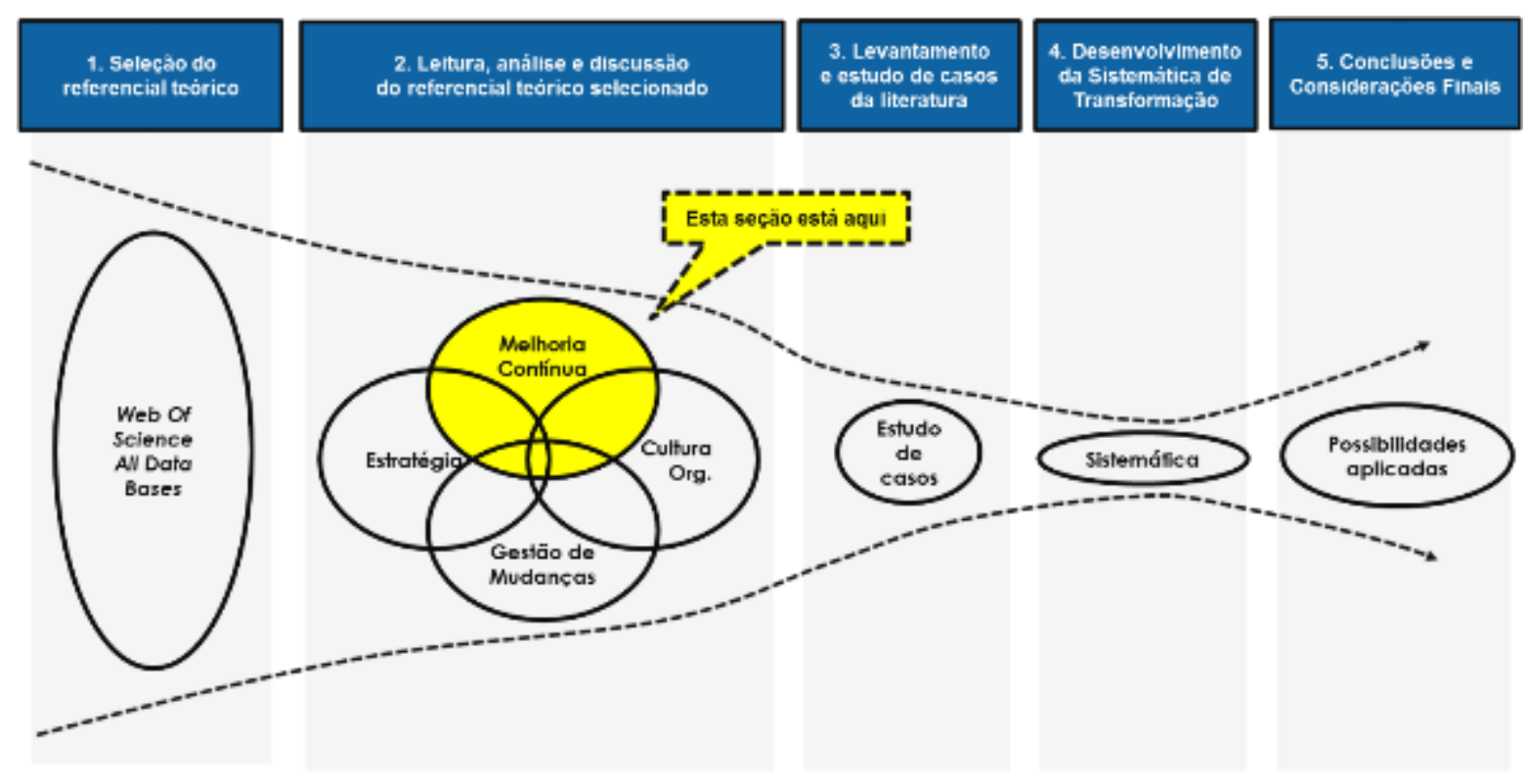

Figura 11 - O papel da revisão sobre Melhoria Contínua no processo da pesquisa 


\subsubsection{O Lean dentro da Gestão de Operações}

A essência de uma operação é adicionar valor durante a transformação de um produto ou serviço (Stevenson, 2011). Para que isso ocorra, a Operação precisa de suporte de outras áreas, como Marketing, Recursos Humanos, Finanças e Vendas. A Gestão de Operações não é a gestão de todas estas áreas, mas, de acordo com Stevenson (2011), ela é responsável por "gerenciar o sistema ou processos que produzem bens e realizam serviços".

Um aspecto chave da Gestão de Operações é a gestão de processos que agregam valor. Nesse sentido, o Lean tem um papel muito importante para a Gestão de Operações por justamente possuir um conjunto de princípios, técnicas e ferramentas que auxiliam as empresas a eliminarem desperdícios em seus processos, de tal maneira a entregarem o maior valor possível a seus clientes, sempre buscando realizar ciclos constantes de melhoria contínua. Sob este ponto de vista, Kumar e Suresh (2009) definem um sistema de transformação através de quatro elementos: (a) input, (b) Processo de Transformação, (c) Output e (d) Controle. Nesse sentido, ao eliminar desperdícios e focar nas atividades que agregam valor sob o ponto de vista do cliente ("output" do processo), o Lean busca continuamente aprimorar o desempenho dos processos. De acordo com Kumar e Suresh (2009) a Gestão de Operações tem o objetivo dê: "prover a capacidade necessária para a organização atender à sua estratégia e seus objetivos". Com relação ao atendimento dos requisitos dos clientes, existe uma série de considerações que devem ser feitas pela Gestão de Operações, envolvendo algumas das principais funções de uma organização (manufatura, logística, cadeia de suprimentos e serviços prestados).

De maneira complementar ao processo de transformação, Kumar e Suresh (2009) sugerem que deve haver o adequado Planejamento do Sistema Produtivo, Organização e Controle. Seja para a produção de bens ou serviços, para melhorar a eficiência e eficácia destes sistemas são amplamente utilizados nas empresas os Programas de Melhoria Contínua. Tais programas podem ser descritos e compostos por: Total Quality Management, Lean Manufacturing e Six Sigma. É importante ressaltar que os modelos de Gestão de Operações dão excessiva ênfase aos aspectos "hard" do sistema, deixando de lado questões "soft": por exemplo, "modelos e comportamentos" aparecem de maneira muito ampla em meio ao detalhamento de questões como previsão de demanda, definição de produtos, layout, etc. 


\section{A evolução histórica do Lean na Gestão de Operações}

No estudo da evolução histórica da Gestão de Operações este trabalho segue a base cronológica definida por Kumar e Suresh (2009). A visão tradicional de gestão da manufatura teve início no século dezoito com o trabalho de Adam Smith. O trabalho de Adam Smith sugere dividir as tarefas de trabalho em atividades menores, e ter trabalhadores especializados nestas atividades para que estes conquistassem maior habilidade e eficiência trabalho. No início do século dezenove, F. W. Taylor dá continuidade ao trabalho de Adam Smith, com o estudo dos métodos científicos. Neste período são desenvolvidas diversas técnicas e ferramentas. O termo Gestão da Produção se torna mais aceitável em torno de 1930 e 1950. Ainda segundo Kumar e Suresh (2009), em 1970 surgem duas mudanças de visão.

A primeira, mais óbvia, remete ao início do uso do termo Gestão de Operações, devido às técnicas e conceitos desenvolvidos anteriormente terém alcançado o setor de serviços, e não apenas a manufatura. A segunda mudança remete a uma ênfase maior em sínteses, e não apenas análises das práticas de gestão. O Quadro 5 retrata a evolução histórica da Gestão de Operações, englobando áreas como Qualidade, Pesquisa Operacional, Logística e Lean.

\subsubsection{O que é o Lean?}

O Lean pode ser reconhecido como uma das filosofias, sistemas ou modelos Melhoria Contínua, sendo esta, inclusive, um dos pilares do Modelo Toyota. A Melhoria Contínua, como o próprio nome sugere, adota um método de melhoria da performance organizacional através do uso de passos pequenos com melhorias incrementais (Irani e Sharp, 1997). Pode ser definida como uma interação contínua entre operações, com melhorias incrementais, aprendizado e inovações radicais (Papadopoulos, 2011).

O Lean pode também ser reconhecido na literatura como Lean Production ou Lean Manufacturing, sendo comumente traduzido como Produção Enxuta. Reconhecido como conjunto de práticas, conceito ou filosofia, é descendente direto do Toyota Production System (TPS), tendo Taiichi Ohno como principal idealizador - após mais de quatro décadas de estudos e experimentos na Toyota Motor Company. O Quadro 6 resume as primeiras quatro décadas do Lean em uma evolução de cinco fases. 


\section{A EVOLUÇÃO HISTÓRICA DO LEAN NA GESTÃO DE OPERAÇÕES}

DATA CONTRIBUIÇÃO

\begin{tabular}{|c|c|c|}
\hline 1776 & Especialização da mão de obra na manufatura & Adam Smith \\
\hline 1799 & Partes intercambiáveis, contabilidade dos custos & Eli Whitney e outros \\
\hline 1832 & Divisão do trabalho por habilidades, início dos estudos de tempo & Charles Babbage \\
\hline 1900 & Estudo científico de tempos e métodos e divisão do trabalho & Frederick W. Taylor \\
\hline 1900 & Estudo dos movimentos de trabalho & Frank B. Gilbreth \\
\hline 1901 & Técnicas de programação dos colaboradores e máquinas & Henry L. Gantt \\
\hline 1910 & Linha de produção em massa & Henry Ford \\
\hline 1915 & Lote econômico para controle de inventário & F. W. Harris \\
\hline 1920 & Jidoka e Autonomação & Sakichi Toyoda \\
\hline 1927 & Relações humanas de trabalho, The Hawthorne Studies & Elton Mayo \\
\hline 1931 & Estatística aplicada à qualidade do produto e gráficos de controle & W. A. Shewart \\
\hline 1935 & Amostragem estatística aplicada ao controle de qualidade & H. F. Dodge e H. G. Roming \\
\hline 1937 & Fundação da Toyota Motor Corporation & Kiichiro Toyoda \\
\hline 1940 & Pesquisa Operacional aplicada na Segunda Guerra Mundial & P. M., Blacker e outros \\
\hline 1946 & Computação digital & John Mauchilly e J. P. Eckert \\
\hline 1947 & Programação linear & G. B. Dantzig e outros \\
\hline 1950 & Programação matemática e processos estocásticos & A. Chames e outros \\
\hline 1951 & $\begin{array}{l}\text { Computador digital comercial: disponibilidade de computadores } \\
\text { em larga escala }\end{array}$ & Sperry Univac \\
\hline 1952 & Just In Time, Judoka (built in quality) e Toyota Production System & Taiichi Ohno \\
\hline 1960 & $\begin{array}{l}\text { Comportamento humano no trabalho: continuidade dos estudos } \\
\text { envolvendo pessoas no trabalho }\end{array}$ & L. Cummings e L. Porter \\
\hline 1970 & Integração das operações dentro da estratégia das empresas & $\begin{array}{l}\text { W. Skinner, J. Orlicky, G. } \\
\text { Wright }\end{array}$ \\
\hline 1980 & Aplicações de qualidade e produtividade no Japão & W. E. Deming e J. Juran \\
\hline 1992 & A máquina que mudou o mundo & Jim Womack \\
\hline 1996 & Lean Thinking & Womack e Jones \\
\hline 2003 & The Toyota Way & Jeffrey Liker \\
\hline 2003 & Lean Software Development & Mary and Tom Poppendieck \\
\hline 2010 & Toyota Kata: gerenciando pessoas para melhoria & Mike Rother \\
\hline 2014 & Creating a Lean Culture & David Mann \\
\hline
\end{tabular}

\section{Quadro 5 - A evolução histórica do Lean na Gestão de Operações}

Fonte: construído pelo autor a partir de Kumar e Suresh (2009)

Rother e Shook (2003) definem o Lean como "o conjunto de práticas com o objetivo de eliminar desperdícios e criar valor", sempre buscando reduzir custos, melhorar a performance, aumentar a produtividade e rentabilidade das organizações, por exemplo. Assim, 
o pensamento enxuto (ou Lean Thinking) tem início com a definição do que é valor para o cliente e, logo após, todas as atividades que não agregam valor sob o ponto de vista do cliente são consideradas como desperdício. Nesse sentido, Womack e Jones (1996) apresentam os cinco princípios da Produção Enxuta, ilustrados na Figura 12.

\begin{tabular}{lll}
\hline ANOS & FASE & ATIVIDADES \\
\hline $1970-1990$ & Descoberta & Crise do Petróleo (1973) gera interesse nos métodos Japoneses. \\
\hline $1991-1996$ & Disseminação & Princípios do Lean passam a ser desenvolvidos na indústria; \\
\hline $1997-2000$ & Implementação & O Pensamento Enxuto ganha amplitude estratégica; \\
\hline $2001-2005$ & Enterprise & Os métodos se expandem para o setor de serviços; \\
\hline $2006-$ Hoje & Performance & Medição do “nível Lean" das organizações; \\
\hline
\end{tabular}

Quadro 6-As fases da Produção Enxuta (quatro décadas de Lean)

Fonte: adaptado de Stone (2012)

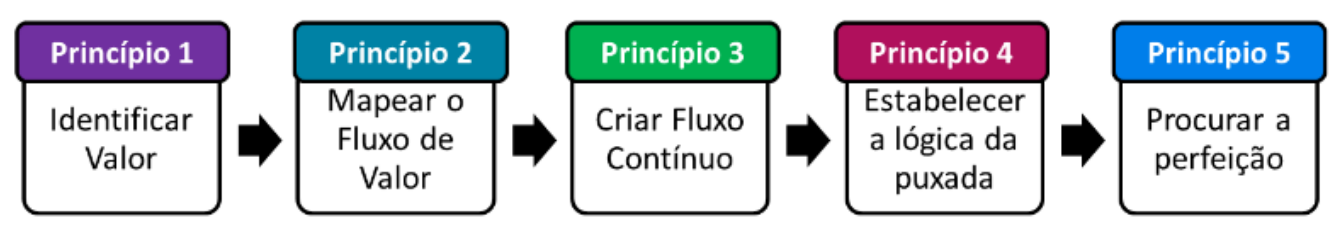

Figura 12 - Os Cinco Princípios da Produção Enxuta

Fonte: adaptado de Womack e Jones (1996)

Ao comparar diferentes unidades organizacionais executando os mesmos projetos, Matthiesen e Johansen (2008) identificaram a forte influência da cultura organizacional nos resultados de um projeto de Melhoria Contínua. Para diversos autores, a adoção bem-sucedida da melhoria contínua e inovação nas organizações envolve um sistema bem complexo, que necessita uma gestão adequada para proporcionar seu máximo benefício e usufruto (Irani e Sharp, 1997). A Melhoria Contínua integra áreas funcionais e quebra barreiras organizacionais, criando uma organização de suporte às melhorias, criação e inovação de processos (Papadopoulos, 2011). Sob este ponto de vista, uma evolução ou mudança cultural faz-se necessária (McLaughlin et al., 2008).

Dentro do Sistema Toyota de Produção (TPS ou STP), ilustrado na Figura 13, um dos conceitos mais famosos é o do Just In Time (JIT), o qual pode ser definido como uma filosofia que busca reduzir sistematicamente os custos totais de manufatura e produzir somente o que for necessário, e quando for necessário (Power e Sohal, 1997). Para almejar tal objetivo, é 
fundamental a melhoria contínua da organização através da implementação de técnicas específicas de gestão da produção, compromisso com a qualidade total e uso do potencial completo dos recursos humano (Power e Sohal, 1997).

Por sua vez, os 14 Princípios do Modelo Toyota estão ilustrados na Figura 14. Estes princípios, propostos por Liker (2005), podem ser descritos como: basear as decisões administrativas em uma filosofia de longo prazo, mesmo em detrimento a metas financeiras de curto prazo (Princípio 1, ou P.1); criar um fluxo contínuo para trazer os problemas à tona (P.2); usar sistemas puxados para evitar a superprodução (P.3); nivelar a carga de trabalho (P.4); construir uma cultura de parar e resolver problemas (P.5); tarefas padronizadas são a base para a melhoria contínua (P.6); usar controle visual para que nenhum problema fique oculto (P.7); usar somente tecnologia confiável e testada (P.8); desenvolver líderes que vivenciem a filosofia (P.9); desenvolver pessoas e equipes excepcionais (P.10); Respeitar sua rede de parceiros $(P .11)$; ver por si mesmo para compreender a situação $(P .12)$; tomar decisões lentamente por consenso, implementá-las rapidamente (P.13); tornar-se uma organização de aprendizagem contínua através da reflexão incansável (P.14).

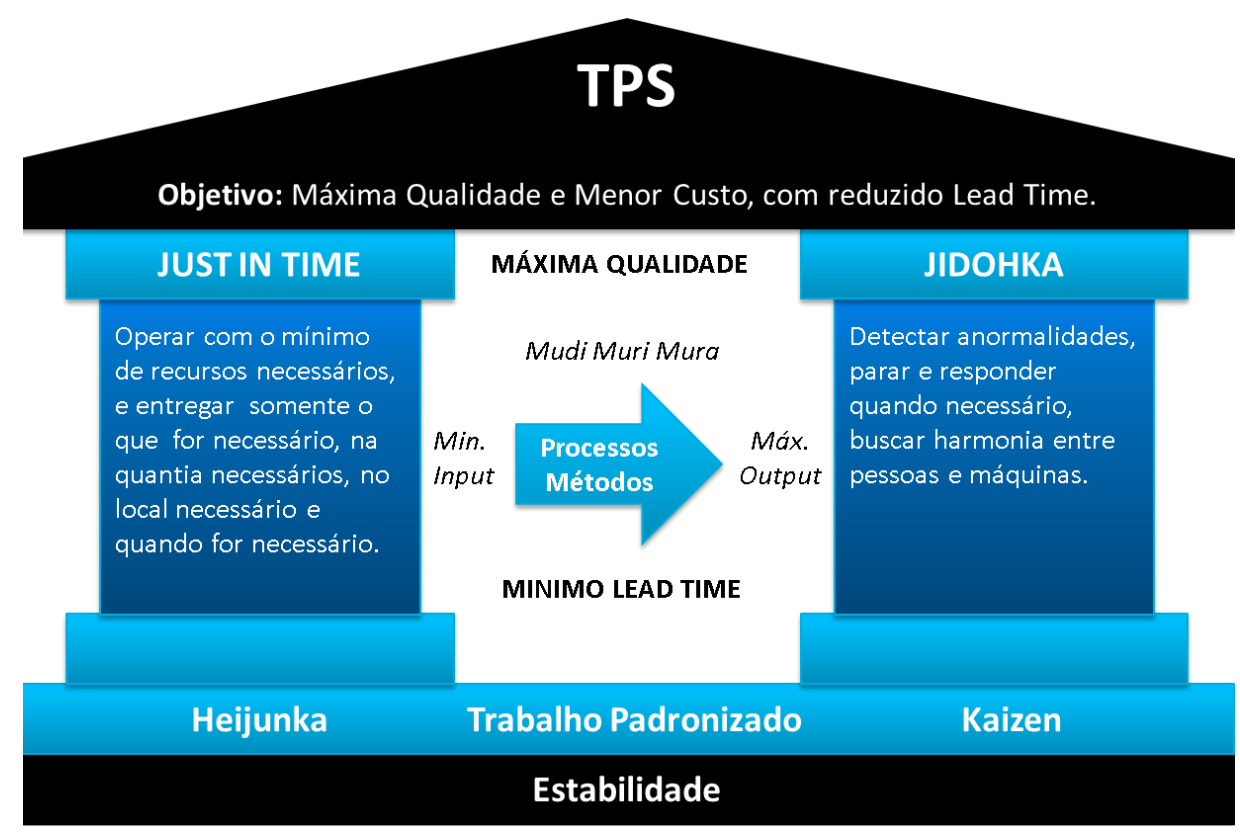

Figura 13 - O Sistema Toyota de Produção (TPS)

Fonte: adaptado de Liker (2005)

A literatura sugere também a necessidade de iniciar um projeto específico e realista por vez, ao invés de iniciar diversos esforços globais sem que haja devido controle do processo de melhoria como um todo (Hines et al., 2008; Bhasin, 2011a; Bhasin, 2012a). Quando o projeto 
for de grandes dimensões, pode ser necessário o desdobramento de vários outros projetos objetivando uma escala de longo prazo. Dentro destes projetos de mudança e melhoria, o medo e a ansiedade devem ser removidos para atingir a confiança necessária. Por este motivo, Bhasin (2012a) sugere que na implantação do Lean faz-se necessário o atingimento de metas específicas de curto prazo.
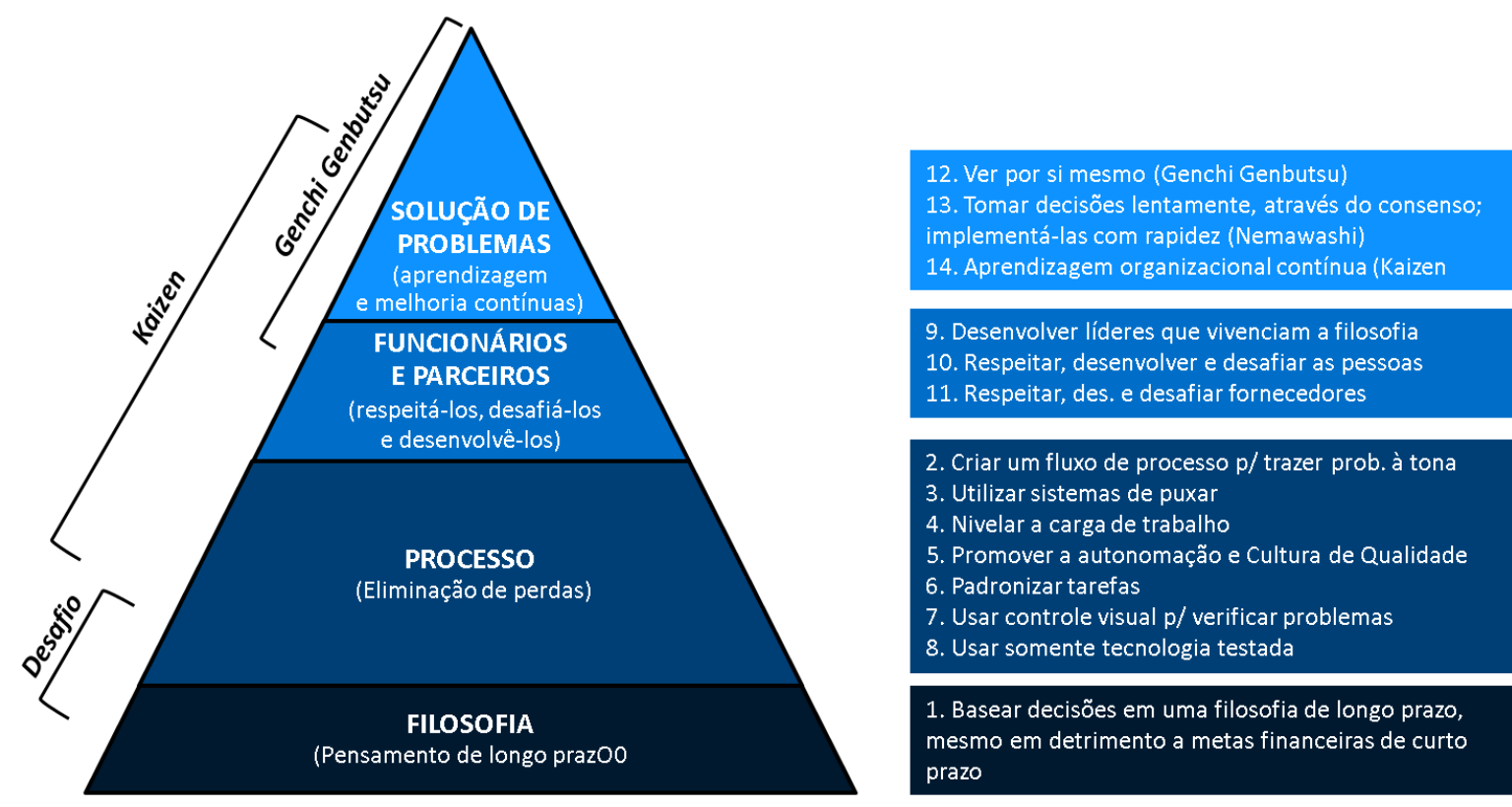

\section{Figura 14 - Os 14 Princípios do Modelo Toyota}

Fonte: adaptado de Liker (2005)

Para identificar o estágio ao qual determinada organização está na Jornada Lean (Lean Journey), Bhasin (2012a) analisou 12 categorias de critérios específicos, os quais são:

1. Segurança global, ordem e limpeza;

2. Fluxo produtivo e operacional;

3. Processos e operações;

4. Gestão Visual;

5. Qualidade do produto projetado;

6. Melhoria Contínua;

7. Estratégia de mudança Lean;

8. Sustentabilidade ${ }^{6}$ das melhorias implementadas;

\footnotetext{
${ }^{6}$ Os autores de Lean utilizam o termo "Sustentabilidade" para remeter à manutenção, no longo prazo, das melhorias implementadas. Portanto, o termo não está associado a questão ambientais, mas sim à manutenção ("sustentabilidade") dos novos padrões de processo definidos.
} 
9. Cultura - orientação para os funcionários;

10. A Cultura Organizacional - práticas organizacionais;

11. Lean tido como um negócio;

12. Filosofia Lean;

Para Bhasin (2012a), cada empresa, ao ingressar na Lean Journey, precisa encontrar sua própria maneira de implementar o Lean, ou seja, não existe um método universal aplicável em todas as organizações. Ainda, o autor considera que este processo de mudança deve ser encarado como uma jornada sem fim, objetivando a melhoria contínua da organização através do investimento de recursos como tempo e dinheiro. Bhasin (2012a) chama atenção também para a importância da existência de auditorias em organizações, sugerindo que o sucesso de uma implantação Lean triunfante está atrelado a um controle estratégico e sistemático da mudança. Sob este ponto de vista, Drew et al. (2004) definem seis lições importantes para a implantação do Lean Manufacturing:

1. O Lean tem início no topo da organização;

2. Estabeleça objetivos ambiciosos para a organização;

3. Resultados rápidos são importantes;

4. Ouça os colaboradores da organização;

5. Busque ajuda de especialistas;

6. "It takes time!'” (“Isso leva tempo!")

De acordo com Liker (2005), sistema produtivo enxuto é muito mais do que um fluxo contínuo, um Just in Time ou uma produção puxada através de um sistema kanban, no Modelo Toyota, se não fossem as pessoas que compreendem a cultura por trás deste sistema, não haveria a excelência operacional e o desempenho organizacional existentes na Toyota. Para Gary Convis, ex-presidente da Toyota Motor Manufacturing de Kentucky, USA, todas as questões técnicas por detrás do TPS (estabilidade, Just in Time, Autonomação, Kaizen, Nivelamento de Produção), somente serão eficazes se as pessoas tiverem uma administração e filosofia corretas, ou seja, novamente, a base de todo o sistema produtivo são as pessoas e sua respectiva cultura organizacional (Liker 2005).

São as pessoas que administram o sistema, são elas que definem o norte verdadeiro, utilizam as ferramentas, verificam e solucionam problemas, apresentam questões e conceitos aos demais funcionários, gerenciam projetos e formam a cultura de apoio ao chão de fábrica, 
também são as pessoas que sustentam o aspecto filosófico do sistema: são elas que colocam o cliente em primeiro lugar, verificam as questões a serem resolvidas, são as pessoas que fazem o Gemba Walk, e são elas que pensam na eficiência e excelência operacional. A Figura 15 ilustra a visão de Gary Convis sobre o Sistema Toyota de Produção (STP), quando então este era presidente da Toyota Kentucky (US). Para Gary, o sistema produtivo era uma combinação de técnicas, com padrões administrativos e filosofia, tendo as pessoas como o ponto central e referencial do sistema (Liker, 2005).

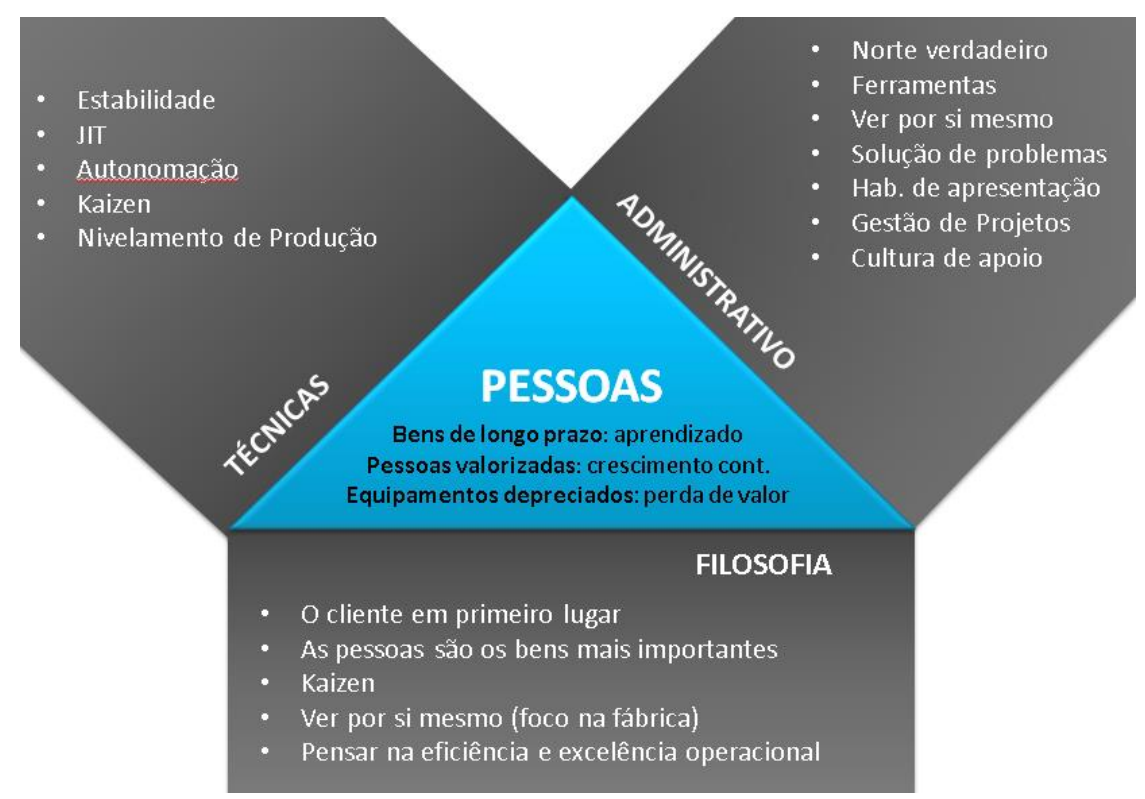

\section{Figura 15 - A visão de Gary Convis sobre o Sistema Toyota de Produção}

Fonte: adaptado de Liker (2005)

\subsubsection{Métodos de Melhoria}

Tendo como objetivo a redução dos defeitos em seus produtos, e aumento da competitividade em um setor com forte expansão, a Motorola desenvolveu nos anos 1980 o Six Sigma, uma estratégia de gestão de negócios (Anacleto, 2011). A partir desta estratégia, foi desenvolvida uma metodologia para gerenciar mudanças, chamada de DMAIC, inspirada no ciclo PDCA (Plan - Do - Check - Act) de Deming.

Embora o DMAIC e o PDCA sejam os modelos de melhoria contínua mais utilizados pelas empresas, existem diversos outros, como: PDSA, Método A3, 7 Passos, DMADV e Improvement Model. Na sequência é realizada uma breve revisão sobre cada um destes 
modelos. Werkema (2012), Clark et al. (2013) definem as fases do ciclo PDCA: P - PLAN: Identificação do problema, análise das causas do mesmo e formulação do estado futuro desejado; D - DO: Um plano para implementar o estado futuro desejado é elaborado, este plano é divulgado aos colaboradores da organização e executado; C - CHECK: Após a implantação das melhorias, estas devem ser monitoradas, e os resultados destas avaliados nesta fase; A - ACT: (a) em caso de sucesso, as mudanças e melhorias implantadas devem ser padronizadas de tal maneira a impedir a recorrência do problema. (b) em caso de insucesso, deve ser iniciado um novo ciclo PDCA no intuito de solucionar o problema. Em caso de sucesso parcial, deve-se realizar (a) e (b). A Figura 16 ilustra os ciclos de melhoria utilizando o PDCA.

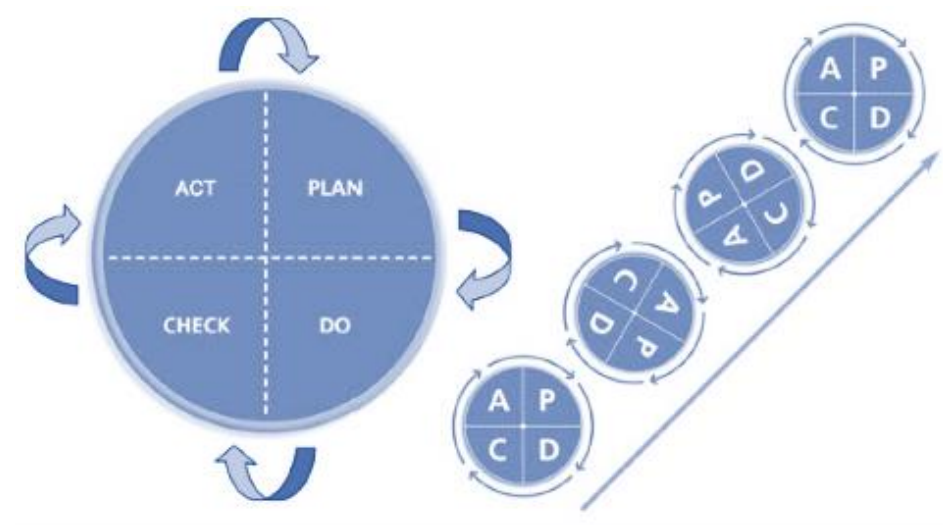

Figura 16-O Ciclo PDCA de Melhoria Contínua

Fonte: Clark et al. (2013)

Martensen e Dahlgaard (1999) sugerem o uso do "ciclo PDSA extendido", no qual o primeiro loop seria um ciclo tradicional do Hoshin Planning, integrando inovação a determinada estratégia de negócio, e o segundo loop focado em criar uma cultura de aprendizado e criatividade. O Modelo de Melhoria, por sua vez, é baseado no PDSA, com acréscimo de três questões fundamentais: (a) O que estamos tentando realizar? (b) como saberemos que uma mudança é uma melhoria? (c) que mudanças podemos fazer que resultarão em melhoria?

Originário do Seis Sigma, a metodologia DMAIC é um elemento utilizado na constituição de equipes visando a execução de projetos de melhoria organizacional alinhadas às metas estratégicas das organizações (Werkema, 2012). Dessa forma, o DMAIC é uma metodologia adequada tanto para a implantação do Lean, Seis Sigma e Lean Seis Sigma. DMAIC é um acrônimo em inglês, para as etapas do ciclo (Werkema, 2012): D - Define: 
consiste na definição do escopo do projeto de melhoria; $\mathbf{M}$ - Measure: é localizado o foco do problema. Para tal, é necessária a coleta de dados da situação atual, variáveis a serem consideradas para análise, fatores insatisfatórios no processo produtivo; A - Analyse: nesta etapa são determinadas as causas dos problemas prioritários. Nos projetos de Lean Manufacturing, a ferramenta de Mapeamento do Fluxo de Valor (MFV) é utilizada para mapear o estado atual e projetar o estado futuro desejado; I - Improve: neste momento são propostas, avaliadas e implementadas melhorias; $\mathbf{C}$-Control: esta etapa é importante para garantir que a melhoria seja mantida a longo prazo. Nesta etapa algumas ferramentas são utilizadas, como: checklists, gráficos de Pareto, gráficos de controle, dentre outras.

Diferentemente do PDCA, o DMAIC dá maior ênfase ao planejamento (as etapas D, M, A e grande parte da etapa I), antes que as implantações sejam executadas, promove análises com profundidade e também dá ênfase em alguns elementos, como voz do cliente, validação dos sistemas de medição e validação do retorno econômico (Werkema, 2012). A Figura 17 traz uma ilustração dos principais Modelos de Melhoria citados neste trabalho. Outros modelos também podem ser encontrados na literatura, como o Método A3, PDSA, DMADV e 7 Passos (Sobek II e Smalley, 2010; Langley et al., 2011), estando todos representados na Figura 18.

\subsubsection{Principais conceitos de Melhoria Contínua}

Tendo em vista que muitos dos conceitos de Melhoria Contínua já são recorrentes na literatura de Gestão de Operações, este trabalho de revisão não irá se aprofundar na discussão destes conceitos (hard). No intuito de que haja uma uniformidade sobre as discussões futuras, o Quadro 7 apresenta uma breve definição dos principais conceitos desta literatura. 


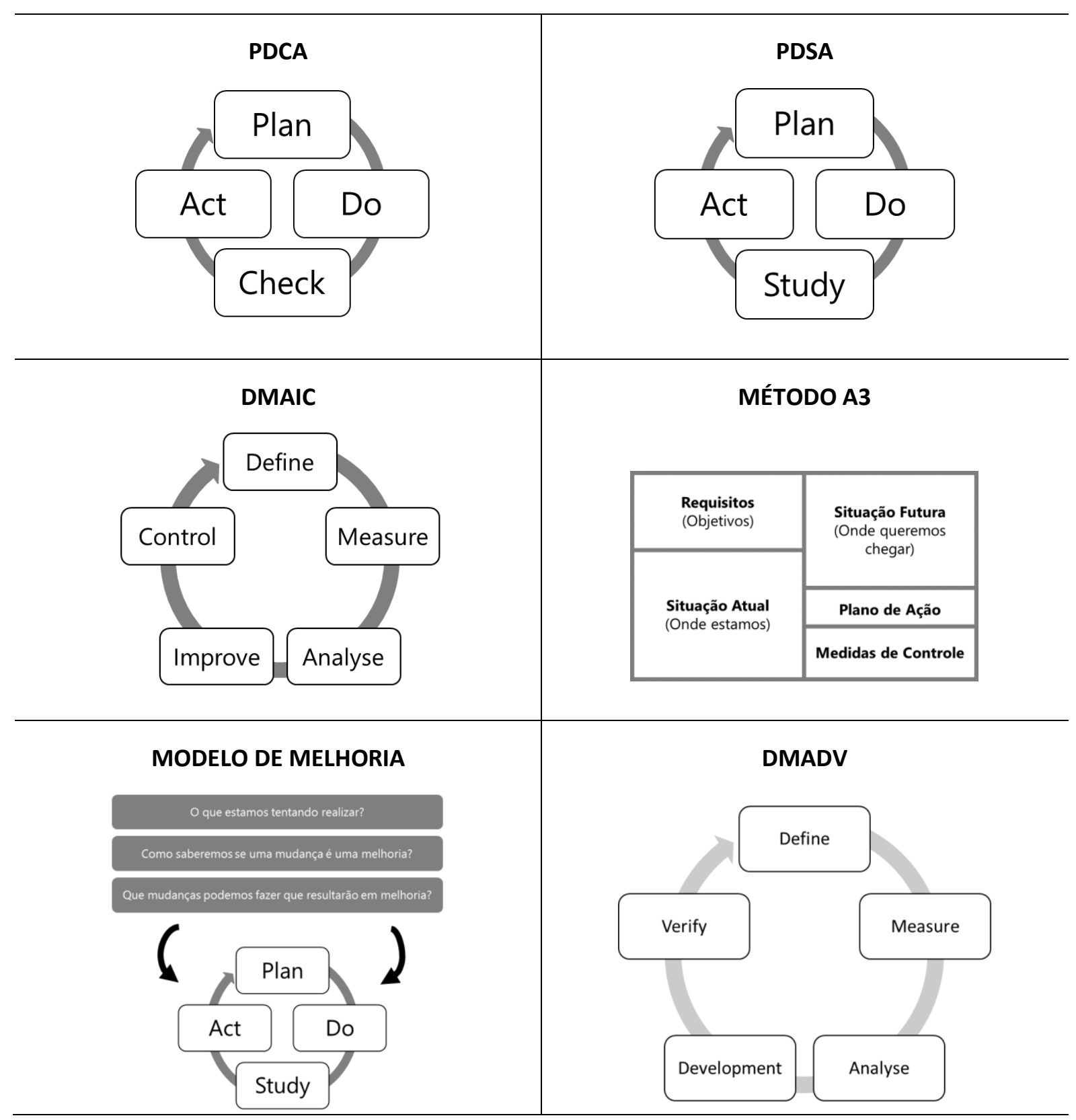

Figura 17 - Ilustração dos principais modelos de melhoria levantados 


\section{CONCEITO DE DEFINIÇÃO ADOTADA NESTE TRABALHO LITERATURA MELHORIA

\begin{tabular}{|c|c|c|}
\hline $\begin{array}{l}\text { Controle Total de } \\
\text { Qualidade }\end{array}$ & $\begin{array}{l}\text { Aplicação dos princípios de Gestão da Qualidade para todas as } \\
\text { áreas da empresa, ao invés de mantê-las apenas nas } \\
\text { atividades de produção. }\end{array}$ & $\begin{array}{l}\text { Feingenbaum } \\
\text { (1986) }\end{array}$ \\
\hline Layout Celular & $\begin{array}{l}\text { Maneira de contribuir para o fluxo contínuo, criando células } \\
\text { de trabalho agrupadas por produto e não por processo. }\end{array}$ & Liker (2005) \\
\hline $\begin{array}{l}\text { Reengenharia de } \\
\text { processos }\end{array}$ & $\begin{array}{l}\text { Repensar fundamentalmente e redesign radicalmente os } \\
\text { processos de negócio para atingir melhorias necessárias, } \\
\text { reduzindo custos, aumentando a qualidade, velocidade e } \\
\text { produtividade dos processos. }\end{array}$ & $\begin{array}{l}\text { Hammer e } \\
\text { Champy } \\
(1993)\end{array}$ \\
\hline $\begin{array}{l}\text { Diagrama } \\
\text { de Ishikawa }\end{array}$ & $\begin{array}{l}\text { Também conhecido como Diagrama de Causa e Efeito, é uma } \\
\text { ferramenta usada para identificar as causas que ocasionam } \\
\text { determinado efeito/problema. }\end{array}$ & $\begin{array}{l}\text { Ishikawa } \\
\text { (1989) }\end{array}$ \\
\hline Kaizen & Palavra japonesa que significa "melhoria". & Liker (2005) \\
\hline $\begin{array}{l}\text { Kaizen } \\
\text { de Fluxo }\end{array}$ & $\begin{array}{l}\text { Melhoria com foco no fluxo de materiais e de informação que } \\
\text { possibilita grandes vantagens para o fluxo de valor. }\end{array}$ & $\begin{array}{l}\text { Rother e } \\
\text { Shook (2003) }\end{array}$ \\
\hline $\begin{array}{l}\text { Kaizen de } \\
\text { Processo }\end{array}$ & Melhoria com foco no fluxo das pessoas e dos processos. & $\begin{array}{l}\text { Rother e } \\
\text { Shook (2003) }\end{array}$ \\
\hline Evento Kaizen & $\begin{array}{l}\text { União de esforços para cumprir as ações definidas em } \\
\text { determinado intervalo de tempo, geralmente realizado em } 1 \\
\text { semana. }\end{array}$ & $\begin{array}{l}\text { Rother e } \\
\text { Shook (2003) }\end{array}$ \\
\hline $5 S$ & $\begin{array}{l}\text { Programa de Melhoria Contínua que permite um ambiente } \\
\text { mais limpo e organizado, possibilitando o desenvolvimento de } \\
\text { outros conceitos e técnicas de melhoria contínua. }\end{array}$ & Liker (2005) \\
\hline $\begin{array}{l}\text { Mapeamento do } \\
\text { Fluxo de Valor }\end{array}$ & $\begin{array}{l}\text { Ferramenta que auxilia a enxergar e entender o fluxo de } \\
\text { material e de informação em determinado fluxo de valor. }\end{array}$ & $\begin{array}{l}\text { Rother e } \\
\text { Shook (2003) }\end{array}$ \\
\hline $\begin{array}{l}\text { Padrão de } \\
\text { Trabalho }\end{array}$ & $\begin{array}{l}\text { Utilizado para facilitar a obtenção da qualidade durante o } \\
\text { processo produtivo, trata-se de uma demonstração prática, } \\
\text { simples e visual da sequência de realização de atividades. }\end{array}$ & Ohno (1988) \\
\hline Fluxo Contínuo & $\begin{array}{l}\text { Um dos pontos centrais do pensamento enxuto, buscando } \\
\text { fazer uma peça de cada vez, de tal maneira a reduzir o } \\
\text { intervalo de tempo entre matéria-prima e produtos acabados } \\
\text { com maior qualidade. }\end{array}$ & Liker (2005) \\
\hline Sistema Puxado & $\begin{array}{l}\text { Quando o fluxo contínuo não for possível, utiliza-se o sistema } \\
\text { puxado, no qual os processos produzem somente a } \\
\text { quantidade "puxada" pelo cliente, obtendo uma produção } \\
\text { com o mínimo de estoque. }\end{array}$ & Liker (2005) \\
\hline Kanban & $\begin{array}{l}\text { Método operacional que carrega as informações na Toyota, } \\
\text { usado para "puxar" a produção. }\end{array}$ & Ohno (1988) \\
\hline Takt Time & $\begin{array}{l}\text { É o ritmo de produção, sendo a frequência que se deve } \\
\text { produzir uma peça ou produto. }\end{array}$ & $\begin{array}{l}\text { Rother e } \\
\text { Shook (2003) }\end{array}$ \\
\hline
\end{tabular}




\begin{tabular}{lll}
\hline $\begin{array}{l}\text { Nivelamento da } \\
\text { Produção } \\
\text { (Heijunka) }\end{array}$ & $\begin{array}{l}\text { É o nivelamento da produção em termos de volume e } \\
\text { variedade de produtos, fazendo com que a mesma } \\
\text { quantidade e combinação sejam produzidas por dia. }\end{array}$ & Liker (2005) \\
\hline Poka-Yoke & Dispositivos à prova de erros. & Ohno (1988) \\
\hline Just In Time & Fazer somente o necessário e quando necessário. & Liker (2004) \\
\hline Desperdício & $\begin{array}{l}\text { Qualquer atividade que absorve recursos e não cria valor para } \\
\text { o cliente final. }\end{array}$ & $\begin{array}{l}\text { Womack e } \\
\text { Jones (1986) }\end{array}$ \\
\hline $\begin{array}{l}\text { Agregação } \\
\text { de Valor }\end{array}$ & $\begin{array}{l}\text { Atividades que sob o ponto de vista do cliente final tornam o } \\
\text { produto ou serviço mais valioso. }\end{array}$ & $\begin{array}{l}\text { Womack e } \\
\text { Jones (1986) }\end{array}$ \\
\hline $\begin{array}{l}\text { Troca Rápida } \\
\text { (SMED) }\end{array}$ & $\begin{array}{l}\text { Conhecido como Single Minute Exchange of Die (SMED), essa } \\
\text { técnica busca reduzir o tempo de setup, permitindo assim que } \\
\text { seja possível reduzir o tamanho dos lotes de produção à } \\
\text { medida em que é possível realizar mais setups por dia. }\end{array}$ & Shingo (1996) \\
& $\begin{array}{l}\text { Sistema visual para facilitar a comunicação, melhorar a } \\
\text { qualidade, produtividade e segurança dos processos }\end{array}$ & Liker (2005) \\
\hline Gestão Visual & & \\
\hline
\end{tabular}

\section{Quadro 7 - Alguns conceitos de Melhoria Contínua}

\subsubsection{Fatores Críticos de Sucesso dos Programas de Lean}

Dentre as 50 empresas auditadas no Reino Unido, Bhasin (2012b) identificou cinco empresas as quais possuíam os melhores resultados de sustentabilidade dos programas de implantação do Lean. Com base no Lambda Wilk, uma distribuição de probabilidade utilizada no teste de hipótese multivariada, o autor conseguiu determinar características comuns apenas para estas cinco empresas. Estas características em comum podem ser diferenciais para o sucesso na implantação do Lean, e são as seguintes:

a) Segurança global, limpeza e ordem;

b) Fluxo produtivo e operacional;

c) Processos e operações;

Estas características foram reveladas por Bhasin (2012b) através da descoberta das seguintes estratégias comuns a estas cinco empresas:

a) Programa de Sustentabilidade ${ }^{7}$ do Lean;

b) Cultura organizacional orientada aos colaboradores;

\footnotetext{
${ }^{7}$ Os autores de Lean utilizam o termo "Sustentabilidade" para remeter à manutenção, no longo prazo, das melhorias implementadas. Portanto, o termo não está associado a questão ambientais, mas sim à manutenção ("sustentabilidade") dos novos padrões de processo definidos.
} 
c) Lean reconhecido como um negócio, ou iniciativa rentável para a empresa;

d) Filosofia utilizada;

e) Estratégia de Gestão da Mudança na Jornada Lean;

Para Bhasin (2012b), estas conclusões revelam o fato de que a Gestão da Mudança e a Cultura Organizacional podem promover o sucesso de empresas ao longo da Lean Journey. Curiosamente, embora as ferramentas e técnicas sejam vitais para o sucesso do Lean Manufacturing, a correlação das ferramentas e técnicas com o sucesso na Lean Journey não foram particularmente significativas (Bhasin, 2012b). Em outras palavras, não é aplicação de uma técnica ou ferramenta do Lean (ex.: aplicação do Kanban ou prática do Evento Kaizen) que irá garantir o sucesso na jornada de melhoria contínua, o sucesso nesta jornada está, na verdade, associado a uma série de crenças e comportamentos por parte da alta gestão e dos colaboradores da empresa.

Sob ponto de vista semelhante, Liker (2005) argumenta que a excelência do sistema produtivo enxuto é muito mais do que um fluxo contínuo, um Just in Time ou uma produção puxada através de um sistema kanban. No Modelo Toyota, são as pessoas que compreendem a cultura por trás deste sistema de excelência operacional, são elas, as pessoas, que dão vida ao sistema produtivo (Liker, 2005). Afinal, são as pessoas que trabalham, dialogam, solucionam problemas diariamente e crescem juntas. Este mesmo raciocínio não é aplicado somente ao Sistema Produtivo Enxuto ou Just in Time (JIT).

Além de Liker (2005), vários outros autores, como Porter (1996) e Gattorna (2004), citam a importância do comportamento das pessoas para o máximo desempenho dos mais variados conceitos de gestão de operações. De acordo com Lee (2007), o engajamento e a capacitação dos funcionários da organização são absolutamente vitais para o sucesso da implantação dos mais diversos conceitos de gestão de operações. Para o sucesso destes conceitos, deve ser reforçado a todos da organização que o processo de mudança e melhoria organizacional não se trata apenas de ferramentas e técnicas, mas sim está relacionado com o comportamento, atitude e comprometimento de todas as pessoas da organização (Ohno, 1988; Bhasin, 2011a; Bhasin, 2011b; Bhasin, 2012a).

Para que seja possível criar uma cultura Lean e obter sucesso nos Programas de Lean, Mann (2010) levanta quatro elementos principais do "Lean Management System" (Sistema de Gestão Lean), e outros dez elementos de suporte do sistema, listados: 
a) Principais elementos do Lean Management System: (1) Trabalho padrão das lideranças; (2) Controles visuais; (3) Daily Accountability Process; (4) Disciplina

b) Elementos de suporte do Lean Management System: O trabalho das lideranças é uma "operação contínua"; Aprendizado contínua; Análise de causa raiz dos problemas; promover disciplina em todo o ambiente (interno e externo); desenvolver um sistema de resposta rápida; Processo de melhoria contínua; Desenvolver Automação; Controle do plano de trabalho; Políticas de Recursos Humanos; avaliar o desenvolvimento do sistema de gestão;

Compreendendo os Programas de Melhoria Contínua de maneira mais ampla, Kovacheva (2010) apresenta seis fatores críticos de sucesso: Alta gerência comunica uma visão de maneira eficaz; Mudança de Cultura Organizacional; Desejo de aprender novas habilidades e conhecimentos; Estratégia holística para desenvolver um sistema integrado; Envolvimento dos colaboradores; Relacionamento entre pessoas.

Complementando as visões anteriores, Dombrowski e Mielka (2013) apresentam cinco princípios da liderança Lean: (1) Cultura de Melhoria Contínua: Busca pela perfeição e Experimentação ("fracassar é tão possível quanto melhorar"); (2) Desenvolvimento de pessoas: Os líderes Lean são exemplos a serem seguidos e Desenvolvimento de novas habilidades; (3) Qualificação: Desenvolvimento dos colaboradores no longo prazo e Aprendizado; (4) Gemba: Gestão do chão de fábrica e Decisões baseadas em fatos; (5) Foco nos clientes com objetivos alinhados em todos os níveis. Com pensamento semelhante ao de Kovacheva (2010), Bhasin e Burcher (2006) afirmam que, embora o Programa de Melhoria Contínua do Lean trate da redução de desperdícios em todos os níveis, dependendo do contexto, ele também se trata de um fortalecimento, evolução ou mudança cultural. Sob este ponto de vista, Bhasin e Burcher (2006) trazem 13 recomendações baseadas na literatura:

1. Tomar decisões no nível operacional com suporte dos outros níveis;

2. Estabelecer uma visão clara de como a organização será depois que o processo de transformação tiver sido finalizado;

3. Estabelecer uma estratégia de mudança capaz de comunicar como os objetivos serão atingidos para todos;

4. Definir responsabilidades para o programa e iniciativas de mudança;

5. Desenvolver os fornecedores baseado em relação de confiança e respeito; 
6. Promover o aprendizado contínuo das pessoas;

7. Sistematicamente e continuamente manter foco no cliente;

8. Promover uma liderança Lean em todos os níveis organizacionais, utilizando métricas do Lean em todos os níveis;

9. Manter o desafio de melhorar constantemente os processos internos;

10. Realizar esforço consciente para maximizar a estabilidade em um ambiente em constante modificação, buscando reduzir as variações;

11. Avaliar a parcela dos colaboradores trabalhando sob condições Lean;

12. Observar a proporção dos departamentos buscando melhoria contínua;

13. O Lean requer um planejamento de longo prazo, uma empresa de tamanho médio necessita de três a cinco anos para consolidar a filosofia Lean;

Com base nestes fatores críticos de sucesso levantados, e também nos princípios e valores dos Programas de Lean descritos anteriormente, o Quadro 8 traz uma compilação do resultado desta análise, envolvendo os fatores críticos de sucesso de Projetos de Transformação a partir de Programas de Lean. O Quadro 8 ilustra o resultado de um exercício de consolidação de conceitos e fatores críticos dos programas de melhoria contínua. Conforme sugerido por (Whetten, 1989), neste exercício optou por "pecar pelo excesso" ao invés de "pecar pela falta", ou seja, foram levantados todos os principais fatores discutidos na literatura que, de alguma maneira, exercem impacto positivo no sucesso dos programas. Este levantamento (dos fatores de sucesso) foi organizado de acordo com dimensões de influência de ações da administração, conforme levantado por Robbins (2005): treinamento, liderança, socialização, autonomia, avaliação de desempenho e plano de recompensas. Foram feitas apenas duas modificações nas dimensões propostas por Robbins (2005) ao tratar de Cultura Organizacional:

a) A perspectiva "Comunicação" foi somada à dimensão "Socialização", buscando passar a importância do processo de comunicação do planejamento e execução das mudanças ao longo do processo de transformação organizacional;

b) Uma nova dimensão foi criada com o nome de "Planejamento e Administração", englobando tanto aspectos de planejamento do processo de transformação, quanto de execução e monitoramento das iniciativas de mudança que ocorrem durante os Programas de Melhoria Contínua; 


\section{FATOR DE SUCESSO}

\begin{tabular}{|c|c|c|c|}
\hline \multirow{6}{*}{$\begin{array}{l}\text { Cultura } \\
\text { Organizacional }\end{array}$} & $\begin{array}{l}\text { Alinhamento } \\
\text { cultural }\end{array}$ & $\begin{array}{l}\text { A administração deve desenvolver e promover uma cultura } \\
\text { organizacional compatível com os princípios e valores } \\
\text { propostos pelo programa de melhoria contínua; }\end{array}$ & $\begin{array}{l}\text { Deming (1986), Mohamed e YuanJuan } \\
\text { (2008), Kovacheva (2010) }\end{array}$ \\
\hline & $\begin{array}{l}\text { Planejamento } \\
\text { de longo prazo }\end{array}$ & $\begin{array}{l}\text { O programa requer um planejamento de longo prazo, por } \\
\text { exemplo, uma empresa de tamanho médio necessita de três } \\
\text { a cinco anos para consolidar a filosofia; }\end{array}$ & $\begin{array}{l}\text { Liker (2005), Bhasin } \\
\text { e Burcher (2006) }\end{array}$ \\
\hline & $\begin{array}{l}\text { Trabalho } \\
\text { em equipe }\end{array}$ & $\begin{array}{l}\text { A cultura organizacional deve promover o suporte e trabalho } \\
\text { em equipe, tendo os líderes como conselheiros que dão } \\
\text { suporte à melhoria dos processos no longo prazo; }\end{array}$ & Mohamed e YuanJuan (2008) \\
\hline & Disciplina & $\begin{array}{l}\text { Os líderes da organização devem estar acompanhando } \\
\text { frequentemente se as pessoas na organização estão } \\
\text { mantendo a disciplina nos demais fatores; }\end{array}$ & Mann (2010) \\
\hline & Foco no cliente & $\begin{array}{l}\text { Os projetos e as mudanças devem ser orientados para } \\
\text { melhorar a proposta de valor aos clientes; }\end{array}$ & Mohamed e YuanJuan (2008) \\
\hline & Estabilidade & $\begin{array}{l}\text { Realizar esforço consciente para maximizar a estabilidade } \\
\text { em um ambiente em constante modificação, buscando } \\
\text { reduzir as variações; }\end{array}$ & Bhasin e Burcher (2006) \\
\hline \multirow{2}{*}{$\begin{array}{l}\text { Estrutura } \\
\text { Organizacional }\end{array}$} & Gestão Visual & $\begin{array}{l}\text { Importante para comparar de maneira prática a } \\
\text { performance atual versus desejada }\end{array}$ & Mann (2010) \\
\hline & $\begin{array}{l}\text { Daily Accountability } \\
\text { Process }\end{array}$ & $\begin{array}{l}\text { A administração deve realizar o follow-up das iniciativas } \\
\text { propostas, e também reforçar os comportamentos } \\
\text { esperados pelas pessoas (ex.: foco nos processos); }\end{array}$ & Mann (2010) \\
\hline \multirow{2}{*}{ Treinamento } & Aprendizado & $\begin{array}{l}\text { Desenvolver uma cultura que promova e considere o } \\
\text { aprendizado contínuo como sendo fundamental para o } \\
\text { sucesso da organização; }\end{array}$ & $\begin{array}{l}\text { Bhasin e Burcher (2006), Mohamed e } \\
\text { YuanJuan (2008), Kovacheva (2010) }\end{array}$ \\
\hline & $\begin{array}{l}\text { Desenvolvimento } \\
\text { das pessoas }\end{array}$ & $\begin{array}{l}\text { A organização deve reconhecer as pessoas como seu ativo } \\
\text { mais importante e desenvolvê-las; }\end{array}$ & $\begin{array}{l}\text { Deming (1986), Mohamed e YuanJuan } \\
\text { (2008) }\end{array}$ \\
\hline
\end{tabular}




\begin{tabular}{|c|c|c|c|}
\hline \multirow{6}{*}{ Liderança } & \multirow{4}{*}{$\begin{array}{l}\text { Lideranças } \\
\text { que promovam } \\
\text { a cultura desejada }\end{array}$} & $\begin{array}{l}\text { Definir responsabilidades para o programa e iniciativas de } \\
\text { mudança do processo de transformação; }\end{array}$ & $\begin{array}{l}\text { Bhasin e Burcher (2006), Mohamed e } \\
\text { YuanJuan (2008), Pamfilie, Draghici e } \\
\text { Draghici (2012) }\end{array}$ \\
\hline & & $\begin{array}{l}\text { Definir um trabalho padrão para que as lideranças tenham } \\
\text { uma rotina de gestão, foco em resultados e } \\
\text { nos processos que influenciam os resultados; }\end{array}$ & Mann (2010) \\
\hline & & $\begin{array}{l}\text { A média gerência exerce um papel fundamental na liderança } \\
\text { do processo, caso não esteja alinhada com as mudanças } \\
\text { propostos, haverá problemas na implementação; }\end{array}$ & Fronda e Moriceau (2008) \\
\hline & & $\begin{array}{l}\text { Promover uma liderança alinhada com os valores e } \\
\text { comportamentos desejados pelo programa; }\end{array}$ & $\begin{array}{l}\text { Deming (1986), Bhasin e Burcher } \\
\text { (2006), Mohamed e YuanJuan (2008) }\end{array}$ \\
\hline & $\begin{array}{l}\text { Metodologia de } \\
\text { Solução de Problemas }\end{array}$ & $\begin{array}{l}\text { As lideranças devem fazer o papel de "Coaching" } \\
\text { organizacional, fornecendo conhecimento técnico para que } \\
\text { as pessoas da organização consigam solucionar os } \\
\text { problemas organizacionais; }\end{array}$ & Rother (2010) \\
\hline & $\begin{array}{l}\text { Definir uma estratégia } \\
\text { holística para desenvolver } \\
\text { um sistema integrado }\end{array}$ & $\begin{array}{l}\text { A alta gerência deve estabelecer uma estratégia de mudança } \\
\text { capaz de comunicar como os objetivos serão atingidos para } \\
\text { todos; }\end{array}$ & $\begin{array}{l}\text { Bhasin e Burcher (2006), Kovacheva } \\
(2010)\end{array}$ \\
\hline \multirow{3}{*}{$\begin{array}{l}\text { Socialização e } \\
\text { Comunicação }\end{array}$} & $\begin{array}{l}\text { Construção e promoção } \\
\text { de confiança }\end{array}$ & $\begin{array}{l}\text { Para que o desenvolvimento e a implementação das } \\
\text { melhorias sejam bem-sucedidos, é importante que haja um } \\
\text { senso de confiança e participação dos colaboradores; }\end{array}$ & Deming (1986) \\
\hline & $\begin{array}{l}\text { Compartilhar } \\
\text { aprendizados }\end{array}$ & $\begin{array}{l}\text { Para promover melhorias em todos os níveis } \\
\text { organizacionais, é importante que os colaboradores } \\
\text { compartilhem os aprendizados obtidos com outros } \\
\text { colaboradores, de tal maneira a fazer com que o } \\
\text { aprendizado não seja de um único individuo, mas sim } \\
\text { de toda a organização; }\end{array}$ & Kovacheva (2010) \\
\hline & $\begin{array}{l}\text { Alta gerência comunica } \\
\text { uma visão de maneira } \\
\text { eficaz }\end{array}$ & $\begin{array}{l}\text { A alta gerencia estabelece e comunica de maneira clara uma } \\
\text { visão de como a organização deverá ser depois do processo } \\
\text { de transformação; }\end{array}$ & $\begin{array}{l}\text { Bhasin e Burcher (2006), Kovacheva } \\
(2010)\end{array}$ \\
\hline
\end{tabular}




\begin{tabular}{|c|c|c|c|}
\hline & $\begin{array}{l}\text { Relacionamento } \\
\text { com os fornecedores }\end{array}$ & $\begin{array}{l}\text { Desenvolver os fornecedores baseado em relação de } \\
\text { confiança e respeito; }\end{array}$ & Bhasin e Burcher (2006) \\
\hline & $\begin{array}{l}\text { Relacionamento } \\
\text { com os clientes }\end{array}$ & $\begin{array}{l}\text { Sistematicamente e continuamente manter foco nos } \\
\text { clientes; }\end{array}$ & Bhasin e Burcher (2006) \\
\hline & $\begin{array}{l}\text { Relacionamento entre as } \\
\text { pessoas da organização }\end{array}$ & $\begin{array}{l}\text { É importante que exista um senso de união entre as pessoas } \\
\text { para que o programa de melhoria contínua tenha sucesso; }\end{array}$ & Kovacheva (2010) \\
\hline Autonomia & $\begin{array}{l}\text { Empowerment } \\
\text { e envolvimento }\end{array}$ & $\begin{array}{l}\text { Ajuda a motivar as pessoas simplesmente por permitir que } \\
\text { as pessoas se sintam capazes e tenham de alguma maneira } \\
\text { uma "voz" no programa, possibilitando assim que elas } \\
\text { assumam responsabilidades no processo de transformação; }\end{array}$ & $\begin{array}{l}\text { Deming (1986), Bhasin e Burcher } \\
\text { (2006), Mohamed e YuanJuan (2008), } \\
\text { Kovacheva (2010) }\end{array}$ \\
\hline $\begin{array}{l}\text { Seleção } \\
\text { de Pessoas }\end{array}$ & Recrutamento & $\begin{array}{l}\text { Selecionar pessoas com habilidades analíticas e atenção a } \\
\text { detalhes, os funcionários devem prosperar na rotina de } \\
\text { melhoria continua e definição de novos padrões; }\end{array}$ & Gattorna (2009) \\
\hline \multirow{4}{*}{$\begin{array}{l}\text { Avaliação de } \\
\text { Desempenho }\end{array}$} & \multirow{2}{*}{$\begin{array}{l}\text { Métricas de } \\
\text { desempenho }\end{array}$} & $\begin{array}{l}\text { Desenvolver e monitorar métricas de desempenho em todos } \\
\text { os níveis da organização alinhadas com os objetivos e } \\
\text { comportamentos desejados do programa; }\end{array}$ & Bhasin e Burcher (2006), Mann (2010) \\
\hline & & $\begin{array}{l}\text { Avaliar a parcela dos colaboradores trabalhando de acordo } \\
\text { com as condições do programa, e também a parcela dos } \\
\text { departamentos buscando melhoria; }\end{array}$ & Bhasin e Burcher (2006) \\
\hline & $\begin{array}{l}\text { Associar as melhorias } \\
\text { com ganhos financeiros }\end{array}$ & $\begin{array}{l}\text { É importante que sejam obtidos e demonstrados resultados } \\
\text { financeiros para motivar a continuidade do processo }\end{array}$ & Schaffer e Thomson (1992) \\
\hline & $\begin{array}{l}\text { Foco nos processos } \\
\text { internos }\end{array}$ & $\begin{array}{l}\text { Manter o desafio de melhorar constantemente os processos } \\
\text { internos; }\end{array}$ & Bhasin e Burcher (2006), Mann (2010) \\
\hline $\begin{array}{l}\text { Sistema de } \\
\text { Recompensas }\end{array}$ & Comportamento Humano & $\begin{array}{l}\text { Os comportamentos desejados devem ser reforçados } \\
\text { através de premiações dos colaboradores com } \\
\text { reconhecimento, respeito e políticas de recursos humanos; }\end{array}$ & Deming (1986), Mann (2010) \\
\hline
\end{tabular}

Quadro 8 -Fatores Críticos de Sucesso de Projetos de Transformação utilizando Programas de Melhoria Contínua 


\subsection{CULTURA ORGANIZACIONAL}

Esta seção sobre Cultura Organizacional tem início com uma introdução sobre o tema - abordando a definição de cultura, discussão sobre variável dependente ou independente, relevância e níveis de cultura. Na sequência, a Seção passa por uma visão dos métodos de diagnóstico, perfis culturais associados a melhoria contínua (tema da seção anterior), e também uma consolidação das ações da administração em termos de desenvolvimento de determinada cultura organizacional

Desta maneira, o texto de revisão sobre Gestão de Operações segue a estrutura das seções em destaque na Figura 18.

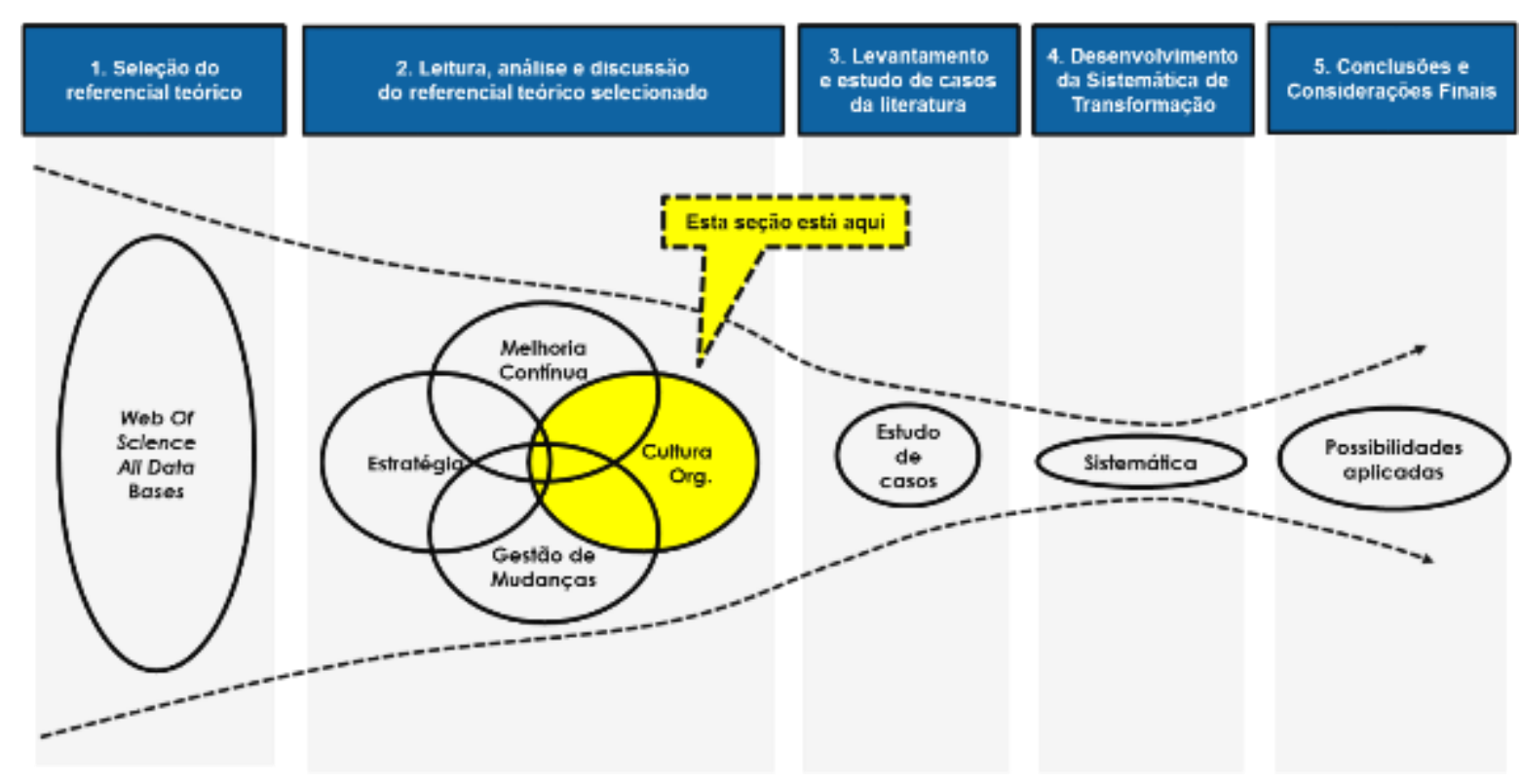

Figura 18 - O papel da revisão sobre Cultura Organizacional no processo de pesquisa

\subsubsection{Introdução à Cultura Organizacional}

$\mathrm{Na}$ linguagem ocidental o termo "cultura" geralmente é atribuído a conceitos relacionados a "civilização" ou "refinamento da mente", sendo o resultado da educação, arte e literatura da cultura de um determinado povo, no entanto, quando dentro do campo da antropologia social, a cultura representa um padrão de pensamento, sentimentos e ações de acordo com definições já concebidas (Hofstede, 2010). Vale ressaltar que Hofstede (2010), junto com Trompenaars e Hampden-Turner (1994), são referências em “Cultura Nacional”, e não necessariamente sejam as principais referências em "Cultura Organizacional". 
Sob o ponto de vista da cultura organizacional como um padrão de comportamentos, os livros "Corporate Culture", de Deal e Kennedy ${ }^{8}$, e "Structure is not Organization", de Waterman, Peters e Phillips (1980), tornaram-na um tópico popular entre os administradores, sejam eles acadêmicos ou não (Buschgens, Bausch e Balkin, 2011). Nesse campo de estudo, cultura representa as normas para o comportamento aceitável, exercendo influência nas relações externas e internas da organização (Hall, 1986), consequentemente, influenciando também o comportamento que os novos colaboradores devem seguir quando entram na empresa (Kotter e Herkettk, 1992). Por afetar comportamentos como inovação, tomada de decisão, comunicação, organização e avaliação de sucesso, a cultura afeta a motivação e o desempenho das pessoas e, consequentemente, o desempenho da organização (Hall, 1986; Kotter e Herkettk, 1992).

Existem inúmeras definições de Cultura Organizacional (Chew e Putti, 1995), como também, diferentes disciplinas irão defini-la de maneiras diversas (Eagleton, 2000). Como consequência, a literatura sobre Cultura pode ser extremamente ampla, diversa e contraditória (Gallear, Ghobadian e Burroughs, 2004). Hofstede (2010, p. 6) define Cultura Organizacional como uma "programação coletiva da mente que distingue os membros de um grupo ou cria categorias que diferenciam as pessoas umas das outras". Outros autores como Trompenaars e Hampden-Turner (1994) e Detert et al. (2000) definem Cultura Organizacional como "valores compartilhados", os quais direcionam a maneira como as pessoas agem, o que prestam atenção e também o que valorizam.

Para se ter uma noção da diversidade de definições existentes sobre Cultura Organizacional, em 1952, décadas antes das principais referências do tema - citadas no parágrafo anterior - terem publicado suas principais obras, Kroeber e Kluckholn (1952) já haviam encontrado cerca de 164 diferentes definições sobre Cultura Organizacional. Heng e Ahmed (2000) julgam este fato totalmente compreensível, tendo em vista que o conceito de Cultura tem sua origem na Antropologia, na qual até mesmo os Antropologistas não chegaram a um consenso sobre uma definição única para Cultura.

Em meio às diferentes definições existentes sobre Cultura Organizacional, Maull, Brown e Cliffe (2001) identificaram quatro grupos de definições sobre Cultura Organizacional:

\footnotetext{
${ }^{8}$ DEAL, T.; KENNEDY, A. (1982). Corporate Culture, Addison Wesley, Readings.
} 
(1) como um conjunto de aprendizados, (2) como um conjunto de crenças, (3) como uma estratégia de negócio ou (4) como uma programação mental que integraria determinados aspectos das três visões anteriores.

Gallear, Ghobadian e Burroughs (2004) discordam de Maull, Brown e Cliffe (2001) com relação à quantidade de grupos de definições. Para os autores, embora existam diferentes definições, está claro que existem três grupos de definições: (1) como um conjunto de valores compartilhados por um grupo, (2) como "o modo de trabalhar aqui" ou "como as coisas são feitas aqui”, (3) e um terceiro grupo enxerga cultura organizacional como uma combinação dos dois grupos anteriores - uma combinação de valores com o modo de fazer as coisas.

Em meio a esta variedade de definições, este trabalho utilizará a definição que mais faz sentido do ponto de vista do planejamento e execução de "Projetos de Transformação". Sob este ponto de vista, o trabalho utilizará uma definição de cultura que esteja alinhada com um conceito de desenvolvimento, evolução e amadurecimento da Cultura Organizacional ao longo de sua própria história. Isto faz muito sentido pelo fato da Cultura Organizacional, em um primeiro momento, ser extremamente influenciada pelo fundador da organização sobre o grupo como um todo e, em um segundo momento, esta mesma cultura passaria a ser o produto das experiências e aprendizados que este grupo teve durante sua história (Schein, 2009).

Sob este raciocínio, neste trabalho, será utilizada como referência a definição de Schein (2009, p. 16) sobre cultura organizacional:

\begin{abstract}
“Cultura organizacional é o padrão de pressupostos básicos que um dado grupo tenha inventado, descoberto ou desenvolvido durante seu processo de aprendizado para lidar com seus problemas de adaptação externa e integração interna, e que tem funcionado bem o bastante para ser considerado válido, e, portanto, para ser ensinado aos novos membros como a forma correta para perceber, pensar, e sentir em relação a esses problemas" (Schein, 2009, p. 16).
\end{abstract}

Neste aspecto, no clássico "Coming to a New Awareness of Organizational Culture", Schein (1984) faz quarto importantes e precisas conclusões sobre cultura:

1. Toda cultura está constantemente em um processo de mudança;

2. Ela tende a cobrir todos os aspectos relacionados a funcionalidades humanas; 
3. Ela é aprendida de acordo com as novas soluções e respostas aos problemas de adaptação ao ambiente interno e externo;

4. Ela é constituída pela composição de padrões de valores e pressupostos básicos de um grupo assumidos como verdadeiros e muitas vezes inquestionáveis;

Complementando o ponto de vista de Schein, Heng e Ahmed (2000) citam a importância de distinguir a "Cultura" de uma "Ideologia", descritas no Quadro 9.

\begin{tabular}{l|cc}
\hline Dimensão & Cultura & Ideologia \\
\hline Natureza & Crenças e valores compartilhados & Crenças e valores \\
\hline Formação & Histórica & Visão \\
\hline Orientação & Status quo & Um futuro melhor \\
\hline Preferência & Ajuste e adaptação & Criar e engajar \\
\hline Ambiente visível & Ordenado & Caótico \\
\hline Ação & Passiva & Ativa \\
\hline Mudança & Gradual & Radical \\
\hline
\end{tabular}

\section{Quadro 9 - Principais diferenças entre Cultura e Ideologia}

Fonte: Heng e Ahmed (2000)

\section{Cultura: variável dependente ou independente?}

Para Maull, Brown e Cliffe (2001) uma discussão filosófica importante sobre o tema é: a Cultura Organizacional é uma variável dependente ou independente, a cultura é algo que as organizações "possuem" ou algo que as organizações "são"?

Como uma variável dependente, Maull, Brown e Cliffe (2001) afirmam que cada cultura é única e fruto de sua história, do desenvolvimento e situação atual na qual se encontra. Para estes autores, neste aspecto, as culturas então são frutos único da sua história, de acordo com as experiências dos indivíduos, seus rituais, suas cerimonias e heróis, enquanto as organizações estão inseridas em um contexto mais amplo do que somente a cultura organizacional. Neste aspecto, para Robbins (2005) algumas das variáveis independentes que poderiam modificar uma cultura organizacional seriam, por exemplo, o sistema de recompensas, a avaliação de desempenho, o treinamento e outras variáveis citadas na Figura 19, de tal maneira a promover ou influenciar a mudança ou fortalecimento de determinada cultura organizacional. 


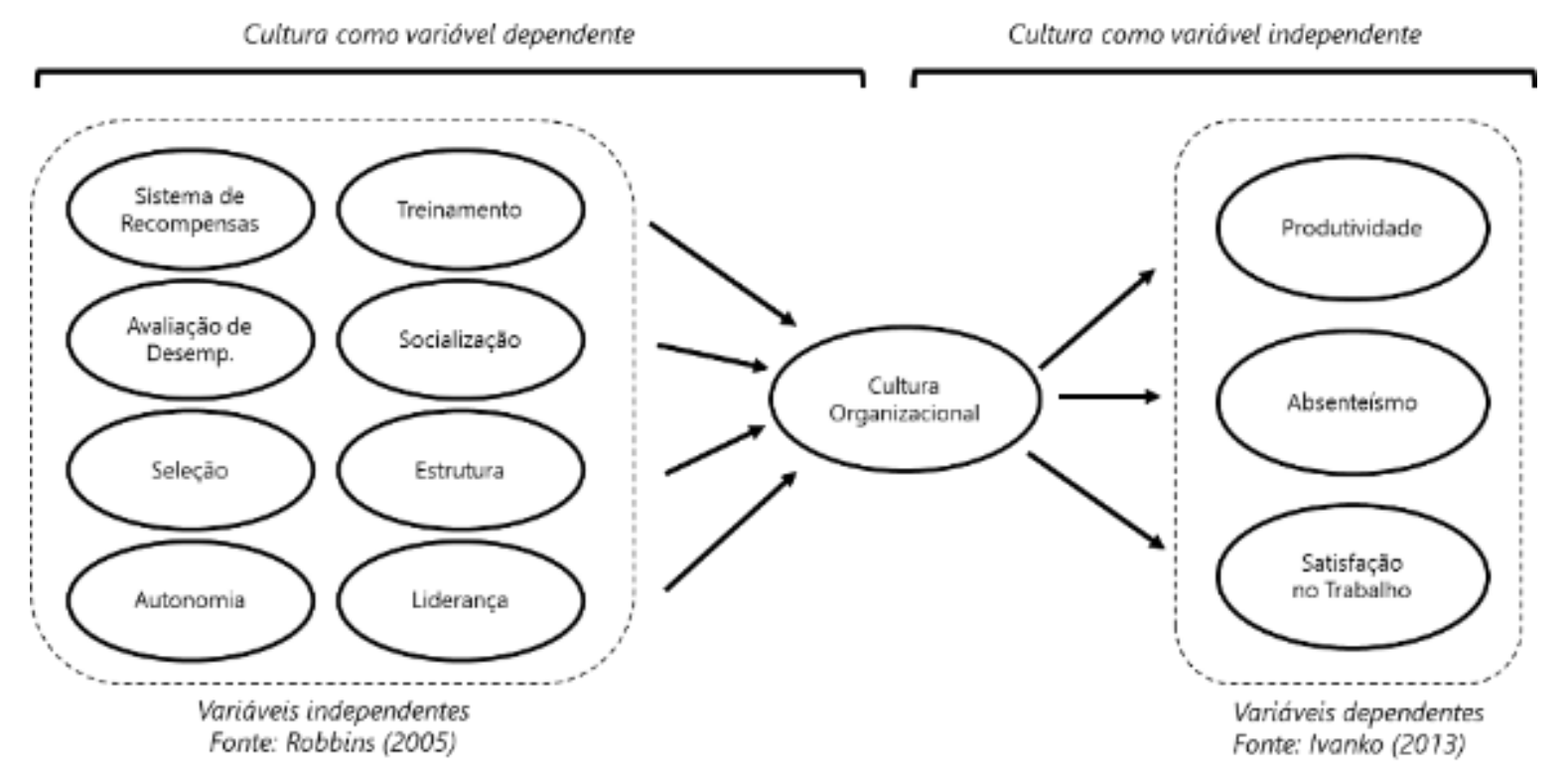

\section{Figura 19 - Cultura Organizacional como variável dependente e independente}

No entanto, a cultura também pode ser vista como uma variável independente, na qual os pesquisadores buscam compreender quais características boas e universais da cultura podem ser incorporadas à organização de tal maneira a promover melhores resultados de acordo com a estratégia corporativa (Maull, Brown e Cliffe, 2001). Segundo Ivanko (2013), vista como uma variável independente, a cultura organizacional pode promover melhores resultados em termos de satisfação no trabalho, absenteísmos e produtividade das pessoas. Ao analisar a cultura como uma variável independente, os autores utilizam a visão de que a cultura seria um objetivo tangível e que pode ser modificado, sofrendo métodos diretos de intervenção de acordo com os resultados desejados (Maull, Brown e Cliffe, 2001). Assim, algumas variáveis dependentes que podem ser afetadas pela cultura organizacional são (Ivanko, 2013):

$\checkmark$ Produtividade: se a empresa é considerada eficaz (atinge as metas) e eficiente (baixo custo de operação ou utilização eficiente dos recursos) ao mesmo tempo (Ivanko, 2013);

$\checkmark$ Absenteísmo: não há dúvida que uma empresa não irá atingir seus objetivos quando o absenteísmo for elevado, todas as empresas devem manter registro deste índice, pois ele acarreta em custo (Ivanko, 2013).

$\checkmark$ Satisfação no trabalho: o equilíbrio entre o esforço e a recompensa que os colaboradores precisam fazer para executar seu trabalho (Ivanko, 2013).

A Figura 19 ilustra estes dois pontos de vista: cultura como variável independente e cultura como variável dependente. Este trabalho irá compreender e analisar a Cultura Organizacional em um contexto amplo, hora como uma variável dependente, hora como uma 
variável independente. Sob o ponto de vista da Cultura Organizacional como variável dependente, este trabalho de revisão também busca levantar, estudar e analisar quais variáveis independentes podem vir a modificar uma determinada cultura organizacional. As variáveis dependentes listadas na Figura 19, como Treinamento, Socialização, Liderança e outras, são descritas no final desta seção.

\section{A relevância da Cultura Organizacional}

É senso comum entre acadêmicos e gestores que a cultura organizacional é um dos fatores chave para o sucesso organizacional (Waterman, Peters e Phillips, 1980; Schein, 1984; Buschgens, Bausch e Balkin, 2011). Ela é de suma importância na discussão contemporânea em virtude do seu impacto no desempenho organizacional (Cameron e Quinn, 2006; Cameron e Green, 2004; Bhasin, 2011a; Bhasin, 2012b), afinal, é a cultura organizacional que dá suporte à estratégia, e não o contrário. As organizações que tenham um alinhamento da cultura organizacional com a estratégia tendem a ser mais bem-sucedidas quando comparadas àquelas que não possuem este alinhamento (Schein, 1984; Pascale, 1990). Cadden, Marshall e Cao (2013) encontraram evidências estatísticas de que as empresas com perfis culturais alinhados, ou coerentes, apresentavam uma performance financeira acima da média.

Quanto mais a cultura estiver em harmonia e alinhada com a estratégia, mais a cultura terá impacto positivo no desempenho organizacional (Cameron e Quinn, 2006; Gattorna, 2009; El-Kouba e outros, 2009). Os resultados de Parish, Cadwallader e Busch (2008) também corroboram com este ponto de vista, os autores identificaram que o alinhamento de uma visão compartilhada está diretamente relacionado com a satisfação e motivação dos colaboradores e, principalmente, tem influência no grau de comprometimento com as mudanças (commitment to change). González-Benito e González-Benito (2005) também encontraram resultados significativos associando um determinado perfil cultural a resultados operacionais ao analisar diversas indústrias espanholas.

Considerando que o conceito de cultura é essencial para viabilizar as estratégias e o processo de mudança, compreender e estudar a cultura organizacional é cada vez mais relevante para o estudo da administração (Shinyashiki, 1995). Nesse contexto, os gestores devem estimular o desenvolvimento de uma cultura que esteja alinhada com a estratégia corporativa, de tal maneira a obter os melhores resultados do negócio (Davis, 1984). Algumas organizações podem não obter o melhor desempenho simplesmente por estarem aplicando 
fórmulas "genéricas" ao invés de buscar desenvolver uma cultura da maneira mais apropriada e produtiva (Maull, Brown e Cliffe, 2001). Segundo Irani e Sharp (1997), para integrar melhoria contínua com inovação - duas filosofias diferentes que em conjunto podem vir a formar uma sinergia construtiva -, é necessário que haja uma cultura organizacional apropriada. Segundo Bengoa, Kaufmann e Vrontis (2012), também é importante gerenciar a cultura organizacional para que haja uma gestão de conhecimento adequada, por exemplo, os autores julgam ser necessário promover uma cultura com altos níveis de confiança entre os seus membros para que de fato haja uma troca de informações transparente e adequada.

Além de questões associadas a resultados do negócio e implementação da estratégia corporativa, o estudo da cultura organizacional também é importante devido ao seu impacto no comprometimento das pessoas. Comprometimento pode ser definido como a força pela qual os indivíduos se identificam e estão envolvidos com uma determinada organização (Steers, 1977 apud ${ }^{9}$ Shinyashiki, 1995). O comprometimento, segundo Shinyashiki (1995), pode ser definido por três fatores: (a) crenças e aceitação dos objetos e valores da organização; (b) desejo de dedicar uma energia considerável em favor da organização; (c) forte desejo de manter-se na organização. Portanto, fica claro o benefício de ter uma forte cultura organizacional, afinal, quanto mais fortes forem os laços entre pessoas e os valores organizacionais, mais forte será o comprometimento das pessoas para com a organização.

Segundo Fleury, Shinyashiki e Stevanato (1997), ao tratar da temática de "valor" do ponto de vista da cultura organizacional, Kluckhohn (1951) faz uma analogia muito interessante com o conceito de força em física: ninguém vê uma força, somente as manifestações da força são observadas diretamente. Nesse sentido, embora as crenças e valores da cultura organizacional não sejam visíveis, estes valores e crenças tem impacto relevante no comportamento humano, e, portanto, pode-se concluir que terão efeito significante no desempenho da organização. Para Buschgens, Bausch e Balkin (2011), a amplitude das variáveis culturais levou a estudos fragmentados sobre uma cultura de inovação, e, consequentemente, ainda existem gaps de conceitos de gestão na teoria presente. Para os autores, as empresas devem ter uma estrutura básica que responda qual cultura deve ser implementada, de tal maneira a proporcionar inovação e, ainda, esta estrutura de gestão deve ser capaz de avaliar o quão eficiente e eficaz a cultura organizacional está sendo.

\footnotetext{
${ }^{9}$ STEERS, R. M. (1997). Antecedents and outcomes of organizational commitment. Administrative Science Quartely, Vol. 22, pp. 45-56.
} 
No clássico de administração, o livro "A Quinta Disciplina - arte e prática da organização que aprende”, Senge (2002) comenta que "o fracasso em sustentar mudanças significativas pode ocorrer diversas vezes, mesmo quando muitos recursos estiverem comprometidos com a mudança". As pessoas parecem não aprender com a mudança, parecem não valorizar as mudanças realizadas. Para Senge (2002), as empresas precisam aprender algo com a mudança! Caso contrário, as mudanças não serão bem-sucedidas e se deterioram com o tempo (fracassam em termos de sustentabilidade das melhorias implementadas). Quando analisado do ponto de vista da cultura organizacional, Peter Senge está implicitamente se referindo a mudanças que não foram absorvidas pela cultura organizacional. Para Schein (2009), esse aprendizado, ou reaprendizado, envolve um processo de evolução cultural englobando diferentes níveis da cultura organizacional. A cultura ganhou uma relevância tão grande no meio acadêmico e corporativo que, atualmente, não há qualquer teorização ou até mesmo intervenção em organizações, que não contenha, explicita ou implícita, uma determinada concepção de cultura organizacional (Freitas, 1991).

\subsubsection{Diagnóstico de cultura organizacional}

\section{Os níveis de cultura}

Hofstede (2010) apresenta diferentes níveis de cultura, como: nacional, regional, gênero, geração, social e organizacional. E de acordo com estes níveis, o trabalho do autor é mais voltado para o nível de cultura nacional. De acordo com cada nível, Hofstede (2010) apresenta maneiras diferentes pelas quais uma cultura se manifesta: através de símbolos, heróis, ritos e valores, como ilustrado na Figura 20.

Para Hofstede (2010), os símbolos representam as palavras, gestos, imagens e objetivos que carregam um significado compartilhado pelo grupo. Os heróis são as pessoas, vivas ou não, reais ou imaginárias, que são valorizados em uma determinada cultura e, portanto, servem como modelos de comportamento. Os ritos são as atividades coletivas com fundo social que são realizadas para manter a unidade e senso de pertencimento ao grupo, são os modos de demonstrar respeito às pessoas, como cerimonias sociais ou religiosas por exemplo. Os símbolos, heróis e rituais podem ser entendidos como as práticas do grupo. Por fim, a essência da cultura está nos valores, os quais seriam tendências de sentimento, representando um lado 
positivo e um lado negativo, como: bem versus mal; sujo versus limpo; feio versus bonito; anormal versus normal; lógico versus paradoxo; racional versus irracional.

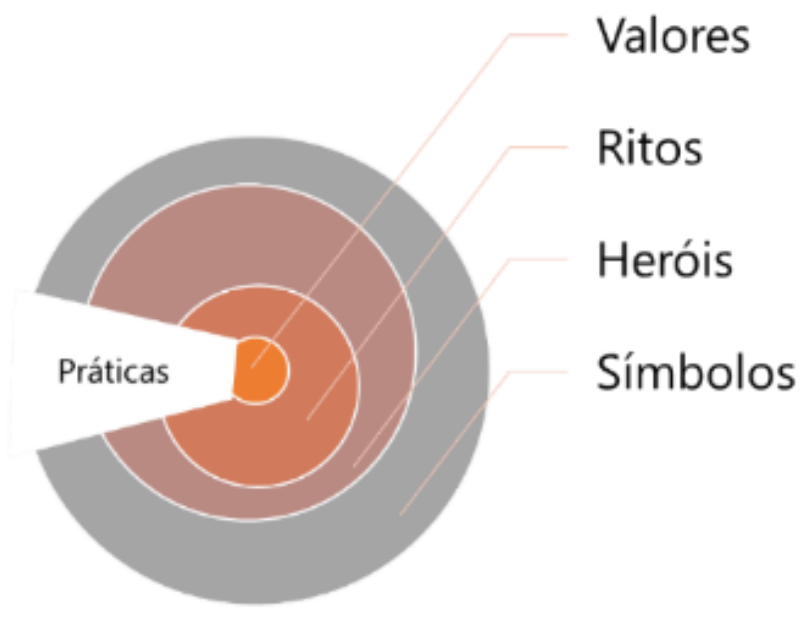

Figura 20 - O diagrama de cebola de Hofstede

Fonte: adaptado de Hofstede (2010)

Em oposição a Hofstede (2010), Schein (1984) argumenta que uma Cultura pode ser analisada em três diferentes níveis, como ilustrado na Figura 21: (a) artefatos visíveis, (b) crenças e valores e (c) suposições básicas.

\section{Artefatos e criações visíveis}

Para ilustrar os artefatos visíveis, Schein (2009) cita o exemplo dos egípcios e dos maias: ambos construíram pirâmides semelhantes e altamente visíveis, mas, as pirâmides possuem significados distintos para culturas distintas, túmulos na Cultura Egípcia, e templos na Cultura Maia. Nesse sentido, é perigoso tentar fazer interpretações dos níveis mais inferiores da cultura a partir dos artefatos e criações. Exemplos: arquitetura, layout dos escritórios, tecnologias utilizadas, maneira de se vestir das pessoas, documentos públicos, gráficos, histórias, etc.

\section{Crenças e valores assumidos}

Certos valores e crenças são confirmados apenas pela experiência compartilhada do grupo, por exemplo, se um gerente convence sua equipe/grupo a agir conforme sua crença, se a solução for bem-sucedida e trazer resultados para o grupo, então o valor percebido pelo grupo na ação será positivo e passará a ser um pressuposto básico do grupo (Schein, 2009). Nesse sentido, as crenças e valores embora não possam 
ser testadas passam por um processo de "validação social" de acordo com as experiências de grupo. Schein (2009) comenta que nenhuma cultura pode provar que sua religião e sistema moral são superiores aos demais, no entanto, se um de seus membros provar e aceitar as crenças e valores de outra cultura, então este membro pode ser "excomungado" (segregado) do grupo. Embora possam ser listadas (crenças e valores), muitas vezes estas listas são abstratas ou contraditórias: é contraditório quando uma empresa está ao mesmo tempo preocupada com os acionistas, funcionários e clientes, ou quando declara possuir os produtos da mais alta qualidade e com o menor preço do mercado (Schein, 2009). Por exemplo, a noção de que os negócios devam ser lucrativos, ou que os remédios sejam bons para a saúde são "apenas" valores.

\section{Pressupostos e suposições fundamentais básicos}

Quando a solução proposta a um problema funciona repetidamente, o grupo passa a aceitar esta solução como uma verdade fundamental, portanto, o que antes era apenas uma hipótese passa a ser considerada um pressuposto básico (Schein, 2009). Esse "consenso" do grupo passa por um processo contínuo de implementação de crenças e valores. Por exemplo, se um grupo desenvolve um Sistema Puxado dentro de um Programa de Melhoria Contínua e esta ação é bem-sucedida, então o grupo passará a valorizar as práticas do Sistema Puxado promovendo mais rodadas de sucesso e aprendizado, e agora provavelmente fazendo resistência a qualquer prática de um Sistema Empurrado. Se as suposições operam apenas no nível do indivíduo, então serão corrigidas facilmente, afinal, o poder dos pressupostos e suposições vem do fato de serem compartilhadas pelo grupo, sendo reforçadas continuamente (Schein, 2009). As suposições básicas são as partes da cultura que não mudam, ou então mudam muito devagar (Schein, 1984). Para Schein (2009) a essência da cultura está nas suposições básicas e, uma vez que as lideranças a compreendam, os outros níveis da cultura, mais superficiais, são facilmente entendidos, de tal maneira que saibam como lidar apropriadamente com eles. Ainda, Schein (1984) reforça que, em uma entrevista de diagnóstico, a pessoa externa saberá que está lidando com um pressuposto básico quando a pessoa interna da empresa julgar a discussão "insana” ou "estúpida”. 


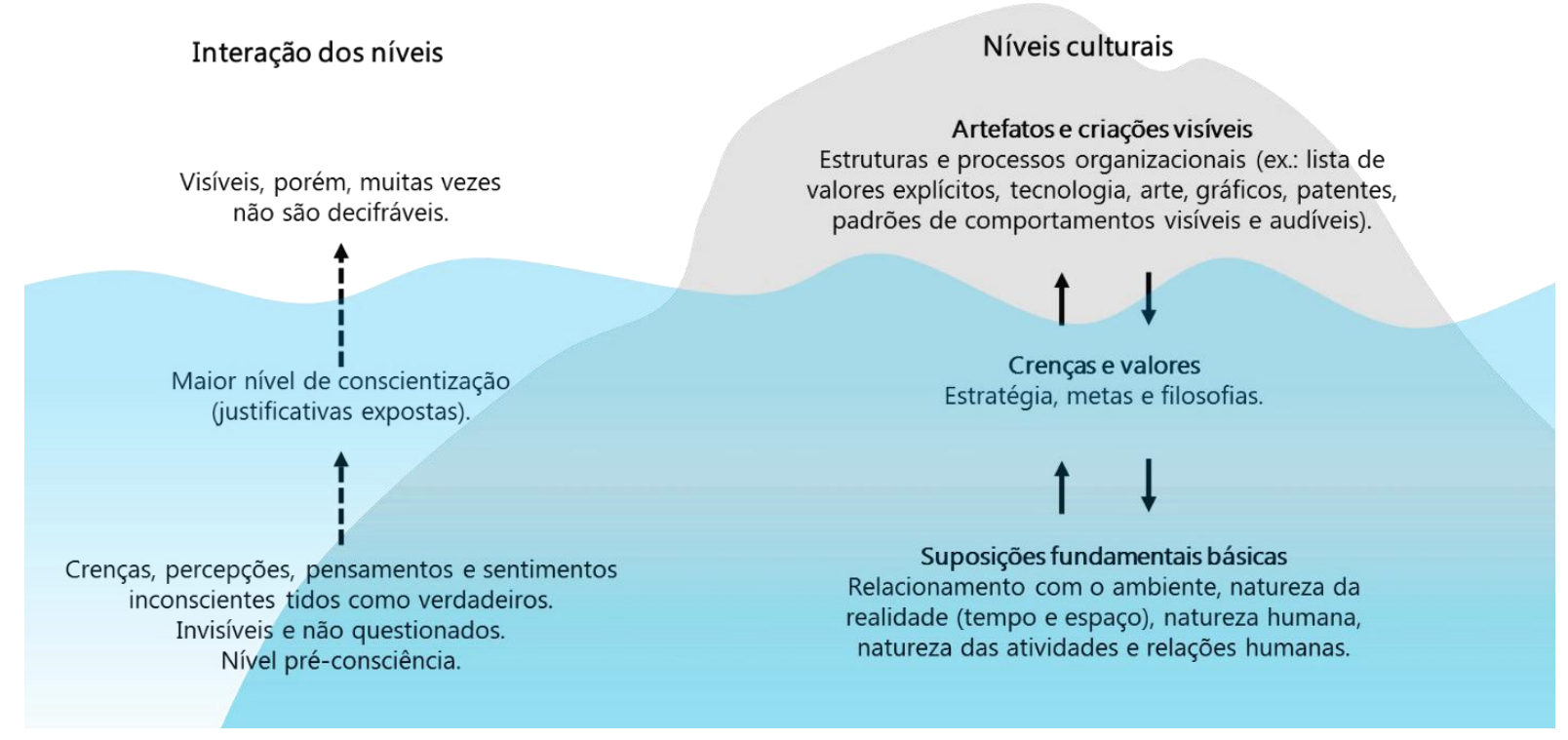

\section{Figura 21 - Os três níveis culturais de Schein}

Fonte: adaptado de Schein (1984)

Reconhecendo a importância destes dois autores (Schein, 2009; Hofstede, 2010) para a literatura em questão, e compreendendo os diferentes pontos de vista apresentados, este trabalho também utilizará a definição de Schein (2009) para os níveis de cultura. Uma das principais justificativas para esta definição é o fato dos níveis propostos por Schein (2009) apresentarem uma compreensão acerca do processo de evolução e mudança da cultura organizacional, entendendo que as crenças e valores são resultado da experiência de um grupo e formam os pressupostos básicos, e que também resultam em artefatos visíveis de uma organização.

Segundo Fleury, Shinyashiki e Stevanato (1997), esses pressupostos representam paradigmas culturais, com alguma ordem existente e consistência suficiente para promover e direcionar a ação do ser humano. Se um determinado grupo compartilha por um intervalo de tempo certas experiências e vivências, lutando contra problemas internos e externos, é bem provável concluir que este grupo passará a compartilhar uma visão de mundo (Fleury, Shinyashiki e Stevanato, 1997). Compreendendo a cultura organizacional segundo a definição de Schein, os pesquisadores Fleury, Shinyashiki e Stevanato (1997) discutem duas características relevantes deste contexto: (1) é importante compreender a cultura organizacional como uma unidade social; (2) o grupo possui uma característica ou necessidade de busca pela estabilidade durante um intervalo de tempo. 
Portanto, se um grupo assume que o trabalho individual é melhor para gerar novas ideias de produto, então, este grupo não consegue assumir rapidamente que o trabalho coletivo irá gerar novas ideias, da mesma maneira, se um grupo acredita que para sobreviver ele deve explorar e conquistar o ambiente externo, não será fácil fazer com que o grupo passe a viver de maneira mais passiva e harmônica (Schein, 1984). Estes são alguns exemplos de paradigmas culturais, o Quadro 10 traz uma lista de alguns destes paradigmas listados por Schein (1984), os quais estão associados com o nível das suposições básicas.

\section{Pressupostos básicos relacionados com paradigmas organizacionais}

\begin{tabular}{cll}
\hline $\mathbf{1}$ & $\begin{array}{l}\text { Relação da } \\
\text { organização com } \\
\text { o ambiente externo }\end{array}$ & $\begin{array}{l}\text { Reflete como as pessoas da organização veem a relação de } \\
\text { dominação do ambiente, submissão, harmonia e definição de nichos } \\
\text { de mercado apropriados, dentre outras questões. }\end{array}$ \\
\hline $\mathbf{2}$ & $\begin{array}{l}\text { Natureza } \\
\text { da realidade } \\
\text { e verdade }\end{array}$ & $\begin{array}{l}\text { Regras de comunicação e comportamento que definem o que é real, } \\
\text { o que é um fato, conceitos básicos como tempo linear ou cíclico, } \\
\text { espaço limitado ou infinito, propriedade individual ou coletiva, } \\
\text { dentre outras definições. }\end{array}$ \\
\hline $\mathbf{3}$ & $\begin{array}{l}\text { Natureza da } \\
\text { natureza humana }\end{array}$ & $\begin{array}{l}\text { Reflete o significado de "ser humano", o homem é bom, mal ou } \\
\text { neutro? O que é melhor, a Teoria X ou Teoria Y10? Os homens são } \\
\text { naturalmente previsíveis ou imprevisíveis? }\end{array}$ \\
\hline $\mathbf{4}$ & $\begin{array}{l}\text { Natureza da } \\
\text { atividade humana }\end{array}$ & $\begin{array}{l}\text { Distingue o que é "certo" do que é "errado" de acordo com } \\
\text { pressupostos sobre a realidade, o ambiente e a natureza humana: } \\
\text { ativo versus passivo, desenvolvimento próprio ou fatalidade, } \\
\text { atividade profissional (trabalho) versus diversão. }\end{array}$ \\
\hline $\mathbf{5}$ & $\begin{array}{l}\text { Natureza do } \\
\text { relacionamento } \\
\text { humano }\end{array}$ & $\begin{array}{l}\text { Define o que é considerado "certo" no convívio entre as pessoas: a } \\
\text { vida deve ser cooperativa ou competitiva, individualizada ou } \\
\text { colaborativa, baseada em leis ou não, dentre outras definições. }\end{array}$ \\
\hline
\end{tabular}

\section{Quadro 10 - Pressupostos básicos relacionados com paradigmas organizacionais}

Fonte: Schein (1984)

A força de uma cultura pode ser definida através da (a) homogeneidade e estabilidade dos valores compartilhados pelo grupo, ou da (b) extensão e intensidade das experiências já compartilhadas pelo grupo (Schein, 1984). Portanto, terá uma cultura forte um grupo que esteja junto por um longo período de tempo, e tenha compartilhado diversas experiências significativas. Uma cultura forte, não necessariamente está relacionada com maior efetividade

\footnotetext{
${ }^{10}$ Segundo Robbins (2005), Douglas McGregor propôs duas visões distintas dos executivos sobre o ser humano: na Teoria X, os funcionários não gostam de trabalhar por natureza e, portanto, precisam ser "forçados" a tal, na Teoria Y, os funcionários podem achar o trabalho tão natural quanto descansar ou se divertir.
} 
ou eficiência organizacional. Embora uma cultura forte possa ser desejável em determinado contexto, a relação da cultura com a eficiência organizacional é um pouco mais complexa.

De acordo com Schein (1984), a variável crítica neste caso é o quão alinhado o perfil cultural está com as necessidades estratégicas do negócio e com o potencial de solução de problemas do ambiente interno. Sob este aspecto, Schein (1984) cita a comparação de uma empresa jovem com uma cultura forte versus uma empresa madura com uma cultura dominante fraca, sendo esta última formada por diversas subculturas que fazem com que a empresa madura seja mais responsiva (flexível) às necessidades do ambiente quando comparada à empresa mais jovem. Portanto, no diagnóstico de cultura, é preciso reconhecer as "unidades" ou "subconjuntos" culturais, os quais podem estar relacionados com unidades geográficas, funcionais, processos ou até mesmo relacionados com níveis hierárquicos.

Ainda, segundo Schein (1984), é preciso reconhecer que as crenças e valores em uma determinada unidade podem ser determinados de acordo com o background das pessoas: pode haver uma cultura da engenharia, da produção, do comercial, do planejamento e controle de produção, da logística, da ciência, do sindicato dos trabalhadores, etc. Pelo fato dos elementos culturais serem fruto de experiências, aprendizados e criações, a compreensão da cultura organizacional passa pelo conhecimento de como ela (cultura) foi formada. Nesse ponto de vista, Schein (1984) acredita que existem duas maneiras de as organizações aprenderem novas situações e experiências:

\section{a) Experiência positiva ou negativa}

O grupo realiza diversas tentativas até obter uma resposta desejável para uma determinada situação, e então, passará a utilizar esta resposta nas próximas situações até que ela (resposta) deixe de funcionar;

\section{b) Ansiedade de aprendizado positiva ou negativa}

Ao contrário do primeiro, desta vez o grupo ainda não "vivenciou uma experiência", mas ele age de acordo com uma ansiedade de aprendizado ou sobrevivência. A autora Coutu (2002) realiza uma entrevista com Schein, e este cita que as evidências são de que, uma mudança real não ocorre enquanto a organização não tenha experimentada uma ameaça real ou então tenha uma expectativa ou ansiedade de aprender algo novo; 
Estas duas maneiras de "desenvolver e criar" uma cultura organizacional, propostas por Schein (1984), estão relacionadas com a solução (ou não) de problemas de origem externa ou interna, sendo o primeiro tipo de problema relacionados à capacidade do grupo de sobreviver no seu ambiente, e o segundo relacionado à habilidade da organização trabalhar como um grupo unido e coeso. Os Quadros 11 e 12 explicitam alguns destes problemas.

\section{Problemas de sobrevivência e adaptação externa vivenciados pelas organizações}

\begin{tabular}{cll}
\hline 1 & Estratégia & $\begin{array}{l}\text { Desenvolvimento de consenso sobre as prioridades, core mission } \\
\text { ou sobre definições de funções do grupo. }\end{array}$ \\
\hline $\mathbf{2}$ & Objetivos & $\begin{array}{l}\text { Desenvolvimento de consenso sobre os objetivos, como por exemplo } \\
\text { fazer com que as metas sejam coerentes com a core mission. }\end{array}$ \\
\hline $\mathbf{3}$ & $\begin{array}{l}\text { Ações para atingir } \\
\text { os objetivos }\end{array}$ & $\begin{array}{l}\text { Desenvolvimento de consenso sobre os meios de atingir os objetivos } \\
\text { - divisão de salários, estrutura organizacional, projetos de mudança, } \\
\text { recompensas, punições, etc. }\end{array}$ \\
\hline $\mathbf{4}$ & $\begin{array}{l}\text { Medição de } \\
\text { Performance }\end{array}$ & $\begin{array}{l}\text { Desenvolvimento de consenso sobre os critérios para medir a } \\
\text { performance do grupo na busca dos objetivos e metas definidos. }\end{array}$ \\
\hline $\mathbf{5}$ & Correções & $\begin{array}{l}\text { Desenvolvimento de consenso sobre estratégias e ações para corrigir } \\
\text { o rumo do negócio quando necessário. }\end{array}$ \\
\hline
\end{tabular}

\section{Quadro 11 - Problemas de sobrevivência e adaptação externa}

\section{Fonte: Schein (1984)}

Embora possa significar apenas um aspecto superficial da cultura, estudar o que os novos membros de uma organização estão aprendendo é uma excelente maneira de entender alguns elementos da cultura organizacional (Schein, 2009). Nesse sentido, os conhecimentos que os "veteranos" passam para os mais novos podem representar características profundas da cultura organizacional, afinal, para Schein (2009) a cultura sobrevive mediante sua transmissão aos novatos. Ou seja, os novatos somente podem decifrar bem a cultura organizacional mediante um processo de feedback fornecido pelos veteranos aos novatos, portanto, existe sempre um processo de treinamento e ensino ainda que este possa ser implícito e não estruturado (Schein, 2009).

Para avaliar e diagnosticar uma Cultura Organizacional existem modelos qualitativos, os quais analisam percepções e experiências de uma equipe sobre a organização, realizam entrevistas ou analisam documentos, como também existem modelos quantitativos, os quais realizam levantamento de dados com percepções de várias pessoas através de questionários. 


\section{Problemas de integração interna vivenciados pelas organizações}

\begin{tabular}{lll}
\hline $\mathbf{1}$ & Linguagem & $\begin{array}{l}\text { Se as pessoas não conseguem se comunicar compreendendo uns aos } \\
\text { outros, não é possível existir um grupo por definição. }\end{array}$ \\
\hline $\mathbf{2}$ & Limites & $\begin{array}{l}\text { Um dos principais pontos da cultura é definir um consenso sobre } \\
\text { quem está dentro e quem está fora, e por qual critério. }\end{array}$ \\
\hline $\mathbf{3}$ & Poder e Status & $\begin{array}{l}\text { Consenso sobre quem deve ganhar e quem deve perder poder e } \\
\text { status, sendo importante para garantir que os membros do grupo } \\
\text { sejam capazes de gerenciar seus próprios sentimentos. }\end{array}$ \\
\hline $\mathbf{4}$ & Relacionamento & $\begin{array}{l}\text { Consenso sobre questões de relacionamento (amizade e intimidade), } \\
\text { toda organização deve definir as "regras do jogo" entre as pessoas. }\end{array}$ \\
\hline $\mathbf{5}$ & $\begin{array}{l}\text { Recompensas } \\
\text { e Punições }\end{array}$ & $\begin{array}{l}\text { Consenso sobre os critérios de alocação de recompensas e punições } \\
\text { promovendo comportamentos desejáveis (ou não). }\end{array}$ \\
\hline $\mathbf{6}$ & Ideologia & $\begin{array}{l}\text { Consenso sobre ideologias e "religiões". Toda organização, assim } \\
\text { como toda sociedade, possui eventos "inexplicáveis" que precisam } \\
\text { de uma resposta para que reduzir a ansiedade dos membros. }\end{array}$ \\
\hline
\end{tabular}

\section{Quadro 12 - Problemas de integração interna}

Fonte: Schein (1984)

Schein (2009) adverte que existe um risco de confundir "sintomas" com "causas" no diagnóstico da cultura organizacional, podendo confundir as manifestações da cultura organizacional com causas subjacentes, por exemplo, não é porque uma empresa possui um ambiente de trabalho informal e aberto que a cultura desta organização seja informal e aberta. Nesse sentido, o modelo qualitativo parte da crença de que o discurso oficial, voluntário e consciente não pode ser entendido como uma manifestação sincera dos pressupostos básicos. É preciso ir além das aparências e questionar os atos falhos dos discursos, suas contradições e lapsos de memória (Fleury, Shinyashiki e Stevanato, 1997).

Segundo Schein (2009), somente é possível considerar trabalhar com elementos culturais quando houver a repetição de um padrão de respostas, valores, comportamentos e pressupostos que sejam compartilhados e continuem, frequentemente, sendo utilizados em novas situações. Portanto, no diagnóstico de cultura é importante obter uma quantidade suficiente de evidências repetidas para identificar padrões. Nesse sentido, a abordagem qualitativa pode ser útil para validar, explicar, iluminar ou reinterpretar dados quantitativos (Fleury, Shinyashiki e Stevanato, 1997). O Quadro 13 apresenta uma compilação de comparações entre as duas metodologias (qualitativa e quantitativa) feita por (Fleury, Shinyashiki e Stevanato, 1997). No diagnóstico de cultura, mais do que encontrar uma 
manifestação cultural compartilhada por todos, o pesquisador depara-se com várias subculturas que estão em conflito umas com as outras, sendo considerado consenso apenas a interseção destas subculturas (Shinyashiki, 1995). Embora muitos possam achar que a abordagem qualitativa seja superior à quantitativa, para Miles (1979) isto não é verdade por existir a possibilidade de combinação de ambas, portanto, desta maneira os pontos fortes de uma metodologia compensariam as desvantagens da outra. Fleury, Shinyashiki e Stevanato (1997) apresentam o seguinte método de triangulação elaborado por Duncan (1986), conforme ilustrado na Figura 22.

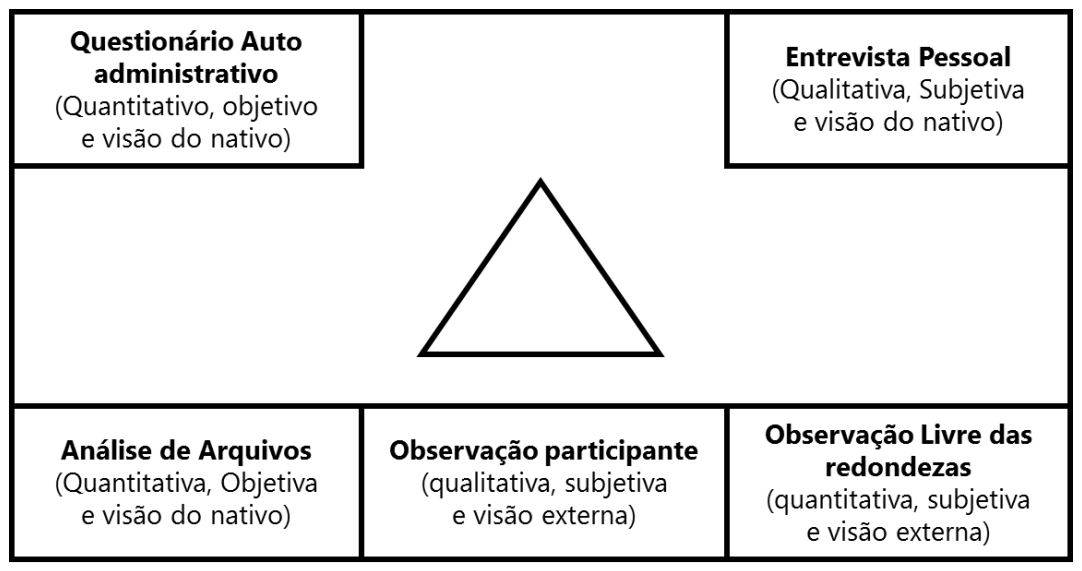

Figura 22 - Triângulo metodológico para o diagnóstico da cultura organizacional

Fonte: Duncan (1986) ${ }^{11}$ apud Fleury, Shinyashiki e Stevanato (1997)

Neste método, o autor sugere a combinação de técnicas, objetivando a triangulação (1) dos dados - tempo, espaço e pessoa -, (2) do investigador, (3) da teoria - perspectivas distintas - e (4) do método - uso de dois ou mais métodos distintos. Segundo Shinyashiki (1995), a abordagem quantitativa é suficientemente robusta para definir as características de um determinado grupo, e também apontar os padrões que poderão, na sequência, serem validados ou explicados pela análise qualitativa. Inclusive, o autor cita o benefício que a abordagem quantitativa promove para a qualitativa, pois esta última terá um foco mais preciso, exigindo uma alocação menor de recursos e tempo. É preciso reconhecer também o benefício que a abordagem quantitativa gera para a área de Recursos Humanos, afinal, depois de identificados os padrões e associações existentes, podem ser identificados fatores que informam com maior precisão os resultados esperados (Shinyashiki, 1995).

\footnotetext{
${ }^{11}$ DUNCAN, W. J. (1986). A proposal for multimethod approach to organizational culture research. Graduate School of Management. University of Alabama.
} 


\begin{tabular}{|c|c|c|}
\hline Crença & É o contexto social que dá significado à cultura & Existem elementos universais que dão significado à cultura \\
\hline Técnicas utilizadas & $\begin{array}{l}\text { Clássicas: observação (participante ou não, sistemática ou não), } \\
\text { análise documental e análise de conteúdo. Alternativas: entrevista } \\
\text { em profundidade (clínica), entrevista em grupo, jogos de } \\
\text { dinâmica de grupos, técnicas projetivas (personificação, etc.) }\end{array}$ & $\begin{array}{l}\text { Questionários ou entrevistas estruturadas que transformam } \\
\text { pontos de vista em valores quantificáveis. }\end{array}$ \\
\hline Influência do pesquisador & O pesquisador determina suas categorias e ideias sobre a cultura & $\begin{array}{c}\text { O pesquisador evita impor suas próprias categorias ou ideias } \\
\text { sobre cultura que não estejam no modelo }\end{array}$ \\
\hline $\begin{array}{l}\text { Possibilidade de compreender temas } \\
\text { não latentes ou não óbvios }\end{array}$ & Grande & (2: \\
\hline Controle racional dos dados & Com o pesquisador / consultor & Com os membros da organização \\
\hline Perspectiva temporal & $\begin{array}{l}\text { Compreende o processo de constituição da cultura } \\
\text { como um fenômeno ao longo do tempo. }\end{array}$ & $\begin{array}{l}\text { Não permite a compreensão do processo de constituição da } \\
\text { cultura como um fenômeno ao longo do tempo. }\end{array}$ \\
\hline $\begin{array}{l}\text { Possibilidade de identificar } \\
\text { focos de resistência }\end{array}$ & (2: & (2: \\
\hline Tempo de coleta de dados & Grande & Pequeno \\
\hline Risco de viés & Pesquisador / Consultor & Membro da organização \\
\hline Validação do método de análise & Alta dificuldade & Baixa dificuldade \\
\hline Praticidade de analisar subconjuntos & Alta dificuldade & Baixa dificuldade \\
\hline Potencial de réplica do método & Baixo & Alto \\
\hline Uso de técnicas estatísticas & Baixa & Alta \\
\hline Principais vantagens & $\begin{array}{l}\text { Adequação da técnica ao objeto de estudo, compreensão da sua } \\
\text { singularidade e estudo com profundidade dos elementos culturais }\end{array}$ & Velocidade, versatilidade, custo, objetividade e precisão \\
\hline Principais desvantagens & $\begin{array}{l}\text { Elevado tempo e custo de análise, com risco de viés do } \\
\text { pesquisador / consultor quando não bem capacitado }\end{array}$ & $\begin{array}{l}\text { Dificuldade de compreender o "como" e o "por que" das } \\
\text { coisas e associações existentes nos resultados obtidos }\end{array}$ \\
\hline
\end{tabular}

\section{Quadro 13 - Comparação das metodologias de diagnóstico de cultura}

Fonte: compilado e adaptado de Fleury, Shinyashiki e Stevanato (1997) 


\section{Alguns dos principais modelos culturais}

Esta seção tem como objetivo compreender a visão conceitual destes modelos, não tem como objetivo fazer uma revisão sobre todos os modelos, nem tampouco aprofundar nos métodos de diagnóstico de cultura, revisando brevemente os modelos de (a) Hofstede (2010), (b) Trompenaars e Hampden-Turner (1994), (c) Organizational Culture Profile (OCP), (d) Cultural Web de Johnson, Scholes e Whittington (2008), (e) The Competing Values Framewok de Cameron e Quinn (2006) são considerados os principais modelos quantitativos de cultura, devido à quantidade de publicações acadêmicas, estudos de validação, citações e uso.

É importante ressaltar que os modelos de Hofstede (2010) e Hampden-Turner (1994) são voltados para compreensão de uma determinada Cultura Nacional, sendo os modelos de Cameron e Quinn (2006) e O`Reilly et al. (1991) os mais indicados para o foco desta pesquisa envolvendo Cultura Organizacional.

\section{a) As dimensões culturais de Hofstede ${ }^{12}$}

Hofstede (2010) utilizou uma grande quantidade de dados sobre os valores de mais de 117 mil colaboradores da IBM em mais de 50 países, utilizando um questionário com 150 questões. A análise estatística destes dados identificou alguns problemas comuns entre as organizações, mas com soluções diferentes de acordo com o país. Estes problemas estavam relacionados com: (a) desigualdade social, incluindo o relacionamento com autoridade; (b) o relacionamento dos indivíduos com o grupo; (c) conceitos de masculinidade versus feminidade e respectivas implicações sociais; (d) as maneiras de se lidar com a incerteza no ambiente.

Estes problemas então representaram quatro áreas de estudo, conhecidas como quatro dimensões culturais no modelo, sendo uma dimensão considerada um aspecto que pode ser medido de acordo com determinada cultura. Nesse sentido, as quatro dimensões propostas pelo modelo são: (a) alta distância do poder versus baixa; (b) individualismo versus coletivismo;(c) Masculinidade versus feminidade; (d) alta aceitação de incertezas versus baixa. Outras duas dimensões posteriormente foram incluídas no modelo: (e) Orientação de longo prazo versus

\footnotetext{
${ }^{12}$ Este modelo é voltado para análise de Culturas Nacionais, não sendo, portanto, adequado para este tipo de trabalho de "Transformação Organizacional". A revisão do modelo, portanto é meramente complementar ao trabalho, no sentido de garantir robustez do ponto de vista cultural.
} 
curto prazo; (f) gratificação versus controle dos desejos humanos. O Quadro 14 apresenta um breve resumo destas dimensões.

Neste estudo, embora Hofstede (2010) tenha um olhar de pesquisa voltada para a organização IBM, os resultados das dimensões culturais acabam sendo mais relacionados ao nível de "Cultura Nacional" do que de "Cultura Organizacional" propriamente dita. Portanto, este modelo pode ser indicado para quando organizações de países distintos forem trabalhar em conjunto, ou até mesmo para compreender as diferenças de uma mesma organização atuando em diferentes países. No entanto, este modelo pode não ser o mais adequado para uma análise alinhamento organizacional como proposto neste trabalho, ou seja, tendo um enfoque direcionado para uma única organização específica.

Dimensão Cultura Características

\section{Culturas típicas}

\begin{tabular}{|c|c|c|c|}
\hline \multirow{2}{*}{1} & $\begin{array}{r}\text { Alta distância } \\
\text { do poder }\end{array}$ & $\begin{array}{l}\text { As pessoas menos poderosas na instituição e } \\
\text { organização estão muito distantes do poder; }\end{array}$ & $\begin{array}{l}\text { Malásia, Países da América } \\
\text { Latina e Árabes }\end{array}$ \\
\hline & $\begin{array}{r}\text { Baixa distância } \\
\text { do poder }\end{array}$ & $\begin{array}{l}\text { As pessoas menos poderosas na instituição e } \\
\text { organização estão próximas do poder; }\end{array}$ & $\begin{array}{l}\text { Áustria, Israel, Dinamarca, } \\
\text { Nova Zelândia e Irlanda; }\end{array}$ \\
\hline \multirow{2}{*}{2} & Individualismo & $\begin{array}{l}\text { As pessoas se preocupam consigo mesmas ou } \\
\text { somente com suas famílias; }\end{array}$ & $\begin{array}{l}\text { USA, Austrália, Reino } \\
\text { Unido, Canadá e Holanda; }\end{array}$ \\
\hline & Coletivismo & $\begin{array}{l}\text { As pessoas possuem uma forte preocupação } \\
\text { com a sociedade de maneira geral; }\end{array}$ & $\begin{array}{l}\text { Guatemala, Equador, } \\
\text { Venezuela e Colômbia; }\end{array}$ \\
\hline \multirow{2}{*}{3} & Masculinidade & $\begin{array}{l}\text { A sociedade é dominada por homens, há uma } \\
\text { clara distinção de gêneros na sociedade; }\end{array}$ & $\begin{array}{l}\text { Japão, Áustria, Venezuela, } \\
\text { Itália, Suíça e México; }\end{array}$ \\
\hline & Feminidade & $\begin{array}{l}\text { A sociedade não é dominada por um único } \\
\text { gênero, há um equilíbrio entre gêneros; }\end{array}$ & $\begin{array}{l}\text { Suécia, Noruega, Holanda, } \\
\text { Dinamarca e Costa Rica; }\end{array}$ \\
\hline \multirow{2}{*}{4} & $\begin{array}{r}\text { Alta aceitação } \\
\text { de incertezas }\end{array}$ & $\begin{array}{l}\text { As pessoas possuem uma necessidade de } \\
\text { correr risco e aceitam muito bem incertezas; }\end{array}$ & $\begin{array}{c}\text { Grécia, Portugal, } \\
\text { Guatemala e Uruguai; }\end{array}$ \\
\hline & $\begin{array}{r}\text { Baixa aceitação } \\
\text { de incertezas }\end{array}$ & $\begin{array}{l}\text { As pessoas se sentem nervosas e evitam toda } \\
\text { e qualquer situação de incerteza; }\end{array}$ & $\begin{array}{l}\text { Singapura, Jamaica, } \\
\text { Dinamarca e Suécia; }\end{array}$ \\
\hline \multirow{2}{*}{5} & $\begin{array}{r}\text { Orientação de } \\
\text { curto prazo }\end{array}$ & $\begin{array}{l}\text { As pessoas focam em decisões de curto prazo, } \\
\text { evitam olhar para o futuro; }\end{array}$ & $\begin{array}{l}\text { USA, países latinos e } \\
\text { africanos; }\end{array}$ \\
\hline & $\begin{array}{r}\text { Orientação de } \\
\text { longo prazo }\end{array}$ & $\begin{array}{l}\text { As pessoas focam em decisões de longo prazo, } \\
\text { sentem-se à vontade olhando para o futuro; }\end{array}$ & $\begin{array}{l}\text { Países do Leste asiático } \\
\text { e Europa Central; }\end{array}$ \\
\hline \multirow[b]{2}{*}{6} & Indulgência & $\begin{array}{l}\text { As pessoas se declaram felizes e capazes de } \\
\text { controlar suas vidas pessoais; }\end{array}$ & $\begin{array}{l}\text { Países da América do Sul } \\
\text { e América do Norte; }\end{array}$ \\
\hline & Restrição & $\begin{array}{l}\text { Poucas pessoas se declaram felizes, as } \\
\text { pessoas sentem que não controlam suas vidas } \\
\text { pessoais; }\end{array}$ & $\begin{array}{l}\text { Países do Leste Europeu } \\
\text { e Ásia. }\end{array}$ \\
\hline
\end{tabular}

Quadro 14 - As quatro dimensões culturais de Hofstede.

Fonte: compilado e adaptado de Hofstede (2010) e Hofstede (2011) 


\section{b) As sete dimensões culturais de Trompenaars e Hampden-Turner ${ }^{13}$}

Para o desenvolvimento deste modelo, Trompenaars e Hampden-Turner (1994) investiram mais de dez anos de pesquisa, entrevistaram mais de 46 mil gerentes em 40 diferentes países. Durante estre trabalho, os autores identificaram algumas características específicas e preferenciais das culturas dos países, sendo representadas em sete dimensões:

1. Universalismo versus Particularismo (Regras versus Relacionamento)

2. Individualismo versus Coletivismo (Foco no indivíduo versus no grupo)

3. Específico versus difuso (Como as pessoas se relacionam)

4. Neutro versus emocional (Como as pessoas expressam emoções)

5. Realizacão versus Atribuicão (Como as pessoas veem o status)

6. Tempo sequencial versus sincronizado (Como gerenciam o tempo)

7. Direcionamento interno versus externo (Relacionamento com o ambiente)

O Quadro 15 apresenta um resumo do modelo das sete dimensões culturais propostas por Trompenaars e Hampden-Turner (1994).

De certa maneira, por olharem a cultura sob o ponto de vista "nacional", a proposta de Trompenaars e Hampden-Turner (1994) é bem semelhante à de Hofstede (2010), sendo que ambas podem não ser as propostas mais adequadas ao objetivo proposto deste trabalho.

\section{c) Organizational Culture Profile (OCP) de O`Reilly}

Para investigar os perfis culturais, O`reilly et al. (1991) desenvolveram um instrumento quantitativo conhecido como Organizational Culture Profile (OCP). O modelo possuí uma série de itens conhecidos como declarações de valor organizacional os quais podem ser mensurados do ponto de vista individual e organizacional.

Segundo os autores, um dos principais objetivos do modelo é "avaliar e medir o alinhamento entre perfil individual e determinado perfil cultural". O Quadro 16 apresenta os itens avaliados no OCP.

\footnotetext{
${ }^{13}$ Este modelo é voltado para análise de Culturas Nacionais, não sendo, portanto, adequado para este tipo de trabalho de "Transformação Organizacional". A revisão do modelo, portanto é meramente complementar ao trabalho, no sentido de garantir robustez do ponto de vista cultural.
} 


\begin{tabular}{|c|c|c|c|}
\hline \multicolumn{2}{|r|}{ Dimensão Cultural } & Características & Culturas típicas \\
\hline \multirow{2}{*}{1} & Universalismo & $\begin{array}{l}\text { Pessoas atribuem muita importância a leias, regras, valores e obrigações. As leis vêm em primeiro lugar } \\
\text { que os relacionamentos. }\end{array}$ & $\begin{array}{l}\text { USA, Reino Unido, Canadá, } \\
\text { Austrália, Alemanha e Suíça. }\end{array}$ \\
\hline & Particularismo & $\begin{array}{l}\text { Pessoas acreditam que as circunstâncias dos relacionamentos ditam as regras que elas vivem. } \\
\text { A resposta a cada situação deve variar de acordo com quem está envolvido. }\end{array}$ & $\begin{array}{l}\text { Rússia, China e países da América } \\
\text { Latina. }\end{array}$ \\
\hline \multirow{2}{*}{2} & Individualismo & $\begin{array}{l}\text { As pessoas valorizam a liberdade e realização, acreditam que devam seguir suas próprias decisões e que } \\
\text { devam proteger a si mesmos. }\end{array}$ & $\begin{array}{l}\text { USA, Canadá, Reino Unido, Nova } \\
\text { Zelândia e Suíça. }\end{array}$ \\
\hline & Coletivismo & $\begin{array}{l}\text { As pessoas acreditam que o grupo é mais importante do que as pessoas, e que isso promove a segurança } \\
\text { de todos. O grupo vem sempre em primeiro lugar que o indivíduo. }\end{array}$ & $\begin{array}{l}\text { Japão, África e países da América } \\
\text { Latina. }\end{array}$ \\
\hline \multirow{2}{*}{3} & Específico & $\begin{array}{l}\text { As pessoas separam a vida pessoal da profissional. Acreditam que o relacionamento não tem impacto em } \\
\text { questões do trabalho, as pessoas podem trabalhar juntas sem serem unidas. }\end{array}$ & $\begin{array}{l}\text { USA, Reino Unido, Alemanha, } \\
\text { Escandinávia e Holanda. }\end{array}$ \\
\hline & Difuso & $\begin{array}{l}\text { As pessoas misturam sua vida pessoa com a vida profissional. Acreditam que um bom relacionamento } \\
\text { entre as pessoas é vital para o atingimento dos resultados do negócio/ }\end{array}$ & $\begin{array}{l}\text { Argentina, Espanha, Rússia, Índia e } \\
\text { China. }\end{array}$ \\
\hline \multirow{2}{*}{4} & Neutro & $\begin{array}{l}\text { As pessoas fazem um esforço muito grande para controlar suas emoções. A razão influencia suas ações } \\
\text { mais do que as emoções. As pessoas não revelam o que estão pensando ou sentindo. }\end{array}$ & $\begin{array}{l}\text { USA, Reino Unido, Suíça, } \\
\text { Escandinávia e Holanda. }\end{array}$ \\
\hline & Emocional & $\begin{array}{l}\text { As pessoas buscam modos de expressar seu sentimento, inclusive de maneira espontânea no trabalho. } \\
\text { Nestas culturas, é aceitável e bem-vindo expressar as emoções das pessoas. }\end{array}$ & $\begin{array}{l}\text { Argentina, Espanha, } \\
\text { Índia e China. }\end{array}$ \\
\hline \multirow{2}{*}{5} & Realização & $\begin{array}{l}\text { As pessoas acreditam que cada um seja aquilo que faz, e valorizam as pessoas de acordo com os resultados } \\
\text { que entregam. Esta cultura valoriza a performance independentemente de quem seja. }\end{array}$ & $\begin{array}{l}\text { USA, Canadá, Austrália } \\
\text { e Escandinávia. }\end{array}$ \\
\hline & Atribuição & $\begin{array}{l}\text { As pessoas acreditam que cada um deva ser valorizado por quem é. Poder, título e posição importam nestas } \\
\text { culturas, e estas posições influenciam o comportamento das outras pessoas. }\end{array}$ & $\begin{array}{l}\text { França, Itália, Japão } \\
\text { e Arábia Saudita. }\end{array}$ \\
\hline \multirow{2}{*}{6} & Tempo Sequencial & $\begin{array}{l}\text { As pessoas gostam que os eventos aconteçam em ordem lógica, colocam grande valor em pontualidade e } \\
\text { em seguir conforme o planejado. É a cultura do "tempo é dinheiro". }\end{array}$ & $\begin{array}{l}\text { Alemanha, } \\
\text { Reino Unido e USA. }\end{array}$ \\
\hline & $\begin{array}{r}\text { Tempo } \\
\text { sincronizado } \\
\end{array}$ & $\begin{array}{l}\text { As pessoas veem o passado, presente e futuro como períodos entrelaçados. Geralmente as trabalham em } \\
\text { vários projetos por vez, e veem os planos como facilmente modificáveis. }\end{array}$ & $\begin{array}{l}\text { Japão, Argentina } \\
\text { e México. }\end{array}$ \\
\hline \multirow{2}{*}{7} & $\begin{array}{r}\text { Direcionamento } \\
\text { interno }\end{array}$ & $\begin{array}{l}\text { As pessoas acreditam que elas podem ter controle sobre o ambiente para atingir os resultados. Isto } \\
\text { influência a maneira como trabalham em equipe nas organizações. }\end{array}$ & $\begin{array}{l}\text { Israel, USA, Austrália, Nova } \\
\text { Zelândia e Reino Unido. }\end{array}$ \\
\hline & $\begin{array}{r}\text { Direcionamento } \\
\text { externo }\end{array}$ & $\begin{array}{l}\text { As pessoas acreditam que a natureza do ambiente as controla. No trabalho e nos relacionamentos, focam } \\
\text { as ações nas pessoas e evitam conflitos sempre que possível. }\end{array}$ & $\begin{array}{l}\text { China, Rússia e } \\
\text { Arábia Saudita. }\end{array}$ \\
\hline
\end{tabular}

\section{Quadro 15 - As sete dimensões culturais de Trompenaars e Hampden-Turner}

Fonte: compilado e adaptado de Trompenaars e Hampden-Turner (1994) 


\begin{tabular}{|c|c|c|}
\hline \# & Fatores & Itens \\
\hline 1 & Competitividade & $\begin{array}{l}\text { Orientação a objetivos } \\
\text { Ênfase em qualidade } \\
\text { Ênfase em Diferenciação } \\
\text { Ênfase em Competição }\end{array}$ \\
\hline 2 & Responsabilidade Social & $\begin{array}{l}\text { Ênfase em reflexão } \\
\text { Orientação para uma boa reputação } \\
\text { Ênfase em responsabilidade social } \\
\text { Ter uma filosofia clara }\end{array}$ \\
\hline 3 & Colaboração & $\begin{array}{l}\text { Ênfase no trabalho em equipe } \\
\text { Livre compartilhamento de informações } \\
\text { Orientação para pessoas } \\
\text { Senso de colaboração }\end{array}$ \\
\hline 4 & Inovação & $\begin{array}{l}\text { Capacidade de inovação } \\
\text { Resposta rápida às oportunidades do ambiente } \\
\text { Risk taking } \\
\text { Ênfase em responsabilização individual }\end{array}$ \\
\hline 5 & Ênfase em recompensas & $\begin{array}{l}\text { Justiça } \\
\text { Oportunidades para crescimento profissional } \\
\text { Pagamento apropriado para alta performance } \\
\text { Louvor para alta performance }\end{array}$ \\
\hline 6 & Performance & $\begin{array}{l}\text { Possuir expectativa elevada para performance } \\
\text { Entusiasmo pelo trabalho } \\
\text { Orientação para resultados } \\
\text { Ênfase em organização }\end{array}$ \\
\hline 7 & Estabilidade & $\begin{array}{l}\text { Estabilidade } \\
\text { Tranquilidade } \\
\text { Segurança no emprego } \\
\text { Poucos conflitos }\end{array}$ \\
\hline
\end{tabular}

\section{Quadro 16 - Fatores e Itens associados ao OCP}

Fonte: O`reilly et al. (1991) e Sarros et al. (2005)

\section{d) Cultural Web}

O modelo Cultural Web, desenvolvido por Johnson, Scholes e Whittington (2008), pode ser considerando um método qualitativo para ilustrar o comportamento e as manifestações simbólicas relacionadas a uma determinada cultura organizacional, incluindo o paradigma organizacional ou os pressupostos básicos tidos como verdadeiros pela organização. Um dos pontos positivos desta ferramenta, é seu foco qualitativo com a possibilidade de analisar a cultura atual (Actual Cultural Web) e também a cultura desejada (Desired Cultural Web) de uma organização. Os elementos desta ferramenta estão ilustrados na Figura 23, e incluem (Johnson, Scholes e Whittington, 2008): 
$\checkmark$ Histórias

○ Quais crenças principais as histórias da organização refletem? Quão compartilhadas são estas histórias? As histórias estão relacionadas com forças ou fraquezas? Episódios de sucesso ou fracasso? Conformidade ou mavericks?

Símbolos

○ Existem símbolos particulares à organização? Quais símbolos de status são utilizados? O que a linguagem e os jargões utilizados significam? Quais aspectos da estratégia estão explícitos?

Estrutura de Poder

○ Como o poder é distribuído pela organização? Quais são as principais crenças e valores das lideranças? Quão forte são essas crenças compartilhadas (idealistas ou pragmáticas)? Quais são as principais barreiras de poder à mudança?

\section{Estrutura Organizacional}

- A estrutura organizacional é mecanicista ou orgânica? A estrutura é flat ou hierárquica? Forma ou informal? A estrutura encoraja a colaboração ou competição? Quais tipos de estrutura de poder a organização suporta?

Sistemas de Controle

- O que é monitorado e controlado de perto? Há ênfase em punições ou recompensas? Quais? Os controles são referentes a estratégias passadas ou atuais? Existem poucos ou muitos mecanismos de controle? Quais?

$\checkmark$ Ritos e Rotinas

○ Quais rotinas são enfatizadas? Quais são as suas histórias? Quais comportamentos promove estas rotinas? Quais são os principais rituais organizacionais? Qual a ênfase dos programas de treinamento? Quão fácil ou difícil seria para mudar os ritos e rotinas?

\section{Paradigma}

- $\mathrm{O}$ que as respostas às questões anteriores sugerem em termos de pressupostos básicos que foram o paradigma organizacional? Como é possível caracterizar a cultura dominante? Quão fácil é mudar esta cultura? 


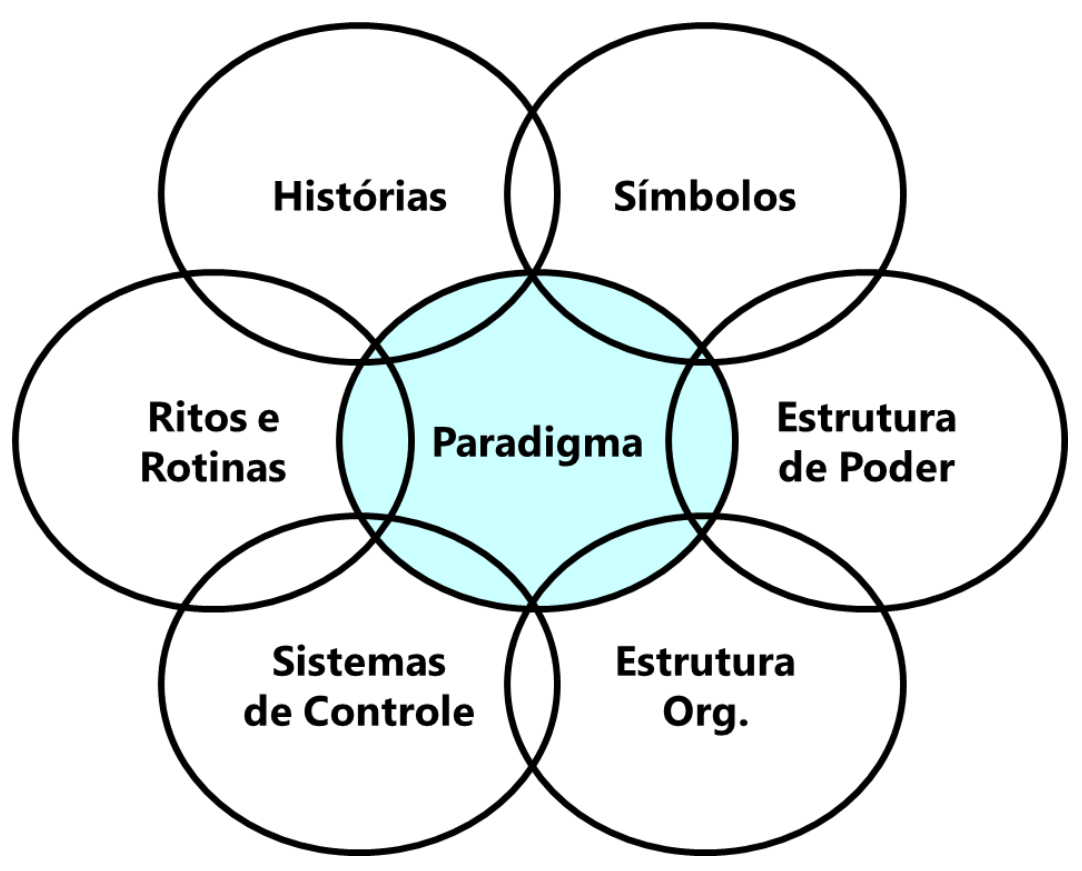

Figura 23 - The Cultural Web

Fonte: Johnson, Scholes e Whittington (2008, pp. 198)

\section{e) The Competing Values Framewok de Cameron e Quinn (2006)}

The Competing Values Framewok (CVF) é um dos mais utilizados e citados na literatura sobre Cultura Organizacional. Howard (1998) utilizou uma amostra de 10 organizações dos EUA para testar a validade do modelo. Lamond (2003) apresentou os resultados envolvendo estudos com 462 gestores. Zu, Robbins e Fredendall (2010) aplicaram o CVF em 226 manufaturas norte-americanas, e encontram relações estatísticas com os perfis culturais e as práticas do TQM. Giritli et al. (2013) também aplicaram o CVF em 499 gestores de mais de 107 empresas do setor de construção da Turquia, e também identificaram que diferentes perfis culturais levavam a diferentes resultados organizacionais.

Gambi et al. (2015) também utilizaram o CVF para analisar a relação da cultura organizacional, com as técnicas da qualidade e a performance organizacional, e concluíram que os gestores precisam ter conhecimento da cultura organizacional para obter o máximo benefício de tais técnicas. Acar (2012) também aplicou o CVF em mais de 344 colaboradores de 37 empresas de logística da Turquia. Todos os estudos utilizando o CVF concluíram que o instrumento OCAI (Organizational Culture Assessment Instrument) é, de fato, robusto e útil para avaliar e diagnosticar uma Cultura Organizacional. 
O CVF utiliza duas dimensões de análise:

- Flexibilidade versus Estabilidade;

○ Flexibilidade: rápida tomada de decisão e dinamismo.

○ Estabilidade: eficácia, ordem e controle.

- Orientação interna versus externa;

○ Orientação interna: integração, conjunto;

○ Orientação externa: rivalidade e diferenciação;

A combinação destas duas dimensões forma quatro quadrantes, os quais definem valores essenciais sob os quais são feitos julgamentos sob uma organização ilustrados na Figura 24 (Cameron e Quinn, 2006). Estes quadrantes são emergentes da análise de indicadores de eficácia organizacional, combinam as principais formas de organização e abordagens para qualidade nas organizações, estilos de liderança e habilidades gerenciais, permitindo identificar perfis de Cultura Organizacional (Cameron e Quinn, 2006). Para avaliar tais perfis de cultura, o CVF de Cameron e Quinn (2006) utiliza-se do Organizational Culture Assessment Instrument (Instrumento de Avaliação da Cultura Organizacional, também conhecido por "OCAI"), um método quantitativo que utiliza questionário para coleta de dados e consiste de seis dimensões de análise. Estas seis dimensões de avaliação estão descritas no Quadro 17. O Quadro 18 descreve os perfis culturais do CVF.

\section{The Competing Values Framework}

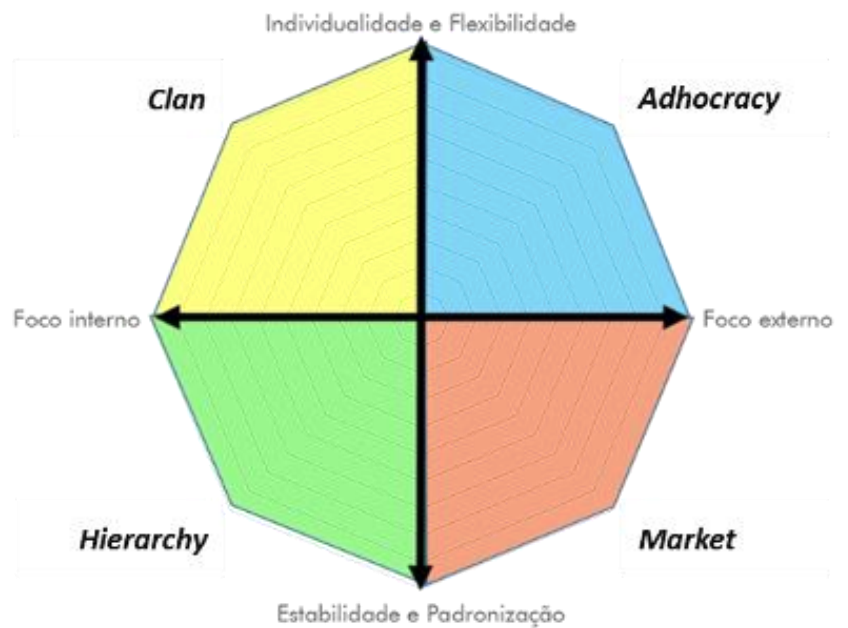

Figura 24 - Ilustração do Competing Values Framework (CVF)

Fonte: adaptado de Cameron e Quinn (2006) 
Com base nos itens de análise do OCAI, é possível fazer um diagnóstico e avaliação de Cultura Organizacional, como ilustrado nas Figura 25 e 26.

Os valores conflitantes, ou "competidores" deste modelo, são representados pelos quadrantes em diagonal. Estes valores sugerem o nome do modelo, CVF. Como ilustrado, cada um destes quadrantes define o perfil dominante de determinado tipo de Cultura Organizacional: (a) Cultura orientada para Criação ou Adhocracy Culture, o nome vem da palavra "ad hoc", implicando em algo temporário, especializado e dinâmico; (b) Cultura orientada para Competição ou Market Culture, em razão do foco nas transações externas com suppliers e clientes, de tal maneira a obter vantagem competitiva; (c) Cultura orientada para Controle ou Hierarchy Culture, é caracterizada pelos padrões de trabalho, regras e procedimentos existentes objetivando manter o controle das operações internas; (d) Cultura de Colaboração ou Clan Culture, tem este nome por sua semelhança com uma organização familiar, de tal maneira a caracterizar uma organização com foco no desenvolvimento de pessoas e no espírito de equipe.

\section{Dimensão do OCAI Descrição}

\begin{tabular}{|c|c|c|}
\hline 1 & $\begin{array}{l}\text { Características } \\
\text { dominantes }\end{array}$ & $\begin{array}{l}\text { Grau de espírito de equipe e união entre as pessoas, o nível de criatividade e } \\
\text { dinamismo, o foco em metas e competição, a preocupação com os sistemas e a } \\
\text { ênfase em eficiência. }\end{array}$ \\
\hline 2 & $\begin{array}{l}\text { Liderança } \\
\text { organizacional }\end{array}$ & $\begin{array}{l}\text { Estilo de liderança predominante na organização. Em um estudo anterior, Quinn } \\
\text { e Rohrbaugh (1981) descreveram oito estilos de liderança incorporados no } \\
\text { OCAI: mentor, facilitador, inovador, broker, produtor, diretor, coordenador e } \\
\text { monitor. }\end{array}$ \\
\hline 3 & $\begin{array}{l}\text { Gestão de } \\
\text { e equipe }\end{array}$ & $\begin{array}{l}\text { Como os colaboradores são tratados, qual o grau de participação e consenso, } \\
\text { como é o ambiente de trabalho. }\end{array}$ \\
\hline 4 & $\begin{array}{l}\text { União } \\
\text { organizacional }\end{array}$ & $\begin{array}{l}\text { Quais são os mecanismos que unificam pessoas e organização, a coesão entre as } \\
\text { pessoas, o compromisso e lealdade para com a organização, o nível de } \\
\text { empreendedorismo e flexibilidade das pessoas, as regras e políticas, a orientação } \\
\text { para metas e competitividade. }\end{array}$ \\
\hline 5 & $\begin{array}{l}\text { Ênfase } \\
\text { estratégica }\end{array}$ & $\begin{array}{l}\text { Disparadores da estratégia: desenvolvimento de pessoas, inovação, estabilidade e } \\
\text { vantagem competitiva, crescimento e aquisições, e estabelecimento de metas. }\end{array}$ \\
\hline 6 & $\begin{array}{l}\text { Critérios de } \\
\text { sucesso }\end{array}$ & $\begin{array}{l}\text { Como sucesso é definido: penetração de mercado, market share, inovação, } \\
\text { sensibilidade com clientes, preocupação com as pessoas da organização, } \\
\text { desenvolvimento de novos produtos e serviços, dependência de custo de produtos } \\
\text { ou serviços, redução de custos e produtividade. }\end{array}$ \\
\hline
\end{tabular}

\section{Quadro 17 - As dimensões de análise do OCAI}

Fonte: adaptado de Cameron e Quinn (2006) 


\section{CLAN CULTURE}

A organização é um lugar aberto e amigável para se trabalhar, onde as pessoas compartilham muito de si mesmas. Líderes são considerados mentores ou até mesmo Figuras familiares. Lealdade entre os grupos e o senso de tradição são fortes. Benefícios de longo prazo são obtidos através da ênfase no desenvolvimento de pessoas. Grande importância é dada à coesão dos grupos. A organização premia o trabalho em equipe, a participação e o consenso.

\section{HIERARCHY CULTURE}

Lugar altamente estruturado e formal. Padrões e regras governam os comportamentos das pessoas. Líderes buscam eficiência e esforçam-se para serem bons coordenadores. Manter um funcionamento sem problemas é o mais crítico. Politicas formais mantém os grupos unidos. Estabilidade, desempenho e eficiência são metas de longo prazo. Sucesso significa entregas confiáveis, planejamento executável e baixo custo. A gestão requer segurança e previsibilidade.

\section{ADHOCRACY CULTURE}

Lugar dinâmico, empreendedor e criativo. Inovação e tomada de risco são práticas comuns dos indivíduos. O comprometimento em refletir sobre aspectos distintos unifica a organização. O objetivo no longo prazo é o crescimento e a aquisição de novos recursos. Sucesso significa obter exclusividade e novos produtos e serviços. É importante ser líder em inovação no setor. Iniciativas e liberdade são encorajadas.

\section{MARKET CULTURE}

A realização do trabalho é o foco do direcionamento de resultados da organização. As pessoas são competitivas e orientadas a objetivos. Líderes são exigentes, produtivos e "durões". A ênfase em vencer é o que unifica a organização. Reputação e sucesso são preocupações comuns. O foco no longo prazo é obter competitividade e resultados mensuráveis. Sucesso significa obter inserção e posição de mercado. Preços competitivos e liderança de mercado são importantes.

\section{Quadro 18 - Os perfis de cultura organizacional do CVF}

Fonte: adaptado de Cameron e Quinn (2006)

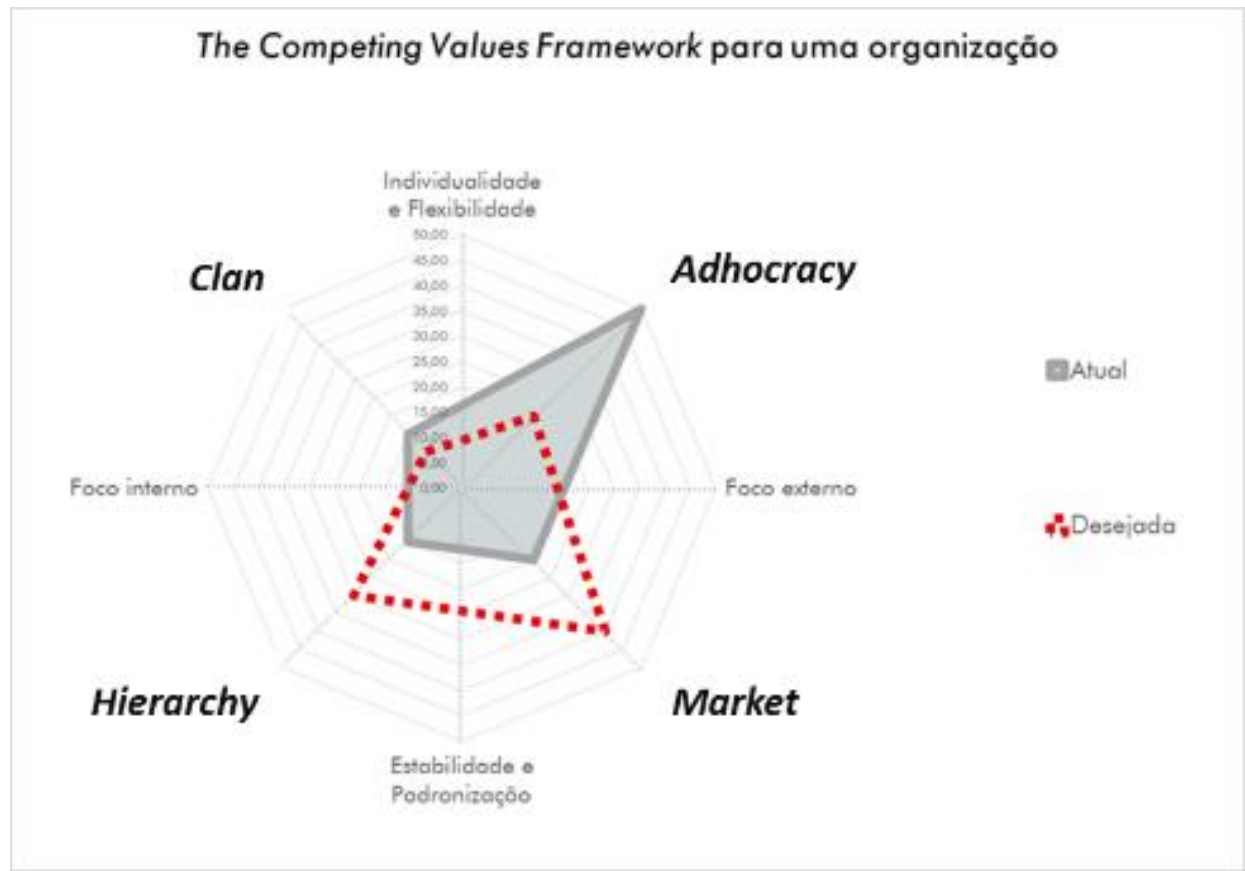

Figura 25 - Ilustração do diagnóstico de Cultura Atual versus Cultura Desejada

Fonte: adaptado de Cameron e Quinn (2006) 
A Figura 26 ilustra perfis médios de culturas de quatro organizações distintas. Os resultados são baseados nos estudos de Cameron e Quinn (2006).

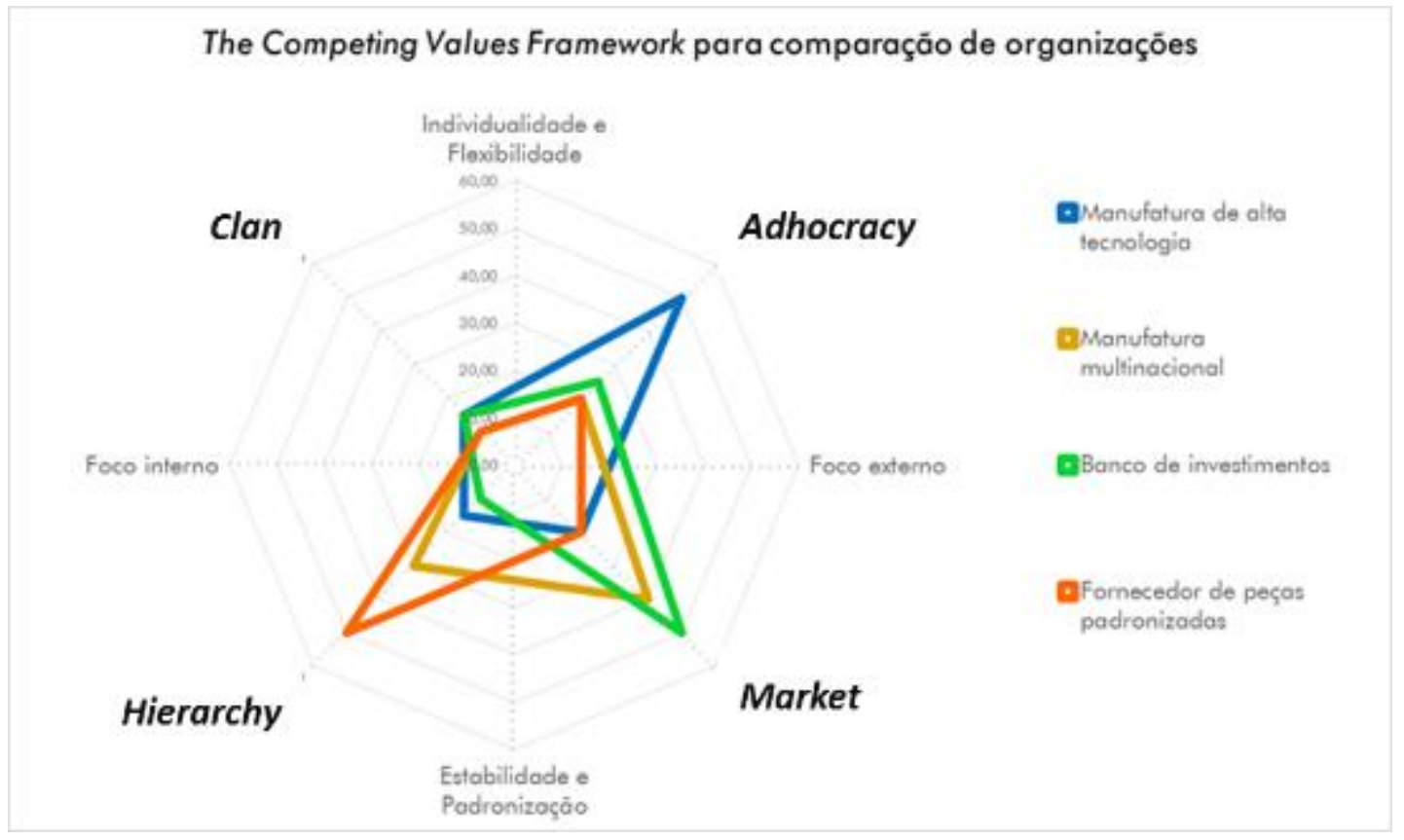

Figura 26 - Resultados de culturas organizacionais identificadas pelo CVF

Fonte: adaptado de Cameron e Quinn (2006)

Provavelmente este é o modelo de análise de Cultura Organizacional mais adequado à proposta de trabalho, e por isto, será considerado o modelo de referência desta pesquisa.

\subsubsection{Cultura Lean}

Devido ao escopo de trabalho, é importante resgatar as principais discussões e definições encontradas na literatura acerca da Cultura Lean.

Segundo Irani e Sharp (1997), a adesão bem-sucedida dos programas de melhoria contínua envolve um sistema complexo com inter-relação com outros subsistemas e processos, os quais necessitam de uma gestão adequada para que os seus respectivos benefícios sejam maximizados. Embora essa discussão não seja recente na literatura, tendo início na década de 1990, ainda parece não existir uma única teoria acerca do perfil cultural que compreenderia uma cultura organizacional orientada para melhoria contínua. 
Alguns comportamentos esperados em uma Cultura Lean são: decisões baseadas no longo prazo, gestores focados com as atividades diárias da linha de frente, operadores focados nas oportunidades de melhoria do sistema produtivo, gestores trabalhando para resolver problemas do sistema com diálogo aberto entre todos os níveis da organização (Drew, McCallum e Roggenhoffer, 2004). As pessoas em uma Cultura Lean buscam constantemente entregar o máximo valor agregado ao cliente, eliminando continuamente as atividades consideradas desperdício como, que gerem excessiva variabilidade do processo ou não permitam a flexibilidade necessária do sistema produtivo (Drew, McCallum e Roggenhoffer, 2004). Compartilhando ponto de vista semelhante ao de Drew, McCallum e Roggenhoffer (2004), e utilizando as definições de Schein (1984) sobre cultura organizacional, Liker e Hoseus (2008) definem resumidamente a Cultura Toyota:

\section{a) Artefatos visíveis e criações}

Equipes pequenas, metodologia de resolução de problemas, análise 5-Why (Cinco porquês, análise de causas raiz), 5S (programa de organização e limpeza de áreas), job rotation (modificações de funções de trabalho para promover e estimular o aprendizado dos colaboradores), reuniões diárias no Gemba (local onde as coisas ocorrem, o nível de operação ou execução das organizações), solução de problemas ágil, newsletters (comunicados), kiosks (gestão visual para promover a comunicação entre as pessoas), surveys (enquetes e avaliações) e líderes motivados;

\section{b) Crenças e valores}

Times de suporte mútuo, padrões claramente definidos, oportunidade dos colaboradores de poderem fazer a diferença (propor, desenvolver e implementar melhorias), preocupação com a segurança física e psicológica dos colaboradores, a comunicação de problemas não é vista como um problema e sim como uma oportunidade de melhoria, recreação e prática esportiva diária, foco na solução dos problemas e não em apontar as pessoas como "culpadas" (os problemas estão no sistema de fluxo de processos, e não nas pessoas que executam as atividades);

\section{c) Suposições básicas}

Os líderes são considerados professores e técnicos, pensamentos envolvem a perspectiva da organização, compromisso contínuo com a segurança das pessoas, 
os líderes integram os mapas de valor da produção com as pessoas, os líderes dão suporte às pessoas que agregam valor;

A Toyota desenvolveu com sucesso o Lean Manufacturing em sua cultura e, por este motivo, as organizações do mundo todo basicamente criaram seus sistemas produtivos enxutos com base no Toyota Production System (Ahmad, 2013). É provável que a Toyota e seus fundadores (Kiichiro Toyoda, Taiichi Ohno, Shigeo Shingo e outros) sejam os grandes "heróis" da Cultura Lean. Para diversos autores (Drew, McCallum e Roggenhoffer, 2004; Liker, 2004; Liker e Hoseus, 2008; Ahmad, 2013), a Cultura Toyota é a base de uma denominada Cultura Lean ideal. Um sólido resumo executivo da cultura que dá suporte ao Sistema Toyota são os 14 Princípios do Modelo Toyota ${ }^{14}$ (Liker, 2004; Fullerton e Wempe, 2009). Estes princípios devem ser o objetivo de um plano equilibrado com foco na melhoria contínua da organização, capaz de aprimorar a eficiência operacional, promover o trabalho em equipe e, principalmente, na promoção de uma Cultura Organizacional na qual as iniciativas Lean sejam duradouras e permanentes (Fullerton e Wempe, 2009).

Embora existam diversos estudos sobre a Cultura Lean e a Cultura Toyota, na literatura, pouco tem sido feito para avaliar a efetividade e o desenvolvimento de ações envolvendo o comportamento das pessoas (Wan e Chen, 2008; Behrouzi e Wong, 2011; Bhasin, 2011a; Ahmad, 2013). Inclusive, ainda que existam diversos estudos sobre a Cultura Lean, na literatura não foi encontrado um diagnóstico ou avaliação de uma Cultura Lean, conforme os diversos métodos existentes de avaliação de cultura. Paro (2012) utiliza o Competing Values Framework para diagnosticar uma Cultura Lean ideal. Para obter este resultado, Paro (2012) utiliza como fonte de dados a experiência em projetos de mudança e o conhecimento de 23 consultores brasileiros especializados em Lean Manufacturing, além de fazer um exercício teórico de associação dos 14 Princípios do Modelo Toyota com o CVF.

Paro e Gerolamo (2015) revisaram esta associação teórica com os 14 Princípios do Modelo Toyota, e os resultados reforçam o forte relacionamento da Cultura Lean ideal com a Cultura de Hierarquia do Competing Values Framework (CVF). O resultado destes trabalhos está ilustrado nas Figuras 27 e 28. Segundo Paro (2012) e Paro e Gerolamo (2015), a Cultura Lean ideal está mais relacionada com um ambiente altamente estruturado e formal, com procedimentos e regras governando o comportamento das pessoas. Nesse ambiente, ainda

\footnotetext{
${ }^{14}$ Os 14 Princípios do Modelo Toyota foram apresentados e discutidos nas Página 53 a 55 deste trabalho, com ilustração na Figura 15.
} 
segundo os autores, as políticas formais mantem as pessoas unidas, sendo crítico manter a ordem e estabilidade dos processos. Sucesso significa ter entregas confiáveis e a baixo custo. Por sua vez, a Cultura Lean ideal está menos associada a um ambiente altamente dinâmico, empreendedor e criativo no qual as pessoas estão comprometidas com o desenvolvimento dos produtos. Ainda, a Cultura Lean está moderadamente relacionada com um ambiente amigável e familiar, no qual as pessoas compartilham muitas informações entre si mesmas, e também está moderadamente relacionada a um ambiente com foco em resultados, no qual as pessoas valorizam competições e são orientadas a atingir determinados objetivos.

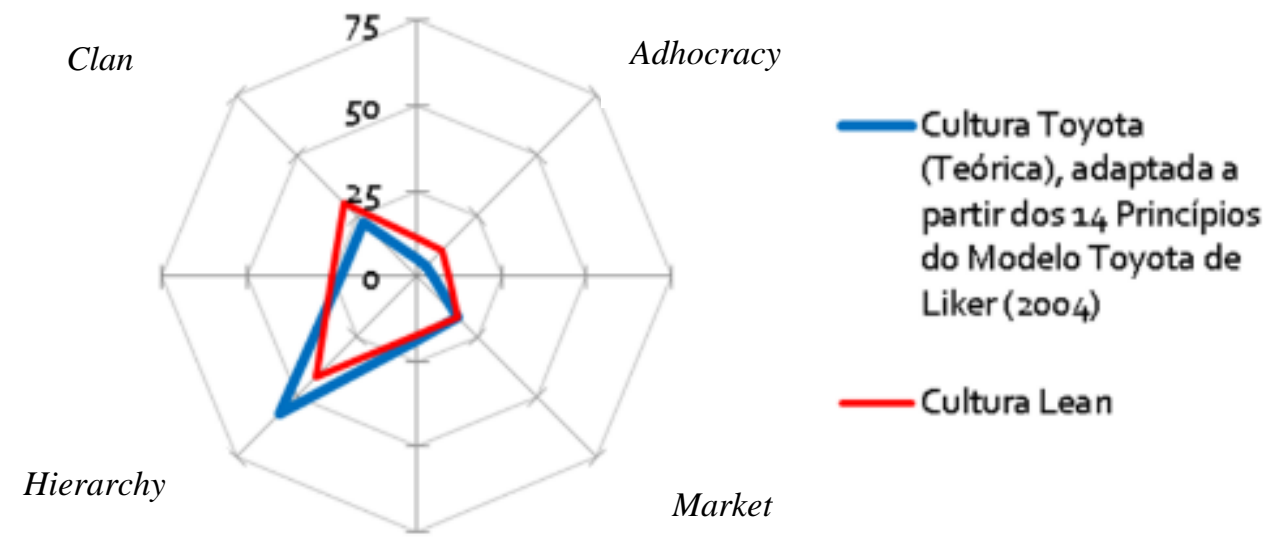

Figura 27 - A Cultura Toyota e a Cultura Lean mapeadas no CVF

Fonte: Paro (2012)

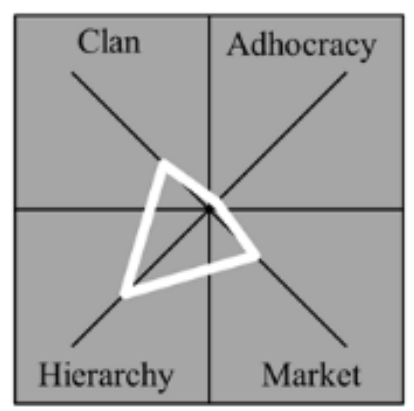

Data

Clan: $25 \%$

Adhocracy: $4 \%$

Market: $25 \%$

Hierarchy: $46 \%$

Theoretical ideal Lean Culture

Figura 28 - A Cultura Lean ideal mapeada no CVF

Fonte: Paro e Gerolamo (2015)

Segundo Mann (2003), quatro elementos transformam uma cultura de produção em massa para uma Cultura Lean: (1) estabelecimento de padrões e responsabilidades pela manutenção destes; (2) acompanhamento da aproximação entre os processos produtivos e as 
atividades de suporte; (3) compreensão das variações na performance do processo com base em dados; (4) tomar ação - reativa e preventiva - para minimizar variações de performance.

Ferreira e Saurin (2008) identificaram que, até o ano de 2002, apenas dois métodos encontrados (Nightingale e Mize, 2002; Kumar e Thomas, 2002) faziam menção específica à satisfação e ponto de vista dos colaboradores da organização com o Lean. Ou seja, a maioria dos métodos de avalição do Lean (Bhasin, 2011a; Hofer e outros, 2011; Behrouzi e Wong, 2011; Eswaramoorthi e outros, 2011; Seyedhosseini e outros, 2011; Unver, 2012; Vinodh e Vimal, 2012; Chauhan e Singh, 2012; Anvari, Zulkifli e Yusuff, 2012) não contemplam a sustentabilidade e absorção do Lean pela Cultura Organizacional.

A inovação não é apenas uma característica essencial das empresas líderes de mercado, e não é limitada apenas ao desenvolvimento de novos produtos e processos, mas pode ser aplicada em todos os aspectos das operações de uma empresa, inclusive na gestão e nas operações (Irani e Sharp, 1997). As empresas que são reconhecidas pela sua capacidade de criar e comercializar novas tecnologias são reconhecidas por suas culturas únicas, como exemplos destas empresas, Buschgens, Bausch e Balkin (2011) citam a Apple, 3M e Google. A Apple oferece aos seus colaboradores o serviço (trabalho na empresa) em troca de um propósito maior, na busca pelo desenvolvimento de tecnologias inovadoras. A $3 \mathrm{M}$ enfatiza a todos os envolvidos (colaboradores, investidores e sociedade) o fato de ser uma empresa fundamentalmente de base científica. O Google celebra a individualidade e liberdade de seus colaboradores, para que estes possam promover e desenvolver soluções inovadoras.

De acordo com Buschgens, Bausch e Balkin (2011), os gerentes que desejam uma estratégia de inovação radical devem utilizar uma cultura de criação (The Competing Values Framework). Caso a inovação não seja o foco principal da estratégia organizacional, ou seja, seja um objetivo de longo prazo secundário, a cultura de competição ou a cultura de colaboração podem ser boas escolhas (Buschgens, Bausch e Balkin, 2011). Os pesquisadores não fazem menção à Cultura de Controle como associada à Inovação, pelo contrário, de acordo com o modelo do CVF, os pesquisadores reconhece esta dimensão como contrária à inovação ao definirem a Cultura Criação como ideal para inovações radicais, e citarem apenas as “dimensões vizinhas” do modelo como associadas a inovação.

Embora definam um perfil cultural ideal, os autores Buschgens, Bausch e Balkin (2011) também reconhecem outras empresas com culturas completamente diferentes das citadas 
anteriormente, e que também inovam (em graus diferentes). São os exemplos da SAS, empresa de software que compete de maneira ágil no mercado, com uma cultura da qual a empresa chama de "família SAS", enfatizando uma empresa que se preocupa com as pessoas em todos os estágios da vida. Inclusive, os autores citam a Toyota Motor Company, uma empresa reconhecida pela sua mentalidade de produção, que é não apenas conhecida pelo processo e cultura de melhoria contínua, mas também é pioneira no desenvolvimento de carros de passageiros com sistemas híbridos de propulsão.

Os resultados de Prajogo e McDermott (2011) compartilham ponto de vista semelhante ao de Buschgens, Bausch e Balkin (2011). De acordo com os autores (Prajogo e McDermott, 2011), tendo novamente o Competing Values Framework como modelo referência, a dimensão cultural orientada para Criação tem o maior impacto em medidas de performance, estando associada a três das quatro medidas do estudo: qualidade do produto, inovação do produto e inovação do processo. Competição está positivamente relacionada com qualidade do produto e do processo, Colaboração associada com qualidade do processo e inovação do processo, e Controle fortemente relacionada com Qualidade do processo.

\subsubsection{Práticas de Gestão de Recursos Humanos}

Ao discutir o conflito entre cultura orientada para Melhoria Contínua e cultura orientada para Inovação Contínua, quando Steiber e Alange (2012) e Prajogo e Sohal (2001) tratam de "perfil da liderança", "desenho da estrutura organizacional", "sistema de avaliação da performance dos colaboradores" e "sistema de recompensas", dentre outros, estes pesquisadores estão se referindo ao que Robbins (2005) intitula de "Ações da Administração" do ponto de vista da Gestão de Recursos Humanos (RH). Estes autores acrescentam apenas o fator "práticas de gestão" das ações listadas por Robbins (2005), sendo que este fator também é citado por diversos outros autores quando discutem cultura organizacional, como Irani e Sharp (1997), Mann (2003) e Liker (2004).

Embora Robbins (2005) seja uma referência em "Comportamento Organizacional" e não especificamente em "Cultura Organizacional", o pesquisador faz uma contribuição relevante an apresentar "grupos de ações da administração" que podem ser analisados e modificados no intuito de criar uma "cultura com foco no cliente". Para Adebanjo e Kehoe 
(1999), fatores como motivação, sistema de recompensas, políticas e estrutura organizacional podem ser compreendidos como "agentes de mudança cultural".

Ao propor ações para desenvolver esta cultura, Robbins (2005) propõe o seguinte grupo de ações, sendo que "estas ações são planejadas para criar funcionários com habilidade, competência e disposição necessárias para solucionar os problemas dos clientes, sempre que surgirem": seleção, treinamento e socialização; desenho da estrutura; autonomia; liderança; avaliação de desempenho; sistema de recompensas. Estes grupos de ações fazem integração com as próximas seções do trabalho. É importante ressaltar que autores como Vakola, Soderquist e Prastacos (2007) compartilham ponto de vista semelhante ao de Robbins (2005) e Gattorna (2009).

\section{a) Seleção de Pessoas}

Segundo Robbins (2005), o início do processo e construção desta cultura (voltada para o cliente) inicia-se com o processo de seleção de pessoas, neste caso, as pessoas contratadas precisam ter características e traços associados ao atendimento diferenciado dos clientes. $\mathrm{O}$ autor cita o caso da Southwest Airlines, que no processo seletivo busca pessoas com traços de extroversão e jovialidade, além da habilidade para ouvir, ter paciência e preocupação com o outro, ou seja, características estas orientadas para pessoas.

\section{b) Treinamento e Socialização}

Como a cultura tem a função de estabilizar as soluções do ambiente interno e externo na organização, ela deve ser ensinada aos novos membros, caso contrário a cultura não serviria sua função básica e os novos membros poderiam ter suas próprias percepções, linguagens, padrões de pensamento, regras e respostas (Schein, 1984). O interesse pelo processo de socialização é interessante não apenas do ponto de vista acadêmico, mas também já está comprovada a preocupação das empresas com a socialização dos membros (Shinyshiaki, 1995).

Do ponto de vista da construção da cultura voltada para o cliente de Robbins (2005), os Treinamentos e práticas de Socialização se fazem necessários devido ao fato das empresas não poderem simplesmente renovar todo o seu quadro de funcionários (seleção de pessoas) buscando pessoas com as características listadas anteriormente. Os treinamentos devem ser frequentemente revistos e atualizados, de tal maneira a reforçar os valores e crenças da cultura organizacional aos colaboradores (Robbins, 2005). O autor não se aprofunda nesta questão, 
citando apenas os exemplos da General Motors, Shell e JPMorgan que, ao buscar mudar o foco dos produtos, desenvolveram programas de treinamento específicos para melhorar o conhecimento dos colaboradores acerca dos produtos, promover uma escuta ativa dos colaboradores, demonstração de paciência e sensibilidade com emoções.

Por exemplo, para Altman e Baruch (2010), o almoço organizacional demonstra-se uma forma útil para promover uma identidade entre as pessoas, para comunicar aspectos de gestão de pessoas e, principalmente, comunicar trabalhos de gestão de mudanças. A compreensão das práticas de socialização é importante, no entanto, o processo é mais complexo do que apenas permanecer em contato com o grupo, é necessário também analisar outros aspectos, como as promoções, por exemplo, as quais podem explicar melhor determinadas orientações de valor das pessoas na organização (Shinyashiki, 1995).

\section{c) Sistema de Recompensas e Plano de Carreira}

Por fim, Robbins (2005) propõe o último grupo de ações para promover uma cultura orientada para os clientes: o sistema de recompensas dos funcionários. Segundo o autor, esta ação é importante para que os funcionários reconheçam os esforços como válidos, nesse sentido, é preciso vincular os pagamentos e as promoções aos comportamentos esperados pelos colaboradores, de acordo com a cultura que deve ser promovida. Sob este ponto de vista, Kerr (1995) apresenta alguns erros comuns de gestão em termos de sistema de recompensas, alguns dos quais estão apresentados no Quadro 19.

\begin{tabular}{|c|c|}
\hline Os gestores desejam... & Mas oferecem recompensas por.. \\
\hline$\checkmark$ Crescimento de longo prazo & $\checkmark$ Ganhos de curto prazo \\
\hline$\checkmark \quad$ Trabalho em equipe & $\checkmark$ Esforço individual \\
\hline$\checkmark$ Objetivos desafiadores & $\checkmark$ "making the numbers" \\
\hline $\begin{array}{l}\checkmark \text { Comprometimento } \\
\text { com Qualidade Total }\end{array}$ & $\begin{array}{l}\checkmark \text { Mudanças de planejamento, } \\
\text { mesmo com alguns defeitos }\end{array}$ \\
\hline$\checkmark$ Solução de problemas & $\checkmark$ Comunicação de boas notícias \\
\hline
\end{tabular}

\section{Quadro 19 - Erros comuns de gestão}

Fonte: adaptado e traduzido de Kerr (1995)

A princípio, Robbins (2005) não trata da questão do "Plano de Carreira", o qual foi inserido neste contexto devido às proposições de Shinyashiki (1995), o qual propõe que o 
departamento de recursos humanos deva olhar este sistema do ponto de vista de orientação de valores para a carreira dos colaboradores.

\section{d) Desenho da estrutura organizacional}

Segundo Robbins (2005), o desenho da estrutura organizacional afeta o comportamento dos colaboradores. Por exemplo, uma estrutura orgânica (mais solta, com baixa especialização, baixa formalização e descentralização) é fundamental para promover uma estratégia e cultura de inovação, enquanto quem uma estrutura mecanicista (com controle rígido, especialização extensiva do trabalho, alta formalização e alta centralização) promoveriam uma estratégia e cultura orientadas para redução e otimização de custos.

Quando discutindo uma cultura voltada para o cliente, Robbins (2005) propõe uma cultura de descentralização (maior autonomia aos funcionários), promovendo a probabilidade de os funcionários satisfazerem melhor os clientes através da promoção de maior flexibilidade no trabalho, ou seja, através da redução de regras e regulamentos. Nesse sentido, a administração deve permitir que os colaboradores ajustem seu comportamento de acordo com as demandas e necessidades dos clientes, afinal, o que o cliente não quer ouvir nunca é "eu não posso resolver isso, você precisa falar com outra pessoa" ou então "isso é contra as políticas da empresa" (Robbins, 2005).

\section{e) Autonomia}

De certa maneira relacionada ao desenho da estrutura organizacional, a autonomia refere a outro grupo de ação da administração identificado por Robbins (2005), justamente por "ser um componente necessário na cultura voltada para o cliente, porque permite que o funcionário possa tomar decisões no momento do atendimento ao cliente”. Sob este aspecto, o autor cita o exemplo da Enterprise-Rente-A-Car que promoveu mais autonomia aos funcionários na construção de uma cultura voltada para os clientes, afinal, um cliente satisfeito é aquele que vê que seu problema foi solucionado com flexibilidade e rapidez pelos funcionários (Robbins, 2005).

Embora Robbins (2005) separe os grupos de ação em "autonomia" e "desenho da estrutura", quando analisando a estrutura organizacional de maneira mais ampla, o autor engloba estes grupos de ação em um único grupo apenas. Possivelmente, o autor tenha feito 
esta distinção para dar maior ênfase à "autonomia", justamente por estar sinalizando a importância deste elemento para a cultura com foco no cliente.

\section{f) Liderança}

A liderança tem o papel de não apenas propor soluções para o grupo, mas também de reduzir a ansiedade do grupo promovendo uma sensação de segurança e um ambiente mais estável, portanto, os líderes devem reportar para o grupo as "respostas já testadas" enquanto que continuam "testando novas respostas" em paralelo, segundo Schein, 1984).

Para Schein (2009), a liderança vem sendo estudada em detalhes muito maiores do que a cultura organizacional, levando a uma frustação na difusão dos conceitos acerca do que a liderança representa: alguém nasceu ou tornou-se um líder? Alguém pode treinar pessoas para se tornarem líderes e quais características estas pessoas devem ter? Nesse sentido, Schein (2009) considera que o foco da liderança deve ser exclusivamente a criação e o gerenciamento da cultura organizacional. Como ilustrado na Figura 29, Cultura e Liderança representam “dois lados da mesma moeda", afinal, é função primordial da liderança ter capacidade para perceber os elementos funcionais e disfuncionais da cultura existente e para gerenciar a evolução cultural, de tal modo que o grupo possa sobreviver em um ambiente mutante (Schein, 2009). Nesse sentido, ou os líderes se tornam conscientes das culturas nas quais estão inseridos ou estas os gerenciarão (Schein, 2009).

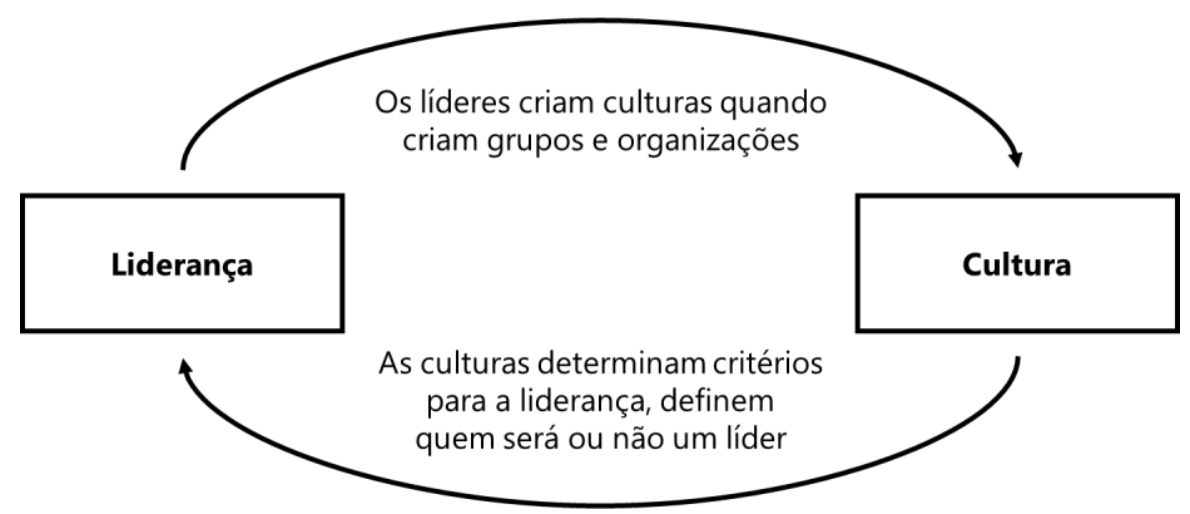

Figura 29 - Cultura e Liderança, dois lados da mesma moeda

Fonte: adaptado de Schein (2009) 
Esse ponto de vista de Schein (2009) é semelhante ao de Bion (1975, apud Fleury, Shinyashiki e Stevanato, 1997) ${ }^{15}$, o qual reconhece que o líder foi escolhido por possuir determinadas características e necessidades de acordo com a escolha do grupo. Portanto, não é o líder que se impõe ao grupo, mas o grupo que escolhe seu líder (Fleury, Shinyashiki e Stevanato, 1997). Robbins (2005) tem a visão de que os líderes expressam a cultura da organização tanto em suas palavras quanto em seus atos, e sob este ponto de vista, propõe que na cultura com foco no cliente os líderes devam expressar constantemente seu comprometimento com os clientes, sendo necessário que o principal executivo da empresa sirva como exemplo. Robbins (2005) cita o exemplo da United Microeletronics, fabricante de microchips de Taiwan, a qual trocou de presidente, justamente pelo fato do presidente anterior tentar mudar a cultura da empresa, reduzindo o foco no cliente e busca pela melhoria da qualidade do serviço prestado.

\section{g) Avaliação de Desempenho}

As avaliações de desempenho com base no comportamento são consistentes para promover uma determinada cultura organizacional, justamente por considerar o funcionário de acordo com suas atitudes, analisando critérios como trabalho em equipe, comprometimento, esforço e capacidade de resolver problemas (Robbins, 2005). Inclusive, para Robins (2005) a avaliação de comportamentos é superior à avaliação de resultados, quando se analisando do ponto de vista de construir ou criar uma nova cultura, justamente por incentivar os colaboradores a adotarem certos comportamentos. Portanto, ao tratar da cultura orientada para o cliente, Robbins (2005) propõe o uso de avaliações voltadas para os clientes, como a opinião dos consultores, afinal, o simples fato dos funcionários saberem que serão avaliados pela qualidade do atendimento já faz com que se preocupem mais com os clientes.

\section{h) Práticas de Gestão}

Robbins (2005) e Gattorna (2009) não citam o elemento “práticas de gestão" como uma ação da administração do ponto de vista de gestão da cultura organizacional. No entanto, os trabalhos de Liker (2004), Irani e Sharp (1997) e Mann (2003) fornecem indícios de que, ao

15 BION, W. R. (1975). Experiências com grupos: os fundamentos da psicoterapia de grupos. $2^{\mathrm{a}}$ edição, Rio de Janeiro, Imago; São Paulo, EDUSP. 
rever as práticas de gestão, é possível promover novas experiências aos colaboradores, modificando consequentemente os valores dos mesmos.

\subsection{GESTÃO DE MUDANÇAS}

Esta seção sobre Gestão de Mudanças tem início com uma introdução sobre o tema, passa por uma revisão das barreiras associadas ao processo de mudança, pelos principais modelos de mudança e, por fim, dá ênfase nos aspectos associados à evolução cultural e na liderança do processo de mudança. Desta maneira, este texto de revisão sobre Gestão de Mudanças segue a estrutura das seções em destaque na Figura 30.

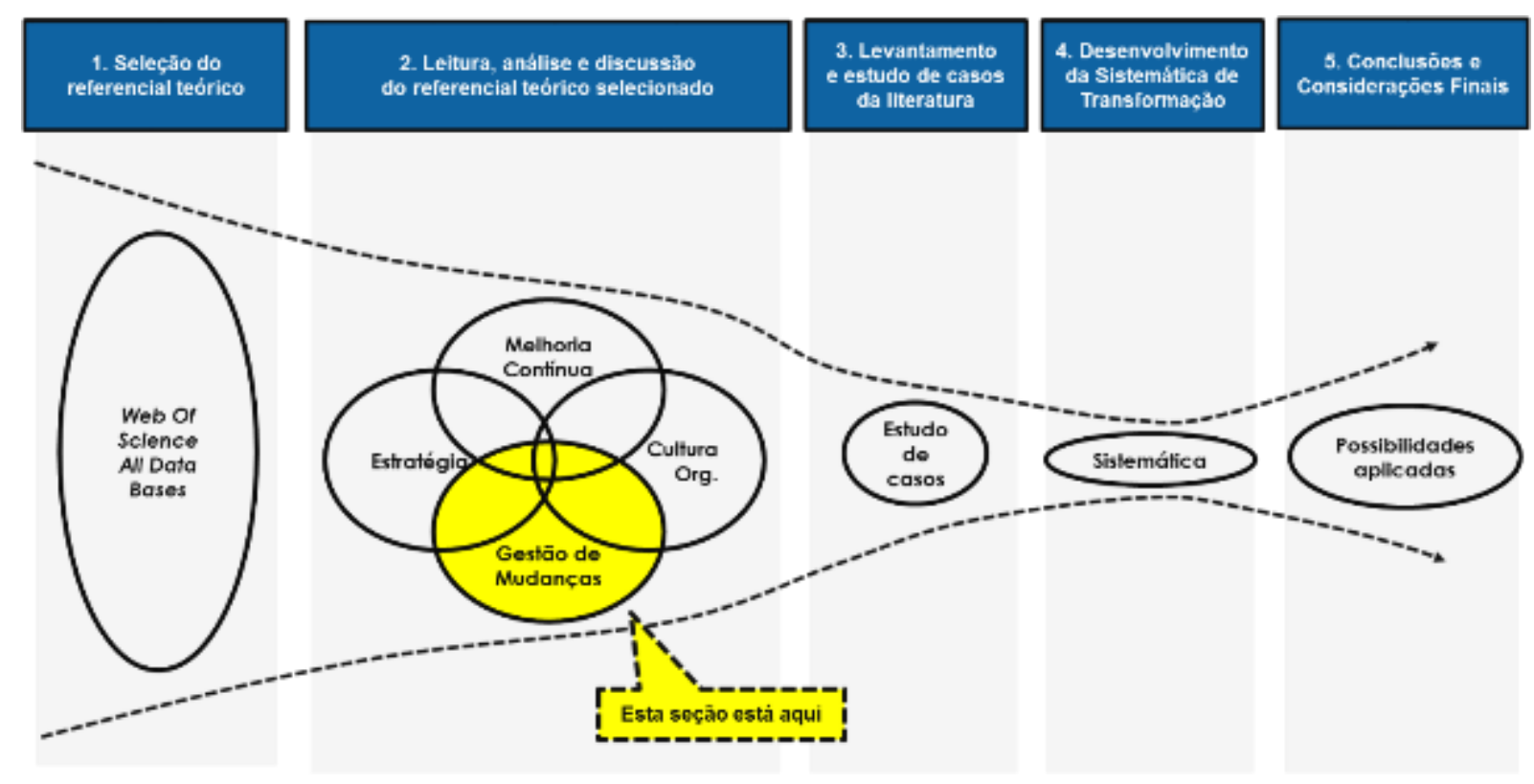

Figura 30 - Estrutura do texto sobre Gestão de Mudanças

\subsubsection{Introdução à Gestão de Mudanças}

Em 1948, Coch e French (1948) já afirmavam que as mudanças nos trabalhos das pessoas seriam cada vez mais frequentes e necessárias para manter as condições competitivas e o desenvolvimento tecnológico. De fato, o cenário nas décadas seguintes foi bem parecido, com um aumento na frequência e velocidade destas mudanças. Para Kotter (1995, p.1), não importa o contexto no qual uma organização está, ela precisa e estará realizando mudanças: 
"Observei mais de 100 organizações tentando se tornarem melhores que seus concorrentes. Incluindo grandes (Ford) e pequenas organizações (Landmark Communications), companhias norte-americanas (General Motors) e de outras regiões do mundo (British Airways), corporações em crise financeira (Eastern Airways) ou que estavam ganhando boa quantidade de dinheiro (Bristol-Myers Squibb). Os esforços de mudança eram de todas as maneiras, como: TQM, reengenharia, reestruturação e mudança cultural. Mas em todas, o objetivo era o mesmo: fazer mudanças fundamentais em como o negócio era conduzido, para que fosse possível competir em um ambiente de mercado desafiador".

As organizações precisam realizar mudanças moderadas pelo menos uma vez por ano, e realizar grandes mudanças a cada quatro ou cinco anos (Kotter e Schelinger, 2008). Tais mudanças podem ser fruto de necessidades externas ou internas (Kotter e Schelinger, 2008). Por disparadores externos de mudança entende-se como: mudanças de legislação, entradas de novos competidores no mercado, concorrentes inserindo novos produtos, novas tecnologias, mudanças nos hábitos de consumo, e outros fatores. Como exemplo de disparadores internos de mudança podem ser citados: problemas ou deficiências internas, lacunas de performance, processos internos ineficientes e diversos outros.

Embora as mudanças sejam necessárias, elas não são facilmente implementadas. Poucos dos esforços de mudança têm sido bem-sucedidos, um dos motivos disto é que muitas destas iniciativas pulam ou não fazem de maneira eficiente certas etapas do processo de mudança buscando agilizar o processo (Kotter, 1995). Sob este ponto de vista, diversos autores apresentaram modelos de mudança (Carnall, 1986; William Bridges, 1991; Kotter, 1995; Nadler e Tushmann, 1997; Senge et al., 1999; Stacey, 2001; Shaw, 2002).

No entanto, a taxa de insucesso dos esforços de mudança continua elevada. Por exemplo, autores estimam que menos de $10 \%$ (dez por cento) das implementações do Lean foram bem-sucedidas na Inglaterra (Hines et al., 2008; Sim e Rodgers, 2009; Atkinson, 2010; Bhasin, 2011b; Bhasin, 2012a). Na literatura há uma dada concordância entre autores de que, pelo menos, dois terços das iniciativas de mudança continuam falhando (Graham, 1991; Walker, 1992; Atkinson, 2010; Sirkin et al., 2005; Bhasin, 2011b; Bhasin, 2012a). Inclusive, até mesmo os esforços que apresentam resultados e sobrevivem, muitos apresentam níveis consideráveis de insatisfação por parte da organização (Hawkes, 1993). 
Nos próximos itens desta seção, trataremos de maneira um pouco mais profunda sobre as principais barreiras e modelos de mudança organizacional, podendo incluir mudanças culturais ou não.

\subsubsection{Barreiras à mudança organizacional}

Dentre as diversas barreiras à mudança organizacional, se não todas, a grande maioria das barreiras está direta ou indiretamente relacionada a aspectos das pessoas na organização (Heller et al., 1998; Gravenhorst et al., 2003;). Segundo Rentes (2000), o sucesso da transformação vai depender das pessoas envolvidas no processo de mudança, as pessoas irão se motivar e realizar mais esforços à medida em que os resultados do processo aparecerem e, no entanto, elas também podem se desmotivar caso os resultados não sejam positivos. Este é um processo em espiral nas organizações, tanto para cima quanto para baixo, que pode significar o sucesso ou insucesso da iniciativa, quando motivar ou desmotivar as pessoas, respectivamente (Rentes, 2000).

Rentes (2000) faz uma compilação precisa das principais barreiras que ocorrem no processo de transformação organizacional. Esta compilação é feita a partir da estrutura conceitual de Sink e Morris (1995), incluindo frentes como treinamento, planejamento, medidas de desempenho, cultura, motivação, infraestrutura, comunicação, política e tecnologia, com acréscimo de sete frentes: burning platform, visão, foco, alinhamento, participação, gerenciamento de processos e sistemas de informação. Estas "frentes de barreiras" do processo de mudança são organizadas por Rentes (2000) em quatro dimensões, conforme ilustrado na Figura 31. Por sua vez, o Quadro 20 traz uma compilação das 38 barreiras listadas nestas quatro dimensões.
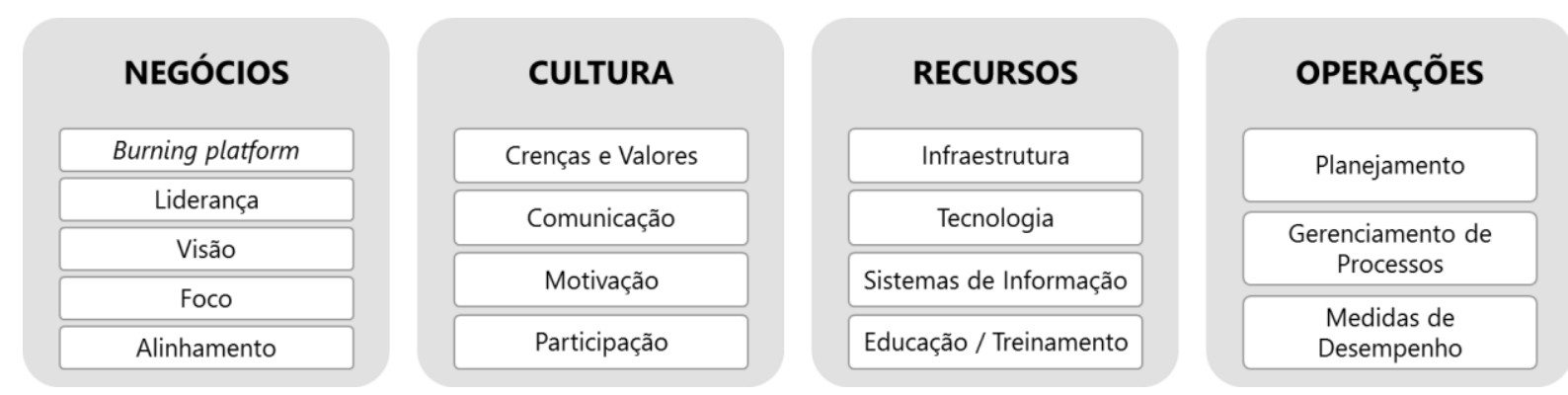

Figura 31 - Dimensões e frentes de análise das barreiras à mudança organizacional.

Fonte: adaptado de Rentes (2000) 


\begin{tabular}{|c|c|c|c|}
\hline Dimensão & Frente & $\#$ & Barreiras \\
\hline \multirow[t]{9}{*}{ Negócios } & Burning platform & 1 & Não identificação clara de uma burning platform ${ }^{16}$ \\
\hline & & 2 & Excesso de complacência \\
\hline & Liderança & 3 & Falhar na criação de lideranças para o processo \\
\hline & Visão & 4 & Falta de uma visão clara para o processo de mudança \\
\hline & Foco & 5 & Falha na focalização de processos e problemas raiz \\
\hline & & 6 & Falha de orientação/foco nas necessidades dos clientes \\
\hline & & 7 & Declarar vitória cedo de mais \\
\hline & Alinhamento & 8 & Falhar no alinhamento de objetivos \\
\hline & & 9 & Falhar na criação de objetivos de curto prazo \\
\hline \multirow[t]{11}{*}{ Cultura } & Crenças e Valores & 10 & Subestimar crenças e valores vigentes \\
\hline & & 11 & Supervalorizar crenças e valores vigentes \\
\hline & & 12 & Negligenciar a ancoragem das mudanças na cultura \\
\hline & Comunicação & 13 & Falha na comunicação da visão e da burning platform \\
\hline & & 14 & Negligenciar a comunicação no processo de mudança \\
\hline & & 15 & Não colher feedback 360 graus \\
\hline & Motivação & 16 & Ausência de um claro sistema de recompensas \\
\hline & & 17 & Permitir que obstáculos bloqueiem a visão \\
\hline & & 18 & Falta de empowerment aos agentes de mudança e equipe \\
\hline & Participação & 19 & Conduzir a transformação de forma apenas topdown \\
\hline & & 20 & Ignorar os receios das pessoas participantes do processo \\
\hline \multirow[t]{11}{*}{ Recursos } & Infraestrutura & 21 & Confundir estrutura de transformação com organizacional \\
\hline & & 22 & Falha na adaptação da estrutura org. à mudança \\
\hline & & 23 & Não criar disponibilidade de tempo na agenda das pessoas \\
\hline & & 24 & Falha na alocação de pessoas à equipe de transformação \\
\hline & Tecnologia & 25 & Subestimar a importância de novas tecnologias \\
\hline & & 26 & Falha na adequação entre necessidade e tecnologia \\
\hline & Sistema de & 27 & Falha na obtenção de dados relevantes à transformação \\
\hline & Informação & 28 & Falha no sistema de divulgação dos resultados da transf. \\
\hline & Educação e & 29 & Falta de conhecimento sobre o processo e ferramentas \\
\hline & Treinamento & 30 & Falha no compartilhamento de conhecimentos \\
\hline & & 31 & Falha no treinamento sobre novas tecnologias \\
\hline \multirow[t]{7}{*}{ Operações } & Planejamento & 32 & Inexistência de cronograma de transf. com milestones \\
\hline & & 33 & Falha na escolha do momento de iniciar a mudança \\
\hline & & 34 & Conduzir o processo vagarosamente \\
\hline & Gestão de & 35 & Falha na criação de uma visão consensual e clara \\
\hline & Processos & 36 & Fragmentação dos processos entre subgrupos \\
\hline & Medição de & 37 & Falha no estabelecimento de critérios de avaliação \\
\hline & Desempenho & 38 & Não manter aderência dos grupos às medidas de avaliação \\
\hline
\end{tabular}

\section{Quadro 20 - Barreiras do Processo de Mudança.}

Fonte: compilado e adaptado de Rentes (2000)

\footnotetext{
${ }^{16}$ Burning platform ("plataforma queimando") são crises geradas para disparar a necessidade de mudança (Rentes, 2000).
} 


\subsubsection{Metáforas organizacionais}

Para compreender como as organizações de fato se modificam, e também ajudar os gestores a entenderem como as empresas funcionam sob diferentes perspectivas, Morgan (1998) define oito metáforas organizacionais.

“Metáfora é uma força importante pela qual os homens criam significado e utilizam um elemento familiar para compreender outro. Uma metáfora nos dá a oportunidade de enriquecer nosso pensamento e tornar nossa compreensão mais profunda, portanto, permitindo que seja possível ver as coisas sob outra perspectiva, além de agir sob outra perspectiva. Aplicadas desta maneira, as metáforas se tornam uma ferramenta importante para promover uma compreensão sobre o que nós entendemos como organização e gestão" (Morgan, 1998, pp. 1).

As metáforas propostas por Morgan (1998) podem ser compreendidas da seguinte maneira: as organizações vistas como (1) Máquinas, (2) Organismo, (3) Cérebro, (4) Cultura, (5) Sistema Político, (6) Prisão psíquicas, (7) Fluxo de Transformação e (8) Instrumentos de Dominação. O Quadro 21 apresenta uma descrição destas oito metáforas, incluindo as principais associações, exemplos, forças e limitações relacionadas a cada metáfora.

Destas oito metáforas propostas por Morgan (1998), Cameron e Green (2009) enfatizam apenas quatro metáforas, ao não atribuírem a devida importância às demais metáforas, a análise que Cameron e Green (2009) fazem sobre os Modelos de Mudança versus as Metáforas de Morgan (1998) carece de profundidade e perspectiva sob o ponto de vista das oito metáforas.

\subsubsection{Modelos de Mudança Organizacional}

Esta seção dá continuidade e revisa o trabalho de revisão da literatura realizado por Cameron e Green (2009), e, por este motivo, resgata por diversas vezes o ponto de vista dos autores sobre os modelos de mudança. Embora o modelo de Cameron e Green (2009) não seja o mais citado e utilizado na literatura, como será demonstrado no Capítulo 4 deste trabalho, é importante reconhecer a contribuição destes autores com relação à ampla revisão realizada na temática de Gestão de Mudanças. 


\begin{tabular}{|c|c|c|c|c|c|}
\hline METÁFORA & DESCRIÇÃO & ASSOCIAÇÕES & EXEMPLOS & FORÇAS & LIMITAÇÕES \\
\hline Máquina & $\begin{array}{l}\text { A organização é vista } \\
\text { como um engenheiro } \\
\text { projetando uma } \\
\text { máquina, como se fosse } \\
\text { uma estrutura operando } \\
\text { perfeitamente }\end{array}$ & $\begin{array}{l}\text { Precisão, velocidade, } \\
\text { clareza, regulamento, } \\
\text { eficiência, hierarquia, } \\
\text { regras }\end{array}$ & $\begin{array}{l}\text { O padrão de trabalho em } \\
\text { uma linha de montagem } \\
\text { (Taylor) ou o trabalho } \\
\text { diário em uma rede de } \\
\text { Fast Food (McDonalds) }\end{array}$ & $\begin{array}{l}\text { Funciona muito bem em } \\
\text { trabalhos operacionais, } \\
\text { quando há alta } \\
\text { frequência de repetição } \\
\text { de tarefas }\end{array}$ & $\begin{array}{l}\text { Pode dificultar a } \\
\text { adaptação a mudanças ou } \\
\text { reduzir drasticamente a } \\
\text { "reflexão" (mindless } \\
\text { and unquestioning) }\end{array}$ \\
\hline Organismo & $\begin{array}{l}\text { A organização é vista } \\
\text { como um organismo } \\
\text { procurando se adaptar } \\
\text { e sobreviver em um } \\
\text { ambiente em mudanças }\end{array}$ & $\begin{array}{l}\text { Adaptação, evolução, } \\
\text { sobrevivência, ciclos de } \\
\text { vida, necessidades, } \\
\text { condições do ambiente, } \\
\text { sistemas vivos }\end{array}$ & $\begin{array}{c}\text { Os resultados dos } \\
\text { estudos de Elton Mayo } \\
\text { em Hawthorne e } \\
\text { a teoria da Hierarquia } \\
\text { das Necessidades de } \\
\text { Maslow }\end{array}$ & $\begin{array}{c}\text { Promove a compreensão } \\
\text { da organização em } \\
\text { congruência com um } \\
\text { ambiente externo }\end{array}$ & $\begin{array}{c}\text { As organizações não são } \\
\text { organismos e o ambiente } \\
\text { externo não é tão } \\
\text { concreto quanto pode ser } \\
\text { presumido }\end{array}$ \\
\hline Cérebro & $\begin{array}{l}\text { A organização é vista } \\
\text { como um cérebro com } \\
\text { capacidade de aprender, } \\
\text { armazenar e disseminar } \\
\text { conhecimento }\end{array}$ & $\begin{array}{c}\text { Aprendizado, } \\
\text { processamento de } \\
\text { informações, inteligência, } \\
\text { feedback, conhecimento, } \\
\text { network e mindset }\end{array}$ & $\begin{array}{c}\text { Os Programas de } \\
\text { Melhoria Contínua que } \\
\text { encorajam os } \\
\text { funcionários a questionar } \\
\text { os modelos existentes e } \\
\text { aprender novas práticas }\end{array}$ & $\begin{array}{c}\text { A visão serve de } \\
\text { guia para promover o } \\
\text { aprendizado e evolução } \\
\text { da organização }\end{array}$ & $\begin{array}{l}\text { Podem existir conflitos } \\
\text { de poder e aprendizado, } \\
\text { e aprender apenas por } \\
\text { aprender pode se tornar } \\
\text { uma simples "ideologia" }\end{array}$ \\
\hline Cultura & $\begin{array}{l}\text { A organização é vista } \\
\text { como uma mini } \\
\text { sociedade, possuindo } \\
\text { valores, ritos, crenças e } \\
\text { ideologias intrínsecas }\end{array}$ & $\begin{array}{c}\text { Sociedade, valores, } \\
\text { crenças, leis, ideologias, } \\
\text { ritos, diversidade, } \\
\text { história, visão } \\
\text { compartilhada, missão e } \\
\text { compreensão } \\
\end{array}$ & $\begin{array}{l}\text { Cultura Toyota como um } \\
\text { fator importante de } \\
\text { vantagem competitiva da } \\
\text { montadora japonesa }\end{array}$ & $\begin{array}{l}\text { Os líderes e os gestores } \\
\text { ganham uma nova } \\
\text { compreensão do seu } \\
\text { papel e sua importância } \\
\text { na organização }\end{array}$ & $\begin{array}{l}\text { Como um Iceberg, a } \\
\text { Cultura tem dimensões } \\
\text { que são invisíveis e o } \\
\text { que é visto é } \\
\text { relativamente pouco } \\
\text { importante }\end{array}$ \\
\hline $\begin{array}{l}\text { Sistema } \\
\text { Político }\end{array}$ & $\begin{array}{l}\text { A organização é vista } \\
\text { como um conflito de } \\
\text { interesses e competição } \\
\text { por poder }\end{array}$ & $\begin{array}{l}\text { Interesses, direitos, poder, } \\
\text { acordos, autoridade, } \\
\text { alianças, liderança, } \\
\text { conflito de gestão }\end{array}$ & $\begin{array}{l}\text { As relações e conflitos } \\
\text { entre partidos políticos }\end{array}$ & $\begin{array}{l}\text { Desmitifica o fato das } \\
\text { organizações serem } \\
\text { racionais ao introduzir a } \\
\text { visão do jogo de poderes }\end{array}$ & $\begin{array}{l}\text { Pode ser vista como } \\
\text { unfriendly além de } \\
\text { reduzir as desigualdades } \\
\text { de poder e influência }\end{array}$ \\
\hline
\end{tabular}


A organização é vista como um sistema que

Prisão psíquica

fica preso em suas

próprias obsessões e

armadilhas mentais

A organização é vista em um contexto mais

Fluxo de

Transformação

amplo, envolvendo paradoxos,

complexidade, caos e

mudanças do ambiente
Processo consciente e inconsciente, repressão e regressão, ego, negação, mecanismos de

enfrentamento e defesa, princípios de dor e prazer, disfunção e workaholics
Os arquétipos de Jung, os quais parecem ter um significado universal e ajudam a dar às pessoas um senso de

pertencimento no mundo
A metáfora encoraja as pessoas a questionarem suas suposições básicas e

suas experiências no

mundo, promovendo

uma nova perspectiva ao

lado "irracional"
Foco no subconsciente pode afetar a atenção em outras fontes importantes de controle

A visão oferece uma nova compreensão sobre a natureza e a fonte das mudanças, os líderes ganham a perspectiva de facilitadores das mudanças
Não oferece controle das mudanças aos gestores, apenas o papel de facilitadores propriedades emergentes
(500 A.C.) sobre

"impossibilidade de

passar pelo mesmo rio duas vezes"
Alienação, repressão, imposição de valores, carisma, manutenção de poder, força, exploração, divisão, regras e interesse corporativo
A peca "Death of a

Salesman" de Arthur

Miller é um exemplo de como as organizações consomem seus empregados
Coloca aspectos éticos e ideológicos como uma preocupação central sobre o papel das organizações
A metáfora pode promover a polarização de grupos sociais caso seja interpretada de maneira equivocada finalidade

Quadro 21 - Descrição de como as mudanças são tratadas de acordo com as metáforas organizacionais 
Dos onze modelos revisados, nove foram contemplados inicialmente na revisão de modelos de mudança do ponto de vista organizacional realizada por Cameron e Green (2009), sendo incluídos apenas os modelos de Kubler-Ross (1969) e Sirkin et al. (2005), sendo o primeiro citado apenas como modelo de mudanças individuais. Ainda, é importante ressaltar que Cameron e Green (2009) analisaram tais modelos de mudança somente do ponto de vista de quatro metáforas organizacionais propostas por Morgan (1998), Máquina, Organismo, Sistema Político e Fluxo. Este trabalho analisa os modelos sob a ótica das oito metáforas, apresentando a consolidação desta análise no Quadro 25 do Capítulo 4.

\section{Modelo 1 - Lewin (1951): Modelo em três etapas}

O modelo proposto por Lewin é importante por ser robusto e aplicável às mudanças organizacionais de maneira geral. Basicamente, ele propõe três etapas como ilustrado na Figura 32. Primeiro, deve-se descongelar o estado atual da organização, ou seja, devem ser identificadas as forças propulsoras e resistências que impossibilitam de se atingir o estado desejado. A próxima etapa envolve identificar as mudanças que precisam ocorrer para atingir o estado desejado. Por fim, a terceira etapa envolve congelar as mudanças realizadas de tal maneira que o processo se torne estável novamente.

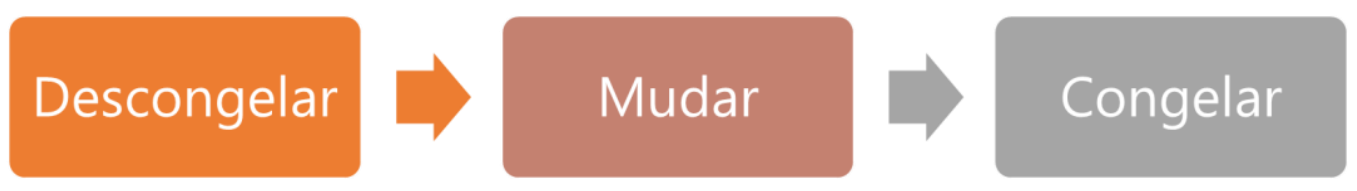

Figura 32 - O modelo em três etapas de Lewin

Fonte: adaptado de Lewin (1951)

O modelo de Lewin foi desenvolvido para capacitar consultores a conduzirem grupos de pessoas, os consultores deveriam trabalhar primeiro na identificação dos problemas com um grupo de pessoas (descongelar), deveriam então desenvolver mudanças e soluções (mudar) para, no final, controlar e reforçar o novo estado atingido (congelar). Um dos principais pontos deste modelo é a proposta da análise de campos de forças, a qual permite que os colaboradores e gestores cheguem a um consenso sobre as mudanças que precisam ocorrer através da análise de forças propulsoras e de resistência do processo. Segundo Cameron e Green (2009), o modelo de Lewin é importante para que os gestores façam um planejamento do processo de mudança, mas, no entanto, em termos de processo de mudança, o modelo ignoraria o fato de que as pessoas irão mudar somente caso fosse estabelecido um senso de urgência - este, seria um 
ponto fundamental da metáfora da organização vista como um organismo. Para estes autores, caso isto não ocorra, seria como tentar "encher um balão sem amarrar a abertura": o balão irá esvaziar, tal qual o processo de mudança não terá estabilidade ao longo prazo.

A grande contribuição de Lewin (1951) está em reconhecer a etapa de "descongelamento" como fundamental para o processo de mudança, poucos modelos tratam da necessidade de compreender profundamente o estado atual. Com relação aos demais modelos, apenas Bridges (1991) trata da etapa "fim" e "entendimento da necessidade de mudança", respectivamente. Embora Cameron e Green (2009) façam algumas críticas ao modelo de Lewin (1951), é necessário reconhecer a contribuição conceitual realizada por Lewin (1951). Com relação às metáforas organizacionais de Morgan (1998), podemos considerar o modelo de Lewin (1951) como tendo uma visão da organização como uma Máquina. Organismo e Sistema político. Máquina, por considerar ser possível "Mudar” e logo em seguida "Congelar" tais mudanças, ou seja, tendo o processo de mudança "como um engenheiro projeta uma máquina". Organismo, por compreender que a organização precisa mudar para se adaptar ao ambiente externo. Sistema Político e Cultura, por enxergar além das ideologias já existentes, o possível conflito de interesses e, desta maneira, reforçar a importância de descongelar o estado atual antes de propor mudanças.

\section{Modelo 2 - Kubler-Ross (1969): A Curva da Mudança}

No livro “On Death and Dying”, de 1969, Elizabeth Kubler-Ross publicou resultados e análises de suas pesquisas, constatando a ideia de que as pessoas passam por um processo psicológico de mudanças durante a última fase de suas vidas, quando estão aguardando a morte. De maneira geral, a ideia é que as pessoas passam por cinco estágios de mudança que preparam as pessoas para a morte após o prognóstico dos médicos: negação e isolamento, raiva, barganha, depressão e aceitação. Quando grandes mudanças ocorrem, cada pessoa reage de uma maneira distinta: as pessoas não experimentam a mesma "jornada de mudanças", a velocidade e a duração de cada fase depende no grau da mudança e no seu impacto individual. Portanto, cada indivíduo irá reagir de maneira diferente ao processo de mudança.

\section{Modelo 3 - Bullock e Batten (1985): Mudança Planejada}

O modelo proposto por Bullock e Batten (1985) envolve o planejamento da mudança seguindo uma lógica de gestão de projetos, envolvendo o estudo, planejamento e ação das ações. Envolve quatro etapas ilustradas na Figura 33. Primeiramente, é feito um estudo para 
verificar quais mudanças precisam ocorrer e quais recursos serão utilizados, depois, é feito o planejamento de quais atividades devem ocorrer para que as mudanças sejam implementadas. Após este planejamento inicial, as ações de mudança são executadas. Tendo o plano de ações executado, por fim, inicia-se a etapa de integração, na qual as mudanças implementadas são formalizadas, divulgadas e compartilhadas com a organização.

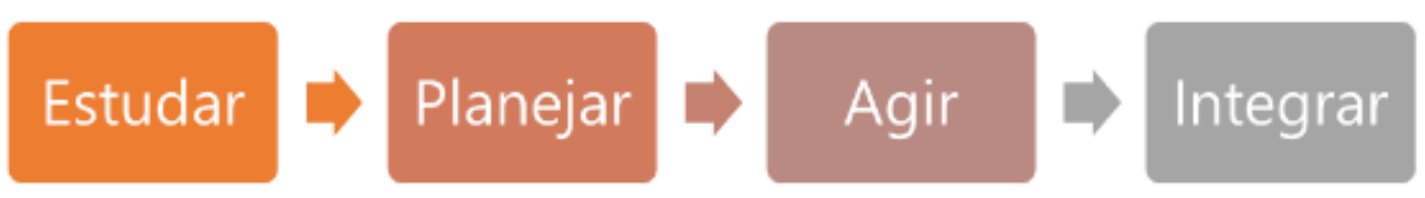

Figura 33 - O modelo da Mudança Planejada

Fonte: adaptado de Bullock e Batten (1985) e Cameron e Green (2009)

Dentre os modelos de mudança descritos nesta seção, este é o modelo que mais se aproxima dos Modelos de Melhoria apresentados na seção “3.1. Gestão de Operações” deste trabalho - ainda que haja uma certa semelhança com o modelo de Lewin, o modelo de Bullock e Batten (1985) segue um raciocínio semelhante ao de modelos como o PDCA e DMAIC.

Na visão de Cameron e Green (2009), este modelo funciona bem somente quando aplicado em problemas isolados, mas não deve ser utilizado para mudanças complexas, as quais podem requerer uma discussão maior sobre a situação atual e os estados futuros possíveis. De maneira geral, as mudanças neste modelo tendem a girar em torno das "ações", desviando o foco de outras questões fundamentais do processo de mudança, como do sistema político, contexto externo, valores e aprendizados das pessoas. Com relação às metáforas organizacionais propostas por Morgan (1998), compreende-se que o modelo proposto por Bullock e Batten (1985) interpreta as organizações como uma Máquina e Cérebro. Máquina, pois, considera e visualiza o processo de mudança como um "engenheiro projetando uma máquina", e Cérebro por inserir a necessidade de "estudar a organização" e, inclusive, por inserir aspectos de disseminação e compartilhamento de conhecimento, ou seja, reconhecendo a existência de aprendizado no processo.

\section{Modelo 4 - Beckhard e Harris (1987): Fórmula da Mudança}

A fórmula da mudança elaborada por Beckhard e Harris (1987) consolida de maneira muito precisa alguns requisitos que precisam ser estabelecidos para que uma mudança possa de fato ocorrer. Esta fórmula, apresentada na Figura 34, mostra que as mudanças somente 
ocorrerão quando o nível de insatisfação das pessoas com a situação atual, o desejo de implementar as mudanças propostas e, também, a praticabilidade da mudança (isto é, baixo risco e capacidade de implementar as mudanças propostas) forem superiores ao custo ("esforço") de realizar a mudança. Caso esta condição não seja estabelecida, as mudanças não ocorrem. Sendo que os três fatores intermediários não compensam um aos outros, ou seja, é necessário que o peso dos três seja alto, caso contrário a probabilidade de insucesso é alta.

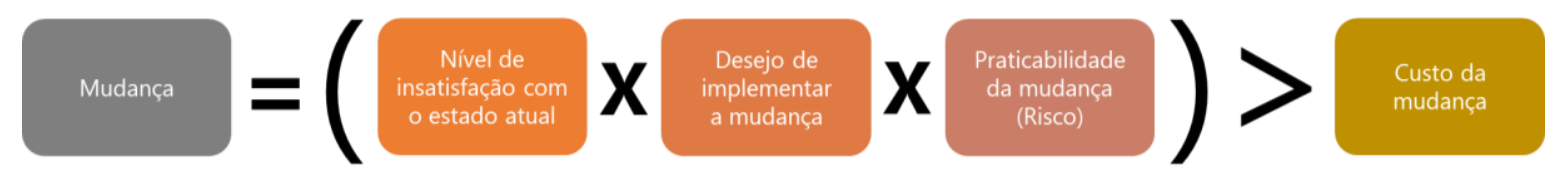

Figura 34 - A fórmula da mudança.

Fonte: adaptado de Beckhard e Harris (1987)

Este modelo é muito interessante devido à sua simplicidade e aplicabilidade. Ele pode ser utilizado em pequenas ou grandes mudanças, em mudanças simples ou complexas. Inclusive, pode ser utilizado em paralelo aos demais modelos de mudança, seja para planejar ou analisar o processo de mudança como um todo. Com relação às metáforas organizacionais de Morgan (1998), este modelo demonstra uma visão das organizações como um organismo procurando se adaptar e sobreviver em seu ambiente, pois está associado ao nível de insatisfação do estado atual, desejo e praticabilidade da mudança. De certo modo, a análise e ruptura entre "vantagens da mudança" versus "custo da mudança" também pode ser considerada como um olhar de prisão psíquica, incluindo, portanto, uma segunda metáfora. Inclusive, devido à abrangência do modelo - desde mudanças simples a complexas, pequenas a grandes -, a metáfora organizacional do Sistema Político pode estar presente quando o modelo for compreendido do ponto de vista de adesão dos diversos envolvidos na mudança.

\section{Modelo 5 - Carnall (1986): Modelo de gerenciamento das transições}

Ilustrado na Figura 35, o modelo de Carnall (1986) traz a perspectiva da administração para a gestão de mudanças, abordando dimensões como "gerenciar as transições eficazmente", "lidar com culturas organizacionais" e "controlar a política organizacional".

Por gerenciar as transições eficazmente, Carnall (1986) trata de gestores que sejam capazes de dar suporte para que as pessoas aprendam com o processo de mudança, e ainda criem um clima favorável à mudança, envolvendo aceitação e riscos, por exemplo. Por lidar com culturas organizacionais o modelo fala em "desenvolver uma cultura adaptável”. Nesse 
sentido, Cameron e Green (2009) citam que seria necessário desenvolver um fluxo de informações mais eficaz, promover autonomia e receptividade entre as pessoas. Por fim, para gerenciar a transição o gerente deve controlar a política organizacional, formando coalizões, controlando prioridades e utilizando especialistas de fora (Cameron e Green, 2009).

Através deste gerenciamento das transições, os gestores estariam oferecendo uma resposta às pressões internas e externas pela mudança, promovendo a criatividade das pessoas, recuperando a autoestima e aprimorando o desempenho da organização através da realização da mudança organizacional e do aprendizado. Segundo Cameron e Green (2009), o modelo de Carnall (1986) faz um paralelo interessante com o modelo de Bridges (1991) por proporcionar uma lista de verificações do ponto de vista gerencial. Portanto, os dois modelos podem ser utilizados em conjunto à medida em que um completaria o outro.

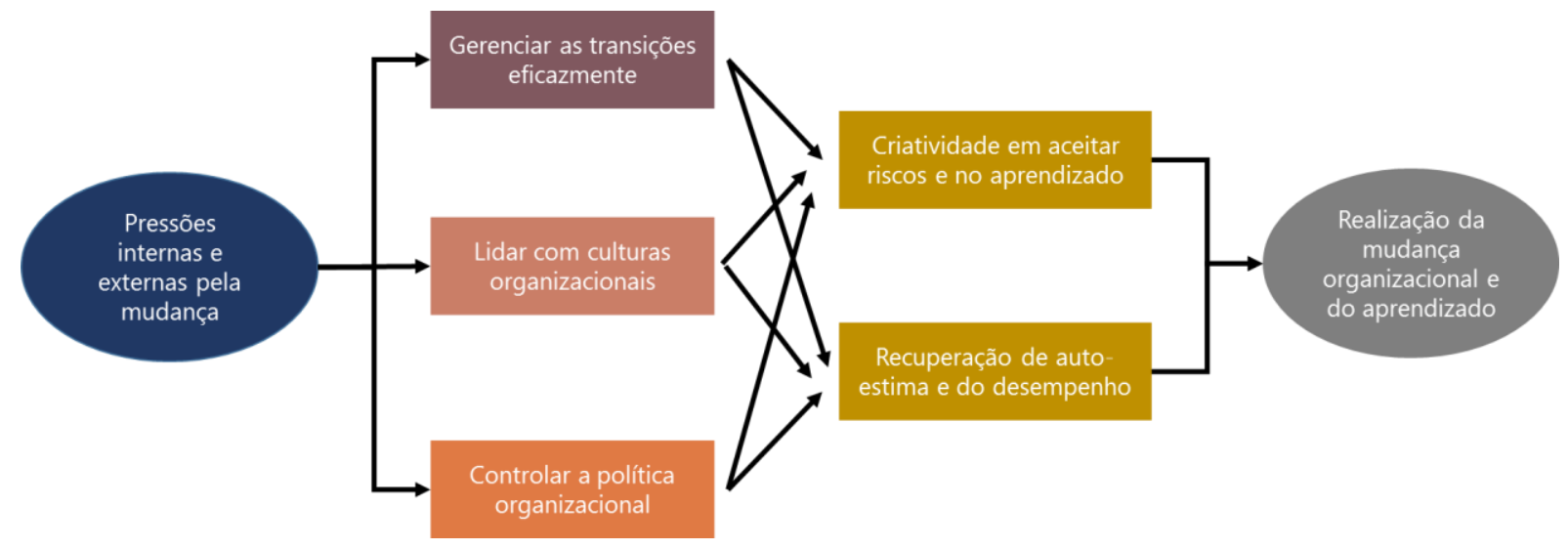

Figura 35 - O modelo de gerenciamento das transições de Carnall

Fonte: adaptado de Carnall (1986) e Cameron e Green (2009)

Com relação às metáforas organizacionais de Morgan (1998), este é um dos modelos que apresenta a maior gama de visões do ponto de vista da organização, por exemplo: compreende a organização como um Organismo por entender que as mudanças são originadas de pressões do ambiente interno ou externo; como um Cérebro por associar a realização da mudança ao aprendizado organizacional, ou seja, um elemento está associado ao outro; embora seja necessário aprofundar-se no momento, o modelo tem uma contribuição relevante para a literatura ao ser o primeiro modelo de mudanças a inserir o aspecto cultural ao inserir a etapa de "lidar com as culturas organizacionais"; por fim, o modelo também enxerga uma organização como um Sistema Político, por tratar da necessidade de gerenciar as transições e também de controlar a política organizacional. 


\section{Modelo 6 - Bridges (1991): Gerenciamento da Mudança}

A princípio um leigo pode julgar este modelo parecido com o modelo das três etapas de Lewin (1951), no entanto, eles possuem propósitos bem distintos, sendo este último modelo citado (Bridges, 1991) mais indicado para mudanças que irão ocorrer inevitavelmente, e o primeiro indicado para mudanças que exijam um planejamento e antecipação. O modelo proposto por Bridges (1991) é ilustrado na Figura 36.

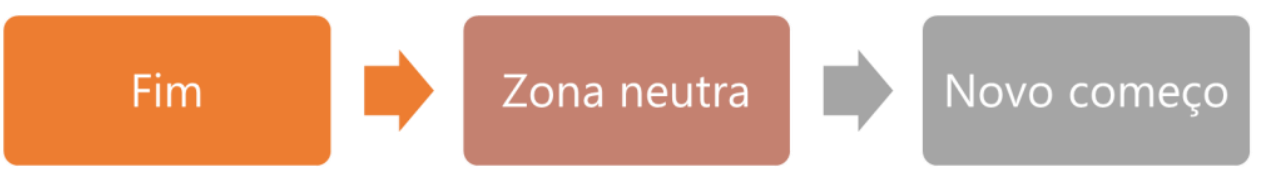

\section{Figura 36 - Modelo de Gerenciamento da Mudança}

Fonte: adaptado de Bridges (1991) e Cameron e Green (2009)

O modelo de Bridges (1991) traz uma primeira etapa bem interessante, o "fim". Isto ocorre pelo fato de que, antes de começar a planejar algo novo, as organizações precisam primeiro terminar de fazer o que já estavam fazendo. E isto faz muito sentido. Depois de terminar o que já estava sendo feito, a segunda etapa do modelo corresponde à "zona neutra". Esta zona neutra remete a um período de desmotivação e ansiedade para que as coisas mudem e seja possível galgar a próxima etapa do modelo: "o novo começo".

De acordo com Bridges (1991), os começos não podem ser previstos ou planejados, e por este motivo também a "zona neutra" muitas vezes não tem uma duração prevista. Na etapa do "novo começo", as pessoas devem: (a) identificar o propósito por detrás da mudança; (b) projetar uma imagem de como a organização será no futuro; (c) elaborar um plano de ações para atingir esta imagem; (d) identificar os resultados esperados pelo processo de mudança.

Para Cameron e Green (2009), este modelo é fundamental quando as organizações se deparam com mudanças inevitáveis, como: mudanças de filiais, fusões e aquisições. Nesse contexto, faz sentido a existência de etapas como "fim" e "zona neutra". Em outras ocasiões, nas quais exijam uma antecipação de oportunidades ou resposta a ameaças externas, este modelo pode vir a não ser útil por justamente incluir estas duas etapas. Por fim, um outro aspecto interessante do modelo é o fato de justamente propor o "encerramento" da situação atual da organização, de tal maneira a evitar que os colaboradores continuem vivenciando a estado anterior mesmo quando já tiverem passado pelo período de mudanças, este aspecto, 
embora tenha grande impacto do ponto de vista dos agentes de mudança, é pouco trabalhado nos demais modelos (Cameron e Green, 2009).

Com relação às metáforas organizacionais propostas por Morgan (1998), há uma diferença clara entre os modelos de Bridges (1991) e Lewin (1951). O primeiro, está mais associado a mudanças que irão ocorrer inevitavelmente, sendo, portanto, necessário colocar um "fim” nas mudanças que já estão ocorrendo e aguardar uma "zona neutra", para iniciar um "novo começo", portanto, sendo este mais associado a uma visão de Fluxo de Transformação, enquanto o modelo de Lewin (1951) está mais associado à metáfora da Organização como uma Máquina, justamente por englobar mudanças planejadas. Ainda com relação às metáforas organizacionais, a etapa "Zona Neutra" pode ser considerada uma visão da organização como uma Prisão Psíquica, por representar um período de geração e superação de ansiedades e desmotivações, antes de um novo começo. Por fim, a etapa "Novo Começo" tende a enxergar a organização como uma máquina, definindo um propósito e ações para alcançar mudanças.

\section{Modelo 7 - Kotter (1995): O modelo dos oito passos}

Este talvez seja o modelo mais utilizado e divulgado em toda a literatura sobre Gestão de Mudanças. O modelo foi desenvolvido a partir da experiência prática de consultoria em mais de 100 organizações de diversos tamanhos e países diferentes. Antes de apresentar o modelo, Kotter (1995) apresenta as oito lições que foram aprendidas em sua experiência com os projetos de mudança organizacional. Basicamente, o modelo segue oito passos como ilustrado na Figura 37.

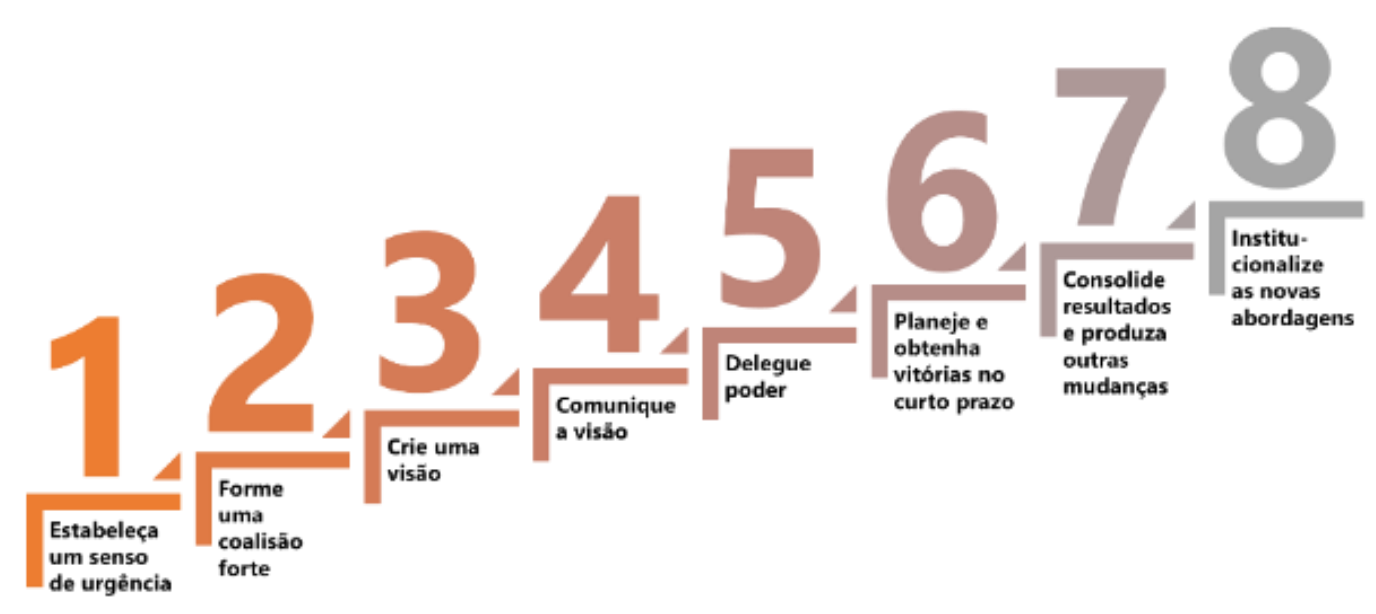

Figura 37 - O modelo dos oito passos de Kotter

Fonte: adaptado de Kotter (1995) e Cameron e Green (2009) 
O primeiro passo envolve o estabelecimento do senso de urgência nas pessoas, ou seja, é discutido os motivadores do processo de mudança de tal maneira a promover a necessidade de mudança nas pessoas. No segundo momento, após estabelecida essa urgência, é definido um grupo de pessoas (coalizão) com poder suficiente para direcionar o processo de mudança. No terceiro passo, esta coalisão é responsável por criar uma visão de onde o processo pretende chegar. Sendo definida esta visão, o quarto passo envolve a comunicação desta visão à organização.

Logo após a comunicação da visão, a coalisão delega poder para que os responsáveis por implementar as mudanças tenham condições para tal, neste momento, são eliminados alguns obstáculos à mudança. O quinto passo envolve a delegação de poder para que as pessoas possam executar a mudança, enquanto o sexto passo envolve o planejamento das mudanças de curto prazo, tendo como foco a obtenção de "quick wins" (resultados de curto prazo), para motivar as pessoas durante o processo de mudança. O sétimo passo envolve a consolidação dos avanços, com recompensa às pessoas e energização do processo com o estabelecimento de novos projetos e novos agentes de mudança. Por fim, o oitavo passo proposto por Kotter (1995) envolve a institucionalização das mudanças já realizadas, de tal maneira a assegurar que os novos comportamentos estabelecidos sejam bem-sucedidos.

Embora este modelo provavelmente seja o mais citado na comunidade acadêmica, Cameron e Green (2009) possuem algumas críticas ao modelo. Para estes autores, o modelo de Kotter (1995) perde "fôlego" no final justamente por potencializar demasiadamente o início. Os autores fazem esta afirmação com base no uso de palavras mais fortes no início, como "urgência", "força" e "visão", conflitando com o uso de palavras mais brandas no final do modelo, tal qual "planejar", "consolidar" e "institucionalizar". Sob este ponto de vista, Cameron e Green (2009) propõe o modelo que chamam de "ciclo da mudança", descrito no final desta seção, o qual segue lógica semelhante à de Kotter (1995). No entanto, é preciso reconhecer que o modelo de Kotter (1995) tem uma relevância e contribuição para a literatura muito superior ao modelo de Cameron e Green (2009), sendo este último extremamente similar ao anterior, e, inclusive, apontando "melhorias" pouco expressivas. Em continuidade aos estudos na área, Kotter (2012) identifica que as organizações muitas vezes possuem uma estrutura organizacional muito rígida (hierarquia), a qual acaba servindo de barreira à implementação de mudanças com uma agilidade maior. Neste caso, o modelo dos oito passos 
pode não ser bem-sucedido justamente devido a esta lenta implementação. Por este motivo, Kotter (2012, p. 28) propõe que as organizações tenham:

“Um segundo sistema operacional dedicado à concepção e à implementação da estratégia - sistema que empregue uma estrutura ágil, em rede, e um conjunto muito distinto de processos. Esse novo sistema operacional avalia continuamente a atividade, o setor e a organização rege com maior agilidade, rapidez e criatividade do que o atual. Complementa, em vez de sobrecarregar, a hierarquia, deixando esta última livre para fazer aquilo que está otimizada para fazer. Aliás, torna a empresa mais fácil de ser administrada e acelera a mudança estratégica”.

Esta nova estrutura, chamada de "Estrutura em Rede", é ilustrada na Figura 38. É importante salientar que esta rede de mudanças não aborda conflitos da política organizacional.

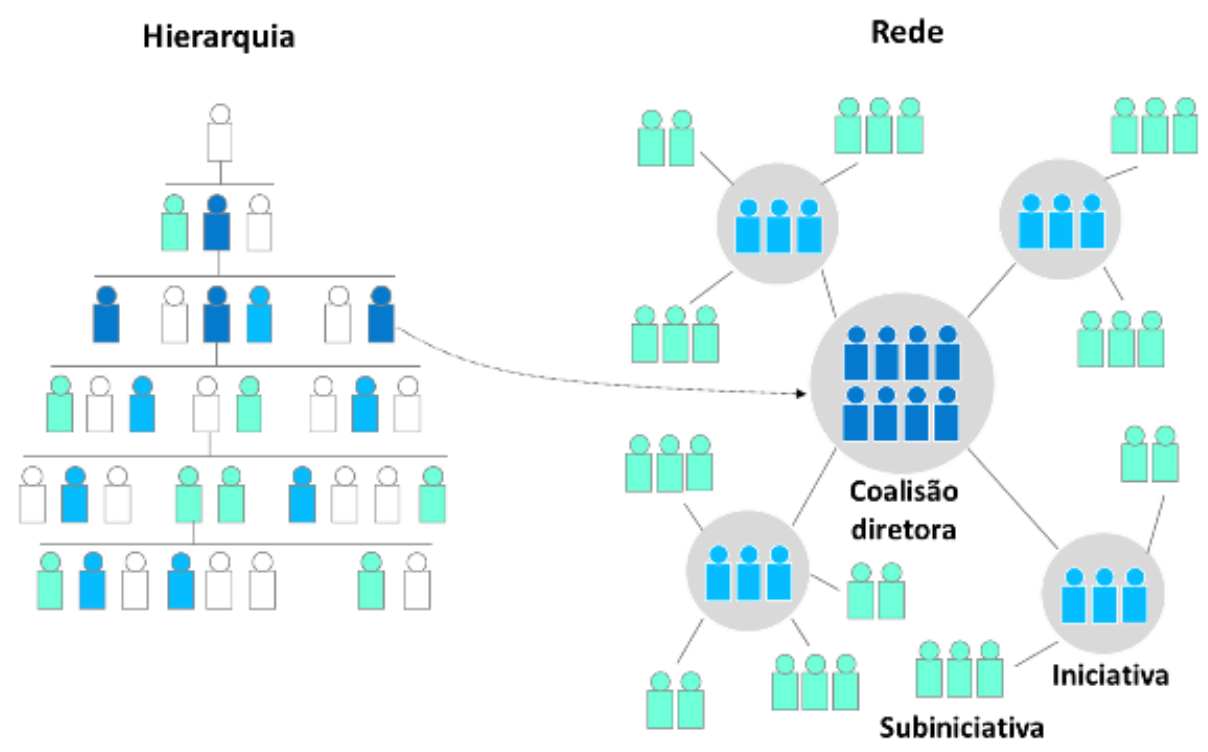

Figura 38 - Estrutura ágil de planejamento e execução de mudanças

Fonte: Kotter (2012)

A partir deste novo conceito de estrutura, Kotter (2012) propõe o que intitula de "Oito Aceleradores - Processos que permitem o funcionamento da rede da estratégia", com pequenas alterações nos nomes das etapas apresentadas no modelo dos "Oito Passos", tendo menos um caráter de reformulação conceitual, mas sim um caráter de "re-branding" do modelo original ao modificar o nome do modelo, dar maior ênfase à necessidade de criar tal estrutura em rede e, inclusive, promover destaque ao primeiro passo do modelo: criar um senso de urgência. $\mathrm{Na}$ 
continuidade deste trabalho, ambos modelos serão referenciados como "Oito Passos do Processo de Mudança".

Com relação às metáforas organizacionais de Morgan (1998), o modelo de Kotter (1995) compreende a organização como uma Máquina, Organismo, Sistema Político e Cultura. A metáfora do organismo está presente no fato do modelo entender que existem “oportunidades" externas, as quais disparam a primeira etapa do modelo (senso de urgência). Por sua vez, a metáfora da Máquina está presente em praticamente todas as outras etapas, envolvendo um planejamento da mudança como um engenheiro projeta uma máquina, envolvendo alguns aspectos de convencimento do ponto de vista político ao tratar de definir uma Visão e Comunicar esta visão, além de buscar "engajar mais pessoas no processo". Inclusive, a etapa "Obter Vitórias de Curto Prazo" pode ser considerada como uma resposta às possíveis barreiras do processo de mudança, ou seja, redução dos potenciais conflitos políticos no processo. Por fim, o modelo de Kotter (1995) apresenta o oitavo passo, "institucionalizar as mudanças na cultura", utilizando-se da metáfora da organização como uma Cultura no último passo do modelo. Portanto, o modelo sugere que as mudanças que forem bem-sucedidas (derem resultados positivos) devem ser institucionalizadas no dia a dia da organização.

\section{Modelo 8 - Nadler e Tushman (1997): Modelo de Congruência}

Ilustrado na Figura 39, o modelo proposto por Nadler e Tushmann (1997) compreende o processo de transformação como a combinação de quatro subsistemas (organizacional informal, organização formal, pessoas e trabalho), os quais devem produzir resultados (desempenho) através de determinadas entradas (estratégia, recursos e ambiente).

O primeiro subsistema do modelo é o "trabalho", o qual se refere às atividades executadas pelas pessoas no dia a dia, envolvendo desde a perspectiva dos processos quanto a remuneração das pessoas. O segundo subsistema são as "pessoas', englobando aspectos técnicos dos colaboradores da organização. Por fim, o modelo trata da organização formal e também da organização informal. A primeira organização remete à estrutura organizacional propriamente dita, aos sistemas e políticas da organização. Por sua vez, a organização informal trata de questões "não declaradas", como poder, influência, valores e normas de conduta.

Dentre os modelos de mudança, este é o modelo mais semelhante aos Modelos de Excelência apresentados na seção “3.1. Gestão de Operações”, principalmente quando comparamos com o EFQM, o MBNQA e o Modelo 7S. Segundo Cameron e Green (2009), isto 
pode ocorrer devido ao fato deste modelo compreender o processo de transformação como a interação de sistemas abertos, considerando a organização como um sistema aberto que sofre influência de fontes internas e externas e produz resultados.

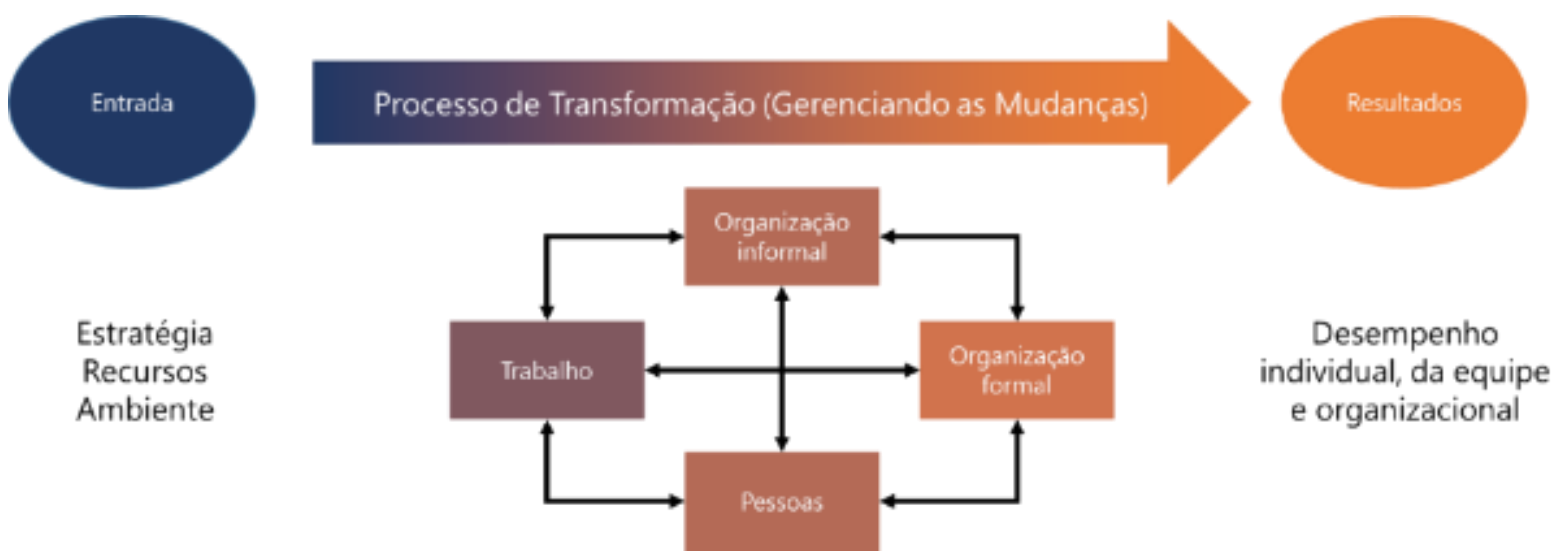

Figura 39 -O modelo da congruência de Nadler e Tushman

Fonte: adaptado de Nadler e Tushman (1997)

Ao invés de ser um modelo para classificar o processo de mudança, este modelo serve para organizar o pensamento dos agentes de mudança, observando aspectos gerenciais, técnicos, sociais e estratégicos. Cameron e Green (2009) tecem uma crítica pertinente ao modelo: este modelo tem foco demasiado nos problemas, não promovendo a construção de uma visão de situação futura e não definindo metas a serem atingidas. Por este motivo, Cameron e Green (2009) sugerem o uso do Modelo 7S ao invés do Modelo de Congruências de Nadler e Tushman (1997), pois ambos utilizam sistemas interligados.

Com relação às metáforas organizacionais propostas por Morgan (1998), é possível considerar este modelo como compreendendo as organizações como um Organismo, por entender que existem entradas ao processo de mudança - estratégia, ambiente e recursos -, como um Sistema Político envolvendo Pessoas, Trabalho Formal e Informal, e também como um Fluxo de Transformação por envolver a combinação de interligados que sofrem influência de um contexto mais amplo.

\section{Modelo 9 - Senge et al (1999): Modelo Sistêmico}

Senge et al. (1999) abordam uma questão complementar a todos os modelos apresentados anteriormente, os autores discutem como o processo de sustentar uma mudança profunda é tão difícil, e quais seriam as causas disto. Nesse sentido, falam em "forças de 
resistência" ou "forças de compensação", as quais agem no sentido de manter o status quo da organização, sendo estas forças oriundas de comportamentos da gestão. O modelo proposto por Senge et al. (1999) não apresenta soluções prontas ou dá métodos de "como fazer", mas sim traz diversas reflexões, ideias e sugestões sobre como lidar com as forças compensadoras da organização (Cameron e Green, 2009).

Em sua essência, o Modelo Sistêmico compreende a organização como um Fluxo de Transformação, ou seja, a organização é vista em um contexto mais amplo, envolvendo conflitos, paradoxos, caos e mudanças constantes no ambiente. Inclusive, pode ser considerado que o modelo também contemple as metáforas da organização como um Organismo e como um Cérebro, por entender que existe uma necessidade de adaptação com relação ao ambiente externo, e também por tratar da importância de promover o aprendizado organizacional.

\section{Modelo 10 - Sirkin et al. (2005): The DICE Model}

Segundo Sirkin et al. (2005), para garantir o sucesso da implementação de mudanças, além de prestar atenção a fatores soft do processo de mudança, é preciso gerenciar adequadamente os aspectos hard através da gestão de quatro elementos: duração (duration), integridade (integrity of performance), compromisso com a mudança (commitment to change) e esforço (effort). Estes fatores foram propostos a partir da análise de mais de 1000 iniciativas de mudança durante 11 anos de projetos do the Boston Consulting Group (BCG). As questões relacionadas aos fatores do modelo são:

○ D-Duração: o projeto possui revisões regulares? Se o projeto terá mais de dois meses para ser finalizado, qual é o tempo médio de revisão?

○ I - Integridade de Performance: o líder do projeto tem habilidade suficiente para atingir os objetivos do projeto? Quão fortes são as motivações e habilidades da equipe? A equipe possuí tempo suficiente para investir no projeto?

○ Ci - Comprometimento da alta gestão: a alta gestão comunica regularmente a importância do projeto? A mensagem é convincente? A mensagem é consistente entre os membros da alta administração e frequente ao longo do tempo? A alta gestão tem colocado os recursos necessários para o sucesso do projeto?

- Cii - Comprometimento do nível operacional: os colaboradores que serão afetados diretamente pela mudança compreendem o motivo pelo qual as mudanças são necessárias? Eles valorizam e acreditam neste motivo? A 
mudança irá valer a pena para estes colaboradores? Eles estão entusiasmados e oferecem suporte para que as mudanças sejam bem-sucedidas?

○ $\boldsymbol{E}$ - Esforço: qual é o esforço médio que os colaboradores devem fazer para que as mudanças ocorram? Será necessária uma carga de trabalho extra? As pessoas têm resistido historicamente às demandas de mudanças solicitadas?

Estes fatores e questões são analisadas de acordo com um conjunto de respostas possíveis e, para cada fator, são distribuídos de um a quatro pontos. A fórmula para calcular a Pontuação DICE (DICE Score) está ilustrada na Figura 40, sendo possível obter até 20 pontos.

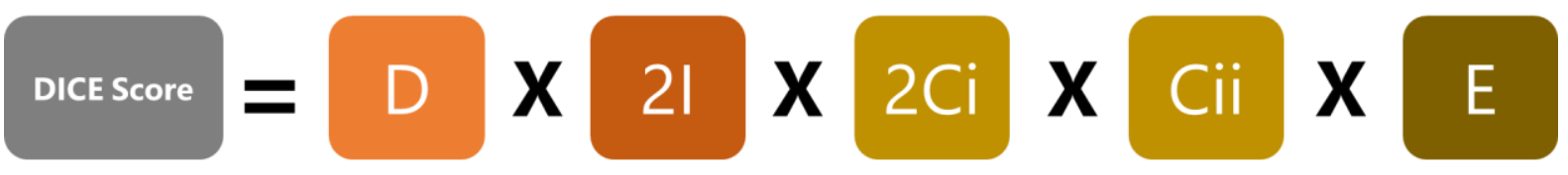

\section{Figura 40 - DICE Model}

Fonte: Sirkin et al. (2005)

Projetos que tenham entre 7 e 14 pontos são considerados como "tendência de serem bem-sucedidos (win zone)", projetos entre 14 e 17 são considerados como "projetos de risco" (worry zone), e projetos acima de 17 pontos são considerados como "risco extremo" (woe zone) e, portanto, devem ser gerenciados com maior atenção.

\section{Modelo 11 - Cameron e Green (2009): Ciclo de Mudanças}

Cameron e Green (2009) fazem um excelente trabalho de revisão dos modelos de Gestão de Mudança, mas, no entanto, carecem de profundidade na proposição de um modelo próprio. Basicamente, os pesquisadores baseiam-se no modelo dos Oito Passos de Kotter (1995), e fazem uma mudança pequena para construírem o seu modelo intitulado de "Ciclo de Mudanças".

Cameron e Green (2009) apenas agruparam os dois últimos passos do modelo de Kotter (1995) em um único passo - o que antes era "consolidar os resultados e produzir outras mudanças" e "institucionalizar as novas abordagens" passou a ser apenas "consolidar" -, e simplesmente modificaram os nomes dos passos anteriores alegando dar maior "força" nas últimas etapas do modelo - por exemplo, passou-se a utilizar palavras como "energizar" ao final do modelo de mudanças. Cameron e Green (2009) preferem ilustrar o modelo como um 
processo de ciclo contínuo e não linear. No entanto, embora Cameron e Green (2009) façam algumas críticas ao modelo de Kotter (1995), este trabalho considera tais críticas pouco relevantes, afinal, o modelo de Kotter (1995) possui mais citações e relevância científica quando comparado ao de Cameron e Green (2009). O modelo proposto e utilizado por Cameron e Green (2009) em projetos de mudança é ilustrado na Figura 41.

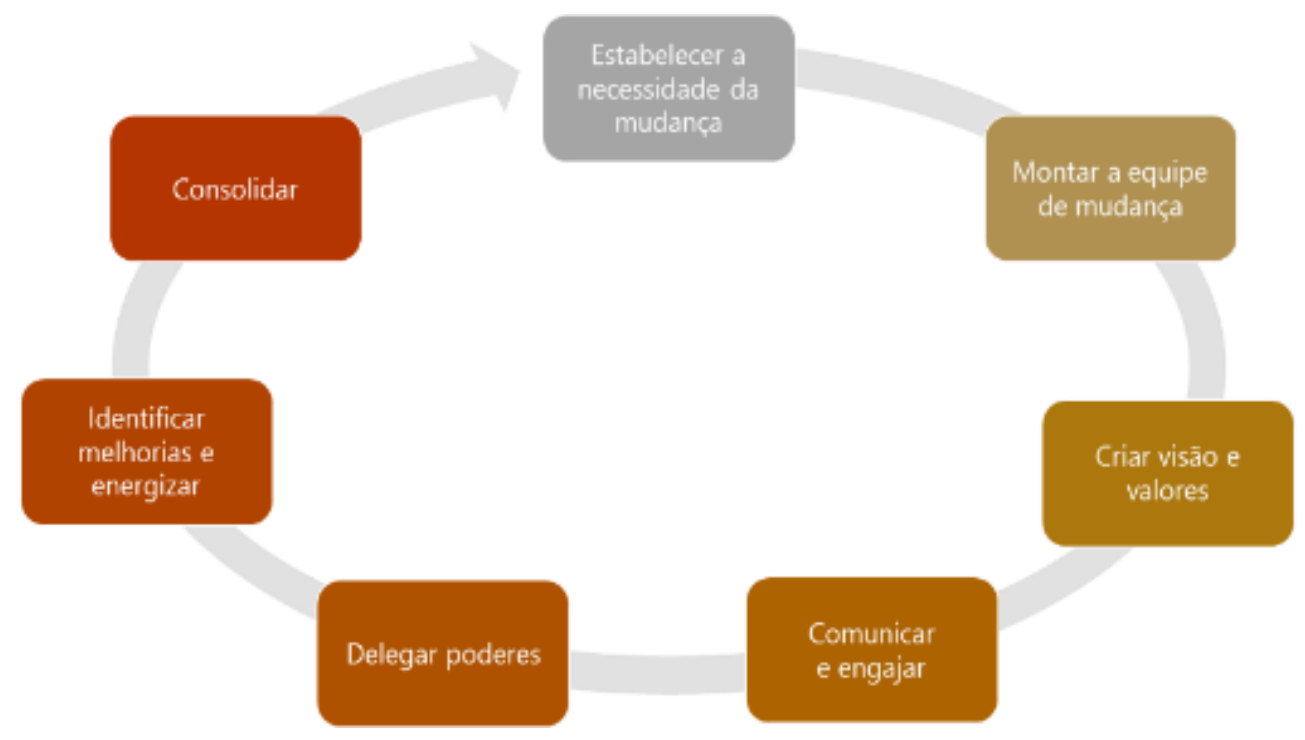

Figura 41 - O ciclo da mudança de Cameron e Green

Fonte: Cameron e Green (2009)

\subsubsection{Melhores práticas de mudança organizacional}

Kandt (2006) é um dos poucos autores que cita princípios e boas práticas de Gestão de Mudanças para beneficiar projetos de Transformação. Embora Kandt (2006) dê ênfase a projetos de implementação de softwares, muitos dos princípios e práticas listadas podem também ser interessantes em diversos outros projetos de transformação.

Princípio 1: os processos de negócio devem dar suporte às necessidades do negócio;

Princípio 2: a organização deve possuir pessoas que sejam capazes de executar e dar suporte aos processos de negócio de maneira bem-sucedida;

Princípio 3: os esforços de mudança devem ser planejados para otimizar o retorno sobre o investimento e também reduzir riscos;

Princípio 4: medição dos processos e da qualidade dos produtos; 
Associado a estes princípios, Kandt (2006) descreve 24 melhores práticas de Gestão de Mudanças que dão suporte às organizações no estabelecimento, execução, monitoramento e controle dos esforços de mudança de softwares. Estas boas práticas de gestão de mudanças são:

\section{* Práticas de Definição / Planejamento}

- Prática 1: faça um alinhamento dos objetivos do esforço de mudança com a estratégia organizacional;

- Prática 2: adquira e mantenha o comprometimento da alta direção;

- Prática 3: crie e mantenha um time de change de alto nível;

- Prática 4: avalie o desejo da organização em querer mudar;

- Prática 5: os times de mudança devem ser instrumentos da mudança;

○ Prática 6: planeje para que ocorram melhorias continuas;

\section{* Práticas de Execução}

- Prática 7: promova uma necessidade urgente para que as mudanças ocorram;

- Prática 8: selecione os processos que precisam mudar de acordo com aqueles processos que têm gerado os maiores retornos de investimento e que possuem o menor risco associado;

- Prática 9: mude no máximo três processos durante um esforço de mudanças;

- Prática 10: estabeleça uma visão para cada processo que precisa ser modificado;

- Prática 11: desenvolva uma compreensão do cenário atual do processo;

- Prática 12: entenda os riscos envolvidos e gere os planos de contingências;

- Prática 13: avaliar as entregas do projeto de acordo com o processo planejado, buscando eliminar ou minimizar os problemas que surgirem;

\section{* Práticas de Monitoramento}

○ Prática 14: selecione e utilize métricas apropriadas;

- Prática 15: faça uma avaliação anual dos processos e realize benchmarking;

- Prática 16: meça continuamente a produtividade das pessoas;

- Prática 17: faça uma análise de portfólio dos sistemas de software e aplicações que a empresa possui;

○ Prática 18: faça uma avaliação dos projetos de software já realizados; 


\section{* Práticas gerais}

○ Prática 19: promova na organização um compromisso para com as mudanças;

○ Prática 20: tenha uma comunicação eficiente;

- Prática 21: a alta gestão deve estar ativamente envolvida;

- Prática 22: ouça o ponto de vista do cliente;

- Prática 23: mantenha a estrutura alinhada;

○ Prática 24: promova um ambiente de criação e inovação;

Apenas as práticas 13, 17 e 18 são bem específicas da implementação de softwares, sendo as demais abrangentes o suficiente de tal maneira a contemplarem outros projetos de transformação.

\subsubsection{Evolução e mudança da Cultura Organizacional}

Com o objetivo de melhorar o desempenho e adaptar-se no mercado de atuação, existem dois caminhos para uma empresa mudar (Archier e Sérleyx, $1989{ }^{17}$ apud Shinyashiki, 1995): (1) imaginar soluções originais, desenvolvê-las e testá-las ou (2) realizar um benchmarking identificando as melhores práticas que já foram bem-sucedidas em outras empresas.

No entanto, ambas abordagens possuem suas limitações. Por exemplo, o primeiro caminho (soluções originais) tem uma limitação com relação ao planejamento e desenvolvimento das mudanças, os quais precisam ser mediados pela cultura organizacional (Schein, 2009). Por sua vez, a segunda abordagem tem sua limitação na dificuldade de implementar teorias e práticas desenvolvidas em países com uma cultura distinta da cultura organizacional (Hofstede, 1987; Shinyashiki, 1995), exemplo: aplicar o Sistema Toyota de Produção, desenvolvido no Japão, em empresas brasileiras. Portanto, em ambas as abordagens, é notório que a Cultura Organizacional irá mudar ou evoluir, de maneira estruturada ou não.

De acordo com Schein (1984), não existe um único modelo de mudança que se enquadra em todas as organizações, sempre, será preciso compreender a cultura organizacional e a dinâmica evolutiva da organização.

${ }^{17}$ ARCHIER, G.; SÉRIEYX, H. (1989). A empresa do $3^{\circ}$ tipo. São Paulo, Nobel. 


\section{Perspectiva evolutiva das organizações}

Em termos de evolução das organizações, Schein (1984) distingue três estágios evolutivos com características e funções distintas do ponto de vista da cultura organizacional: (1) Grupo em formação, organização jovem conquistando seu ambiente e com alta influência do fundador; (2) Organização na meia-idade, em fase de mudanças e questionamento de seu posicionamento no ambiente; (3) Organização madura, mais estável em seu ambiente.

Estes estágios são descritos baixo e ilustrados na Figura 42.

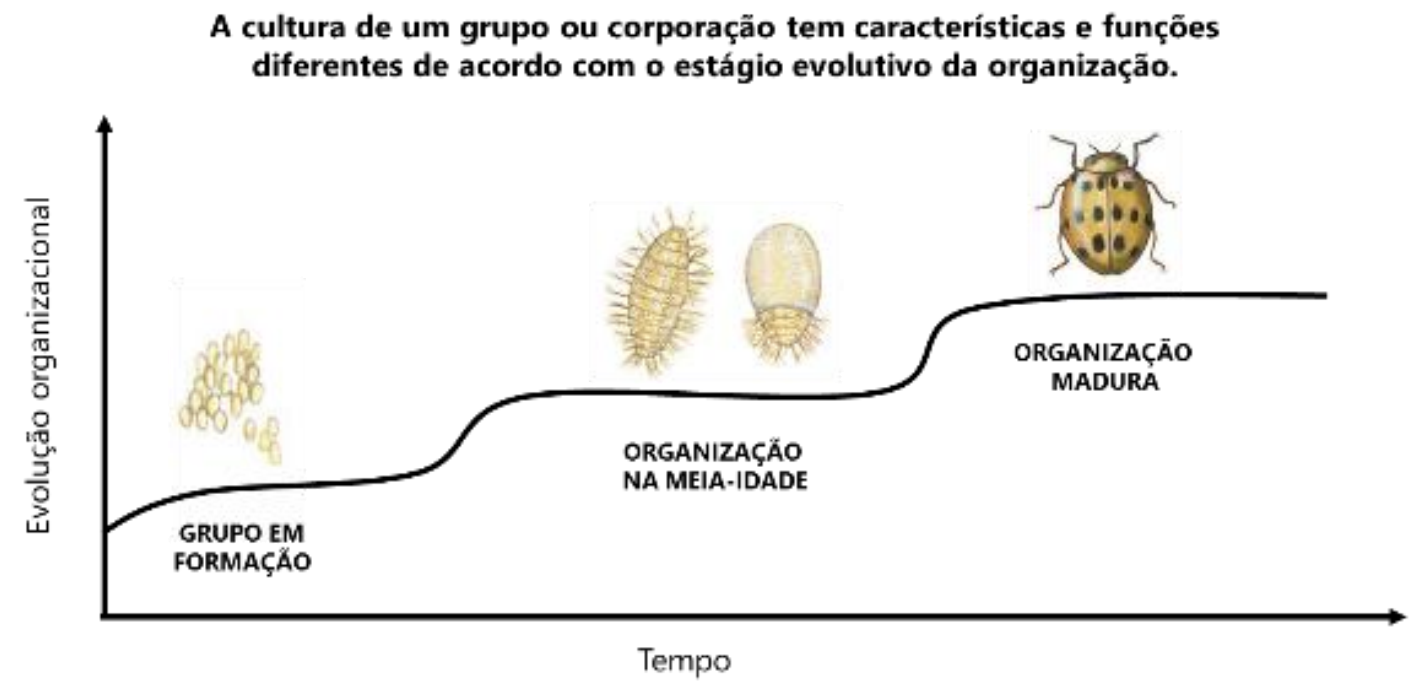

Figura 42 - Perspectiva evolutiva de mudança e gestão da cultura organizacional

Fonte: adaptado de Schein (1984)

- Estágio 1: Grupo em formação: segundo Schein (1984), neste estágio a cultura organizacional tem como função promover a "identidade" que mantém o grupo unido. As mudanças que ocorrem são articuladas pelo fundador, e se não forem adaptáveis ao ambiente externo, a empresa não irá sobreviver. Mesmo que alguém (na empresa) identifique as mudanças necessárias, as chances de mudar a cultura são pequenas.

- Estágio 2: Organização na meia-idade: a cultura pode ser modificada ou gerenciada, mas desde que sejam identificadas as fontes de estabilidade da cultura atual (Schein, 1984). Neste estágio evolutivo, a organização já começa a ter mais departamentos e unidades, e começa a enfrentar o conflito de ser mais estável ou conquistar maior flexibilidade, de ter maior foco interno ou externo. Segundo Schein (1984), neste 
estágio faz-se necessário uma intervenção externa para que haja maior compreensão da cultura atual, no intuito de aprimorar a eficácia da tomada de decisões estratégicas.

- Estágio 3: Organização madura: neste estágio, o mercado e os produtos já estão mais maduros ou já existe um elevado grau de estabilidade (Schein, 1984). As mudanças que ocorrerem serão sempre dolorosas. Não existirá um único modelo de mudança, será necessário utilizar uma variedade de técnicas para modificar algumas partes da organização (Schein, 1984).

A força de uma cultura é formada pela duração do tempo em que um grupo está junto, e também pela intensidade das experiências compartilhadas pelo grupo, portanto, uma organização que tiver uma cultura e uma liderança fortes (coalisão), por exemplo, possui uma chance baixa de mudar sua cultura somente com a entrada (seleção) de novos membros (Schein, 1984). Afinal, a coalisão atual será tão forte que servirá de resistência às mudanças que os novos membros tentem promover. Schein (1984) cita o exemplo das organizações militares: recebem novos membros todo e ano, com mentalidades e comportamentos muitas vezes diferentes e, ainda assim, continuam possuindo uma cultura sólida e forte.

Sob este ponto de vista, Schein (2009) apresenta dois fatores chave para uma evolução ou mudança cultural bem-sucedida: (1) gerenciar o grande volume de ansiedade que acompanha um processo de reaprendizagem deste nível (organizacional), e (2) avaliar se o potencial genético para a nova aprendizagem ainda está presente, ou seja, se a organização terá folego para desaprender e reaprender novamente. Segundo Schein (2009), para entender como uma cultura muda, primeiro, precisamos entender como as culturas são formadas ou criadas. Nesse sentido, o autor propõe seis maneiras pelas quais uma cultura organizacional pode evoluir, sendo influenciada pelos líderes da organização, estas maneiras são:

1. Evolução na qual a organização naturalmente se adapta ao ambiente;

2. Evolução específica das equipes dentro da organização;

3. Evolução dirigida através das percepções culturais por parte dos líderes;

4. Evolução através do encorajamento das equipes em aprenderem umas com as outras, ou seja, as subculturas aprendem com aquelas que estão mais adaptadas a determinado momento da organização;

5. Mudança planejada e administrada através da criação de sistemas paralelos de direcionamento e com forças tarefas orientadas a projetos; 
6. Destruição total ou parcial com a entrada de uma nova liderança na organização (falência, mudança de rumo, reestruturação, etc.);

Diversos autores (Spear, 2004; Black, 2007; Bhasin, 2012a) reconhecem que as equipes internas da empresa possuem as pessoas mais bem preparadas para realizarem uma evolução ou mudança cultural. Com base em suas experiências, Cameron e Green (2009) reúnem algumas diretrizes para abordar os problemas da evolução ou mudança cultural, de tal maneira a objetivar uma mudança cultural bem-sucedida. Primeiramente, é imprescindível fazer uma ligação com a visão, missão e objetivos organizacionais, uma evolução ou mudança cultural como um objetivo isolado não faz sentido, uma organização somente deve objetivar uma mudança cultural quando a cultura atual não for capaz de sustentar adequadamente a realização dos objetivos estratégicos (Cameron e Green, 2009). Quanto maior o número de membros da organização atraídos no sentido desta visão, convencidos por uma visão inspirada e não compelidos de uma maneira coerciva, maior será a probabilidade de uma evolução ou mudança cultural bem-sucedida.

Inclusive, é necessário criar um sentido de urgência e reforçar continuamente a necessidade de mudança (Rentes, 2000; Cameron e Green, 2009). Em muitos casos, a introdução de um elemento estranho, resultado de uma fonte externa ou interna, no sistema organizacional, pode vir a ser uma boa maneira de realizar uma mudança. Na Figura 43 é retratado o modelo psicodinâmico de Satir et al. (1991) apud Cameron e Green (2009), com ênfase em mudanças individuais em ambientes familiares, o qual retrata a introdução deste elemento estranho com o objetivo de almejar uma mudança.

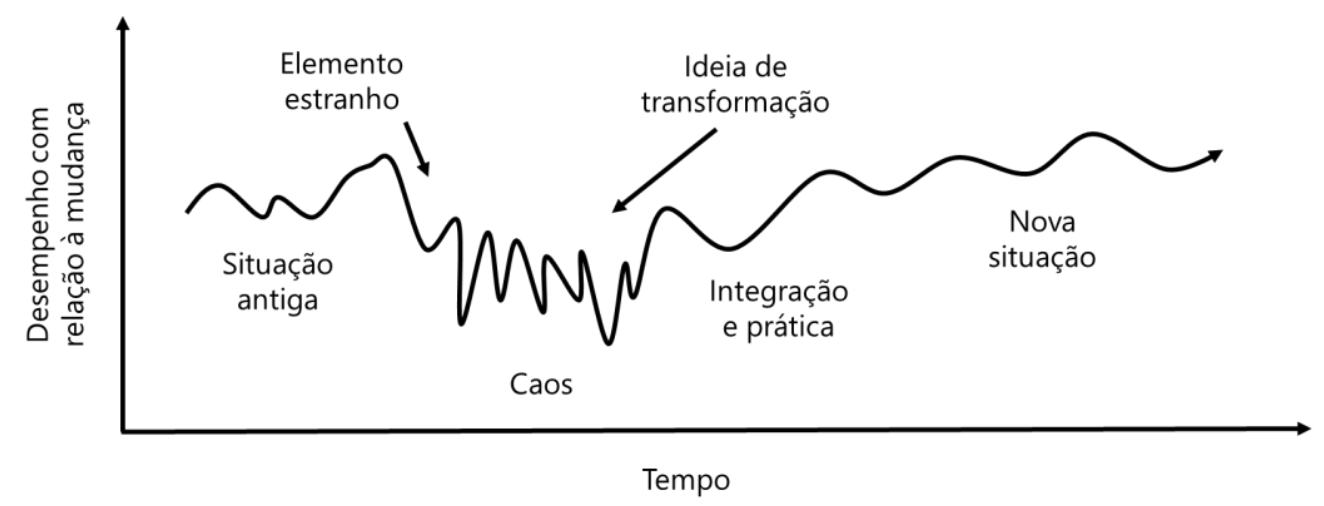

Figura 43 - O modelo psicodinâmico de Virgina Satir

Fonte: Satir et al. (1991) apud Cameron e Green (2009) 
Este elemento estranho pode ser o início de um problema novo, uma doença ou, no mundo corporativo, pode ser um novo diretor ou executivo-chefe com ideias de reestruturação, uma equipe de consultoria interna ou externa com desejo de reformular processos, seja o que for, este elemento deve ter a força necessária para fazer iniciar o processo de evolução ou mudança cultural, como também é preciso que sejam estruturados planos e processos de implantação concisos e transparentes para não permitir que o andamento da mudança seja interrompido (Cameron e Green, 2009). No modelo psicodinâmico de mudanças de Satir et al. (1991, apud Cameron e Green, 2009), ilustrado na Figura 43, desempenho está relacionado com desempenho das pessoas em relação à mudança, e não atrelado a desempenho organizacional. Desta maneira, modelo de Satir et al. (1991), é possível notar que na situação antiga há certa resistência em aderir à mudança e, com a inserção de um elemento estranho, inicia-se um momento de "caos", no qual as pessoas passam a questionar a mudança, surgindo elementos de raiva e desorganização.

Porém, é neste período de caos que surge a ideia transformadora, um entendimento com a realidade da situação e um sentido de aceitação da necessidade de mudança e, a partir do momento em que esta ideia transformadora é compreendida pelas pessoas, a mudança vai progressivamente estendendo-se pela organização. $\mathrm{Ou}$ seja, neste momento, as responsabilidades pela mudança são por todos, os novos objetivos e processos são compreendidos e, como consequência, os resultados da mudança são atingidos e uma nova situação surge. Assim, as diretrizes de Cameron e Green (2009), para uma mudança cultural bem-sucedida, são as seguintes:

1. Considere os problemas dos interessados: é preciso responder às perguntas: até que ponto as mudanças propostas vão beneficiar os interessados no processo? Os stakeholders (clientes, parceiros, equipes e fornecedores) vão de fato sentir uma melhoria positiva? Se algumas partes forem prejudicadas, como estas irão reagir a esta mudança negativa? É de extrema importância considerar os problemas das pessoas dentro do escopo da mudança, de tal maneira que estas sejam envolvidas ao máximo no processo, pois, caso contrário, não importa as razões ou objetivos da mudança, caso esta seja conduzida de modo incorreto, ofensivo ou mal planejado, se voltará contra a própria organização. 
2. Lembre-se de que o "como" é tão importante quanto o "que": a cultura organizacional está relacionada com a maneira pela qual as coisas são realizadas na organização, ou seja, se uma empresa tem um conjunto de valores intrínsecos, consequentemente a gestão da mudança cultural deve estar alinhada com tais valores. Um valor estabelecido, como "ética", "transparência" ou "trabalho em equipe", por exemplo, torna-se inútil se os agentes da mudança, ou um executivo-chefe, não cumprirem o prometido, ou não explicarem claramente as razões pelas quais o planejamento sofreu modificações.

3. Apoie-se no velho e construa o novo: toda cultura, assim como toda pessoa, tem seus pontos positivos e negativos. Consequentemente, no processo de gestão da mudança cultural, é preciso assegurar a permanência dos aspectos positivos da cultura vigente.

4. Desenvolva mecanismos favoráveis à mudança: para sustentar os valores, objetivos e comportamentos da nova cultura organizacional, é preciso desenvolver mecanismos favoráveis à mudança, como exemplo, Cameron e Green (2009) sugerem a criação de sistemas de remuneração, controle do planejamento e desempenho. Ou seja, é preciso fazer com que os membros da organização tenham objetivos claramente definidos e estejam alinhados com os objetivos organizacionais.

5. Aja como um modelo a ser imitado: é fundamental que os agentes da mudança sejam o exemplo dos novos valores, agindo como modelos a serem seguidos. Ainda, é preciso que estes agentes da mudança também deem o suporte necessário às pessoas e equipes durante a mudança, principalmente nos períodos de caos, confusão, preocupação e solução de problemas. Cameron e Green (2009) sugerem que sejam adotadas algumas estratégias específicas para mudança individual e mudança de equipe.

6. Crie uma comunidade de líderes direcionados e flexíveis: durante o processo de mudança, é preciso que haja não apenas clareza dos objetivos finais, mas também capacidade de liderança e gerenciamento para superação dos problemas que surgirem. De acordo com Cameron e Green (2009), muitos membros da organização esperam uma liderança bem definida, confiante e direcionada durante o período de mudanças, mas, por outro lado, também desejam líderes que reflitam “o que está acontecendo lá embaixo" e, paralelamente, ajustem seus planos de acordo as necessidades. 
7. Insista na responsabilidade coletiva pela mudança: um erro comum no processo de gestão da mudança cultural é transformar o departamento de Recursos Humanos no responsável pela mudança cultural, enquanto o executivo-chefe e os diretores são responsáveis pela mudança na estratégia comercial (Cameron e Green, 2009). Ou seja, para os autores, a decomposição funcional de uma mudança cultural está destinada ao fracasso, pois distancia os diretores dos problemas culturais, de tal maneira a negligenciar sua responsabilidade como modelo a ser seguido. Mesmo que as ideias iniciais acerca da necessidade de mudança estejam corretas, a mudança cultural pode fracassar caso o processo de mudança não seja corretamente conduzido.

Nesse processo, os gerentes devem seguir uma estratégia de coerência entre os objetivos da empresa e o sistema social, de tal maneira que os indivíduos, ao internalizarem os novos valores da empresa os apliquem como uma maneira de autocontrole, estes mesmos valores também podem ser aplicados a grupos, como por exemplo nos times de desenvolvimento de produtos (Buschgens, Bausch e Balkin, 2011). Quando novos gestores assumem cargos de poder, estes precisam reconhecer, também, que a renovação de seu compromisso constante para com os valores organizacionais, é a base para o sucesso do sistema produtivo como um todo (Cole, 2011). A alta direção é responsável por promover as melhores práticas, manter o foco nos processos produtivos, solucionar problemas destes processos, garantir a flexibilidade, a efetiva socialização dos novos colaboradores com os valores da organização e fornecer o devido suporte à cultura organizacional. A pesquisa de Fronda e Moriceau (2008) identificou que no processo de mudança irão existir conflitos caso a média gerência não seja devidamente envolvido no processo de mudança.

Embora exista uma literatura sobre mudança de cultura e outra sobre programas de melhoria contínua ou projetos de transformação, a literatura conjunta destas áreas ainda está demasiadamente ampla e distante, em outras palavras, não existe ainda uma sistematização que dê suporte e ao mesmo tempo promova o alinhamento da mudança ou evolução da cultura organizacional com os programas de melhoria contínua. Até o momento, o autor apenas reconhece que antes da implantação de qualquer técnica ou ferramenta de Melhoria Contínua, é necessário obter uma cultura favorável à jornada - a menos que a cultura da organização seja capaz de sustentar comportamentos adequados à implantação (Liker, 2005). Para Ohno (1988), nas fases iniciais da jornada de Melhoria Contínua, deve ser reforçado a todos da organização que o processo de implantação não se trata apenas de ferramentas e técnicas, mas sim está 
relacionada com o comportamento, atitude e comprometimento de todas as pessoas da organização. Para Liker (2005), é importante que exista um "Sensei" nesse processo de mudança cultural, uma pessoa que, além de ser o agente responsável pela mudança, é capaz de compreender o sistema como um todo de maneira imparcial. Para Lee (2007), por exemplo, o engajamento e a capacitação dos funcionários da organização são absolutamente vitais para o sucesso da implantação.

Todos estes autores parecem estar corretos, no entanto, as opiniões e pontos de vistas parecem isolados do todo. Parece não haver um processo sistematizado de como o "Sensei", as pessoas da organização ou o agente responsável pelo processo de mudança devam, de fato, conduzir este processo. Ao rever a literatura em questão, a segunda recomendação de Cameron e Green (2009), sobre o processo de mudança de cultura bem-sucedido, parece ainda não ter sido devidamente explorada neste contexto: lembre-se que o "como" é tão importante quanto o "o que". Na literatura sobre mudança de cultura envolvendo os programas de melhoria contínua, muito se tem discutido "o que" é necessário, e pouco se sabe sobre o "como".

\subsection{ESTUDOS DE CASO LEVANTADOS}

Esta seção tem um objetivo diferente com relação às seções anteriores deste trabalho. As seções anteriores revisaram “o que já é conhecido "em caráter teórico, ou seja, quais são os conceitos e modelos já publicados. Como ilustrado na Figura 44, esta seção busca agregar uma visão diferente sobre "o que é praticado", ou pelo menos publicado, em termos de aplicação prática do Processo de Transformação envolvendo Projetos de Lean.

Embora esta análise careça de profundidade de discussão, justamente por envolver diversos estudos de caso, ela se faz importante para agregar um olhar sobre o ponto de vista dos gestores e pesquisadores. Primeiro, sob o ponto de vista dos gestores e consultores, visa identificar características de como os projetos de transformação ocorrem - ou pelo menos são tratados -, e, em um segundo momento, sob o ponto de vista dos pesquisadores, busca identificar qual é a visão e a amplitude de análise. Desta maneira, espera-se melhorar a revisão deste trabalho com o estudo destes casos.

Os principais estudos de caso encontrados na revisão sistemática e exploratória, ao invés de serem distribuídos nas três seções anteriores (Gestão de Operações, Cultura Organizacional e Gestão de Mudanças), são consolidados e brevemente discutidos nesta seção. 
Para efeito de síntese e análise, os diversos casos encontrados são organizados em três categorias de análise ("lentes do pesquisador"): a) projeto de transformação, b) cultura organizacional, c) estratégia organizacional e d) processo de transformação com evolução ou mudança cultural. Os critérios desta classificação estão descritos no Quadro 22.

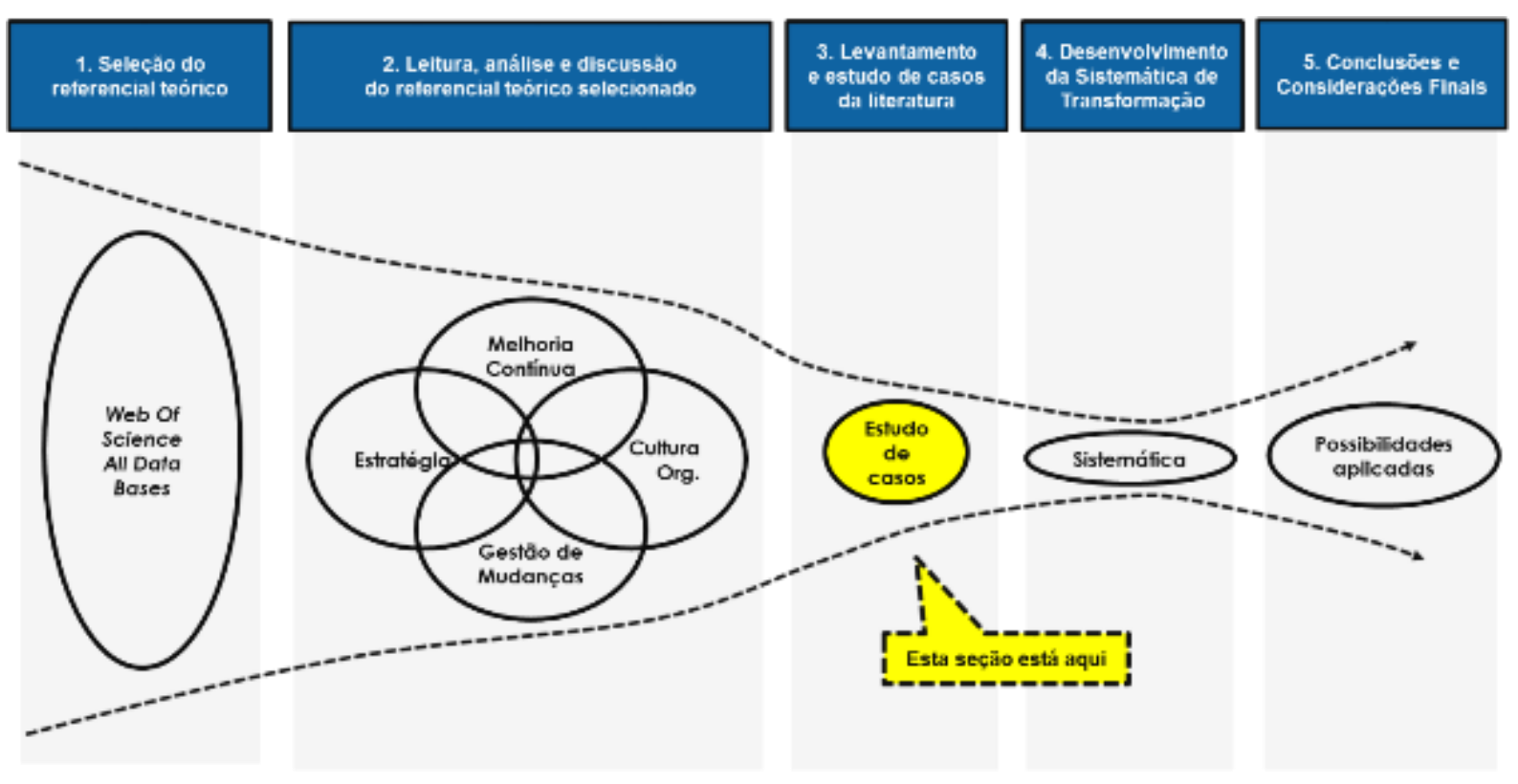

Figura 44 - Estrutura do texto de revisão dos estudos de caso da literatura

Dos 190 artigos inicialmente levantados pela Revisão Bibliográfica Sistemática deste trabalho, foram levantados 15 estudos de casos presentes em 16 artigos, existindo uma única sobreposição de discussão sobre o mesmo estudo de caso entre os autores Wilms, Hardcastle e Zell (1994) e Shook (2010), pois o último autor retoma a discussão sobre a joint venture da GM e Toyota em um artigo com caráter histórico para as empresas.

Tipos de classificação dos estudos de caso

\begin{tabular}{|c|c|c|c|}
\hline $\begin{array}{c}\text { Projeto de } \\
\text { Transformação (hard) }\end{array}$ & $\begin{array}{c}\text { Cultura } \\
\text { Organizacional (soft) } \\
\end{array}$ & $\begin{array}{c}\text { Estratégia } \\
\text { Organizacional (hard) } \\
\end{array}$ & $\begin{array}{l}\text { Evolução e Mudança } \\
\text { Cultural (soft) }\end{array}$ \\
\hline $\begin{array}{l}\text { Descrição do processo } \\
\text { de transformação: quais } \\
\text { são os projetos e ações } \\
\text { executados? Qual o } \\
\text { objetivo destas ações e } \\
\text { projetos? Como estas } \\
\text { iniciativas foram } \\
\text { executadas? }\end{array}$ & $\begin{array}{l}\text { Diagnóstico ou análise da } \\
\text { cultura: quais são as } \\
\text { crenças e valores da } \\
\text { organização atual? Qual é o } \\
\text { perfil cultural atual } \\
\text { predominante? }\end{array}$ & $\begin{array}{l}\text { Descrição da estratégia: } \\
\text { quais eram os desafios e } \\
\text { objetivos estratégicos? } \\
\text { Onde se pretendia chegar } \\
\text { em termos de estratégia? } \\
\text { Quais ações foram } \\
\text { realizadas nesse sentido? }\end{array}$ & $\begin{array}{l}\text { Descrição da evolução ou } \\
\text { mudança cultural: houve } \\
\text { mudança de perfil cultural? } \\
\text { Como era a cultura antes e } \\
\text { como ela é agora? O que } \\
\text { mudou? Quais ações foram } \\
\text { feitas? }\end{array}$ \\
\hline
\end{tabular}

\section{Quadro 22 - Critérios utilizados para a classificação dos estudos de caso}

A Figura 45 ilustra a disposição dos 15 estudos de caso de acordo com as quatro classificações apresentadas no Quadro 22. Nesta Figura, é possível identificar a existência de 
praticamente "dois mundos" com visões distintas sobre os estudos de casos em análise. O primeiro mundo, representado pelo olhar dos "Projetos de Transformação" apresenta uma característica mais hard, dando pouca ênfase a questões invisíveis do ponto de vista cultural, como por exemplo de crenças e pressupostos básicos. Foram identificados 4 artigos com este olhar. Já o segundo mundo tem um caráter mais soft, sendo representado por 11 estudos de casos que possuem uma abordagem de análise mais forte do ponto de vista da cultura organizacional, não abordando de maneira concisa questões mais hard.

O fato que chama atenção nesta análise é justamente a existência destes dois mundos de maneira "separada", e, portanto, a ilustração da Figura 45 indica que estes mundos (hard e soft) "pouco se conversam", e, portanto, a análise destes estudos de caso pode repercutir em diferentes vieses de pesquisa. Alguns casos fazem apenas uma descrição do perfil de determinada cultura organizacional, sem fazer menção ao processo de transformação, outros, por sua vez, fazem menção ao processo de transformação sem fazer uma análise de cultura organizacional. Este é, talvez, um dos cernes de discussão deste trabalho, e um dos principais pontos a serem discutidos no desenvolvimento da sistemática proposta. No intuito de direcionar o foco de discussão do trabalho envolvendo aspectos e características intrínsecas de cada um dos 15 estudos de caso, este trabalho optou por fazer uma breve descrição e segmentação dos estudos de caso, apresentada no Quadro 23.

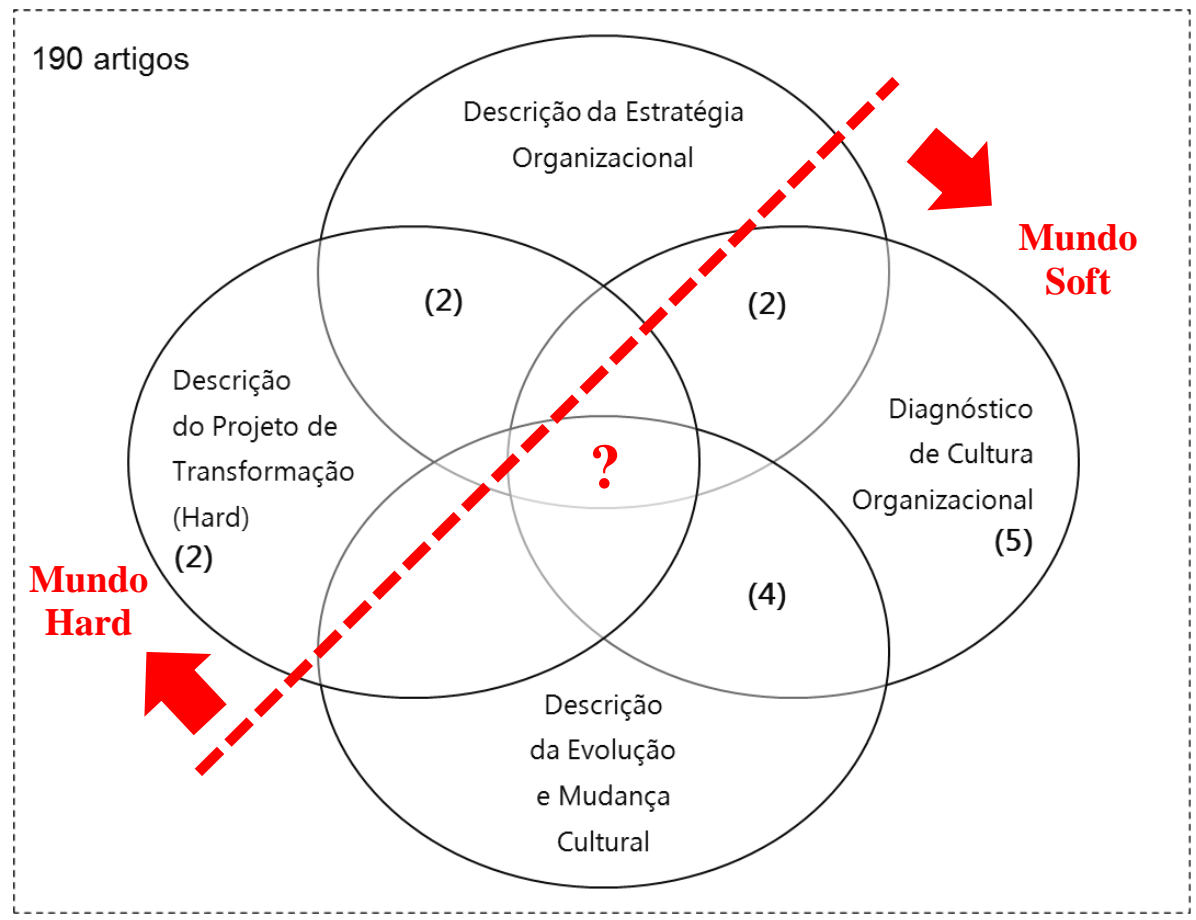

Figura 45 - Segmentação dos estudos de caso (soft versus hard) 


\begin{tabular}{|c|c|c|c|c|c|c|c|}
\hline \multirow[b]{2}{*}{ \# } & \multirow[b]{2}{*}{ Case } & \multirow[b]{2}{*}{ Referência } & \multicolumn{4}{|c|}{ Descrição } & \multirow[b]{2}{*}{ Principais contribuições } \\
\hline & & & $\begin{array}{l}\text { Projeto de } \\
\text { Transformação } \\
\text { (hard) }\end{array}$ & $\begin{array}{c}\text { Cultura } \\
\text { Organizacional } \\
(\text { soft })\end{array}$ & $\begin{array}{c}\text { Estratégia } \\
\text { Organizacional } \\
\text { (hard) }\end{array}$ & $\begin{array}{c}\text { Evolução e } \\
\text { Mudança } \\
\text { Cultural (soft) }\end{array}$ & \\
\hline 1 & GM e Toyota (NUMMI) & $\begin{array}{l}\text { Wilms, Hardcastle } \\
\text { e Zell (1994) e } \\
\text { Shook (2010) }\end{array}$ & - & Sim & - & Sim & $\begin{array}{l}\checkmark \text { Discussão sobre as diferenças culturais entre GM e Toyota; } \\
\checkmark \quad \text { Levantamento das principais práticas de gestão e } \\
\text { comportamentos que levarão à mudança de cultura na planta; } \\
\checkmark \quad \text { Constatação da validade teórica dos modelos de Schein; } \\
\checkmark \quad \text { Apresentação dos principais valores da Toyota; }\end{array}$ \\
\hline 2 & $\begin{array}{l}\text { Hay Management } \\
\text { Consultants }\end{array}$ & $\begin{array}{l}\text { Heracleous e Langham } \\
\text { (1996) }\end{array}$ & - & Sim & - & - & $\begin{array}{l}\text { Aplicação do método Cultural Web para compreensão da } \\
\text { cultura atual e projeção da cultura desejada; }\end{array}$ \\
\hline 3 & $\begin{array}{l}\text { Velden Engineering } \\
\text { Components }\end{array}$ & Irani e Sharp (1997) & - & Sim & Sim & - & $\begin{array}{l}\checkmark \text { Estratégia de "Padronização dos Processos"; } \\
\checkmark \text { Contraponto ao case do Google, pois aqui os Gerentes } \\
\text { acreditam em Padronização, Melhoria Contínua e Inovação; }\end{array}$ \\
\hline 4 & $\begin{array}{l}\text { Programa de mudança } \\
\text { cultural de uma } \\
\text { multinacional }\end{array}$ & $\begin{array}{l}\text { Silvester, Anderson } \\
\text { e Patterson (1999) }\end{array}$ & - & Sim & - & Sim & $\begin{array}{l}\text { Uso de modelo sócio cognitivo para analisar diferentes } \\
\text { causas da mudança cultura; }\end{array}$ \\
\hline 5 & Nissan Revival Plan & Ghosn (2002) & Sim & - & Sim & - & $\checkmark$ Descrição dos times cross-functional do projeto; \\
\hline 6 & $\begin{array}{l}\text { Quatro estudos de caso de } \\
\text { mudança no setor público }\end{array}$ & Soltani e Lai (2007) & Sim & - & - & - & $\begin{array}{l}\checkmark \quad \text { As análises apontam o ineficiente envolvimento da alta } \\
\text { administração como principal falha no processo de mudança; }\end{array}$ \\
\hline 7 & $\begin{array}{l}\text { Cadeia de valor do setor } \\
\text { de FMCG (Fast Moving } \\
\text { Consumer Goods) }\end{array}$ & $\begin{array}{l}\text { Mohamed e YuanJuan } \\
\quad(2008)\end{array}$ & - & $\operatorname{Sim}$ & - & - & $\begin{array}{l}\checkmark \text { Relação estatística entre alinhamento cultural e performance } \\
\text { financeira das empresas na cadeia de valor; }\end{array}$ \\
\hline 8 & Programa Global do Lean & $\begin{array}{l}\text { Matthiesen e Johansen } \\
\qquad(2008)\end{array}$ & Sim & - & - & - & $\begin{array}{ll}\checkmark & \text { Discussão de três estratégias de implementação do Lean em } \\
\text { nível corporativo; } \\
\checkmark \quad \text { Levantamento de seis diferentes opiniões expressas pelos } \\
\text { envolvidos no processo de mudança; }\end{array}$ \\
\hline
\end{tabular}




\begin{tabular}{|c|c|c|c|c|c|c|c|}
\hline 9 & Mudança no setor público & $\begin{array}{l}\text { Fronda e Moriceau } \\
\qquad(2008)\end{array}$ & - & Sim & - & Sim & $\begin{array}{l}\text { Caso a média gerência não seja incluída no processo de } \\
\text { mudança, a alta administração terá problemas na } \\
\text { implementação das mudaças propostas; }\end{array}$ \\
\hline 10 & Sistema de Saúde (USA) & Mallak e Lyth (2009) & - & Sim & - & - & $\begin{array}{l}\checkmark \quad \text { A gestão da cultura organizacional pode ser vista como um } \\
\text { mecanismo de integração organizacional; } \\
\checkmark \quad \text { É preciso ter um método estruturado para definir a cultura } \\
\text { desejada, e a cultura deve ser medida em toda a organização; } \\
\checkmark \quad \text { É preciso ir além das Surveys padrões, afinal a cultura é local } \\
\text { e não global (não existe um único instrumento); } \\
\checkmark \quad \text { Defina planos de ação após compreender melhor a cultura; }\end{array}$ \\
\hline 11 & $\begin{array}{l}\text { Empresa de segurança } \\
\text { privada na África do Sul }\end{array}$ & Kokt e Merwe (2009) & - & Sim & - & - & $\checkmark$ Aplicação do CVF para investigar a cultura organizacional; \\
\hline 12 & $\begin{array}{l}\text { Escola de Gestão na } \\
\text { República Checa }\end{array}$ & Eger (2010) & - & Sim & - & Sim & $\begin{array}{l}\checkmark \text { Aplicação de um método de avaliação da cultura } \\
\text { organizacional em uma escola em dois momentos diferentes; }\end{array}$ \\
\hline 13 & Bayer Corporation & Babe (2011) & Sim & - & Sim & - & $\begin{array}{l}\checkmark \text { Estrutura de transformação em quatro áreas: (1) } \\
\text { Crescimento, (2) Suporte ao Negócio, (3) Supply Chain } \\
\text { Management e (4) Cultura Organizacional. No entanto, não } \\
\text { entra em detalhes da área de Cultura Organizacional; } \\
\checkmark \text { Slogan do processo de transformação: "Simplify, } \\
\text { Standardize and Automate"; }\end{array}$ \\
\hline 14 & Google & $\begin{array}{l}\text { Steiber e Alange } \\
\text { (2012) }\end{array}$ & - & Sim & Sim & - & $\begin{array}{ll}\checkmark & \text { Descrição qualitativa da Cultura Google; } \\
\checkmark & \text { Discussão sobre Cultura de Melhoria Contínua v.s. Inovação; } \\
\checkmark & \text { Necessidade de "re-branding" do TQM; }\end{array}$ \\
\hline 15 & Hyundai v.s. Toyota & Shim e Steers (2012) & - & Sim & - & - & $\begin{array}{l}\checkmark \text { Estudo comparativo das diferenças de cultura e liderança } \\
\text { entre a Hyundai e Tovota; }\end{array}$ \\
\hline
\end{tabular}

\section{Quadro 23 - Descrição e segmentação dos estudos de caso levantados na literatura}




\section{DESENVOLVIMENTO}

Esta seção apresenta o desenvolvimento da sistematização proposta, organizando a sequência de pesquisa e também o texto em três princípios fundamentais de uma pesquisa propostos por Quivy e Campenhoudt (1995): (4.1) Ruptura, (4.2) Construção e (4.3) Constatação. Ainda, a seção inclui uma análise e discussão sobre as questões de pesquisa levantadas por Whetten (1989), abordando "o quê" constituí a sistematização proposta, "porquê", "quem", “onde", “quando" e "como" ela poderia ser aplicada. A Figura 46 ilustra o posicionamento desta seção no processo de pesquisa.

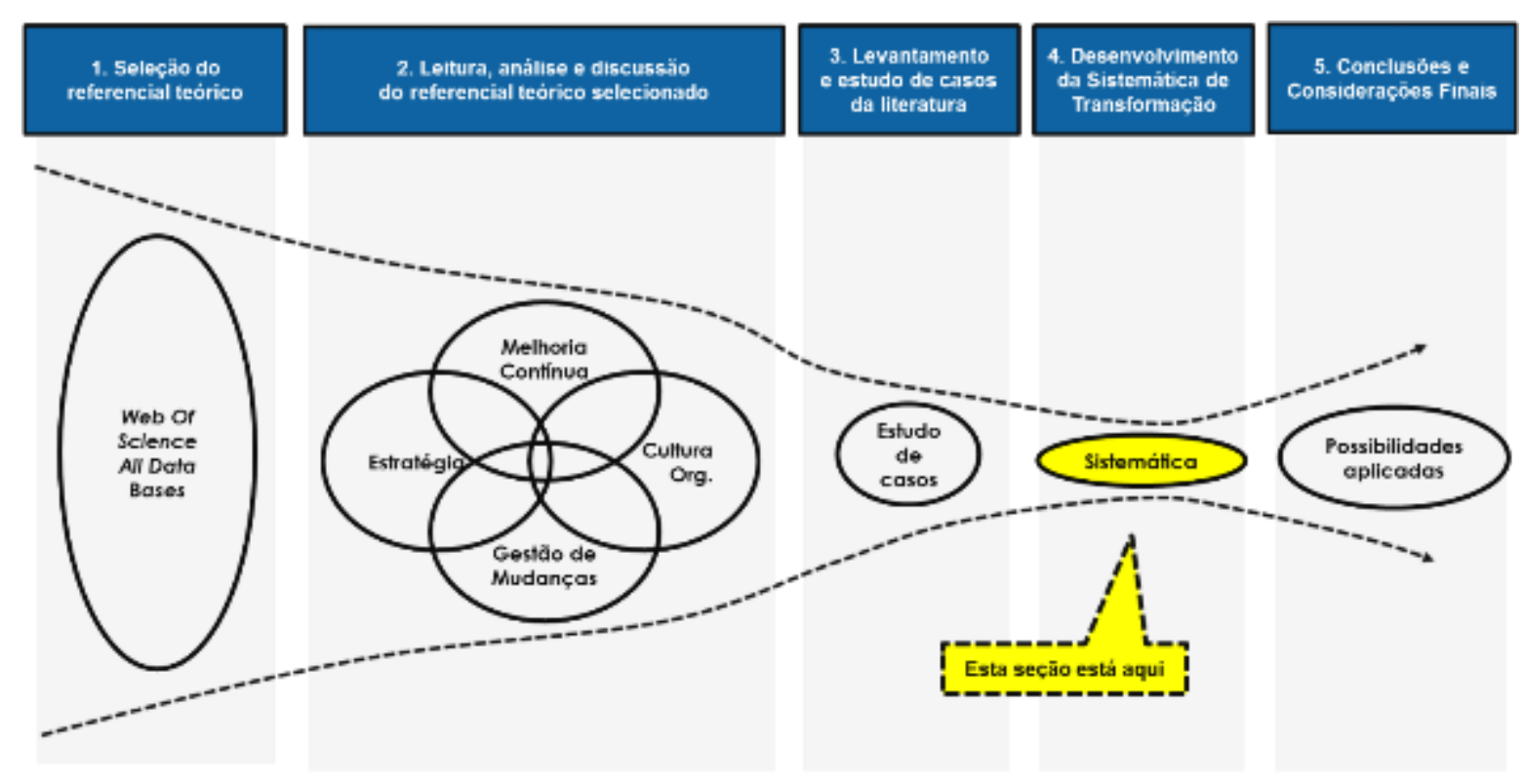

Figura 46 - Visão geral do posicionamento desta seção no processo de pesquisa

\subsection{Ruptura}

Para facilitar o posicionamento lógico do leitor com relação à fundamentação teórica do trabalho, esta seção segue a mesma sequência de estrutura da Seção 3 (Fundamentação Teórica). O objetivo aqui é "romper" com a bagagem teórica atual, identificando possíveis 
armadilhas e lacunas, no intuito de manter o foco da discussão nos aspectos críticos e vulneráveis da teoria atual. Com isso, espera-se reduzir o risco de propagar aparências enganosas e preconceituosas na construção da sistemática proposta.

\section{Ruptura: literatura sobre Alinhamento Estratégico}

Basicamente, os diversos autores de estratégia (Kaplan e Norton, 2005; Sull, Homkes e Sull, 2015; Prosser, 2015) parecem concordar com a lógica de Treacy e Wieserma (1993): o sucesso da estratégia ocorre quando há um alinhamento coerente da estratégia ("proposta de valor”) com a execução no nível operacional (“entrega do valor”).

No entanto, toda vez que as organizações buscam construir, fortalecer ou modificar este alinhamento, desenvolvendo um projeto de mudança, por exemplo, a taxa de insucesso destes projetos encontrada na literatura tem sido muito elevada. Esta taxa de insucesso tem sido semelhante tanto na literatura sobre estratégia (Kaplan e Norton, 2005; Sull, Homkes e Sull, 2015; Prosser, 2015) quanto na literatura sobre Lean (Graham, 1991; Walker, 1992; Sirkin et al., 2005; Atkinson, 2010; Bhasin, 2011; Bhasin, 2012). Em ambas literaturas, a taxa de insucesso dos projetos fica em torno de $66 \%$ a $90 \%$ dos casos levantados. Esta taxa é relativamente muito alta e causa um impacto profundo na competitividade das empresas e, portanto, no crescimento das organizações.

Em um contexto amplo, este insucesso pode ocorrer em pelo menos dois momentos: na definição da "proposta de valor" (planejamento) ou então na "entrega do valor". Kaplan e Norton (2005) consideram que a definição de um mapa estratégico (“proposta de valor”), por exemplo, seja uma commodity. O que os autores querem dizer com isto? Eles querem afirmar que qualquer empresa pode definir rapidamente uma nova estratégia ou uma nova proposta de valor, mas, poucas conseguem, de fato, executar e implementar tal estratégia. Portanto, uma das principais lacunas deste processo estaria na execução da estratégia. As empresas ainda têm falhado na gestão dos intangíveis, na perspectiva de Aprendizado e Crescimento, na base do Balanced Scorecard (Kaplan e Norton, 2005). Nessa perspectiva, os autores consideram a cultura organizacional como um dos aspectos mais importantes e, todavia, menos trabalhado pelos gestores. Portanto, é necessário ter um olhar cauteloso e, até mesmo questionar, se a base conceitual atual de estratégia no que tange a "entrega de valor", ou em outras palavras a 
"execução da estratégia" pela cultura organizacional seria, de fato, capaz de preencher esta lacuna de conhecimento. Embora ainda careça de robustez teórica, pelo levantamento bibliográfico realizado neste trabalho, a resposta a esta pergunta parece ser "não". Muitas empresas e autores podem recomendar a construção de mapas estratégicos ("proposta de valor"), no entanto, a estratégia tende a falhar na "entrega da proposta de valor". Aparentemente, na literatura não existe um modelo de análise e avaliação do alinhamento cultural dos projetos de mudança com a cultura organizacional atual, como, por exemplo, sugerido pelo Competing Values Framework.

\section{Ruptura: literatura sobre Melhoria Contínua}

Duas constatações deste trabalho são muito relevantes para a literatura:

1. Cultura Organizacional como fator de insucesso: a Cultura Organizacional é apontada como a principal causa de insucesso dos Programas de Melhoria Contínua do Lean (Delloite e Touche, 2002; Lean Enterprise Institute Survey, 2004; Lean Enterprise Institute Survey, 2005);

2. Cultura Organizacional como fator de sucesso: com base nas principais referências do Lean (Liker, 2005; Bhasin e Burcher, 2006; Mohamed e YuanJuan, 2008; Kovacheva, 2010), foi possível constatar que os Fatores Críticos de Sucesso dos Programas de Melhoria Contínua do Lean estão associados a grupos de ações da administração do ponto de vista de mudança de cultura conforme proposto por Robbins (2005) e Gattorna (2009), evidenciando novamente que a Cultura Organizacional exerce um papel fundamental no sucesso de tal programa;

Especificamente com relação aos Fatores Críticos de Sucesso dos Programas de Melhoria Contínua, envolvendo a Produção Enxuta, levantados e listados no Quadro 8, na seção "3.2.5 - Fatores Críticos de Sucesso do Lean", foi possível identificar que tais fatores poderiam ser organizados de acordo com os elementos de Gestão de Recursos Humanos listados por Robbins (2005) e Gattorna (2009) para promover o alinhamento da Cultura Organizacional com determinada estratégia. ${ }^{18}$

\footnotetext{
${ }^{18}$ Interpretando a Cultura Organizacional como uma variável dependente, Robbins (2005) cita estes fatores como possíveis ações da administração para promover uma Cultura com "foco no cliente".
} 
Portanto, tendo estes grupos de fatores críticos associados a promoção de uma determinada "Cultura Lean", capaz de promover Excelência Operacional e melhoria contínua dos processos, é possível reconhecer a Cultura Organizacional como sendo um dos principais fatores críticos de sucesso dos programas de melhoria contínua. A Figura 47 traz um resumo dos Fatores Críticos de Sucesso detalhados anteriormente no Quadro 8.

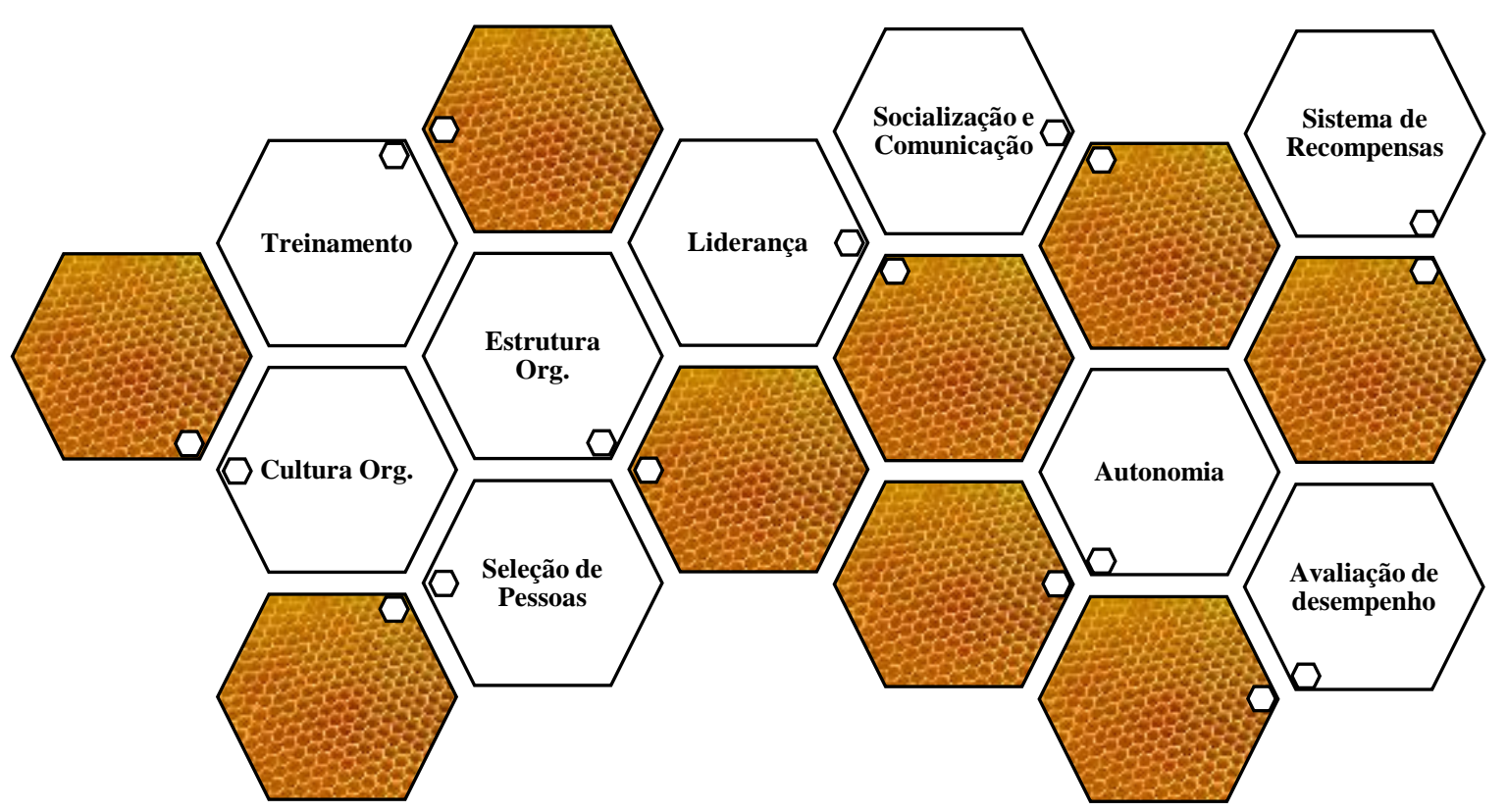

Figura 47 - Grupos de Fatores Críticos de Sucesso dos Programas de Lean

Inclusive, esta hipótese não é construída somente com base neste indício (fator crítico de sucesso), ela também faz sentido do ponto de vista das principais causas de insucesso de tais programas, como levantado nas pesquisas de Deloitte e Touche (2002), Lean Enterprise Institute Survey (2004) e Lean Enterprise Institute Survey (2005).

Desta maneira, compreender a Cultura Organizacional como um Fator Crítico de Sucesso do Lean faz muito sentido, principalmente se ela for compreendida em um contexto mais amplo, sendo considerada tanto uma variável dependente quanto uma variável independente, semelhantemente à ilustração da Figura 19, no Capítulo 3, de acordo com a base teórica de Robbins (2005) e Ivanko (2013). Isto faz sentido do ponto de vista dos elementos que devem promover uma determinada cultura (cultura como variável dependente), e também sob a ótica da cultura promover resultados que sejam catalisadores ou disparadores das mudanças do Lean (cultura como variável independente). 
A constatação de que a Cultura Organizacional exerce papel chave no sucesso do Lean pode já representar um avanço significante para o conhecimento da área de Melhoria Contínua. Esta visão pode exercer uma influência nos modelos de implantação do Lean, principalmente devido à lacuna existente: assim como os modelos de estratégia não contemplam uma análise e avaliação cultural dos projetos de mudança com a estratégia, os modelos de Melhoria Contínua carecem da mesma deficiência. Os modelos de Melhoria Contínua acabam tendo um caráter mais hard do que soft, ou seja, tendem a visualizar as organizações como se fossem "máquinas", e projetam mudanças como um engenheiro projeta um novo carro.

Embora existam diversos modelos de melhoria na literatura, o raciocínio e a lógica de passos lineares dos modelos é basicamente a mesma. De certa maneira, todos passam pelos seguintes passos: definir um objetivo, entender os problemas que impossibilitam o atingimento deste objetivo no cenário atual com respectiva compreensão de causas raízes, proposição de um estado futuro desejado para solucionar as causas dos problemas, definição de um plano de implementação das melhorias e, por fim, uma etapa verificação, medição e controle das melhorias realizadas na etapa anterior. Esta lógica é ilustrada na Figura 48.

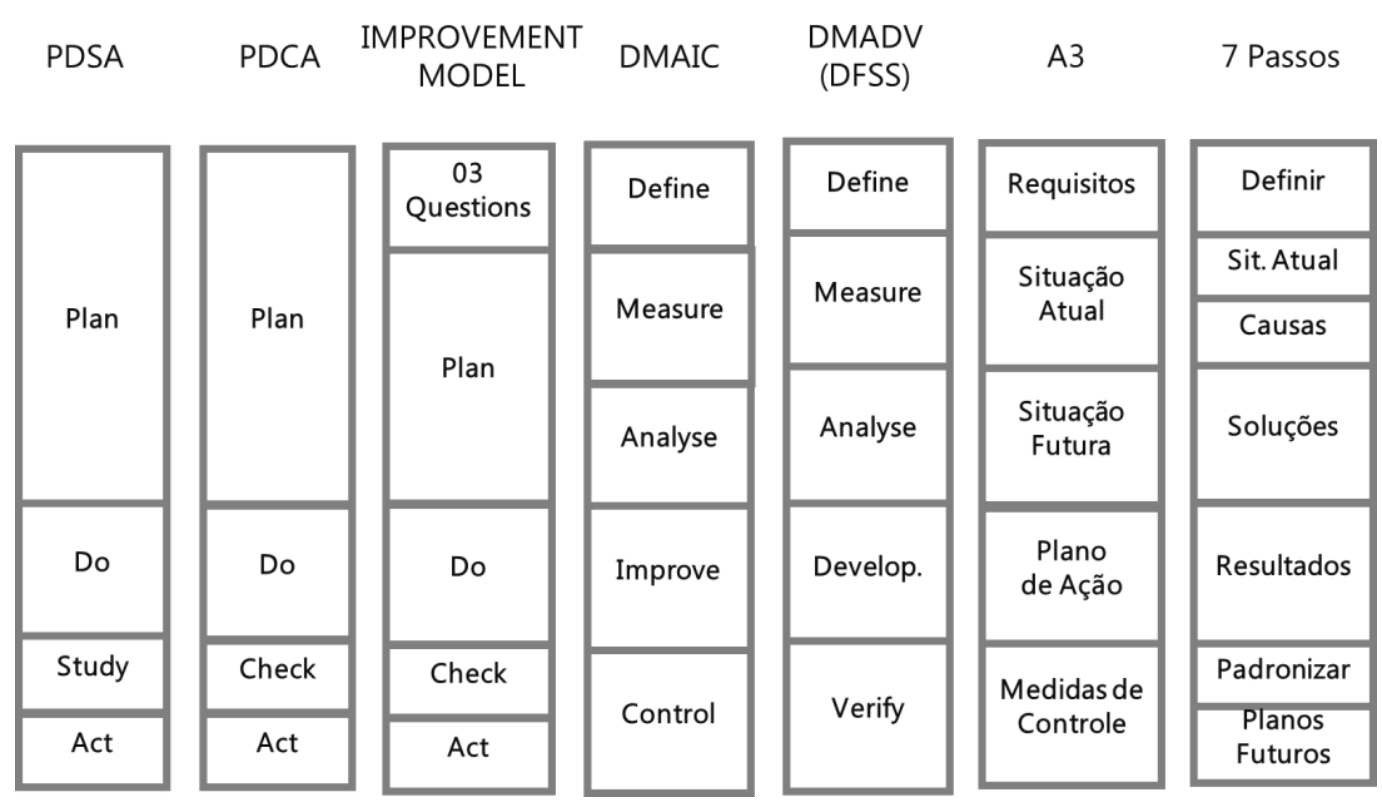

Figura 48 - Comparação dos Modelos de Melhoria

O único grande diferencial identificado foi com relação ao "Modelo A3", o qual realiza uma distinção do nível de melhoria de acordo com o nível organizacional, possuindo tipos de "Projeto A3" de acordo com o nível da melhoria, seja ela no nível Estratégico, Tático ou 
Operacional. Desta maneira, são levantadas as principais lacunas da literatura sobre Melhoria Contínua:

$\checkmark$ Embora diversas pesquisas apontem a Cultura Organizacional como um fator crítico de sucesso do Lean, os modelos de melhoria não contemplam elementos de análise e avaliação da Cultura Organizacional (atual ou desejada);

$\checkmark$ Por não serem citados nos modelos do Lean, aparentemente os Fatores Críticos de Sucesso dos Programas de Melhoria Contínua não são aplicados de maneira sistemática e formal em todos os casos de implantação do Lean;

$\checkmark$ Os modelos de melhoria possuem um caráter excessivamente hard, e tendem a visualizar as organizações como uma "máquina", projetando mudança organizacionais como um engenheiro projeta um carro, portanto, é possível esperar que a aplicação dos modelos atuais não irá ter um olhar crítico sob o ponto de vista da cultura organizacional;

$\checkmark$ Os modelos de melhoria são lineares e seguem, basicamente, o mesmo raciocínio (identificar um problema, propor mudanças e controlar os resultados obtidos), não sendo projetados sob o ponto de vista de compreender as organizações de uma maneira mais ampla e robusta, como, por exemplo, identificando e avaliando uma determinada Cultura Organizacional, desconsiderando, portanto, a existência de uma "mini sociedade" na organização, a qual possui valores, crenças e ideologias intrínsecas;

\section{Ruptura: literatura sobre Cultura Organizacional}

Como discutido anteriormente, a Cultura Organizacional é um fator fundamental para o sucesso dos Programas de Melhoria Contínua. Nesse sentido, faz-se muito importante utilizar uma ferramenta que torne possível analisar e mensurar o quão próximo (ou não) uma determinada organização está desta “Cultura Lean" ideal, afinal, este alinhamento cultural será importante para o sucesso da iniciativa do Programa Lean.

Dentre os modelos de diagnóstico de cultura levantados, inicialmente, alguns foram aqui desconsiderados por estarem mais adequados para análise do ponto de vista da Cultura Nacional, e não da Cultura Organizacional como definido no escopo deste trabalho. 
Os modelos que analisam esta cultura pretendida, este trabalho considera o modelo do Competing Values Framework (Cameron e Quinn, 2006) como sendo o mais adequado aos objetivos deste trabalho. O modelo já foi amplamente testado e validado e, além de possuir a maior quantidade de publicações e relacionamento com cases, consegue fazer um relacionamento conceitual muito importante com outros dois elementos do processo de transformação das empresas: estratégia e liderança. Este trabalho não se propõe a avançar mais nestes dois campos de conhecimento, no entanto, reconhece sim a amplitude e importância de explorar o alinhamento destes campos com determinada Cultura Organizacional. Com relação à definição de uma Cultura Lean ideal, este trabalho seguirá como referência os trabalhos de Paro (2012) e Paro e Gerolamo (2015), os quais fazem uma associação teórica do CVF com os 14 Princípios do Modelo Toyota. No entanto, é preciso reconhecer que a literatura ainda carece de uma validação mais robusta desta denominada "Cultura Lean ideal". O resultado destes trabalhos foi apresentado na "Seção 3.3.3 - Cultura Lean".

Sob o ponto de vista da Cultura Organizacional como variável dependente, até o presente momento, este trabalho de revisão identificou os seguintes elementos como variáveis independentes do ponto de vista de mudança ou evolução da cultura organizacional:

1. Estrutura Organizacional (Robbins, 2005; Gattorna, 2009);

2. Sistema de Recompensas e Plano de Carreiras (Robbins, 2005; Gattorna, 2009);

3. Avaliação de Desempenho (Robbins, 2005; Gattorna, 2009);

4. Treinamento (Robbins, 2005; Gattorna, 2009);

5. Socialização e Comunicação Interna (Gattorna, 2009);

6. Seleção de Pessoas (Robbins, 2005; Gattorna, 2009);

7. Autonomia (Robbins, 2005);

8. Liderança (Robbins, 2005; Gattorna, 2009) e Práticas de Gestão (Mann, 2010);

9. Processos (Gattorna, 2009);

10. Sistemas de Informação / TI (Gattorna, 2009);

É importante salientar que Robbins (2005) faz referencia para a determinação destes elementos ao buscar definir "ações da administração" para promover uma cultura com "foco no cliente". A princípio, estes elementos estão coerentes e fazem sentido do ponto de vista dos fatores críticos de sucessos dos Programas de Lean. De qualquer maneira, nesta questão reside mais uma lacuna de pesquisa que pode vir a ser explorada: estes elementos estão de fato relacionados com a promoção de uma determinada cultura organizacional? Como este 
fenomeno ocorre? Existem outros elementos associados a este fenomeno? Se sim, quais? Estas são apenas algumas das questões que poderiam ser discutidas no futuro, mas que o presente trabalho não se propõe a responder.

Desta maneira, foram identificadas as seguintes lacunas do ponto de vista da Cultura Organizacional:

$\checkmark$ Em diversos momentos, Schein (2009) comenta sobre "mudança" e "evolução" da cultura organizacional. Para o pesquisador, os gestores precisam gerenciar esta mudança ou evolução, pois, caso não o façam, será a cultura organizacional quem estará gerenciando a organização. No entanto, nos estudos de caso levantados esse processo ocorre de maneira inconsciente ou não previamente planejada;

$\checkmark$ Sob o ponto de vista de mudança de cultura ou promoção de uma determinada cultura organizacional, ainda existem várias lacunas a serem exploradas no futuro;

$\checkmark$ É preciso distinguir entre modelos de diagnóstico de Cultura Nacional e Cultura Organizacional, para não repercutir em erros de análise, algo simples, que não foi identificado na literatura de Gestão de Operações;

$\checkmark$ Com relação à Cultura Lean ideal, embora o presente trabalho utilize o perfil do CVF mapeado por Paro (2012) e Paro e Gerolamo (2015) como referência, é importante reconhecer que este estudo não apresenta robustez suficiente para tal afirmação, sendo seu uso importante neste trabalho apenas do ponto de vista conceitual na construção da sistemática proposta, ou seja, novamente, têm-se a identificação de outra importante lacuna de pesquisa;

\section{Ruptura: Literatura sobre Gestão de Mudanças}

Dentre os modelos de Gestão de Mudanças levantados, é importante salientar que o modelo dos Oito Passos de Kotter (1995 e 2009) se destaca e segue sendo o modelo mais citado e utilizado na literatura. $\mathrm{Na}$ análise de citações dentre os artigos da Revisão Bibliográfica Sistemática (RBS), o modelo dos Oito Passos de Kotter (1995 e 2009) foi citado 20 vezes. O segundo modelo mais citado (Senge et al., 1999) possui seis citações na RBS, e o terceiro (Bridges, 1991) cinco. Os demais modelos possuem entre 0 e 3 citações, conforme ilustrado no Quadro 24. Esta quantidade de citações obviamente não fornece o grau de relevância dos modelos, mas sim dá indícios dos modelos mais utilizados e citados na literatura. 


\begin{tabular}{c|l|c|c}
\hline$\#$ & Modelo / Metáfora & $\begin{array}{c}\text { Citações na } \\
\text { RBS (Qtd.) }\end{array}$ & $\begin{array}{c}\text { Citações na } \\
\text { RBS (\%) }\end{array}$ \\
\hline 1 & Kotter (1995) - Os Oito Passos & 20 & $49 \%$ \\
\hline 2 & Senge et al. (1999) - Modelo Sistêmico & 6 & $15 \%$ \\
\hline 3 & Bridges (1991) - Gestão da Mudança & 5 & $12 \%$ \\
\hline 4 & Lewin (1951) - Três Etapas & 3 & $7 \%$ \\
\hline- & Nadler e Tushman (1997) - Modelo e Congruência & 3 & $7 \%$ \\
\hline 5 & Beckhard e Harris (1987) - Fórmula da Mudança & 2 & $5 \%$ \\
\hline 6 & Bullock e Batten (1985) - Mudança Planejada & 1 & $2 \%$ \\
\hline- & Sirkin et al. (2005) - O Modelo DICE & 1 & $2 \%$ \\
\hline 7 & Kubler-Ross (1969) - A Curva de Mudança & 0 & $0 \%$ \\
\hline- & Carnall (1986) - Gestão de Transições & 0 & $0 \%$ \\
\hline- & Cameron e Green (2009) - Ciclo de Mudanças & 0 & $0 \%$ \\
\hline
\end{tabular}

\section{Quadro 24 - Quantidade de citações dos Modelos de Mudança com base na RBS}

Associado aos modelos de mudança, ao analisar as metáforas de uma organização propostas por Morgan (1998), é preciso notar que não existe uma única maneira de "enxergar" uma organização, e também não existe uma metáfora correta em detrimento às demais, em outras palavras, não há "certo e errado", de fato, cada metáfora revela um determinado olhar sobre o arcabouço organizacional. A partir destas metáforas, é possível entender que as organizações precisam capturar os aprendizados e o conhecimento construído em todos os níveis (organização como um cérebro), precisam também promover mudanças estratégicas que possuam uma visão inspiradora (organização vista como uma máquina), mudanças possuem "vencedores e perdedores" dentro da organização (organização vista como um sistema político), precisam ser projetadas de tal maneira a satisfazer as necessidades dos indivíduos (organização vista como um organismo) e, ainda, as mudanças nem sempre ocorrem somente através de planos de ação, fluxogramas ou agendas, há uma determinada "impotência" dos gestores perante o processo de mudança organizacional (organização vista como fluxo e transformação). 


\begin{tabular}{|c|c|c|c|c|c|c|c|c|}
\hline Modelo / Metáfora & Máquina & Organismo & Cérebro & Cultura & $\begin{array}{l}\text { Sistema } \\
\text { Político }\end{array}$ & $\begin{array}{c}\text { Prisão } \\
\text { Psíquica }\end{array}$ & $\begin{array}{l}\text { Fluxo de } \\
\text { Transf. }\end{array}$ & $\begin{array}{c}\text { Inst. de } \\
\text { Dominaçãao }\end{array}$ \\
\hline $\begin{array}{l}1 \text { - Lewin }(1951) \\
\text { - Três Etapas }\end{array}$ & $\mathrm{X}$ & $\mathrm{X}$ & & $\mathrm{X}$ & $\mathrm{X}$ & & & \\
\hline $\begin{array}{l}2 \text { - Kluber-Ross (1969) } \\
\text { - A Curva de Mudança }\end{array}$ & & $\mathrm{X}$ & & & & $\mathrm{X}$ & $\mathrm{X}$ & \\
\hline $\begin{array}{l}3 \text { - Bullock e Batten (1985) } \\
\text { - Mudança Planejada }\end{array}$ & $\mathrm{X}$ & & $\mathrm{X}$ & & & & & \\
\hline $\begin{array}{l}4 \text { - Beckhard e Harris } \\
\text { (1987) - Fórm. Mudança }\end{array}$ & & $\mathrm{X}$ & & & $\mathrm{X}$ & $\mathrm{X}$ & & \\
\hline $\begin{array}{l}5 \text { - Carnall (1986) } \\
\text { - Gestão de Transições }\end{array}$ & & $\mathrm{X}$ & $\mathrm{X}$ & $\mathrm{X}$ & $\mathrm{X}$ & & & \\
\hline $\begin{array}{l}6 \text { - Bridges (1991) } \\
\text { - Gestão da Mudança }\end{array}$ & $\mathrm{X}$ & & & & & $\mathrm{X}$ & $X$ & \\
\hline $\begin{array}{l}7 \text { - Kotter (1995) } \\
\text { - Os Oito Passos }\end{array}$ & $\mathrm{X}$ & $\mathrm{X}$ & & $X$ & $\mathrm{X}$ & & & \\
\hline $\begin{array}{l}8 \text { - Nadler e Tushman } \\
\text { (1997) - Modelo e } \\
\text { Congruência } \\
\end{array}$ & & $\mathrm{X}$ & & & $\mathrm{X}$ & & $\mathrm{X}$ & \\
\hline $\begin{array}{l}9 \text { - Senge et al. (1999) - } \\
\text { Modelo Sistêmico }\end{array}$ & & $\mathrm{X}$ & $\mathrm{X}$ & & & & $\mathrm{X}$ & \\
\hline $\begin{array}{l}10 \text { - Sirkin et al. (2005) - } \\
\text { The DICE Model }\end{array}$ & $\mathrm{X}$ & & & & & & & \\
\hline $\begin{array}{l}11 \text { - Cameron e Green } \\
\text { (2009) - Ciclo de Mudanças }\end{array}$ & $\mathrm{X}$ & $\mathrm{X}$ & & $\mathrm{X}$ & $\mathrm{X}$ & & & \\
\hline
\end{tabular}

Quadro 25 - Associação dos Modelos de Mudança com as metáforas organizacionais 
Estas metáforas são pouco exploradas na literatura. Cameron e Green (2009, por exemplo, não analisaram os modelos de mudança sob o ponto de vista da Cultura. Um ponto fundamental e, talvez um dos mais relevantes desta pesquisa, seja complementar a revisão (dos modelos de mudança) feita por Cameron e Green (2009) com uma associação dos Modelos de Mudança levantados da literatura, porém, desta vez incluindo todas as metáforas organizacionais propostas por Morgan (1998). Desta maneira, é possível identificar "pontos cegos" e deficiências dos modelos. Esta associação foi desenvolvida no trabalho, e o resultado é ilustrado no Quadro 25.

A descrição das associações de cada modelo com as metáforas organizacionais segue a lógica já discutida na seção “3.4.5 - Modelos de Mudança Organizacional”. O primeiro ponto de destaque desta análise, é o fato dos modelos apresentarem visões diferentes sob uma organização. Os modelos com a maior pluralidade de visões, chegam a obter no máximo quatro visões diferentes sob uma organização. Era de se esperar que este número fosse pequeno, afinal, a princípio nenhum dos modelos foi desenvolvido a partir deste ponto de vista. A maioria dos modelos compreende a organização como uma "máquina”, nada diferente do que já observado nos modelos de melhoria, ou então, interpretam a organização como um “organismo" tentando se adaptar em seu ambiente.

Pelo levantamento realizado, todos os modelos apresentam pelo menos uma destas duas visões. Tudo indica que a principal lacuna da literatura não está aqui, mas sim no fato de poucos modelos contemplarem de maneira robusta as metáforas da organização como "Cultura" e como "Cérebro". O modelo mais citado e referenciado na literatura (Kotter, 1995), por exemplo, analisa a questão "Cultural" e do "Sistema Político" com pouca profundidade. A cultura organizacional é citada e discutida apenas no último passo do modelo, acreditando ser possível "institucionalizar" ou "colar" as mudanças na cultura organizacional.

Com relação ao processo de implementação dos modelos de mudança, é possível notar que os modelos com etapas moderadamente lineares (Lewin, 1951; Bullock e Batten, 1985; Bridges, 1991; Kotter, 1995; Cameron e Green, 2009) possuem uma sequência lógica semelhante, tendo como grande exceção na etapa "Fim" como proposto no modelo de Bridges (1991). Nesse sentido, chama atenção o fato do modelo mais citado na literatura (Kotter, 1995) não abordar a necessidade de encerrar as mudanças que já estavam ocorrendo ("Fim"). Esta lógica é ilustrada na Figura 49. 


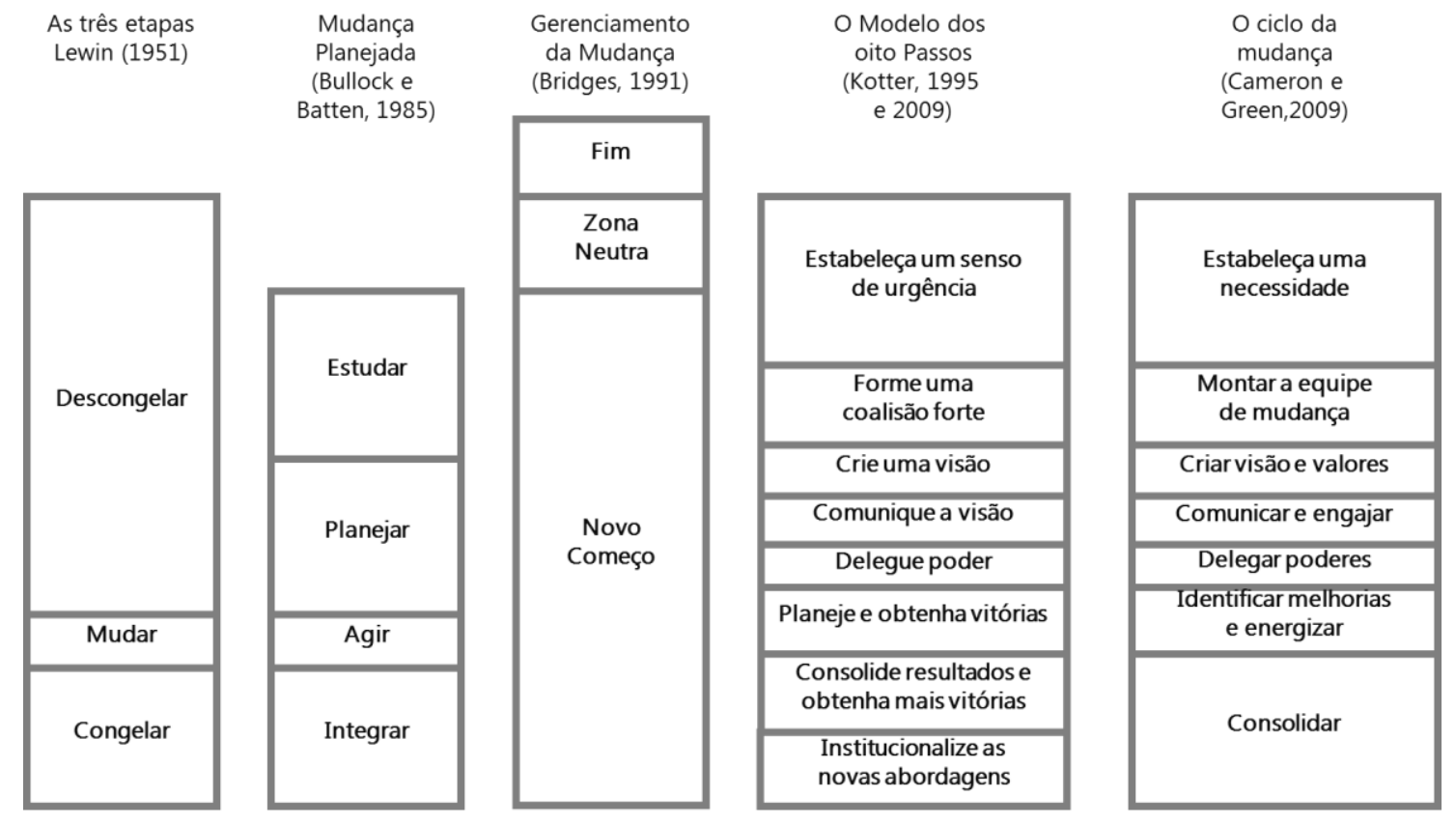

Figura 49 - Comparação dos Modelos de Mudança com etapas lineares

De maneira resumida, foram identificadas as seguintes lacunas na literatura sobre Gestão de Mudanças:

$\checkmark$ As metáforas organizacionais propostas por Morgan (1998) exercem um papel muito importante do ponto de vista de compreensão de uma organização e, no entanto, são pouco exploradas na literatura;

$\checkmark$ Ainda com relação ao ponto de vista das metáforas organizacionais, ao analisar os Modelos de Mudança foi possível encontrar um aparente "ponto cego" na visão dos modelos, afinal, alguns tornem explícita a importância da Cultura Organizacional no processo de mudança, nenhum deles deixa claro como a cultura pode mudar ou evoluir ao longo do processo de transformação;

Kotter (1995) não dá grande ênfase à etapa “fim" proposta por Lewin, ou seja, em um determinado processo de mudança pode vir a existir uma possível lacuna de "priorização" das iniciativas de mudança, justamente por não discutir o encerramento das atividades que já estavam sendo executadas. Em outras palavras, se considerarmos que as mudanças já existentes na organização não são encerradas, mas somente é promovido um senso de urgência em torno de uma nova mudança, então é possível concluir que pode existir uma dispersão de esforços em torno de objetivos diferentes. Este fato faz muito sentido do ponto de vista do contexto atual, no qual as organizações fazem mudanças cada vez mais frequentes: ou seja, antes 
de iniciar uma nova grande mudança, talvez seja necessário encerrar ou congelar algumas mudanças já em andamento, as quais inclusive podem vir a ser conflitantes com a nova estratégia.

\subsubsection{Estudo de Caso da Literatura}

Em um universo de 190 artigos, inicialmente levantados na Revisão Bibliográfica Sistemática deste trabalho, foram identificados 15 estudos de caso associados à temática de pesquisa (projetos de transformação envolvendo implementação ou discussão de práticas de Melhoria Contínua). Todos estes estudos de caso foram lidos, analisados e classificados em quatro grupos: casos que envolvessem descrição do (a) Projeto de Transformação, (b) da Estratégia Organizacional, (c) do Diagnóstico da Cultura Organizacional e (d) da Evolução ou Mudança de Cultura Organizacional. De acordo com esta classificação, foi possível identificar a existência de "dois mundos conceituais" que aparentemente não se conversam: o primeiro mundo utiliza uma lente que analisa os casos sob o ponto de vista do Projeto de Transformação, tendo uma abordagem mais "hard"; por sua vez, o segundo mundo utiliza uma lente mais "soft", analisando os casos sob o ponto de vista da Cultura Organizacional.

A principal oportunidade de pesquisa aqui está no fato de nenhum dos estudos de caso apresentar um Projeto de Transformação associado com um Diagnóstico de Cultura Organizacional, ou pelo menos uma proposta de alinhamento cultural já no início do processo de transformação. Como já levantado na revisão de Gestão de Mudanças, as evidências encontradas levam a acreditar que, pelo fato do modelo dos Oito Passos de Kotter (1995) ser a abordagem mais aceita e utilizada na literatura, e também pelo fato dos Modelos de Melhoria terem um caráter hard e não soft, a aplicação prática do Projeto de Transformação tende a considerar aspectos culturais somente no último momento dos métodos: no momento de "consolidar as mudanças na cultura" (Oito Passos) ou na etapa de "Controle do Processo" (Modelos de Melhoria).

\subsubsection{Resumo: principais lacunas da teoria}

A partir dos diversos pontos analisados na literatura atual levantada sobre Estratégia, Melhoria Contínua, Cultura Organizacional e Gestão de Mudanças, foi construída a Figura 50, contemplando a principal lacuna prática e teórica identificadas neste trabalho. 
As análises da Fundamentação Teórica deste trabalho indicam que as organizações tendem a definir projetos com base em uma estratégia (ou pelo menos a partir de uma "visão estratégica" envolvendo definições menos formais) e, a partir disso, executam tais projetos sem necessariamente contemplar aspectos de diagnóstico ou gestão da cultura organizacional sejam eles antes ou depois da definição da estratégia. Esta parece ser a prática mais comum das organizações, como identificado nos estudos de caso na literatura. E, por isso, aumenta-se o risco dos projetos entrarem em "choque" com a cultura organizacional atual da organização, a qual por sua vez pode vir a "comer a estratégia definida anteriormente no café da manhã do dia seguinte" ("culture eats strategy for breakfast"19, como sugerido por Peter Drucker).

Isto pode estar ocorrendo por diversos motivos, dos quais seis possíveis motivos podem ser destacados com base na revisão da literatura:

(1) Os modelos de melhoria e mudança tentam "consolidar as mudanças na cultura" somente no final do processo de mudança, não antevendo já no início do processo possíveis conflitos que possam vir a existir;

(2) Estes mesmos modelos não fazem uma associação dos Projetos de Transformação com a estratégia da organização. Ou seja, em um contexto no qual as mudanças são cada vez mais frequentes, não é possível identificar quais são os projetos prioritários, apenas tem-se a criação de um "senso de urgência" em torno do processo de mudança;

(3) Os modelos de mudança dão pouca ênfase no controle e monitoramento das mudanças realizadas, não tornando claro como ocorre o processo de mudança ou evolução cultural;

(4) O planejamento e a execução dos projetos não contemplam elementos de gestão da cultura organizacional (os quais serão tratados como "gatilhos de aceleração do processo de mudança" na seção a seguir);

(5) A literatura de Gestão de Operações tende a banalizar o termo "cultura organizacional", atribuindo na maioria dos casos o fracasso de toda iniciativa de mudança à cultura, sem que necessariamente seja realizada um estudo específico da cultura organizacional atual e desejada da organização, como, por exemplo, sugerido pelo Competing Values Framework;

\footnotetext{
${ }^{19}$ Esta frase é atribuída a Peter Drucker (Fonte: COFFMAN, CURT. (2013). Culture Eats Strategy for Lunch. Hardcover. Liang Addison Press, $1^{\text {st }}$ Edition).
} 
(6) O levantamento de casos de implementação da Produção Enxuta na literatura tende a indicar que o departamento de Recursos Humanos raramente é envolvido no processo de mudança;

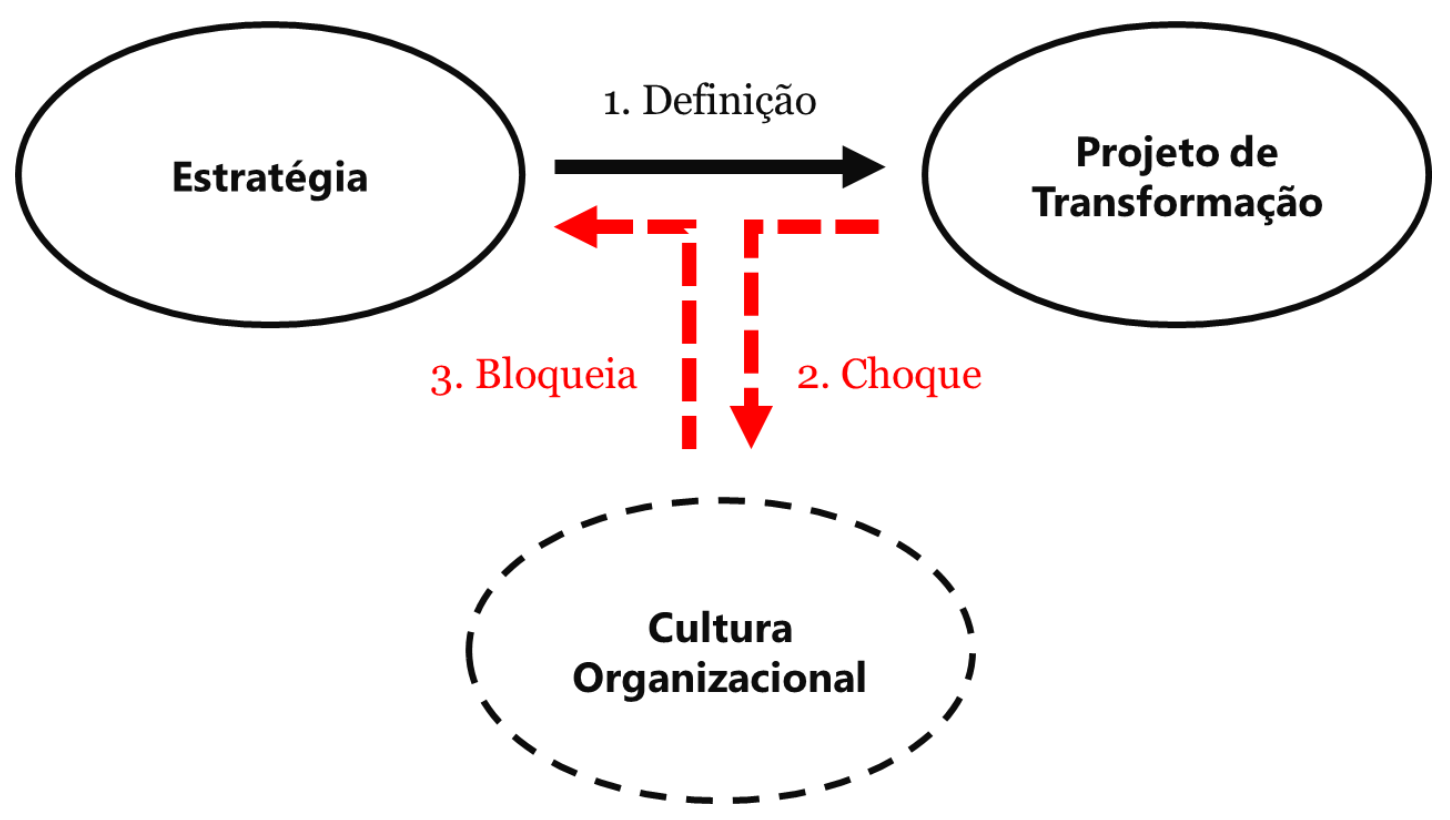

Figura 50 - Principal ruptura da teoria atual no processo de transformação

A Figura 50 ilustra a principal ruptura da teoria deste trabalho: como identificado na literatura, tanto os modelos quanto os estudos de caso apresentam uma tendência de definir uma estratégia (formal ou não) sem uma compreensão profunda da Cultura Organizacional. Nesse momento, o planejamento estratégico fica de certa maneira carente de restrições, podendo projetar e definir quaisquer ações de mudança dentro de um chamado "Projeto de Transformação". Após a definição da estratégia, os consultores vão embora e/ou os gestores delegam aos gerentes de projeto das grandes empresas (ou média gerencia no caso de empresas de tamanho médio), e estes ficam responsáveis pela execução do "Projeto de Transformação", que na maioria das vezes entra em choque e encontra resistência da Cultura Organizacional. Dessa maneira, o Projeto de Transformação fracassa. Na verdade, os dados da literatura apontam que cerca de $66 \%$ a $90 \%$ dos projetos falham: não atingem os resultados esperados, os projetos são entregues parcialmente ou então não são duradouros no longo prazo. Como consequência disso, como diria Peter Drucker, a "cultura come a estratégia no café da manhã", bloqueando grande parte do planejamento inicial na maioria dos casos. 
As seis lacunas discutidas anteriormente e ilustradas na Figura 50 representam o principal ponto de ruptura da teoria atual, os quais podem ajudar a entender o motivo dos projetos de mudança apresentam taxas de insucesso elevadas.

Este trabalho parte do pressuposto de que os profissionais que irão desafiar o status quo da organização através de um novo planejamento, devam compreender que a organização hora tem uma cultura como variável independente (quando o estado atual da organização for ser avaliado, de tal maneira a analisar o alinhamento entre a cultura e estratégia atuais), e em outro momento a cultura passa a ser variável dependente (quando o estado futuro da organização está sendo planejado, e portanto deve ser considerado "como modificar a cultura" quando houver um desalinhamento entre cultura e estratégia), e em outro momento a cultura passa a ser uma

\subsection{Construção}

\subsubsection{Definições e Visão Macro}

A construção da sistemática teórica passa, inicialmente, pela análise crítica e ruptura da literatura atual conforme discutido anteriormente e, também, pela decisão e consideração de alguns pontos importantes já existentes na literatura.

\section{$\checkmark$ Estratégia}

○ Para definição do foco estratégico, o artigo Value Disciplines de Treacy e Wieserman (1993) foi selecionado como modelo de discussão sobre posicionamento estratégico neste trabalho, ilustrado na Figura 52;

- Para definição de um mapa estratégico, o Balanced Scorecard de Kaplan e Norton (2005) foi selecionado por justamente considerar objetivos intangíveis (soft) associados a questões tangíveis (hard);

\section{Melhoria Contínua}

○ Com relação à Cultura Lean ideal, este trabalho seguirá a referência de Paro (2012) e Gerolamo e Paro (2015) sobre a Cultura Toyota mapeada teoricamente a partir dos 14 Princípios do Modelo Toyota (Liker, 2005) tendo como referência o modelo do Competing Values Framework (Cameron e Quinn, 2006); 


\section{$\checkmark$ Cultura Organizacional}

- Dentre os modelos de diagnóstico da Cultura Organizacional, o modelo do Competing Values Framework (Cameron e Quinn, 2009) foi selecionado como referência para o mapeamento e compreensão dos diferentes tipos de cultura organizacional. Isto se justifica pelo fato do modelo já ter sido amplamente testado e validado academicamente, e também por abrir oportunidades de alinhamento com posicionamento estratégico e perfis de liderança, além de permitir o mapeamento de uma Cultura Atual versus Cultura Desejada;

○ Como "gatilhos", "aceleradores" ou "disparadores" do processo de transformação cultural ${ }^{20}$, neste trabalho serão considerados os elementos propostos por Robbins (2005) e Gattorna (2009), ilustrados na Figura 47, por estarem coerentes com os fatores críticos de sucesso dos Programas de Lean e adequados do ponto de vista de ações de Gestão de Recursos Humanos.

\section{$\checkmark$ Gestão de Mudanças}

○ Conforme analisado na RBS deste trabalho, Kotter (1995) possui o modelo mais citado e referenciado na literatura sobre Gestão de Mudanças e, portanto, a sistemática de transformação proposta deverá contemplar aspectos ou etapas deste modelo;

○ Com relação às metáforas organizacionais propostas por Morgan (1998), é desejável que esta sistematização teórica contemple a maior quantidade de metáforas possíveis sobre uma organização, de tal maneira a projetar uma sistemática que seja robusta em termos de visões e compreensão sobre o que representa uma organização e quais serão os possíveis desafios do ponto de vista do processo de mudança;

A partir destas considerações, a Figura 51 apresenta uma visão ampla e conceitual de uma sistemática de transformação, contemplando o conhecimento de diversos aspectos do processo de mudança e implementação do Lean. Conceitualmente é importante salientar que

\footnotetext{
${ }^{20}$ Este trabalho acredita que a Cultura Organizacional não muda em um curto espaço de tempo, em outras palavras, não muda de uma hora para a outra assim como é feito com a implementação de ferramentas do Lean (Ex.: aplicação do Sistema Puxado ou SMED), mas, na verdade, uma Cultura Organizacional pode ser "transformada" ao longo do tempo e, portanto, a Cultura pode então mudar ou evoluir.
} 
a Figura 51 faz um contraponto conceitual com a Figura 50 apresentada anteriormente, a qual ilustrava a principal ruptura deste trabalho com a teoria atual.

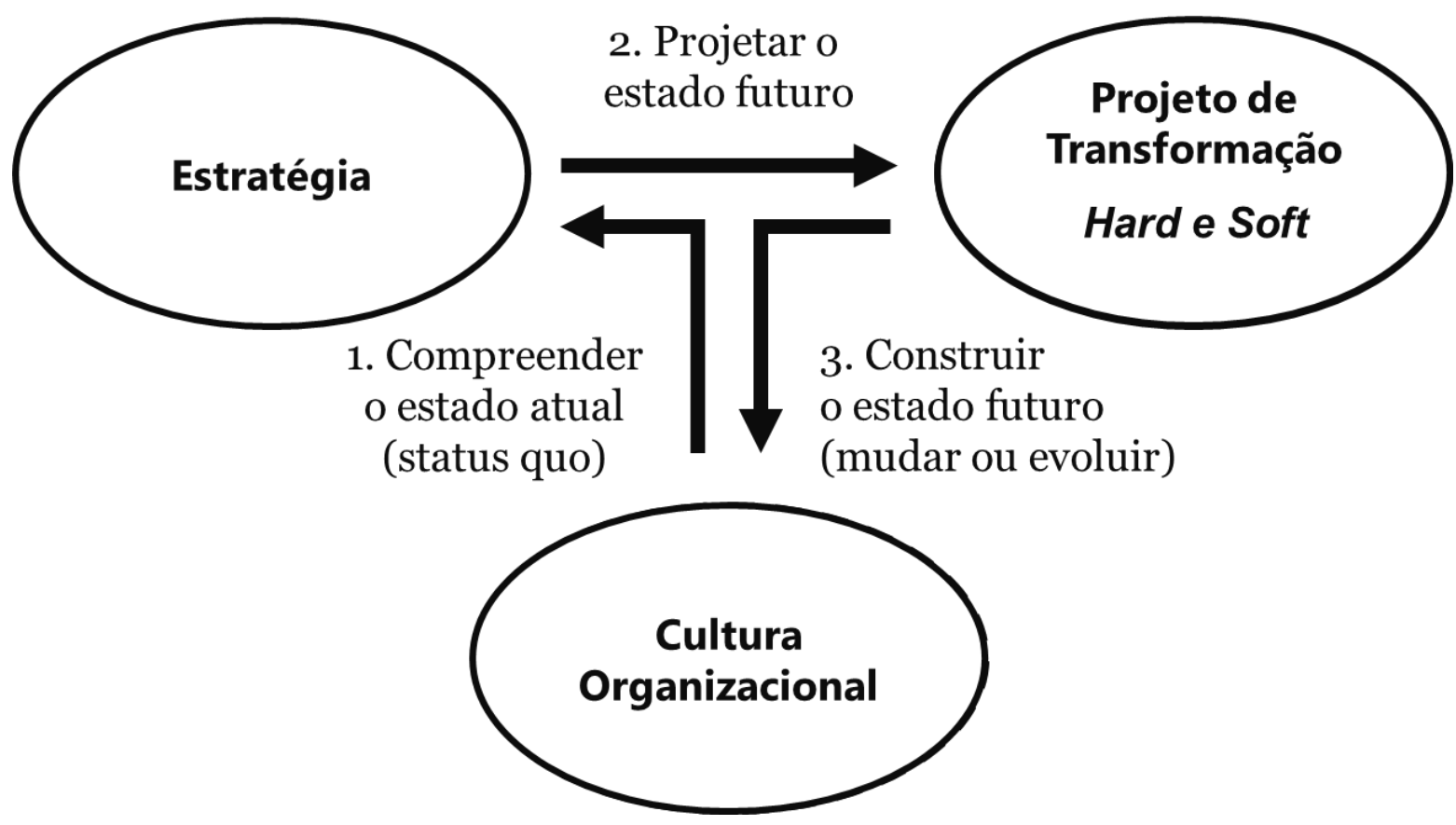

Figura 51 - Sistemática de Transformação ("Sistemática T”)

A Figura 51 faz uma síntese ao mesmo tempo de maneira simples e relevante de todo o trabalho, justamente por apresentar uma sistemática que busca reduzir o risco das iniciativas de mudança entrarem em choque com a cultura organizacional, ao inserir uma etapa de compreensão da cultura organizacional atual antes mesmo da definição da estratégia.

É importante salientar que esta proposta visualiza Estratégia e Cultura Organizacional hora como variável dependente, hora como variável independente. Quando se trata da “avaliação da situação atual”, a proposta está compreendendo a Cultura Organizacional como variável independente e a Estratégia como variável dependente, portanto a organização naquele momento possui uma dada Cultura responsável pela execução da Estratégia presente, seja essa estratégia formal ou não. Quando no momento de “planejamento da situação futura”, a proposta passa a visualizar a Estratégia como variável independente e a Cultura como variável dependente, portanto, a proposta parte do pressuposto de que a Estratégia deva ser concebida sob o ponto de vista de fazer evoluir ou mudar a Cultura Organizacional atual. Nesse sentido, 
a conexão entre essas "duas lentes" ocorre através do chamado "Projeto de Transformação (hard and soft, ou técnico e comportamental), o qual conceitualmente deverá ser variável dependente da Estratégia e variável independente da Cultura. Caso isso não ocorra, e o Projeto seja variável independente da Estratégia e variável dependente da Cultura, algum desalinhamento ou lacuna de análise provavelmente ocorreu, e é preciso voltar às etapas de "Avaliação da Situação Atual" e "Planejamento da Situação Futura".

A “Sistemática T" (Transformação) parte do pressuposto de que, antes de elaborar um Mapa Estratégico, por exemplo, é preciso compreender o status quo presente na Cultura Organizacional Atual, utilizando, por exemplo, modelos culturais como o Competing Values Framework (CVF) associado a modelos de Posicionamento Estratégico, como exemplo do modelo proposto por Treacy e Wieserma (1993). Portanto, existem três avaliações do alinhamento cultural: a cultura organizacional atual, a cultura desejada pelos colaboradores e, por fim, a cultura futura que será promovida pelo projeto de transformação. Os perfis culturais do CVF foram construídos a partir de dimensões como "Critérios de Sucesso" e "Ênfase Estratégicas", permitindo desta maneira fazer uma associação com o modelo de Treacy e Wieserma (1993), como ilustrado na Figura 52.

Competing Values Framework

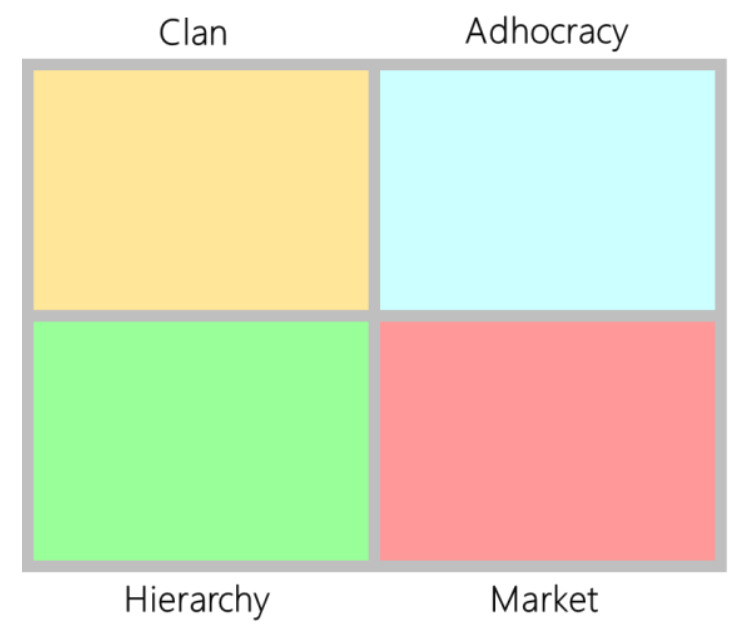

Value Disciplines associadas ao CVF

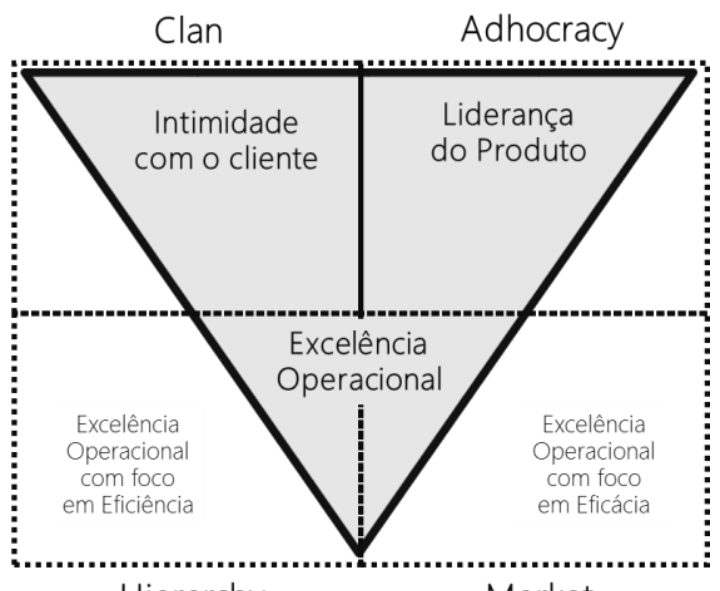

Hierarchy

Market

\section{Figura 52 - Value Disciplines associadas ao Competing Values Framework}

Desta maneira, a partir da compreensão do perfil da Cultura Organizacional Atual, de acordo com o CVF, é necessário promover um alinhamento da estratégia definida (Value Disciplines) com esta cultura. Inclusive, é preciso neste momento avaliar se existem algumas mudanças culturais que precisam ocorrer de acordo com a estratégia definida, no intuito de 
almejar o alinhamento entre a Cultura Organizacional e a Estratégia pretendida. Comparativamente com a teoria atual, o simples fato de compreender melhor o estado atual da organização, já dá subsídios para que os gestores ou agentes de transformação possam antever os eventuais choques que as iniciativas de mudança podem ter com a cultura organizacional.

Depois de avaliado e planejado este alinhamento entre a Cultura Organizacional Atual e a Estratégia definida, é possível projetar, a partir da estratégia, qual o Portfólio de Projetos ou Plano de Transformação que deve ser executado para se atingir a visão de futuro desejada. Estes projetos podem ter caráter técnico (hard) e/ou comportamental (soft), sendo necessário o desenvolvimento de projetos comportamentais principalmente quando a estratégia demandar adaptações ou mudanças na cultura organizacional. Dado o contexto atual no qual as organizações realizam diversas mudanças ao mesmo tempo e, cada vez de maneira mais frequente, na definição do esforço de mudança que irá ocorrer, é importante avaliar a priorização dos esforços e também o alinhamento destes esforços de mudança já existentes com a estratégia definida, no intuito de concentrar esforços e manter foco nas prioridades estratégicas. Nesse momento, pode ser necessário encerrar ou congelar determinados esforços de mudança. Inclusive, no intuito de garantir a sobrevivência e implementação deste novo foco estratégico, por questões políticas, pode ser necessário manter alguns projetos já existentes, no sentido de manter o apoio político de determinados subgrupos da organização. Esta abordagem é ilustrada na Figura 53.
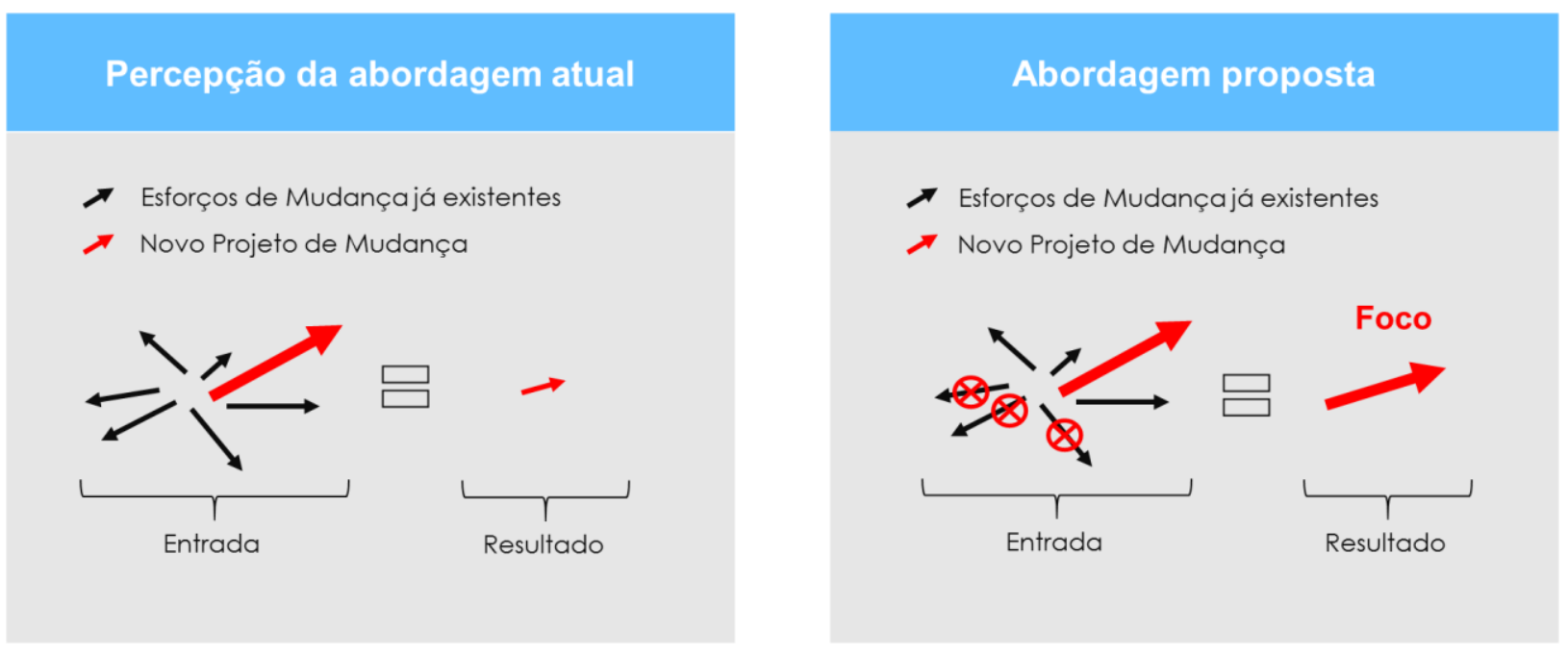

Figura 53 - Abordagem proposta de congelamento de algumas iniciativas estratégicas

Tendo a Estratégia e o Projeto de Transformação sido alinhados com a Cultura Organizacional Atual, ou com a Cultura Organizacional Desejada de acordo com o modelo do 
Competing Values Framework, é possível que existam pelo menos duas frentes de trabalho focadas em garantir o sucesso desta grande iniciativa estratégia:

$\checkmark$ Frente 1 (Hard): Planejamento e Execução do Projeto de Transformação;

$\checkmark$ Frente 2 (Soft): Monitoramento, avaliação e definição de mudanças de acordo com a evolução da Cultura Organizacional, no intuito de oferecer suporte e alavancar a execução da Frente 1 (hard);

Estas duas frentes de trabalho devem garantir o devido suporte ao sucesso na execução da estratégia pretendida pela organização. Para que este processo completo se torne viável e didático, é proposta a seguinte sistematização do processo de transformação possuindo etapas que evitam ou minimizam o risco de possíveis falhas no processo de mudança, funcionando desta maneira com um "guia de referência" para os gestores e agentes de transformação. Esta estratégia de desconstrução da teoria atual e reconstrução de um modelo novo é semelhante à já utilizada por Kotter (1995) na construção do modelo dos Oito Passos, a diferença é que neste trabalho há uma preocupação maior com a compreensão da Cultura Organizacional já no início do processo de mudança (ver Figura 51) e, inclusive, preocupação com a priorização das iniciativas de mudanças (ver Figura 53).

\subsubsection{Proposta das etapas}

Depois de um período de amadurecimento e formalização das falhas identificadas e descritas na Seção 4.2.2, este trabalho teve um processo de construção da Sistemática de Transformação proposta, tendo como principal referência o Modelo dos Oito Passos de Kotter (1995). A Figura 54 ilustra o modelo dos Oito Passos Revisados, desta vez tendo uma ênfase maior no processo de mudança ou evolução cultural, e reconhecendo que a Cultura Futura deve ser construída ao longo de todo o processo de mudança, e não somente institucionalizada na cultura ao final do processo. A Figura 55, por sua vez, ilustra a visão completa do Processo de Transformação Cultural, no qual o processo de mudança precisa compreender que irá ser necessário fazer mudar ou evoluir a cultura, e que para isso muitas vezes terá que gerar pressão suficiente para confrontar os pressupostos básicos anteriores, criar novas experiências e promover, portanto, novos pressupostos básicos. 


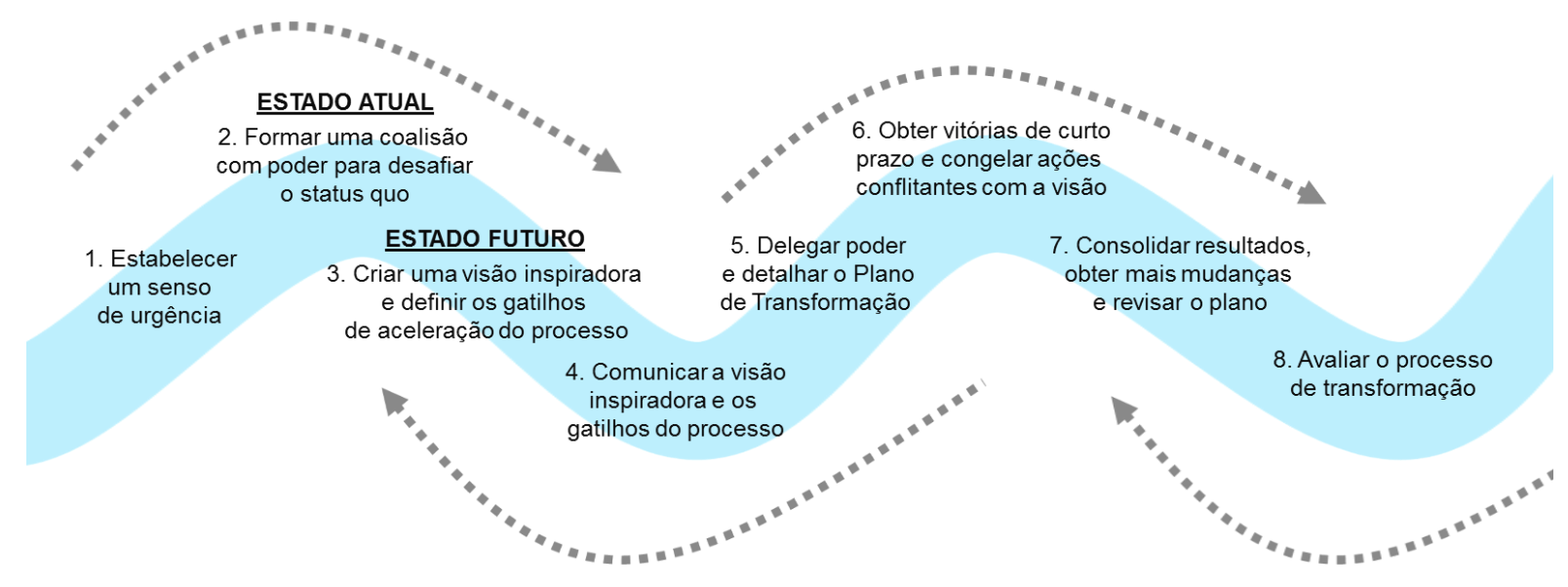

Figura 54 - O Modelo dos Oito Passos Revisado

Com relação ao modelo dos Oito Passos de Kotter (1995), esta revisão do modelo dos Oito Passos traz dois diferenciais fundamentais:

\section{Foco na Cultura para reduzir a taxa de insucesso das iniciativas de mudança}

Há mais de 20 anos os projetos de mudança falham, sendo a Cultura Organizacional e o processo de mudança apontados como a principal causa desse insucesso. Parece que os agentes de mudança ainda não aprenderam como realizar mudanças de maneira eficaz. Por isso, é proposto que o processo de mudança ou transformação deva fazer mudar ou evoluir a cultura organizacional, justamente para garantir o sucesso do processo - em termos de resultados, implementação dos diversos projetos e longevidade dos mesmos. Portanto, a revisão do modelo dos Oito Passos reconhece que a mudança de cultura deve ocorrer ao longo de todo o processo de mudança, e não somente no final. Portanto, é preciso relacionar a "Sistemática T" ao processo de mudança e, no Passo 2, logo no início de processo de mudança, compreender o status quo (estado atual) e, no Passo 3, projetar uma cultura futura (estado futuro). Isso é fundamental no sentido de antecipar os problemas futuros e reduzir o risco de o processo de mudança falhar (taxa de insucesso).

\section{Uso de gatilhos de aceleração do processo de mudança cultural}

No sentido de reforçar a mudança ou evolução da cultura organizacional, é proposto o projeto e implementação de gatilhos de aceleração do processo de mudança (ver a seção 3.3.4 com as "Práticas de Gestão de Recursos Humanos), nos Passos 3 
(definição) e 4 (comunicação e implementação). Tais gatilhos servem tanto como aceleradores do processo de mudança, como reforço para garantir a efetividade da mudança ou evolução cultural. É fundamental que tais gatilhos (projeto soft de transformação) sejam responsáveis por gerar e controlar a ansiedade das pessoas durante o processo de mudança e, associados aos projetos hard de transformação, possam produzir novas experiências positivas (resultados e benefícios) as quais devem ser construídas sob o ponto de vista de alterar os pressupostos básicos da organização. Somente os gatilhos não alteram os pressupostos básicos, crenças e valores. É preciso promover uma experiência positiva para que isso ocorra, portanto, é necessário conceber um Projeto de Transformação mais robusto contemplando aspectos hard (técnicos, associados a aspectos operacionais e tecnológicos) e soft (comportamentais, associados aos gatilhos de transformação).

Por sua vez, o Quadro 26 apresenta o detalhamento das etapas e atividades associadas à Sistemática de Transformação. É importante ressaltar que a partir da etapa "5 - Comunicar a visão e os gatilhos", têm-se início duas atividades em paralelo com as demais: Monitoramento da evolução dos esforços de mudança e Comunicação das mudanças realizadas, dos resultados e também dos benefícios atingidos. 


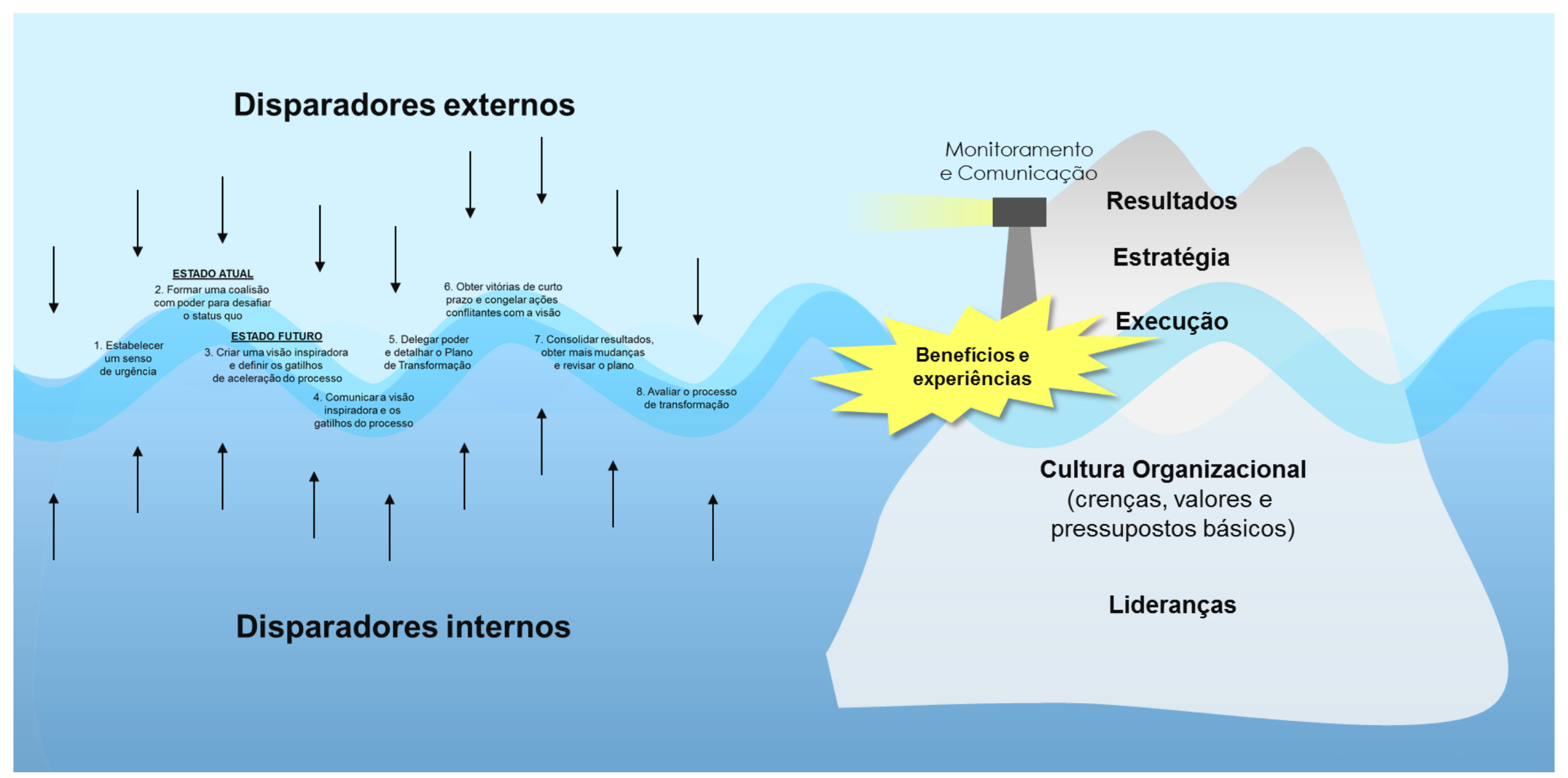

Figura 55 - O modelo dos oito passos revisado e o processo de transformação cultural 


\begin{tabular}{|c|c|c|c|}
\hline \# & Etapa & Principais questões da etapa & Principais entregas da etapa \\
\hline 1 & $\begin{array}{l}\text { Estabelecer um } \\
\text { senso de urgência }\end{array}$ & $\begin{array}{l}\text { Qual é o principal disparador da necessidade de } \\
\text { mudança? Por que a organização precisa mudar? }\end{array}$ & $\begin{array}{l}\text { Avaliar rapidamente quais são os disparadores do processo de mudança, e estabelecer } \\
\text { um senso de urgência com relação à necessidade de mudança. }\end{array}$ \\
\hline \multirow[t]{8}{*}{2} & \multirow{8}{*}{$\begin{array}{l}\text { Formar uma } \\
\text { coalisão com poder } \\
\text { suficiente para } \\
\text { desafiar o status quo }\end{array}$} & \multirow[t]{2}{*}{$\begin{array}{l}\text { Quais são as pessoas que possuem poder, credibilidade e } \\
\text { conhecimento suficiente para desafiar o status quo? }\end{array}$} & $\begin{array}{l}\text { Definir a equipe interna de coalisão com poder político suficiente para garantir a } \\
\text { efetividade do processo de mudança. }\end{array}$ \\
\hline & & & $\begin{array}{l}\text { Avaliar a necessidade de consultar expertise externa para guiar o processo de mudança } \\
\text { e, caso necessário, integrar estas pessoas na equipe de coalisão do projeto. }\end{array}$ \\
\hline & & $\begin{array}{l}\text { Todos da equipe de coalisão estão alinhados sobre o real } \\
\text { motivo pelo qual a organização precisa desafiar o status } \\
\text { quo e mudar? }\end{array}$ & Alinhamento da equipe de coalisão sobre o status quo. \\
\hline & & \multirow[t]{5}{*}{$\begin{array}{l}\text { Qual é o contexto atual da organização nas três dimensões } \\
\text { da Sistemática de Transformação? Quais são as principais } \\
\text { lacunas históricas de desempenho? }\end{array}$} & $\begin{array}{l}\text { Compreensão das forças internas e externas que podem servir de disparadores do } \\
\text { processo de mudança (Análise SWOT). }\end{array}$ \\
\hline & & & $\begin{array}{l}\text { Avaliação do desempenho atual e desejado da organização, com identificação das } \\
\text { principais lacunas de performance. }\end{array}$ \\
\hline & & & Diagnóstico e avaliação da Cultura Organizacional atual. \\
\hline & & & Compreensão e avaliação do Posicionamento Estratégico atual da organização. \\
\hline & & & $\begin{array}{l}\text { Avaliação dos principais projetos em andamento ou já realizados no passado recente da } \\
\text { organização. }\end{array}$ \\
\hline \multirow[t]{2}{*}{3} & \multirow{2}{*}{$\begin{array}{l}\text { Criar uma visão } \\
\text { inspiradora e } \\
\text { definir os gatilhos } \\
\text { de aceleração do } \\
\text { processo }\end{array}$} & $\begin{array}{l}\text { Todos da equipe de coalisão estão alinhados sobre o } \\
\text { verdadeiro propósito de existência da organização? Este } \\
\text { propósito está coerente com o desejo de transformação? }\end{array}$ & Alinhamento, revisão e validação do propósito da organização. \\
\hline & & $\begin{array}{l}\text { Onde a organização pretende chegar com as mudanças } \\
\text { que estão por vir? }\end{array}$ & Definir uma visão coerente, simples e inspiradora. \\
\hline
\end{tabular}

165 


\begin{tabular}{|c|c|c|c|}
\hline & & $\begin{array}{l}\text { Estas mudanças podem ser implementadas pela } \\
\text { organização? }\end{array}$ & $\begin{array}{l}\text { Construção do alinhamento desejado nas três dimensões da Sistemática de } \\
\text { Transformação, envolvendo Cultura, Estratégia e Projeto de Transformação. }\end{array}$ \\
\hline & & $\begin{array}{l}\text { Se as mudanças forem implementadas de maneira bem- } \\
\text { sucedida, o que os principais interessados e envolvidos no } \\
\text { processo têm a ganhar com isto? Estes benefícios fazem } \\
\text { valer a pena o esforço e alocação de recursos que } \\
\text { ocorrerá? }\end{array}$ & $\begin{array}{l}\text { Avaliar quais serão os benefícios para os principais interessados e envolvidos no } \\
\text { processo de transformação. }\end{array}$ \\
\hline & & $\begin{array}{l}\text { Quais são os gatilhos que serão utilizados para disparar o } \\
\text { processo de mudança? }\end{array}$ & $\begin{array}{l}\text { Realizar uma avaliação e propor mudanças gatilhos a partir dos Elementos de Gestão } \\
\text { de Recursos Humanos. É importante que estes gatilhos reforcem o "senso de urgência" } \\
\text { do engajamento das pessoas no processo de mudança. }\end{array}$ \\
\hline \multirow[t]{3}{*}{4} & \multirow[t]{3}{*}{$\begin{array}{l}\text { Comunicar a visão } \\
\text { e os gatilhos }\end{array}$} & \multirow[t]{2}{*}{$\begin{array}{l}\text { Os principais interessados e envolvidos no processo de } \\
\text { transformação conhecem a visão de futuro da organização } \\
\text { e estão motivados com as mudanças que estão por vir? }\end{array}$} & $\begin{array}{l}\text { Realizar diversas ondas de comunicação em diferentes meios abordando a visão de } \\
\text { futuro da organização (estratégia e cultura). Novamente, é importante que esta } \\
\text { comunicação reforce o "senso de urgência" em torno do processo de mudança. }\end{array}$ \\
\hline & & & $\begin{array}{l}\text { Realizar trabalhos individuais com os Líderes e as pessoas chave do processo de } \\
\text { transformação, identificando e avaliando a forma como se sentem, além de definir } \\
\text { planos de ações individuais para que estas pessoas possam crescer na organização e } \\
\text { estimular outras pessoas em prol da Cultura Organizacional desejada. }\end{array}$ \\
\hline & & $\begin{array}{l}\text { Quais serão os ganhos e as perdas das pessoas como } \\
\text { processo de mudança? }\end{array}$ & $\begin{array}{l}\text { Além do processo de comunicação de maneira geral, é importante também ter um } \\
\text { trabalho individualizado de alinhamento dos líderes e pessoas chave do processo de } \\
\text { transformação, avaliando como cada pessoa se sentem com o processo e definindo } \\
\text { novas açôs (coletivas ou individuais) para o sucesso da jornada coletiva. Nesse } \\
\text { momento, é fundamental ter o suporte de uma equipe especializada que compreenda } \\
\text { modelos mais profundos do ponto de vista dos indivíduos, como o de Kluber-Ross } \\
\text { (1969) e Satir et al. (1991), de tal maneira a reduzir resistência e garantir a efetividade } \\
\text { do processo de transformação. }\end{array}$ \\
\hline \multirow[t]{3}{*}{5} & \multirow[t]{3}{*}{$\begin{array}{l}\text { Delegar poder e } \\
\text { detalhar o Plano } \\
\text { de Transformação }\end{array}$} & $\begin{array}{l}\text { Quais outras pessoas precisam estar mais envolvidas nas } \\
\text { próximas ondas de engajamento do processo de mudança? }\end{array}$ & $\begin{array}{l}\text { Mapear os principais Stakeholders que precisam participar do processo, e definir } \\
\text { responsáveis para as principais entregas do processo de mudança. }\end{array}$ \\
\hline & & $\begin{array}{l}\text { Quais ações e mudanças devem ocorrer? Qual é a lógica } \\
\text { de desdobramento destas mudanças, do ponto de vista } \\
\text { hierárquico e do fluxo de valor? }\end{array}$ & \multirow{2}{*}{$\begin{array}{l}\text { Detalhar o Plano de Transformação seguindo a lógica de Desdobramento do Método } \\
\text { A3, distinguido cenários de curto, médio e longo prazo. Como sugestão, é interessante } \\
\text { consultar e revistar sistemática aspectos "hard" do processo de mudança, como por } \\
\text { exemplo, utilizar o DICE MODEL de Sirkin } \text { et al. (2005). }\end{array}$} \\
\hline & & $\begin{array}{l}\text { Quais são os principais Quick Wins planejados? Como é } \\
\text { possível garantir que estas açães trarão resultados } \\
\text { significativos de curto prazo? Quando as mudanças }\end{array}$ & \\
\hline
\end{tabular}

166 


\begin{tabular}{|c|c|c|c|}
\hline & & $\begin{array}{l}\text { deverão ocorrer? Como as mudanças serão avaliadas? } \\
\text { Quais são as respectivas metas e objetivos? }\end{array}$ & \\
\hline & & $\begin{array}{l}\text { Quem serão as pessoas responsáveis pela execução destas } \\
\text { mudanças? Os times de projeto serão multidisciplinares? }\end{array}$ & \\
\hline & & $\begin{array}{l}\text { Haverá uma frente de projeto dedicada aos aspectos de } \\
\text { mudança comportamentais? }\end{array}$ & \multirow{2}{*}{$\begin{array}{l}\text { Observar eventuais lacunas organizacionais e avaliar o alinhamento das três dimensões } \\
\text { da Sistemática de Transformação. Estruturar uma frente de projeto que mantenha foco } \\
\text { no processo de mudança e também em questões comportamentais (cultura } \\
\text { organizacional), ou seja, trabalhando aspectos do lado soft da mudança. Em muitos } \\
\text { casos, além de trabalhos aspectos comportamentais em nível coletivo (equipe ou } \\
\text { organização), será necessário trabalhar aspectos soft em nível individual, afinal, cada } \\
\text { indivíduo terá percepções e experiências diferentes desta jornada de transformação. }\end{array}$} \\
\hline & & $\begin{array}{l}\text { Quais mudanças esta frente de gestão de mudanças deverá } \\
\text { realizar na organização? Como estas mudanças serão } \\
\text { avaliadas? }\end{array}$ & \\
\hline \multirow[t]{6}{*}{6} & \multirow{6}{*}{$\begin{array}{l}\text { Obter vitórias de } \\
\text { curto prazo e } \\
\text { congelar as ações } \\
\text { conflitantes com } \\
\text { a visão de futuro }\end{array}$} & $\begin{array}{l}\text { Qual é o planejamento e escopo de implementação das } \\
\text { Quick Wins? Qual o resultado esperado? }\end{array}$ & \multirow[t]{3}{*}{ Implementação de mudanças que gerem resultados expressivos já no curto prazo. } \\
\hline & & $\begin{array}{l}\text { Qual a estratégia e o plano detalhado de implementação } \\
\text { das Quick Wins? }\end{array}$ & \\
\hline & & $\begin{array}{l}\text { Como as Quick Wins serão avaliadas? Como os resultados } \\
\text { das Quick Wins serão controlados? }\end{array}$ & \\
\hline & & $\begin{array}{l}\text { Quais são as ações e projetos de mudança em andamento } \\
\text { atualmente na organização? Quais mudanças são } \\
\text { conflitantes com a estratégia ou cultura futura? }\end{array}$ & $\begin{array}{l}\text { Obter informações e realizar alinhamento sobre as mudanças em andamento. Definir } \\
\text { quais ações podem ser concluídas e quais devem ser congeladas, bem como deixar } \\
\text { claro o motivo de cada definição. }\end{array}$ \\
\hline & & $\begin{array}{l}\text { Qual o prazo limite para que estas mudanças conflitantes } \\
\text { com a visão estratégica sejam encerradas ou congeladas? }\end{array}$ & $\begin{array}{l}\text { Comunicar aos gestores, líderes de projeto e equipes quais ações podem ser concluídas } \\
\text { e qual o prazo limite para este encerramento, tal como comunicar quais ações precisam } \\
\text { ser congeladas e qual o procedimento a ser seguido. Comunicar de maneira } \\
\text { transparente e objetiva o motivo de ambas escolhas. }\end{array}$ \\
\hline & & $\begin{array}{l}\text { Quais serão os ganhos e as perdas das pessoas com a } \\
\text { mudança? }\end{array}$ & $\begin{array}{l}\text { Em muitos casos é importante mostrar para as pessoas os ganhos e as perdas com a } \\
\text { mudança. Este fato deve ser trabalhado de maneira cuidadosa e individualizada por } \\
\text { uma equipe especializada. }\end{array}$ \\
\hline 7 & $\begin{array}{l}\text { Consolidar } \\
\text { resultados, obter }\end{array}$ & $\begin{array}{l}\text { Os resultados obtidos até o momento são satisfatórios? } \\
\text { Quais são as lições aprendidas até o momento? }\end{array}$ & Avaliar os resultados e as lições aprendidas até o momento. \\
\hline
\end{tabular}




\begin{tabular}{|c|c|c|c|}
\hline & \multirow[t]{5}{*}{$\begin{array}{l}\text { mais mudanças e } \\
\text { revisar o plano }\end{array}$} & $\begin{array}{l}\text { O escopo das Quick Wins pode ser expandido para outras } \\
\text { áreas além dos projetos pilotos? }\end{array}$ & Avaliar as Quick Wins implementadas. \\
\hline & & $\begin{array}{l}\text { Quais são as próximas etapas do Plano de } \\
\text { Transformação? }\end{array}$ & Analisar a evolução do Plano de Transformação. \\
\hline & & $\begin{array}{l}\text { Existem outras ações, não contempladas anteriormente no } \\
\text { plano de transformação, que poderiam ser realizadas? }\end{array}$ & Realizar novas ondas (ciclos) de mudança e engajamento de pessoas. \\
\hline & & $\begin{array}{l}\text { Quais outras pessoas poderiam ser incluídas no processo } \\
\text { de transformação? }\end{array}$ & $\begin{array}{l}\text { Avaliar as próximas ondas de mudança, a continuidade e ampliação do escopo do } \\
\text { Plano de Transformação. }\end{array}$ \\
\hline & & $\begin{array}{l}\text { Quando as próximas ações serão realizadas? Quem serão } \\
\text { os responsáveis pela realização destas mudanças? }\end{array}$ & Retornar à etapa 8 e obter mais vitórias. \\
\hline \multirow[t]{3}{*}{8} & \multirow[t]{3}{*}{$\begin{array}{l}\text { Avaliar o processo } \\
\text { de transformação }\end{array}$} & $\begin{array}{l}\text { O processo de transformação produziu os resultados } \\
\text { esperados? Quais foram os aprendizados do processo? }\end{array}$ & Avaliar as conquistas e aprendizados do processo. \\
\hline & & Foi possivel atingir um novo status quo? & $\begin{array}{l}\text { Realizar uma nova avaliação das três dimensões da Sistemática de Transformação: } \\
\text { estratégia, cultura e projeto. }\end{array}$ \\
\hline & & $\begin{array}{l}\text { Quais benefícios os interessados e envolvidos no processo } \\
\text { de transformação tiveram? Quais são os próximos passos: } \\
\text { é preciso retornar aos passos anteriores, entrar em um } \\
\text { período de consolidação das mudanças implementadas ou } \\
\text { já iniciar um novo Processo de Transformação? }\end{array}$ & $\begin{array}{l}\text { Avaliar e comunicar os benefícios obtidos. Após profunda avaliação do processo de } \\
\text { transformação, é preciso definir a necessidade de gerar novas açôes de mudança } \\
\text { alinhadas aos objetivos do processo de transformação, retornar a etapas anteriores do } \\
\text { processo ou até mesmo definir novas ações de consolidação (congelamento) das } \\
\text { mudanças efetuadas de maneira bem-sucedidas, garantindo assim a manutenção das } \\
\text { mudanças no longo prazo. Por fim, de tempos e em tempos será necessário iniciar o } \\
\text { processo novamente. }\end{array}$ \\
\hline
\end{tabular}

\section{Quadro 26 - Detalhamento dos passos da Sistemática de Transformação}




\section{O Iceberg Organizacional}

Existem diversas maneiras e dimensões de visualizar uma organização. Schein (2009), por exemplo, cita os Artefatos visíveis, crenças, valores e pressupostos básicos. O Balanced Scorecard de Kaplan e Norton (2005), por sua vez, visualiza uma organização em quatro perspectivas: financeira, clientes, processos e aprendizado. O modelo de Gattorna (2009) visualiza a organização em quatro dimensões: mercado, estratégia, cultura e liderança. Os modelos de melhoria (ver o Método A3 seção 3.2.4), compreendem a organização em três níveis: estratégico, tático e operacional.

Existem diversas formas de olhar uma organização, assim também como existe uma divisão de dois mundos na teoria e prática: o mundo hard (técnico) e o mundo soft (comportamental), como identificado no levantamento dos estudos de caso deste trabalho. No entanto, é preciso reconhecer que uma organização não é apenas um ou outro, mas sim os dois mundos ao mesmo tempo. No objetivo de integrar estes dois mundos, este trabalho apresenta também a proposta das "cinco dimensões de análise do alinhamento organizacional", conforme ilustrado na figura a seguir: resultados, estratégia, execução, cultura e liderança.

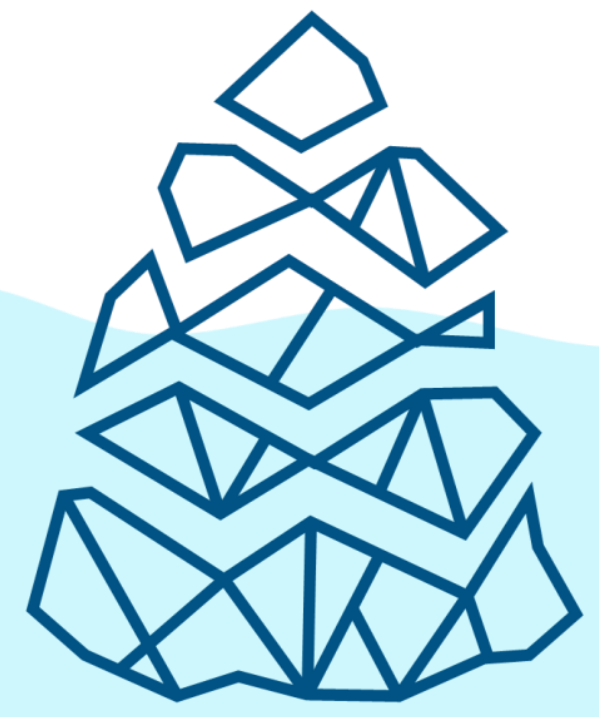

\section{Resultados}

\section{Estratégia}

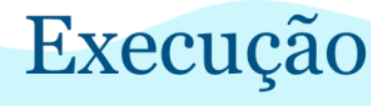

Cultura

Liderança

Figura 56 - Cinco dimensões de análise do alinhamento organizacional

Portanto, a partir destas cinco dimensões é possível avaliar o estado atual (status quo) e projetar o estado futuro das organizações de maneira ampla, projetando não apenas as novas 
experiências que as lideranças precisam realizar, como também reconhecendo que estas precisam estar conectadas com a Cultura Futura a ser promovida, a qual no nível de Execução deve dar subsídio à estratégia futura para produzir resultados positivos. São as novas experiências e os novos resultados positivos que irão promover uma mudança do ponto de vista das crenças, valores e pressupostos básicos (nível cultural). Para que isso ocorra, tanto quanto a existência de projetos soft (envolvendo os gatilhos de aceleração do processo de mudança), quanto projetos hard (técnicos, operacionais e tecnológicos) para, juntos, desafiar o status quo, promover pressões e ansiedade positiva.

\subsection{Constatação}

\section{Validação dos conceitos propostos}

A sistemática teórica proposta pode ser validada, do ponto de vista conceitual, através das falhas identificadas tanto na literatura quanto nos estudos de caso presentes na literatura. Esta abordagem, além de ser semelhante à utilizada por Kotter (1995), tem como referência as falhas já identificadas pelo mesmo autor.

\section{Falha 1: Foco em mudanças "urgentes", porém nem sempre "prioritárias".}

Muitos dos modelos de mudança (teoria) e casos levantados (prática) começam gerando uma crise em torno de uma mudança urgente, não possuindo uma compreensão clara da importância e prioridade desta mudança em detrimento às demais possibilidades. Por que é preciso realizar esta mudança? E por que ela tem que ocorrer agora? Por que não serão realizadas outras mudanças? Estas, são apenas algumas das perguntas que os modelos de mudança atuais (teoria) e os estudos de caso levantados (prática) parecem não responder. Tão importante quanto identificar quais mudanças devem ocorrer, é entender e compreender de maneira profunda o motivo pelo qual estas mudanças precisam ocorrer.

Provavelmente, com o fortalecimento do modelo dos Oito Passos de Kotter (1995) em detrimento aos demais modelos, tudo indica que houve um certo esquecimento da importância da etapa "Descongelar" proposta por Lewin (1951). Segundo Lewin (1951), antes de começar a planejar as mudanças que irão ocorrer, deve-se descongelar o estado atual da organização, ou seja, devem ser identificadas as forças propulsoras e resistências que impossibilitam de se 
atingir o estado desejado. Os estudos de caso levantados aparentam seguir a lógica de Kotter (1995), e por este motivo podem repercutir o erro de realizar mudanças que sejam "urgentes", porém não “importantes”. Inclusive, justamente por não realizar um diagnóstico da cultura organizacional, as mudanças propostas podem não estar alinhadas com a Cultura Atual da organização, ou até mesmo, podem ser conflitantes com a Cultura Desejada para a organização no futuro. Lewin (1951) sugere que na etapa "Descongelar" o agente de mudança deva fazer a análise do "Campo de Forças", de tal maneira que seja possível tornar visíveis as forças propulsoras e de resistência já imaginando o estado final desejado com as mudanças. Ou seja, antes de iniciar a etapa "Mudar", Lewin (1951) propõe uma compreensão mais ampla e profunda sobre como deverá ser o processo para obter participação e envolvimento.

Ainda, neste momento de definição das mudanças, outra falha que pode ocorrer é justamente não analisar ou compreender de maneira profunda a Cultura Organizacional atual (“Culture eats Strategy For Breakfast"21, como já citado por Peter Drucker). Segundo Carnall (1986), é preciso compreender bem não apenas as pressões externas (recessão, entrada de concorrentes, novas tecnologias no mercado e outros fatores), mas também as pressões internas (estrutura organizacional, confiança, tecnologias, fluxo de caixa, desempenho dos processos e outros fatores internos).

\section{Falha 2: Ausência de uma estrutura sólida para desafiar o status quo.}

A estrutura organizacional das empresas foi elaborada para executar as necessidades operacionais das empresas, mas são rígidas demais para se ajustar às rápidas mudanças pelas quais as organizações precisam atravessar. Segundo Kotter (1995), muitos programas de mudança falham justamente por começarem com apenas uma ou duas pessoas. Esforços que não possuam uma coalisão forte e com poder suficiente para desafiar o status quo organizacional não irão conseguir chegar às próximas etapas do processo de transformação.

Associada à questão de formar uma coalisão forte, Kotter (2012) questiona a limitação que as estruturas organizacionais hierárquicas, mais voltadas para executar as necessidades operacionais das empresas, possam proporcionar para a efetividade do processo de mudança. Segundo o autor, é preciso começar a elaborar uma "estrutura de mudanças ágeis" em paralelo à estrutura organizacional. A estrutura ágil de planejamento e execução de mudanças, proposta

\footnotetext{
${ }^{21}$ Esta frase é atribuída a Peter Drucker (Fonte: COFFMAN, CURT. (2013). Culture Eats Strategy for Lunch. Hardcover. Liang Addison Press, $1^{\text {st }}$ Edition).
} 
por Kotter (2012), ilustra este conceito. Nesta etapa, não é preciso montar toda a estrutura, mas, é preciso que a Coalisão Diretora seja formada já abordando este conceito, incluindo, portanto, líderes multidisciplinares e com poder suficiente nos diversos departamentos da estrutura organizacional.

\section{Falha 3: Ausência de uma visão inspiradora.}

A ausência de uma visão inspiradora pode não promover o engajamento necessário das pessoas no processo de transformação e, inclusive, pode promover a falta de foco e alinhamento da coalisão em torno de visões conflitantes. Kotter (1995, p. 7) argumenta sobre a necessidade de se estabelecer uma visão:

"Em toda transformação bem-sucedida na qual eu pude participar, a coalisão diretora desenvolveu uma figura do futuro que fosse relativamente fácil de ser comunicada aos diversos interessados no processo, aos clientes e aos funcionários. Uma visão sempre inspira as pessoas para além dos números que são geralmente encontrados em planos de cinco anos. Uma visão diz algo que ajuda a clarificar a visão da direção na qual a organização pretende mudar... (...) sem uma visão inspiradora, os esforços de mudança podem facilmente se dissolver em uma lista de projetos confusos e incompatíveis que podem levar a organização em uma direção errada ou a lugar algum”.

Complementando o ponto de vista de Kotter (1995), é importante que esta visão traga uma resposta à "Fórmula da Mudança" proposta por Beckhard e Harris (1987). A Fórmula da Mudança contempla fatores que demonstram que as mudanças somente ocorrerão quando o nível de insatisfação das pessoas com a situação atual, o desejo de implementar as mudanças

propostas e, também, a praticabilidade da mudança (isto é, baixo risco e capacidade de implementar as mudanças propostas) forem superiores ao custo de realizar a mudança. Portanto, estes são alguns elementos que precisam ser solucionados e respondidos através de uma visão inspiradora, de tal maneira a conquistar o maior número de adeptos no processo de mudança.

\section{Falha 4: Subestimar a relevância da Cultura Organizacional.}

Pouco se discute a importância de Gerenciar a Cultura Organizacional antes, durante ou após o Processo de Transformação. Este fenômeno se repete tanto na literatura quanto nos 
estudos de caso levantados. Inclusive, o principal modelo de mudança, Os Oito Passos de Kotter (1995), considera aspectos cultura somente no último passo: "consolidar as mudanças realizadas na cultura organizacional", como se fosse possível simplesmente "colar as mudanças na cultura". A cultura organizacional é um fenômeno mais complexo do que isto. Não é possível mudar uma cultura, mas é possível transformá-la. E essa transformação exige um processo contínuo de direcionamento das crenças e valores por parte da liderança.

Dependendo do contexto, tanto do ponto de vista da Estratégia, da Cultura Organizacional e também do Projeto de Transformação, o fator Cultura Organizacional pode ser encarado como uma barreira ou como uma alavanca impulsionadora do processo de transformação. Nesse sentido, antes ou até mesmo durante o processo de transformação, é necessário reduzir ou eliminar algumas crenças e valores, assim também como pode ser necessário estimular, promover ou fazer crescer outras crenças e valores as quais estejam alinhadas com o propósito da organização.

Sob este ponto de vista, a literatura (Adebanjo e Kehoe, 1999; Mann, 2003; Robbins, 2005; Vakola, Soderquist e Prastacos, 2007; Gattorna, 2009) propõe uma série de práticas de Gestão de Recursos Humanos que podem ser utilizadas como "impulsionadoras" ou "gatilhos" desse processo de gestão e alinhamento cultural. Por exemplo, antes do início do Programa de Lean envolvendo a aplicação de ferramentas (hard), alguns elementos como Estrutura Organizacional, Sistema de Avaliação de Desempenho e Sistema de Recompensas, para não citar outros, podem ser revistos e alterados em busca de estimular e direcionar os recursos humanos em prol das mudanças que estão por vir. Desta maneira, pode ser possível reduzir possíveis barreiras ou até mesmo impulsionar novos comportamentos desejáveis.

\section{Falha 5: Não comunicar a visão do processo e não gerar senso de urgência.}

A falha de não comunicar a visão do processo de mudança já foi amplamente discutida nos textos de Gestão de Mudanças, além de ser uma etapa do modelo dos Oito Passos de Kotter (1995). Segundo Kotter (1995), muitos esforços de transformação falham justamente por não agregarem milhares de pessoas no processo de mudança e, para que isto ocorra, é preciso que haja comunicação contínua e frequente. 


\section{Falha 6: Não encerrar as mudanças já existentes.}

Novamente, com o fortalecimento do modelo proposto por Kotter (1995), aparentemente houve uma negligencia das etapas "Fim" e "Zona Neutra" propostas por Bridges (1991). Com efeito desta prática, as organizações podem repercutir o erro de realizar mudanças que sejam "urgentes", porém não "importantes" ou, o que pode ser pior, podem realizar simultaneamente mudanças que sejam conflituosas ou dissonantes. Segundo Bridges (1991), é fundamental encerrar as mudanças que já estão ocorrendo (“fim”) antes de iniciar novas mudanças. Dado o contexto atual no qual as organizações estão inseridas, com mudanças cada vez mais frequentes e ágeis, é preciso reconhecer a importância de, em determinado momento do processo de mudança, avaliar a direção das mudanças que já estavam ocorrendo na organização: será que todas precisam de fato ocorrer? Seriam todas as mudanças estratégicas? Provavelmente não. Por se tratar de um Processo de Transformação grande, haverá uma grande alocação de recursos. E esta alocação de recursos tem que ocorrer para que o processo seja bem-sucedido. Caso os gerentes fiquem duelando pelo uso de recursos em projetos distintos, há o risco de a motivação das pessoas reduzir, disseminando esforços e o desejo para que o processo de transformação seja bem-sucedido. Inclusive, por se tratar de um processo de transformação, um aspecto crucial é que haja foco em uma única grande mudança associada à visão estratégica da organização.

\section{Falha 7: Realizar mudanças de curto prazo desconexas de um plano maior.}

Como já apresentado na "Seção 3.4.3 - Barreiras à Mudança Organizacional”, segundo Rentes (2002) a inexistência de uma Plano de Transformação com milestones pode significar uma barreira às mudanças transformacionais. Isto pode ocorrer tanto pela ausência de "foco" no processo de planejamento e implementação das mudanças, como também pelo fato de, depois das primeiras mudanças implementadas, os envolvidos no processo perderem a visão das próximas ondas de mudança que estão por vir.

Por se tratar de um processo de transformação, deve haver uma sequência de mudanças estruturadas, e não apenas uma única mudança. Portanto, é importante que haja um alinhamento sobre quais são as mudanças planejadas e quando estas mudanças deverão ocorrer, justamente por tratarmos de planejamentos e implementações que irão ocorrer ao longo dos próximos anos. Esta é uma falha identificada em muitos dos modelos de mudança atuais, os 
quais de certa maneira negligenciam os aspectos hard das mudanças, como também nos estudos de caso levantados.

\section{Falha 8: Não obter resultados no curto prazo.}

O processo de mudança requer um tempo de amadurecimento, mas, se não houverem resultados visíveis no curto prazo, é muito provável que os esforços de mudança se dispersem, comprometendo toda a jornada (Schaffer e Thomson, 1992). Segundo Kotter (1995), a maioria das pessoas não irá embarcar na jornada de longo prazo caso não haja resultados expressivos nos primeiros 12 ou 24 meses do processo de mudança. A qualidade do processo de transformação será equivalente ao impacto dos resultados que forem obtidos, se não forem obtidos bons resultados a qualidade da mudança irá cair, dá mesma maneira que se forem obtidos bons resultados, a qualidade da mudança tende a crescer (Kotter, 1995). A obtenção de bons resultados motiva as pessoas a continuarem na jornada.

Para Schaffer e Thomson (1992), um programa de mudança bem-sucedido começa com resultados. Kotter (1995) parece também concordar com este ponto de vista, tanto que insere um passo específico em seu modelo para abordar a necessidade de obter "Quick Wins" durante o processo de mudança, as quais produzam resultados significativos. A única diferença é que, antes de chegar aos resultados, o modelo de Kotter (1995) parte da necessidade de formular consenso, visão e comunicação sobre o processo de mudança que está por vir.

\section{Falha 9: Declarar vitória cedo demais.}

Obter vitórias de curto prazo é importante para motivar e engajar pessoas no processo de mudança, no entanto, apenas vitórias de curto prazo não garantem a efetiva concretização do processo de transformação: é preciso realizar mais mudanças que reforcem o projeto de transformação. Segundo Kotter (1995), depois de algum tempo de trabalho os gerentes podem querer declarar vitória quando tiverem obtido o primeiro ganho de performance significativo, mas, embora celebrar uma vitória seja importante, declarar "guerra vencida" pode ser demasiado cedo. Por este motivo, é importante que os gestores tenham definido um Plano de Transformação de curto, médio e longo prazo, de tal maneira que antecipadamente tenham a visão de quais mudanças precisam ocorrer e, desta maneira, possam realizar o devido controle e monitoramento das mudanças. 
Falha 10: Não avaliar os resultados e aprendizados do processo e, consequentemente, não definir os próximos passos da evolução organizacional.

Schaffer e Thomson (1992) e Carnall (1986) concordam que o processo de mudança precisa produzir resultados, inclusive, Carnall (1986) acrescenta que grandes mudanças estão associadas com aprendizados. Portanto, uma possível falha que os gestores podem cometer é não avaliar e mensurar os resultados e os aprendizados do processo. Isso pode ser importante não apenas para medir a efetividade das mudanças realizadas até o momento, mas também para definir quais serão as próximas mudanças: é preciso corrigir algum ponto específico? Desenvolver um novo projeto? Reforçar algum comportamento? Instituir novas práticas? Reformular a visão do processo de mudança? Em que momento será declarada a vitória? Estas são algumas perguntas que precisam ser respondidas ou pelo menos levantadas, e este deveria ser o momento apropriado.

\section{Resultados Esperados}

Além de fornecer uma proposta teórica de sistemática para o processo de alinhamento da Cultura Organizacional com o alinhamento dos projetos de melhoria, o primeiro resultado esperado com este trabalho é o subsídio teórico e estímulo à discussão sobre Cultura Organizacional dentro da área de Gestão de Operações.

Com relação à aplicação prática, caso a sistemática seja devidamente validada, é provável esperar que pesquisadores, consultores, gestores e agentes de mudança possam fazer uso desta proposta teórica nas próximas iniciativas de transformação organizacional, objetivando desta maneira reduzir a taxa de insucesso das iniciativas de mudança, as quais variam entre 66\% a 90\% dos casos (Graham, 1991; Walker, 1992; Sirkin et al., 2005; Bicheno e Holweg, 2009; Atkinson, 2010; Bhasin, 2011b; Saurin et al., 2011; Bhasin, 2012a). Seria muita ingenuidade acreditar que esta taxa de insucesso possa ser eliminada com a simples aplicação desta proposta teórica, porém, dada a relevância do contexto de gestão de mudanças para as organizações, é preciso reconhecer que todo esforço para garantir a efetividade das ações de mudança é relevante. 


\section{Validação prática}

A construção da sistemática proposta foi feita a partir de 15 estudos de caso levantados na literatura e tem embasamento teórico nas falhas levantadas anteriormente, não possuindo validação prática por ainda não ter sido ainda aplicada - está no campo na teorização. Com relação aos estudos de caso presentes na literatura, é importante reforçar que todos possuem visões distintas sobre o processo de transformação, podendo estas visões serem agrupadas em duas lentes: alguns pesquisadores acabam tendo uma visão "hard" enquanto outros abordam aspectos mais "soft". Em todos os casos analisados, não foi levantado um único estudo de caso que fizesse uma análise integrada entre Estratégia, Cultura Organizacional e Projeto de Transformação, o que novamente inviabiliza uma validação prática da sistemática proposta.

A ausência de uma aplicação prática da sistemática proposta representa uma limitação da pesquisa e, portanto, faz-se necessário a execução de trabalhos futuros, com caráter prático, no intuito de constatar a validade de tal proposta teórica. 


\section{CONCLUSÕES E \\ CONSIDERAÇÕES FINAIS}

\subsection{Conclusões}

\section{Sintese}

Este trabalho envolveu o estudo e análise da literatura relacionada à intersecção de quatro grandes áreas, Estratégia, Melhoria Contínua, Cultura Organizacional e Gestão de Mudanças - disponíveis no Capítulo 3. Além deste estudo da literatura existente, o trabalho propôs uma sistemática conceitual no contexto de Projetos de Transformação envolvendo os trabalhos de Lean, e ainda sintetizou recomendações e apresentou os potenciais benefícios desta sistematização - disponíveis no Capítulo 4. Desta maneira, ao atender os objetivos específicos de pesquisa, é possível concluir que o trabalho atendeu seu objetivo de "propor uma sistematização teórica do processo de transformação organizacional de desenvolvimento dos Programas de Lean envolvendo mudança ou evolução cultural'.

Desta maneira, ao atingir o objetivo proposto por este trabalho, foi possível responder à questão de pesquisa: como pode ser sistematizado o processo de transformação organizacional abrangendo aspectos de mudança e evolução da cultura organizacional? Sob o ponto de vista deste trabalho teórico, a resposta a esta questão está presente no Capítulo 4 deste trabalho, sendo ilustrada nas Figuras 51, 54 e 55, com descrição detalhada no Quadro 26. Nesse sentido, a principal contribuição deste trabalho está na consolidação de conceitos, já presentes na literatura, através da proposição de uma Sistemática de Transformação. A partir deste conjunto de conhecimentos e conceitos, tanto os pesquisadores da área podem ter um ponto de referência para direcionar futuras pesquisas, quanto os gestores e agentes de mudança podem ter um corpo de conhecimentos que sirva como "guia do processo de transformação".

Embora o resultado final do trabalho possa ser considerado relevante para a literatura em questão, o objetivo do trabalho tenha sido atingido e a questão de pesquisa respondida, é 
importante ressaltar que o trabalho possuí limitações do ponto de vista prático. Trata-se de um trabalho teórico que carece de implementação prática para ter sua validade prática constatada. De qualquer forma, este trabalho possui relevância para a literatura do ponto de vista de analisar “o que está presente na literatura", "o que não está presente" e "o que precisa ser desenvolvido" em termos conceituais, sobretudo, para a área de Gestão de Operações. Portanto, este trabalho pode ser compreendido como disparador de pesquisas e trabalhos futuros nessa temática.

\section{Aprendizados obtidos}

Embora a literatura sobre Estratégia, Lean, Gestão de Mudanças e Cultura Organizacional seja vasta e profunda em cada uma das grandes áreas separadamente, como constatado neste trabalho, ela é pouco robusta do ponto de vista "superficial", ou seja, na fronteira do conhecimento entre estas quatro grandes áreas. Isto pode explicar o fato de muitos autores de Gestão de Operações banalizarem o termo "Cultura Organizacional” em seus trabalhos, abordando este elemento importante com pouca profundidade. Nesse sentido, os principais aprendizados obtidos neste trabalho fazem menção à revisão e consolidação da literatura sobre estas quatro grandes áreas, sempre tendo como foco os Projetos de Lean.

Sob o ponto de vista estratégico, o sucesso de implementação da estratégia ocorre quando há um alinhamento coerente entre a "proposta de valor" (plano estratégico) e a "entrega de valor" (execução no nível operacional). Por sua vez, o insucesso na implementação está associado a falhas no planejamento, na execução ou até mesmo no alinhamento entre proposta (plano estratégico) e entrega de valor (execução operacional). Para tratar deste alinhamento, foi identificado na literatura um possível relacionamento entre o modelo das Disciplinas de Valor ("Proposta de Valor") de Treacy e Wieserma (1993) com o modelo do Competing Values Framework ("Entrega de Valor") de Cameron e Quinn (2006), sendo, portanto, modelos de referência para realizar o alinhamento entre estratégia e execução.

Com relação aos projetos de mudança que objetivam modificar o contexto estratégico, na prática diversos autores apontam para uma elevada taxa de insucesso: cerca de $66 \%$ a $90 \%$ dos projetos falham (Graham, 1991; Walker, 1992; Kaplan e Norton, 2005; Sirkin et al., 2005; Atkinson, 2010; Bhasin, 2011; Bhasin, 2012; Sull, Homkes e Sull, 2015; Prosser, 2015). Neste cenário apresentado, tendo os Projetos de Lean como pano de fundo, a Cultura Organizacional 
é indicada como sendo a principal causa deste insucesso (Touche, 2002; Lean Enterprise Institute Survey, 2004; Lean Enterprise Institute Survey, 2005).

Inclusive, como já apresentado nos Fatores Críticos de Sucesso do Lean, a Cultura Organizacional pode ser compreendida como um dos principais fatores crítico de sucesso pois, como constatado, é possível associar todos os fatores críticos aos elementos de administração de Recursos Humanos, os quais são utilizados por Robbins (2005) e Gattorna (2009) como elementos de ação do ponto de vista de mudança cultural.

No contexto da literatura sobre Lean e Melhoria Contínua, além da identificação dos Fatores Críticos de Sucesso do Lean, já apresentados, foi possível identificar que os modelos de melhoria apresentam passos lineares que seguem raciocínios e lógicas semelhantes: todos passam pela definição de um objetivo, identificação de problemas e causas raiz, proposição de mudanças e um estado futuro, definição de um plano de ação e, por fim, terminam com o controle das mudanças implementadas. Como já discutido, esses modelos visualizam as organizações como "máquinas" e por isso dão ênfase em aspectos "hard" em detrimento a aspectos "soft". Como consequência, é esperado que a aplicação única e exclusiva destes modelos implique em certas negligências do ponto de vista cultural. Ou seja, não compreendem a organização como um sistema social ("mini sociedade", possuindo valores, crenças e ideologias intrínsecas.

Por sua vez, na literatura sobre Gestão de Mudanças, foi identificado que os modelos de mudança possuem visões e níveis de compreensão diferentes de uma determinada organização. Ao fazer o relacionamento dos modelos encontrados na literatura com as metáforas organizacionais propostas por Morgan (1998), foi possível identificar que os modelos possuem alguns "pontos cegos" em determinadas metáforas. Por exemplo, sob o ponto de vista deste trabalho, são poucos os modelos que enxergam as organizações como "Cérebro", "Cultura", "Prisão Psíquica", "Fluxo de Transformação" e "Instrumento de Dominação". A grande maioria dos modelos tende a visualizar as organizações como "Máquina" e "Organismo". Neste aspecto, foi também identificado que o modelo mais citado na literatura, os Oito Passos de Kotter (1995), não faz menção à organização como um "cérebro" e "fluxo de transformação", além de tratar com pouca profundidade a organização como "cultura" e "sistema político". Por fim, é importante reforçar que o modelo de Kotter (1995) não faz menção à etapa "fim" proposta por Lewin, portanto, há um risco de que as iniciativas de mudança já existentes entrem em conflito com as novas mudanças propostas - isto faz sentido 
no contexto atual, no qual as organizações estão realizando mudanças cada vez mais frequentes, muito provavelmente em um ritmo maior atualmente do que quando comparado à década de 90.

Com relação à literatura sobre Cultura Organizacional, foi identificado que na maioria dos casos a compreensão da cultura organizacional não ocorre de maneira sistemática no processo de transformação. São raros os estudos de caso envolvendo os Projetos de Lean que fazem menção à mudança ou evolução cultural. Inclusive, sob o ponto de vista de "mudança cultural" ainda existem inúmeras lacunas na literatura a serem exploradas. Do ponto de vista dos modelos de Cultura Organizacional, é preciso distinguir entre modelos de Cultura Nacional e Cultura Organizacional. Neste trabalho, envolvendo Cultura Organizacional, considera-se o modelo Competing Values Framework como sendo o mais indicado para a realização do alinhamento entre Cultura Organizacional, Estratégia e Projeto de Transformação. Com relação à cultura Lean ideal mapeada neste modelo, este trabalho compreende tal cultura como tendo o perfil da Cultura de Hierarquia: foco interno (processos) com ênfase em estabilidade.

Por fim, este trabalho identificou 15 estudos de caso advindos da RBS envolvendo uma associação com pelo menos uma das quatro grandes áreas de estudo, e a partir desta compreensão pode constatar a existência de dois mundos conceituais: o primeiro enfatizando aspectos "soft" e o segundo enfatizado aspectos "hard".

\section{Principais entregas do trabalho}

O principal objetivo deste trabalho foi realizado: o processo de transformação de desenvolvimento dos Programas de Lean foi estudado e, a partir deste estudo, foi desenvolvida e proposta uma sistematização teórica do processo de transformação envolvendo mudança ou evolução cultural. Por sua vez, todos os objetivos secundários do trabalho levantados na Seção 1.3.2 foram também atingidos.

Com a concretização dos objetivos propostos, este trabalho realizou as seguintes entregas de pesquisa, já discutidas na seção “4. Desenvolvimento" deste trabalho:

a) Discussão e consolidação da Literatura sobre quatro grandes áreas de conhecimento (Estratégia, Lean, Cultura Organizacional e Gestão de Mudanças);

b) Levantamento dos modelos de mudança mais citados no escopo da Revisão Bibliográfica Sistemática (RBS) deste trabalho; 
c) Relacionamento dos Modelos de Mudança com as metáforas organizacionais;

d) Identificação dos Fatores Críticos de Sucesso dos Programas de Lean;

e) Elaboração e proposta da "Sistemática T." (Sistemática de Transformação);

f) Proposta do Modelo dos Oito Passos (Kotter, 1995) revisado;

g) Proposta de Cinco dimensões de alinhamento organizacional;

\section{Sobre a "Sistemática T."}

Este tópico retoma as principais questões sobre "o que constituí uma contribuição teórica" sob o ponto de vista de Whetten (1989). Segundo este autor, para a literatura é muito importante que existam pesquisas teóricas, pois elas são responsáveis pelo processo de construção de conceitos de melhoria de teorias existentes, desde que o processo de desenvolvimento e os critérios de avaliação das proposições sejam claros e bem aceitos. Desta maneira, são respondidas as seguintes perguntas sobre a proposição teórica deste trabalho: Por que a sistemática foi desenvolvida agora? Por que a sistemática é importante? Por que dessa forma? O que é novo na sistemática? Quem se importa com a sistemática proposta?

\section{Por que a sistemática foi desenvolvida agora?}

Em aproximadamente duas décadas os Programas de Lean se espalharam não apenas pelo setor automobilístico, mas também por diversas empresas de serviços: bancos, hospitais e hotéis, para não citar outros exemplos, passaram a alocar recursos organizacionais para desenvolver e implementar tais práticas e conceitos (Talib et al., 2010). Ou seja, neste momento, nos mais diversos segmentos, no mundo inteiro uma quantidade significativa de organizações está desenvolvendo Projetos de Lean, sendo que muitos destes podem vir a falhar ou ter resultados abaixo do esperado ${ }^{22}$.

O grande problema não está em desenvolver os Projetos de Lean, mas sim no fato de que a grande maioria dos esforços de mudança tem falhado: por exemplo, menos de $10 \%$ das empresas no Reino Unido realizaram uma implantação bem-sucedida do Lean (Hines et al., 2008; Sim e Rodgers, 2009; Atkinson, 2010; Bhasin, 2011; Bhasin, 2012). E como já citado

\footnotetext{
${ }^{22}$ Não foi identificado na literatura analisada por este trabalho uma estimativa do custo desta taxa de insucesso.
} 
diversas vezes, alguns estudos apontam fatores relacionados a Gestão de Mudanças e Cultura Organizacional como sendo as principais causas deste insucesso.

É importante reconhecer também que, embora o foco deste estudo seja nos Programas de Lean, vários estudos abordam a importância da Cultura Organizacional nas áreas mais diversas, como: School Management (Eger, 2010), Supply Chain Management (Cadden, Marshall e Cao, 2013), Knowledge Management (Bengoa et al., 2012), Total Quality Management (Steiber e Alange, 2013) dentre inúmeros outros. Portanto, uma melhor compreensão do relacionamento da Cultura Organizacional com o processo de mudança envolvendo os Programas de Lean pode ser útil não apenas para este escopo de projeto, mas também pode servir como fonte de compreensão ou até mesmo inspiração para pesquisas nas mais diversas áreas de gestão.

Ainda, outro aspecto importante é o fato de que, hoje, as mudanças nas organizações ocorrem em uma frequência muito maior do que há décadas atrás. Neste contexto, o principal modelo de mudança na literatura foi concebido sob o ponto de vista de "criar um senso de urgência" em prol de determinada mudança. Ou seja, caso existam dez mudanças ocorrendo uma organização, o modelo não propõe o encerramento ou congelamento de algumas destas ações, e isso está diretamente relacionado com o "foco das mudanças". Algumas organizações podem estar cometendo a falha de realizar mudanças conflitantes no mesmo momento, dissolvendo desta forma esforços valiosos.

\section{Por que a sistemática é importante?}

Embora a Cultura Organizacional seja indicada como um dos principais Fatores Críticos de Sucesso dos Programas de Lean (Deming, 1986; Liker, 2005; Bhasin e Burcher, 2006; Mohamed e YuanJuan, 2008; Kovacheva, 2010; Mann, 2010), e seja amplamente discutido na literatura a importância da Cultura para a Estratégia das organizações, o processo de mudança ou evolução da cultura organizacional nos projetos de Lean é pouco explorado na literatura, não existindo um modelo de mudança que trate desta questão específica.

Com base na literatura (conceitos e estudos de caso levantados), o cenário atual dominante ocorre de maneira semelhante à ilustrada na Figura 50. Os projetos de transformação envolvendo os Programas de Lean são desenvolvidos e implementados sem considerar aspectos da Cultura Organizacional, o que por sua vez pode repercutir em diversos problemas e falhas, como por exemplo: 
1. As soluções implementadas podem não ser incorporadas à cultura organizacional, prejudicando o sucesso do modelo proposto por Kotter (1995), e consequentemente potencializando o insucesso do projeto no curto ou longo prazo;

2. Pode haver um desgaste excessivo dos agentes de mudança tentando convencer as demais pessoas de que o projeto de transformação será bem-sucedido (quando muitas vezes pode estar ocorrendo um choque de crenças e valores), enfrentando as barreiras à mudança de número 10 a 20 conforme listadas por Rentes (2000);

A Figura 51, por sua vez, ilustra a sistemática na qual os projetos de transformação são desenvolvidos a partir de uma determinada visão estratégica, porém sem alinhamento com a cultura organizacional, promovendo desta maneira um desbalanceamento organizacional, ocasionado as duas potenciais falhas listadas anteriormente. Uma forte evidência deste contexto é o fato de que nenhum dos 15 estudos de caso levantados da literatura faz menção integrada e estrutura à Estratégia, à Cultura Organizacional e ao Projeto de Transformação.

\section{Por que a sistemática é dessa forma?}

A sistemática segue o modelo de Kotter (1995) como referência, justamente por ser o modelo mais robusto e citado na literatura, e apenas acrescenta alguns elementos que, com base na literatura levantada, podem repercutir em falhas no modelo de Kotter (1995) do ponto de vista de mudança e evolução cultural. Como já citado na "Seção 4.1 - Ruptura", para cada uma das etapas da sistemática proposta foi identificada e descrita a possível falha que vir a ocorrer em um projeto de mudança, sendo muitas já foram discutidas por Kotter (1995).

\section{O que é novo na sistemática?}

Com relação à Fundamentação Teórica (Seção 3), é importante ressaltar que este trabalho desenvolveu uma vasta Revisão Bibliográfica Sistemática e Exploratória envolvendo quatro grandes áreas de estudo: Estratégia, Lean, Cultura Organizacional e Gestão de Mudanças. A revisão destas áreas isoladamente, a princípio, não é uma novidade, mas, a revisão, integração, consolidação e discussão destas áreas de conhecimento de maneira conjunta e sob o ponto de vista de um mesmo objeto de estudo (Programas de Lean) é consideravelmente uma novidade relevante para a literatura. A partir desta consolidação e investigação do conhecimento atual presente na literatura, é possível identificar o que já é conhecido na literatura, quais respostas não são comumente discutidas e abordadas na literatura 
envolvendo gestão de operações (campo de referência dos Projetos de Lean), e quais respostas ainda não foram respondidas pela literatura. Esta é a grande novidade neste trabalho.

Por sua vez, o desenvolvimento da Sistemática de Transformação proposta, tendo um caráter teórico, é relevante para a literatura por consolidar e agregar conhecimentos destas áreas distintas em um mesmo objeto de estudo: os Programas de Lean. Neste contexto, a proposta conceitual é importante no sentido de:

1) Relacionamento da Cultura, Estratégia e Projeto de Transformação: a sistemática relaciona Cultura Organizacional e Estratégia com os Projetos de Transformação e, consequentemente, torna explícito de maneira simples e didática um dos principais motivos pelo qual "Culture Eats Strategy For Breakfast”, promovendo suporte ao estudo de disciplinas de Estratégia e Gestão de Mudanças;

2) Compreensão do status quo: a sistemática segue o modelo dos Oito Passos de Kotter (1995) como referência, e incorpora, já no seu primeiro passo, uma avaliação do status quo e compreensão da organização como "cultura";

3) Encerramento das iniciativas anteriores: ainda, seguindo o modelo de Kotter (1995) como referência, a sistemática resgata a etapa "Fim" proposta por Bridges (1991) e insere, no meio do processo de mudança - após a definição da visão -, uma etapa de "congelamento ou encerramento" dos projetos de mudança que não estejam alinhados com esta visão;

4) Alinhamento entre Cultura e estratégia organizacional: a partir da compreensão da Cultura Organizacional Atual, a sistemática possibilita a definição de ações objetivando atingir um alinhamento entre a "Proposta de Valor" (Estratégia) e a “Execução de Valor” (Cultura / Operação);

5) Definição de gatilhos de aceleração do processo de transformação: a sistemática resgata os elementos de gestão de Recursos Humanos citados por Robbins (2005) e Gattorna (2009) como práticas de mudança cultura, e os utiliza como "gatilhos" de aceleração do processo de mudança, ou seja, como ações que irão impulsionar o processo de mudança; 


\section{Quem se importa com a sistemática proposta?}

Primeiramente, por ser concebida dentro da área de Gestão de Operações, esta sistemática proposta pode ser útil para promover a discussão sobre Cultura Organizacional dentro da Gestão de Operações, servindo então para que professores, alunos e pesquisadores tenham um ponto de referência para incitar a discussão, compreensão do objeto de estudo e definir futuras pesquisas. Com relação à eventual aplicação prática, esta sistemática proposta pode vir a ser útil para profissionais que estejam envolvidos com determinado Projeto de Lean, Gestão de Mudança de maneira ampla, Planejamento Estratégico ou até mesmo com Gestão de Pessoas. Nesse sentido, gestores, agentes de mudança, consultores, pesquisadores, educadores e alunos de áreas relacionadas a gestão podem utilizar a sistemática em seu específico campo de atuação. Por fim, as "organizações" de uma maneira ampla podem vir a ser o maior beneficiado desta sistemática, justamente por ela ter sido concebida sob o ponto de vista de impactar na principal causa de insucesso dos projetos de mudança: a cultura organizacional.

\subsection{Limitações da Pesquisa}

\section{Limitações conceituais}

O trabalho apresentou uma ampla revisão da literatura na "Seção 3 - Fundamentação Teórica”, envolvendo uma Revisão Bibliográfica Sistemática (RBS) e Exploratória, tendo como objetivo incorporar os principais conceitos para a construção da sistemática proposta. É importante enfatizar que além de tratar dos conceitos existentes na literatura, a "Seção 3.5 Estudos de caso" identificou e analisou 15 estudos de caso levantados na revisão da literatura, no intuito de analisar a abordagem prática destes casos.

Além desta fundamentação teórica, a "Seção 4 - Desenvolvimento" apresentou a construção e descrição da sistemática proposta segundo três princípios de uma pesquisa teórica: (1) ruptura dos modelos atuais, (2) construção e (3) constatação da proposta. No entanto, a constatação da proposta teórica realizada é uma das principais limitações deste trabalho justamente por não envolver, neste momento, uma aplicação prática da teoria proposta. Com efeito, faz-se necessário que trabalhos futuros tenham um caráter prático no intuito de constatar a validade da proposição teórica deste trabalho. 
Todavia, devido à abrangência dos temas discutidos (Estratégia, Lean, Cultura Organizacional e Gestão de Mudanças), é preciso reconhecer que tanto a Fundamentação Teórica quanto o Desenvolvimento da Sistemática de Transformação podem apresentar limitações conceituais, principalmente do ponto de vista de Estratégia e Cultura Organizacional. Muitos outros conceitos poderiam ser pesquisados sobre o assunto no intuito de tornar o desenvolvimento da sistemática mais robusto. Pesquisas futuras abordando esse assunto poderão cobrir eventuais deficiências desta pesquisa.

\section{Limitação do método}

Embora o método utilizado tenha seguido os protocolos de uma Revisão Bibliográfica Sistemática (RBS), é preciso reconhecer que os artigos levantados apresentam o "estado da arte" dentro das áreas de estudo iniciais (Lean, Cultura Organizacional e Gestão de Mudanças), porém, são raros os casos em que há uma maturidade de integração entre as áreas de estudo. Por este motivo, podem existir questões fundamentais que influenciem nos Projetos de Lean que ainda não foram discutidas na literatura, ou seja, aparentemente a literatura sobre desenvolvimento da Cultura Lean pode não estar madura e robusta o suficiente. Inclusive, este mesmo fenômeno pode ocorrer na literatura sobre mudança de cultura organizacional. Por sua vez, a literatura sobre Estratégia foi inserida ao trabalho somente sob o ponto de vista de revisão exploratória, e não como revisão sistemática, novamente, isto pode repercutir em vieses de pesquisa. Todas essas limitações são evidenciadas na análise dos 15 estudos de caso levantados na revisão da literatura: nenhum destes casos fazia menção a descrição de aspectos relacionados à Cultura Organizacional, Projeto de Transformação e Estratégia Organizacional de maneira integrada, as menções ocorriam sempre de maneira isolada.

\section{Limitação da sistemática proposta}

Pelo caráter teórico do método de pesquisa, a principal limitação da sistemática proposta está na ausência de uma constatação e validação prática. Esta limitação é minimizada pelo fato da sistemática ser concebida tendo o principal modelo de mudança com referência (Kotter, 1995), mas, ainda assim, futuras pesquisas práticas podem ser úteis para avaliar a confiabilidade e eficácia desta proposta teórica. 


\subsection{Trabalhos e Pesquisas futuras}

A partir dos resultados e conclusões deste estudo, diversas pesquisas e trabalhos futuros poderiam ser citados como importantes, dos quais podem ser destacados os seguintes:

$\checkmark$ Monitoramento dos perfis culturais das empresas brasileiras;

$\checkmark$ Monitoramento da taxa de sucesso e insucesso das iniciativas de mudança no Brasil;

$\checkmark$ Expansão da revisão bibliográfica para outros tipos de projeto além do Lean, dentre os quais podem ser citados: Fusões e Aquisições, Redução de Complexidade, Sustentabilidade, Capitalismo Consciente, Gestão da Cadeia de Suprimentos, Total Quality Management (TQM), Six Sigma, Design Thinking, Gestão do Conhecimento, Gestão de Informações, Gestão de Inovações, Customer Relationship Management (CRM), e outros;

$\checkmark$ Pesquisa-ação envolvendo aplicação da Sistemática de Transformação nos mais variados segmentos de atuação das organizações;

$\checkmark$ Análise e compreensão dos aspectos "soft" envolvendo projetos de mudança;

$\checkmark$ Análise e compreensão dos possíveis alinhamentos estratégicos envolvendo os diferentes perfis culturais do Competing Values Framework;

$\checkmark$ Validação do Competing Values Framework no Brasil;

$\checkmark$ Análise dos "estágios evolutivos" das organizações;

$\checkmark$ Continuidade da revisão sobre Evolução Cultural e/ou Alinhamento Estratégico;

$\checkmark$ Estudos de caso envolvendo Evolução Cultural e/ou Alinhamento Estratégico;

$\checkmark$ Análise conceitual dos fatores críticos de sucesso envolvendo Gestão de Projetos; 


\section{REFERÊNCIAS}

ACAR, A. (2012). Organizational culture, leadership styles and organizational commitment in Turkish logistics industry. 8th International Strategic Mangament Conference.

ADEBANJO, D.; KEHOE, D. (1999). An investigation of Quality culture Development in UK industry. International Journal of Operations e Production Management, Vol. 19, No. 7, pp. 633-649.

AHMAD, S. A. S. (2013). Culture and Lean Manufacturing - Towards a Holistic Framework. Australian Journal of Basic and Applied Sciences, v. 7, n. 1, p. 334-338.

ALTMAN, Y.; BARUCH, Y. (2010). The Organizational lunch. Culture and Organization, Vol. 16, No. 2, pp. 127-143

ANACLETO, P. (2011). Uma descrição da implantação da Manufatura Enxuta: estudo de caso em uma montadora de máquinas agrícola. Trabalho de Conclusão de Engenharia de Produção na Universidade Federal de São Carlos.

ANVARI, A.; ZULKIFLI, N.; YUSUFF, R. M. (2012). A dynamic modeling to measure Lean performance within Lean attributes. The International Journal of Advanced Manufacturing Technology, v.66, n.5-8, p. 667-677.

ASHKENAS, R. (2015). We Still Don`t Know the Difference Between Change and Transformation. Harvard Business Review, January.

ATKINSON, P. (2010). Lean is a cultural issue. Management Services, v. 54, p. 35-44.

BABE, G. S. (2011). The CEO of Bayer Corporation On Creating a Lean Growth Machine. Harvard Business Review, July-August, pp. 41-45.

BECKHARD, R. F.; HARRIS, R. T. (1987). Organization transitions: managing complex change, AddisonWesley, Reading, MA.

BEHROUZI, F.; WONG, K. Y. (2011). Lean Performance evaluation of manufacturing systems: a dynamic and innovative approach. Procedia Computer Science, v. 3, p. 388-395.

BENGOA, D.S.; KAUFMANN, H. R.; VRONTIS, D. (2012). A new organizational memory for cross-cultural knowledge management. Cross Cultural Management International Journal.

BHASIN, S. (2011a) Performance of organizations treating Lean as an ideology. Department of Quality Assurance, NOMS Civil Service College, Rugby, UK. Business Process Management, Emerald Group Publishing Limited.

BHASIN, S. (2011b). Measuring the Leanness of an organization. NOMS College, Stretton-under-Fosse, UK. International Journal of Lean Six Sigma, Emerald Group Publishing Limited.

BHASIN, S. (2012a). An appropriate change strategy for Lean success. Management Decision, Emerald Group Publishing Limited.

BHASIN, S. (2012b). Prominent obstacles to Lean. International Journal of Productivity and Performance Management. Vol. 16, No. 4.

BHASIN, S.; BURCHER, P. (2006). Lean viewed as a philosophy. Journal of Manufacturing Technology Management. Vol. 17, pp. 56-72. 
BICHENO, J.; HOLWEG, M. The Lean Toolbox: the essential guide to Lean transformation. 4 th ed. Buckingham: Picsie, 2009, 290 p.

BLACK, J. (2007). Design rules for implementing the TPS. International Journal of Production Research. Vol. 45, No. 16.

BRIDGES, W. (1991). Managing Transitions. Perseus, Reading, MA.

BULLOCK, R. J.: BATTEN, D. (1985). It`s just a phase we`re going through, Group and Organization studies. Vol. 10, pp. 383-412.

BUSCHGENS, T. BAUSCH, A.; BALKIN, D. B. (2013). Organizational culture and innovation: a meta-analytic review. Journal of Product Innovation Management. v. 30, n. 4, pp. 763-781.

BUSCHINGER, D.; CAVAlCANTI, G. A. S.; HOUNSELL, M. S. (2014). Mecanismos de busca acadêmica: uma análise quantitativa. Revista Brasileira de Computação Aplicada, Passo Fundo, V. 6, n. 1, pp. 108-120.

CADDEN, T.; MARSHALL, D.; CAO, G. (2013). Opposites attract: Organisational culture and supply chain performance. Supply Chain Management Int. Journal, Emerald, 18, pp. 86-103.

CAMERON, E.; GREEN, M. (2004). Gerenciamento de mudanças: guia completo, com modelos, ferramentas e técnicas, para entender e implementar as mudanças nas organizações. Título original "Making Sense of Change Management”. Editora Clio, São Paulo.

CAMERON, K. S.; QUINN, R. E. (2009). Diagnosing and Changing Organizational Culture: based on the competing values framework. San Francisco: Jossey Bass, pp. 242.

CARNALL, C. A. (1986). Managing Change in Organizations. Prentice Hall, Londres.

CHAUHAN, G.; SINGH, T. P. (2012). Measuring parameters of Lean manufacturing realization. Measuring Business Excellence, v. 16, n. 3, p. 57-71.

CHEW, I. K.; PUTTI, J. (1995). Relationship on work-related values of Singaporean and Japanese managers in Singapore. Human Relations, 48 (10), pp. 1149-1170.

CLARK, D. M.; SILVESTER, K.; KNOWLES, S. (2013). Lean Management Systems: creating a culture of continuous quality improvement. J. Clin. Pathol., Vol. 66, pp.638-643.

COCH, L.; FRENCH, J. R. (1948). Overcoming resistance to change. Human Relations, Vol. 1, pp. 512-542.

COLE, R. (2011) What Really Happened to Toyota? MIT Sloan Management Review.

COUTU, D. (2002). Edgar Schein: The Anxiety of Learning - the darker site of organizational learning. HBS Working Knowledge.

DAVIS, S. (1984). Managing Corporate Culture, Balinger, Cambridge, MA.

DELOITTE E TOUCHE (2002). The road to world class manufacturing, Deloitte e Touche.

DEMING, W. E. (1986). Out of the crisis. Cambridge, MA: MIT Press.

DESHPANDÉ, R.; FARLEY, J. U.; FREDERICK, E. W. (2000). Triad lessons: generalizing results on high performance firms in five business-to-business markets. Vol. 17, pp. 353-362.

DETERT, J. R.; SCHROEDER, R. G.; MAURIELL, J. J. (2000). A framework for linking culture and improvement initiatives in organizations. Academy of Management Review, 25(4), pp. 850-863.

DOMBROWSKI, U.; MIELKE, T. (2013). Lean Leadership - fundamental principles and their application. CIRP Conference on Manufacturing Systems.

DUNPHY, D.; STACE, D. (1990). Under new management: Australian organizations in transition. Sydney: McGraw-Hill. 
EAGLETON, T. (2000). The ideas of Culture. Oxford, Blackwell Publishers.

EGER, L. (2010). Application of the corporate culture in the field of school management. Ekonomika a Management, Vol 3, pp. 26-32.

EMILIANI, M. C. (1998). Lean behaviors. Management Decision, Vol. 36, pp. 615-631.

ESWARAMOORTHI, M.; KATHIRESAN, G. R.; PRASAD, P. S. S.; MOHANRAM, P. V. (2011). A survey on

Lean practices in Indian machine tool industries. The International Journal of Advanced Manufacturing Technology, v. 52, n. 9-12, p. 1091-1101.

FEINGENBAUM, ARMAND VAI. (1986). Total Quality Control. Editora McGraw, 3rd Edition.

FERREIRA, C. F.; SAURIN, T. A. (2008). Avaliação qualitativa da implantação de práticas da produção enxuta: estudo de caso em uma fábrica de máquinas agrícolas. Revista Gestão e Produção, v. 15, n. 3, p. 449-462.

FLEURY, M. T.; SHINYASHIKI, G.; STEVANATO, L. A. (1997). Entre a Antropologia e a Psicanálise: dilemas metodológicos dos estudos sobre cultura organizacional. Revista de Administração de Empresas, São Paulo, v. 32, n. 1, pp. 23-37.

FONSECA, J. J. S. (2002). Metodologia da pesquisa científica. Fortaleza, UEC. Apostila.

FREITAS, M. E. (1991). Cultura organizacional: formação, tipologia e impactos. São Paulo, Makron Books.

FRONDA, Y.; MORICEAU, J. (2008). I am not your hero: change management and culture shocks in a public sector Corporation. Journal of Org. Change Management, Vol. 21, No. 5, pp. 589-609.

GAMBI, L. N.; BOEER, H.; GEROLAMO, M.; JORGENSEN, F.; CARPINETTI, L. C. R. (2015). The relationship between organizational culture and quality techniques, and its impact on operational performance. International Journal of Operations \& Production Management, Vol. 35, NO. 10, pp. 1460-1484.

GARUD, R.; GEHMAN, J.; KUMARASWAMY, A. (2011). Complexity arrangements for sustained innovation: lessons from 3M Corporation. Organization Studies, Vol. 32, pp. 737-767.

GATTORNA, J. (2009). Living Supply Chains: alinhamento dinâmico de cadeias de valor. São Paulo: FT Prentice Hall, 286 p.

GERHADT, T. E.; SILVEIRA, D. T. (2009). Método de Pesquisa. UAB/UFRGS. Porto Alegre, Editora da UFRGS

GHOSN, C. (2002). Saving the business without losing the company. Harvard Business Review, January/02.

GIL, A. C. (2007). Como elaborar projetos de pesquisa. São Paulo, Editora Atlas, $4^{\text {a }}$ Edição.

GIRITLI, H.; ONEY-YAZICI, E.; TOPÇU-ORAZ, G.; ACAR, E. (2013). The interplay between leadership and organizational culture in the Turkish construction sector. International Journal of Project Management, Vol. 31, pp. 228-238.

GRAHAM, I. (1991). Take your time to total quality success. Works Management, pp. 17-21.

GRAVENHORST, K. M. B.; WERKMAN, R. A.; BOONSTRA, J. J. (2003). The change capacity of organizations: general assessment and five configurations. Applied Psychology: and international review, Vol. 54, pp. 83-105.

HALL, R. W. (1986). Attaining manufacturing Excellence. Irwin, New York.

HAMMER, M.; CHAMPY, J. (1993). Reengineering the corporation - a manifesto for Business Revolution, Harper, New York.

HANDEL, MICHAEL J. (2009). Theories of Lean management: an empirical evaluation. Social Science Research. Vol. 44, pp. 86-102. 
HAWKES, A. (1993). How do you manage flexible firm? The total quality model. Work, Employment and Society, pp. 397-415.

HELLER, F.; PUSIC, E.; STRAUSS, G; WILPERT, B. (1998). Organizational participation - myth and reality. Oxford University Press.

HENG, M. SH.; AHMED, P. K. (2000). Applying the concept of ideology to achieve management excellence. International Conference on Management of Innovation and Technology. ICMIT, 2000. Management in the 21 st Century.

HENG, S. H. M.; AHMED, P. K. (2000). Applying the concept of ideology to achieve management excellence. ICMIT.

HINES, P., FOUND, P., GRIFFITHS, G., HARRISON, R. (2008), Staying Lean thinking not just surviving, London: Taylor and Francis Group.

HOFER, A. R.; HOFER, C.; EROGLU, C.; WALLER, M. A. (2011). An institutional theoretic perspective on forces driving adoption of Lean production globally: China vis-à-vis the USA. The International Journal of Logistics Management, v. 22, n. 2, p. 148-178.

HOFSTEDE, G. J. (2010). Cultures and Organizations: Software of the Mind. McGraw-Hill, 3th edition.

HOFSTEDE, G. J. (2011). Dimensionalizing Cultures: The Hofstede Model in Context. Online Readings in Psychology and Culture, Vol. 2 (1).

HOWARD, L. (1988). Validating the competing values framework model as a representation of organizational cultures. The International Journal of Organizational Analysis. Vol. 6, n. 3, pp. 231-250.

IRANI, Z.; SHARP, J. (1997). Integrating continuous improvement and innovation into a corporate culture: a case study. Technovation. Vol. 17, No. 4, pp. 199-206.

ISHIKAWA, KAORU. (1989). Introduction to Quality Control. 1st Ed.

IVANKO, STEFAN. (2013). Organizational Behavior. Collected and edited by Prof. Ivanko. University of Ljubljana, Faculty of Public Administration.

JOHNSON, GERRY; SCHOLES, KEVAN; WHITTINGTON, RICHARD (2008). Exploring Corporate Strategy. Eighth edition. Prentice Hall - Financial Times.

KANDT, RONALD KIRK (2006). Software Engineering Quality Practices. Chapter 2, Organizational Change Management Principles and Practices. Published by Auerbach Publications.

KAPLAN, ROBERT; NORTON, DAVID (2004). Measuring the Strategic Readiness of Intangible Assets. Harvard Business Review.

KAPLAN, ROBERT; NORTON, DAVID (2005). Creating the Office to Strategy Management. Balanced Scorecard Collaborative, Inc.

KERR, STEVEN (1995). On the folly of rewarding A, while hoping for B. The Academy of Management Executive, Feb, Vol. 9, No. 1.

KLUBER-ROSS, E. (1969). On death and dying. T, New York.

KLUCKHOHN, C. (1951) Values and values orientation in theory of action. In: PARSONS, T.; SHILS, E. (1951). Toward a general theory of action. Cambridge, Mass. Harvard University Press.

KOKT, D.; MERWE, C. (2009). Using the Competing Values Framework (CVF) to investigate Organisational culture in a major private security company. SAJEMS, Vol. 12, No. 3, pp. 343-352.

KOTTER, J. P.; HESKETT, J. L. (1992). Corporate Culture and Performance, The Free Press, New York. 
KOTTER, J. P. (1995, 2009). Leading Change - Why Transformation Efforts Fail. Harvard Business Review.

KOTTER, J. P.; SCHESINGER, L. A. (2008). Choosing strategies for change. Harvard Business Review, Vol. 57, pp. 106-114.

KOTTER, J. P. (2012). Mude depressa - como conferir o dom da adaptação a sua organização. Harvard Business Review, Novembro, 2012, pp. $28-38$.

KOVACHEVA, A. V. (2010). Challenges in Lean implementation - Successful transformation towards Lean enterprise. Master Thesis in Strategy, Organization and Leadership. AARHUS SCHOOL OF BUSINESS, University of Aarhus.

KROEBER, A. L.; KLUCHHOLM, C. (1952). Culture - a critical review of concepts and definitions. Vintage, New York.

KUMAR, A.; THOMAS, S. (2002). A Software tool for screening analysis of Lean practices. Environmental Progress, v. 21, n. 3, p. 12-16.

KUMAR, S. A.; SURECH, N. (2009). Operations Management. New Age International Publishers.

LAMOND, D. (2003). The value of Quinn`s competing values model in an Australian context. Journal of Managerial Psychology. Vol. 18, pp. 46-59.

LANGLEY, Gerald; MOEN, Ronald; NOLAN, Kevin; NORMAN, Clifford; PROVOST, Lloyd. (2011). Modelo de Melhoria - uma abordagem prática para melhorar o desempenho organizacional. $1^{\mathrm{a}}$ Edição.

LEAN ENTERPRISE INSTITUTE (2004). The State of Lean Survey. Disponível em www.Lean.org, acesso em 15/10/2014.

LEAN ENTERPRISE INSTITUTE (2005). The Lean Survey Survey. Disponível em www.Lean.org, acesso em 15/10/2014

LEE, Q. (2007). Implementing Lean manufacturing. Institute of Management Services Journal, Vol. 51, No. 3, pp. 14-19.

LEWIN, K. (1951). Field theory in social science, Harper and Row, Nova York.

LIKER, J. K. (2005). O Modelo Toyota: 14 princípios de gestão do maior fabricante do mundo. Bookman.

LIKER, J.; HOSEUS, M. (2008). Toyota Culture: the heart and soul of the Toyota Way. India: McGraw-Hill.

MALLAK, LARRY A.; LYTH, D. (2009). Using Desired Culture Analysis to Manage Decentralized Operations. Engineering Management Journal, Vol. 21, No. 2, pp. 27-32.

MANN, David. (2010). Creating a Lean Culture - tools to sustain Lean Conversions. Second Edition. CRC Press, Taylor e Francis Group.

MARTENSEN, A.; DAHLGAARD, J. (1999). Integrating business excellence and innovation management: developing vision, blueprint and strategy for innovation in creative and learning organizations. Total Quality Management, Vol. 10, pp. 627-635.

MATTHIESEN, R.V.; JOHANSEN, J. (2008). Lean Transformation of multinational concerns. Lean Business Systems and Beyond.

MAULL, R.; BROWN, P.; CLIFFE, R. (2001). Organisational culture and quality improvement. International Journal of Operations e Production Management. Vol. 21, No. 3, pp. 302-326.

McLAUGHLIN, P.; BESSANT, J.; SMART, P. (2008). Developing an organization culture to facilitate radical innovation. International Journal of Technology Management, Vol. 44, Nos. 3/4, pp. 298-323. 
MELLO, R. G. S. (2014). Utilização de Big Data Analytics nos Sistemas de Medição de Desempenho: estudos de caso. Projeto de Dissertação de Mestrado apresentado ao Programa de Pós-Graduação em Engenharia de Produção da UFSCar, para o exame de Qualificação.

MILES, M. B. (1979). Qualitative data as an attractive nuisance: the problem of analysis. Administrative Science Quarterly, v. 24, pp. 590-601.

MOHAMED, SALUM SOUD.; YUANJUAN, QIN. (2008). The impact of Organizational Culture on the implementation of TQM Programs. ISECS - International Colloquium on Computing Communication, Control and Management.

MORGAN, GARETH. (1998). Images of Organization. The Executive Edition.

NADLER, D. A.; TUSHMAN, M. L. (1997). Competing by design: the power of organizational architecture, Oxford University Press, Nova York.

NIGHTINGALE, D. J.; MIZE, J. H (2002). Development of a Lean Enterprise Transformation Maturity Model. Information Knowledge Systems Management, v. 3, n. 1, p. 15-30.

O`REILLY, CHARLES A.; CHATMAN, JENNIFER; CALDWELL, DAVID. (1991). People and organizational culture: a profile comparison approach to assessing person-organization fit. Academy of Management Journal, Vol. 34, No. 3, pp. 487-516.

OHNO, T. (1988). Toyota Production System - beyond large-scale production. Portland.

PAMFILIE, R.; DRAGHICI, A. J. P.; DRAGHICI, M. (2012). The Importance of Leadership in driving a strategic Lean Six Sigma management. Social and Behavioral Sciences, Vol. 58, pp. 187-196.

PAPADOPOULOS, T. (2011). Continuous improvement and dynamic actor associations: a study of Lean thinking implementation in the UK National Health Service. Vol. 24, No. 3, pp. 207-227.

PARISH, J. T.; CADWALLADER, S.; BUSCH, P. (2008). Want to, need to, ought to: employee commitment to organizational change. Journal of Organizational Change Management, Vol, 21, No. 1, pp. 32-52.

PARO, P. E. P. (2012). Diagnóstico da Cultura Lean - baseado no Competing Values Framework. Trabalho de Conclusão do Curso apresentado à Escola de Engenharia de São Carlos (EESC/USP) para a obtenção do título de Engenheiro de Produção.

PARO, P. E. P.; GEROLAMO, M. C. (2015). Diagnosing and understanding the ideal Lean Culture - based on the 14 principles of the Toyota Way. Global Journal on Humanities e Social Sciences. Vol. 02, pp. 50-59. Available from: http://www.world-education-center.org/index.php/pntsbs.

PASCALE, R. (1990). Managing on the Edge. How Successful Companies Use Conflict to Stay Ahead, Penguin Books, London.

POWER, D. J; SOHAL, A. S. (1997). An examination of the literature relating to issues affecting the human variable in just-in-time environments. Technovation. Vol. 17 (11/12), pp. 649-666.

PRAJOGO, D. I.; SOHAL, A. S. (2001). TQM and innovation: a literature review and research framework. Technovation, Vol. 21, pp. 539-558.

PRAJOGO, D. I.; McDERMOTT, C. M. (2011). The relationship between multidimensional organizational culture and performance. Int. Journal of Op. Management, Vol. 31, pp. 712-735.

PRODANOV, C. C.; FREITAS, E. C. (2013). Metodologia do Trabalho Científico: métodos e técnicas da pesquisa e do trabalho acadêmico. $2^{a}$ Edição, Brasil. ASPEUR. Universidade Feevale. 
PROSSER, DANIEL F. THIRTEENERS (2015). Why only 13 percent of Companies Successfully Execute Their Strategy, and how yours can be one of them. Greenleaf Book.

QUIVY, R.; CAMPENHOUDT, L. (1995). Manual de Pesquisa em Ciências Sociais. Disponível no dia 08/02/2015 às 11h47 em: http://www.fep.up.pt/docentes/joao/material/manualinvestig.pdf

RENTES, ANTONIO FREITAS. (2000). TransMeth - Proposta de uma Metodologia para Condução de Processos de Transformação de Empresas. Tese apresentada à EESC/USP como parte dos requisitos para obtenção do título de Professor Livre Docente.

ROBBINS, S. P. (2005). Comportamento organizacional. 11a edição. São Paulo, Pearson Prentice Hall.

ROSS, J. E. (1993). Total Quality Management: Text, Cases and Readings. Delray Beach, St. Lucie Press.

ROTHER, M.; SHOOK, J. (2003). Aprendendo a enxergar - mapeando o fluxo de valor para agregar valor e eliminar desperdício. São Paulo. Lean Institute Brasil.

ROTHER, MIKE (2010). Toyota Kata - gerenciando pessoas para melhoria, adaptabilidade e resultados excepcionais. Editora Bookman.

SARROS, JAMES; GRAY, JUDY; DENSTEN, IAIN; COOPER, BRIAN (2005). The Organizational Culture Profile Revisited and Revised: An Australian Perspective. Australian Journal of Management, Vol. 30, No. 1.

SATIR, V.; BANMEN, J.; GERBER, J; GOMORI, M. (1991). The Satir Model: family therapy and beyond. Science and Behavior Books. California.

SAURIN, T.; MARODIN, G.; RIBEIRO, J. (2011). A framework for assessing the use of Lean production practices in manufacturing cells. International Journal of Production Research, v. 46, n. 23, p. 32-51, 2011.

SCHAFFER, R. H.; THOMSON, H. A. (1992). Successful Change Programs Begin with Results, Harvard Business Review, January-February, 1992, p. 80-89.

SCHEIN, E. H. (1984). Coming to a New Awareness of Organizational Culture. MIT, Sloan Management Review.

SCHEIN, E. H. (2009). Organizational Culture and Leadership. 3rd Edition.

SENGE, P. M. (2002). A quinta disciplina - arte e prática da organização que aprende. Editora Best Seller.

SEYEDHOSSEINI, S. M.; TALEGHANI, A. E.; BAKHSHA, A.; PARTOVI, S. (2011). Extracting Leanness criteria by employing the concept of Balanced Scorecard. Expert Systems with Applications, v. 38, n. 8, p. 10454-10461.

SHIM, W. S.; STEERS, R. M. Symmetric and asymmetric leadership cultures: a comparative study of leadership and organizational culture at Hyundai and Toyota. Journal of World Business, Vol. 47, pp. 581-591, 2012.

SHINYASHIKI, G. T. (1995). Estudo quantitativo dos pressupostos básicos da cultura organizacional. Revista de Administração, São Paulo, v. 30, n. 3, p. 60-72, julho/setembro.

SHOOK, J. (2010). How to Change a Culture: Lessons from NUMMI. MIT Sloan Management Review.

SILVESTER, J.; ANDERSON, N.; PATTERSON, F. (1999). Organizational culture change: an inter-group attributional analysis. Journal of Occupational and Organizational Psychology, Vol. 72, pp. 1-23.

SIRKIN, H. L.; KEENAN, P.; JACKSON, A. (2005). The Hard Side Of Change Management. Harvard Business Review, October, 2005.

SISODIA, RAJ.; WOLFE, DAVID; SHETH, JAG. (2014). Firms of Endearment - how world class companies profit from passion and purpose. Second Edition. Pearson Education. 
SLOAN SCHOOL OF MANAGEMENT (2002). Operations Management - lecture notes. Spring. Disponível em http://ocw.mit.edu/courses/sloan-school-of-management/15-760a-operations-management-spring2002/lecture-notes/lecture1_feb6.pdf.

SMEDS, RIITA. (1994). Managing Change towards Lean Enterprises. International Journal of Operations e Production Management. Vol. 14, No. 3, pp. 66-82.

SNEE, RONALD D. (2010). Lean Six Sigma - getting better all the time. International Journal of Lean Six Sigma. Vol. 1, pp. 9-29.

SOBEK II, DUWART; SMALLEY, ART. (2010). Entendendo o pensamento A3 - um componente crítico do PDCA da Toyota.

SOLTANI, E.; LAI, P. (2007). Managing Change Initiatives: fantasy or reality? The case of public sector organizations.

SPEAR, S. (2004). Learning to lead at Toyota. Harvard Business Review, Vol. 82, pp. 78-87.

STEIBER, A.; ALANGE, S. (2012). Do TQM Principles need to change? Learning from a comparison to Google Inc. Total Quality Management e Business Excellence. Nov, pp. 1-14.

STEVENSON, WILLIAM J. Operations Management. (2011). Published by McGraw-Hill Education, New York, NY, US.

STONE, KYLE B. (2012). Four decades of Lean: a systematic literature review. International Journal of Lean Six Sigma. Vol. 3, No. 2, pp. 112-132.

SULL, DONALD; HOMKES, REBECCA; SULL, CHARLES. (2015). Por que a execução da estratégia falha e o que fazer a respeito. Harvard Business Review, Março 2015.

TALIB, F.; RAHMAN, Z.; QURESHI, M. (2010). The relationship between total quality management and quality performance in the service industry: a theoretical model. International Journal of Business Management and Social Sciences. Vol. 1, No. 1, pp.113-128.

TRANFIELD, D.; DENYER, D.; SMART, P. (2003). Towards a Methodology for Developing EvidenceInformed Management Knowledge by Means of Systematic Review. British Journal of Management, v. 14, n. 3, p. 207-222.

TREACY, MICHAEL; WIESERMA, FRED. (1993). Customer Intimacy and Other Value Disciplines. Harvard Business Review, Jan-Feb.

TROPMENAARS, F.; HAMPDEN-TURNER, C. (1994). Nas ondas da cultura. Editora Educador.

UNVER, H. O. (2012). An ISA-95-based manufacturing intelligence system in support of Lean initiatives. The International Journal of Advanced Manufacturing Technology, v. 65, n. 5-8, p. 853-866.

VAKOLA, M.; SODERQUIST, E.; PRASTACOS, G. (2007). Competency management in Support of Organisational change. International Journal of Manpower, Vol, 28, No. 3/4, pp. 260-275.

VINODH, S.; VIMAL, K. E. K. (2012). Thirty criteria based Leanness assessment using fuzzy logic approach. The International Journal of Advanced Manufacturing Technology, v. 60, n. 9-12, p. 1185-1195.

WALKER, T. (1992). The contributions of Total Quality Management to a theory of work performance. Academy of Management Review, Vol. 19, pp. 510-536.

WAN, H. D.; CHEN, F. F. (2008). A Leanness measure of manufacturing systems for quantifying impacts of Lean initiatives. International Journal of Production Research, v. 46, n. 23, p. 6567-6584. 
WATERMAN, R. H.; PETERS, T. J.; PHILLIPS, J. (1980). Structure is not organization. Business Horizons. June 1980.

WHETTEN, David A. (1989). What constitutes a Theoretical Contribution? Academy of Management Review, Vol. 14, No. 4, pp. 490-495.

WILMS, W.; HARDCASTLE, A.; ZELL, D. (1994). Cultural Transformation at NUMMI. MIT Sloan Management Review.

WOMACK, J. P.; JONES, D. T.; ROOS, D. (2004). A Máquina que mudou o mundo: baseado no estudo do Massachusets Institute of Technology sobre o future do automóvel. Rio de Janeiro: Elsevier.

ZU, X.; ROBBINS, T.; FREDENDALL, L. (2010). Mapping the critical links between Organizational culture and TQM/Six Sigma practices. International Journal of Production Economics, Vol 123, pp. 86-106. 